\title{
EVERYDAY PRACTICES OF RACE, CLASS AND GENDER
}

by

Donna Baines

A thesis submitted in conformity with the requirements for the degree of Doctor of Philosophy Graduate Department of Social Work University of Toronto

@ Copyright by Donna Baines (1998) 
National Library of Canada

Acquisitions and Bibliographic Services

395 Wellington Street Ottawa ON K1A ON4 Canada
Bibliothèque nationale du Canada

Acquisitions et services bibliographiques

395, rue Wellington Ottawa ON KIA ON4

Canada
The author has granted a nonexclusive licence allowing the National Library of Canada to reproduce, loan, distribute or sell copies of this thesis in microform, paper or electronic formats.

The author retains ownership of the copyright in this thesis. Neither the thesis nor substantial extracts from it may be printed or otherwise reproduced without the author's permission.
L'auteur a accordé une licence non exclusive permettant à la Bibliothèque nationale du Canada de reproduire, prêter, distribuer ou vendre des copies de cette thèse sous la forme de microfiche/film, de reproduction sur papier ou sur format électronique.

L'auteur conserve la propriété du droit d'auteur qui protège cette thèse. $\mathrm{Ni}$ la thèse ni des extraits substantiels de celle-ci ne doivent être imprimés ou autrement reproduits sans son autorisation. 


\begin{abstract}
EVERYDAY PRACTICES OF RACE, CLASS AND GENDER

by

DONNA BAINES

A thesis submitted in conformity with the requirements

for the degree of Doctor of Philosophy

Graduate Department of Social Work

University of Toronto
\end{abstract}

1998

Most approaches to social work do not engage with the question of how multiple bases of subordination such as race, class and gender shape and organize social life. While a number of critical social work theorists have addressed themselves to issues of oppression, none of this work explicates the way that race, class and gender overlap, contest and generally play themselves out in everyday life (Carniol, 1990; Dominelli, 1988; Mullaly, 1993; Wineman, 1984). This thesis looks at the everyday practices of front line critical social workers in order to understand how race, class and gender are played out in the social work endeavor. Data were collected from five focus groups and nine in-depth interviews involving a total of twenty-one participants. Agency and community documents and policies acted as secondary data sources and were used to provide a sense of context.

At the level of formal theory, the informants displayed a good knowledge of critical theory. However, at the level of talking about everyday social work practice, the informants tended to employ liberal, ideological constructions of race, class and gender. In contrast, at the level of practice, that is while employing techniques that are directly associated with the critical model of social work, a 
shift occurred within the relations and identities of workers and clients. This shift was typified by a reported commonality of cause and struggle, shared new identities as social justice fighters, and a mutual sense that the existing order, or pieces of it, are unjust and must be collectively changed. These shifts underscore the importance of continuing to develop and work with these explicitly critical social work practice techniques.

This study also identified various agency policies and processes that neutralize race, class and gender conflicts without resolving them. Finally, the study identified structures and policies that enhance and support critical practice. In sum, these findings are important because improving our understanding of how race, class and gender are depoliticized can enhance our capacity to resist oppression and build new structures, relations and identities based on shared struggle and social justice agendas. 


\section{ACKNOWLEDGEMENTS}

The critical space Dr. Sheila Neysmith created for myself and other students was an essential component of this project. I was extremely fortunate to have her act as my thesis supervisor for the majority of my dissertation work. Not only is Sheila's rapid turn-around time on drafts the stuff of legends, her insights, thoroughness, commitment and support on many levels were greatly appreciated throughout my doctoral work and will serve as an example for me in my work within and outside of academia.

Acting as my Supervisor through my Comprehensive Paper and Thesis Proposal, Dr. Ernie Lightman's accessibility, encouragement and enthusiasm cannot be overstated. Emie's extraordinary ability to balance cynicism, humour and optimism have helped many Ph.D. students, including this one, pursue and investigate ways to introduce greater justice to the micro worlds of everyday social work and the macro worlds of social policy, structures and systems.

As my external committee member, Dr. Roxana Ng contributed rigour and key theoretical and political insights. The support and intellectual challenge she offers to all her students is outstanding and was an important element in the completion of this project.

My external reviewer, Dr. Gillian Walker, provided an exciting and challenging tone to the defense. Her comments opened up new ways of seeing things that had become somewhat stale and I greatly appreciate the way she combined theoretical challenges with questions of practical, political struggles for social justice. Likewise, the work of my internal examiner, Dr. Judy Globerman, is warmly acknowledged for her thoroughness and insightful methodological comments.

My informants showed outstanding integrity and insight in their contributions to this project. Their willingness to critically review their own practices as well as those of their agencies ensured that the data gathered was very rich and full of many of the important conflicts within the everyday lives of progressive social workers. I cannot thank them enough for their hard work on this project and in the building of better ways to do social work.

Through the Ph.D. process, the enthusiasm and energy of fellow students provided the impetus to think more clearly, demand more justice and be willing to take those intellectual/political risks around asking unpopular questions and seeking hard answers. In particular, I am grateful to all the members of the Dorothy Livesay Collective 1994 to 1997 (Shari Brotman, Catrina Brown, Xiao Bei Chen, Suzanne Dudziak, Susan McGrath, Jane McMichael, Ken Moffat, Carol-Anne O'Brien, Janet Parsons, Shoshana Pollack, and Frank Wang) as well as to the friendship and support of Holly Baines.

I would also like to acknowledge the Social Sciences and Humanities Research Council for their financial support throughout my doctoral studies.

Jim Stanford's consistent and unruffled faith in my scholarly abilities provided the bedrock for this Ph.D. project. The way that his own social justice work is rooted in the everyday workplace 
struggles of men and women, as well as the highly political but "privatized" struggles to be a full coparent and very present and supportive partner, makes Jim a most excellent accomplice in this adventure called life. He and our daughter, Maxine "TT" Baines, provided endless diversion, humour and zeal to the entire ridiculous process. 


\section{TABLE OF CONTENTS}

I. Introduction 1

II. Literature Review $\quad 5$

Defining the Critical Social Work Literature 5

Radical/Structural Social Work 7

Feminist Social Work 11

Anti-Racist Social Work 15

Postmodern and Poststructural Social Work $\quad 22$

Other Problems $\quad 26$

$\begin{array}{ll}\text { Consciousness } & 26\end{array}$

$\begin{array}{ll}\text { Experience } & 30\end{array}$

$\begin{array}{ll}\text { Political Action } & 32\end{array}$

Bureaucracy, Professionalism and Other Forms
of Social Organization

$\begin{array}{ll}\text { Conclusion } & 39\end{array}$

$\begin{array}{lr}\text { III. The Problem } & 40\end{array}$

$\begin{array}{lr}\text { Delineating the Problem } & 40\end{array}$

Discussion of Terms $\quad 42$

Race, Class and Gender $\quad 42$

Other Terms 44

IV. The Research Project $\quad 50$ 
Critical Focus

Qualitative Research Design 51

Data Collection: The Entry Points 52

Methods and Process $\quad 52$

$\begin{array}{ll}\text { The Workers } & 56\end{array}$

$\begin{array}{ll}\text { Documents } & 58\end{array}$

$\begin{array}{ll}\text { Validity } & 59\end{array}$

Analytic Process 61

$\begin{array}{ll}\text { Analytic Framework } & 64\end{array}$

1. Social Relations 65

2. Ideology and Consciousness 65

3. The Politics of Culture and Socioeconomic
Politics

$\begin{array}{ll}\text { V. The Context } & 69\end{array}$

The Roots of Social Work $\quad 69$

The Rise and Decline of the Welfare State 69

$\begin{array}{ll}\text { Liberalism } & 73\end{array}$

$\begin{array}{ll}\text { Changes in Demographics } & 74\end{array}$

$\begin{array}{ll}\text { VI. Class } & 76\end{array}$

$\begin{array}{ll}\text { How Class is Depoliticized } & 76\end{array}$

$\begin{array}{ll}\text { Seven Mechanisms that Formalize Class } & 79\end{array}$

vii 
Discursive Practices that Depoliticize Class

Class as a Description, Not a Relation

The Poor and the Middle Class

The Poor

The Middle Class

Class as a Cultural Injustice

Class as a Piece of Social Organization

Repoliticizing Class

Structures

Solidarity-based Social Work

Unions as Tools

Summary

VII. Gender

How Gender is Depoliticized

Women's Committees

Discursive Practices of Sexism is

No Longer/Not an Issue

Constructing Male Violence:

Professionalism and Therapy

The Invisibility of Relations of Reproduction

Importing Market Relations: Private Practice Feminist Therapy

Repoliticizing Gender

Feminist Pieces of Social Organization 
How Race is Depoliticized

Funders and Organizational Change

Race is "In" and Other Issues are "Out"

Hiring

Multi-"ism" Strategies

Access and Language

Other Pluralist Policies

Neoliberalism and Race: White Backlash

Repoliticizing Race

Worker's Formulations of Race: Static, Relational, Racisms, as well as Colonialism and Globalization

Multi-"ism" Anti-Racist Work

Race Needs Its Moment

Experience and Just Principles

Race and Pieces of Social Organization

Summary

IX. Dyads: Class and Gender; Race and Gender; Race and Class 
Race and Class

$\begin{array}{ll}\text { Summary } & 246\end{array}$

$\begin{array}{llr}\text { X. Race, Class and Gender } & 248\end{array}$

$\begin{array}{ll}\text { Introduction } & 248\end{array}$

The Multilayers of Race, Class and Gender $\quad 249$

No Consensus: Intersecting, Separable or

Inseparable

$\begin{array}{lr}\text { Oppressions and Cultural Approaches } & 258\end{array}$

Political Correctness and Pretending We

Already Know $\quad 262$

Frameworks for Working with Race, Class and Gender 265

$\begin{array}{ll}\text { Summary } & 268\end{array}$

$\begin{array}{lr}\text { XI. Conclusion } & 270\end{array}$

Race, Class and Gender are Depoliticized

$\begin{array}{ll}\text { Differently } & 274\end{array}$

$\begin{array}{ll}\text { Race, Class and Gender in Praxis } & 279\end{array}$

Recommendations and Ongoing Questions $\quad 284$

XII. Appendices

Appendix I - Discussion Guide - Focus Group A-1 289

Appendix 2 - Discussion Guide - Focus Group B-1 291

Appendix 3 - Interview Guide - A 293

Appendix 4 - Interview Guide - B 295

Appendix 5 - Discussion Guide - Focus Group A-2 297

Appendix 6 - Discussion Guide - Focus Group B-2 298 
Appendix 7 - Discussion Guide - Focus Group C-1

Appendix 8 - Interview Guide - C

Appendix 9 - Interview Guide - D,E,F,G,H,I

Appendix 10 - Themes - Focus Group A-1

Appendix 11 - Themes - Focus Group B-2

Appendix 12 - Preliminary Results Diagram - Race

Appendix 13 - Preliminary Results Diagram - Class

Appendix 14 - Preliminary Results Diagram - Gender

Appendix 15 - Preliminary Results Diagram - Race and Class

Appendix 16 - Preliminary Results Diagram - Class and Gender

Appendix 17 - Preliminary Results Diagram - Gender and Race

Appendix 18 - Preliminary Results Diagram - Race, Class and Gender

Appendix 19 - Mapping

Appendix 20 - Final Mapping

Appendix 21 - Research Protocol - Ethics Submission

Appendix 22 - Consent Form - Focus Group

Appendix 23 - Information Sheet - Focus Group

Appendix 24 - Consent Form - Interview 


\section{Chapter One}

\section{Introduction}

Critical social work is part of a larger social project aimed at the liberation of subordinated groups and the establishment of a socially just society (Bailey and Brake, 1975; Brake and Bailey, 1980; Dominelli, 1988; Mullaly, 1993). The goal of theory within this paradigm is the illumination of ways that injustice in the form of domination and subordination are perpetuated and the development of new, socially just relations and structures. While it is not requisite that theory directly inform practice, its ultimate validity test is located in political practice and struggles for social justice (Fraser, 1989). Questions such as how social relations like race, class and gender organize our everyday lives are central issues of debate within the critical tradition (Walker, 1990).

In many ways, social work has come late to the project of understanding how multiple bases of subordination such as race, class and gender overlap, reinforce, contest and generally play themselves out in everyday life. While a number of critical social work theorists have addressed themselves to this topic, most of the models do not illuminate the way that multiple social relations shape and organize social work practices and relationships (Carniol, 1990; Dominelli, 1988; Mullaly, 1993; Wineman, 1984). This thesis looks at how the everyday practices of frontline critical social workers reveals new ways to understand class, race and gender. Data were collected from five focus groups and nine in-depth interviews involving a total of twenty-one participants. Agency and community documents and policies acted as secondary data sources and were used to provide a sense of context. The study participants were all self-defined critical social workers who took the necessity of social or cultural restructuring or both as the frame for their everyday practice. 
The data were analyzed utilizing a three-part frame consisting of:

1. an understanding of race, class and gender as social relations that organize the details and patterns of our everyday lives (Bannerji, 1995, 1993; Ng, 1993a, 1993b, 1990, 1988; Smith, $1990,1987)$.

2. a Gramscian notion of consciousness as a contradictory whole consisting of pieces of ideology and pieces that prefigure more egalitarian and socially just social relations (Sassoon, 1987a, 1987b).

3. a framing of the critical politics required by this era as the unity of cultural (recognition) and socioeconomic (redistributive) politics (Fraser, 1997).

The thesis proceeds from an overview of the critical social work literature and its associated weaknesses to a delineation of the problem of this study. This is followed by a discussion of the methodology, and context of this thesis as well as a more detailed description of the analytic frame. Subsequent chapters explore the findings and analysis in light of a critical epistemology and analytic frame. Each of class, race and gender are initially discussed separately followed by a chapter in which the dyads of race and gender, gender and class and class and race are explored. The last chapter examines the way the constellation of class, race and gender was formulated and applied in everyday social work practice. Emancipatory possibilities emerging from the data are discussed in the conclusion.

This study shows that liberal ways of understanding, acting upon and explaining social problems and relations infiltrate all areas of social work practice, even where workers are attempting to build more critical ways of thinking and practicing. However, a schism was observable between the formal theory of progressive social workers and the ways that they talked about how class, race and gender were part of their everyday work. The data showed that there were three levels at which race, class and gender were formulated. The first was the level of formal theory. Progressive social 
workers displayed a fairly good knowledge of formal critical theory. The second was the level of practice theory or integrating a critical analysis into how workers talked about their work. At this level, the workers tended to employ liberal or quasi-liberal notions of race, class and gender. The third was the use of techniques that are associated with the critical model of social work. These techniques included critical consciousness raising, collaboration, the building of egalitarian agencies, and the politicization of clinical practice. When utilizing these critical techniques, a shift in relations between workers and clients was noted. This shift was typified by a reported commonality of cause, shared identities between workers and clients as social justice fighters, and a sense that the existing order, or pieces of it, are unjust and must be changed. This shift in relations and identities creates the possibility for more fluid and politicized ways of formulating anti-racism, anti-sexism and classconscious practice.

These findings are important because progressive social workers need to understand that ideology is very present in their work. In order to practice social work in ways that are critical and anti-oppressive progressive social workers require a greater understanding of what ideology is and how to identify and decode its operation within everyday talk, agency policy, service delivery and social policy. Moreover, the political, cultural and economic conditions of the present era indicate that social workers must develop new ideas and strategies for resisting oppression in everyday practice. This study argues that there are certain ways that agencies and services are organized that enhance the possibility of practicing social work in more politicized and liberatory ways. This provides useful insights around how to restructure our agencies and services along more egalitarian lines. During this era of massive social service and economic restructuring the findings of this study provide lessons as to how public provision might be restructured in order to promote socially just and 
equal relations.

Thirdly, this study identifies various agency policies and procedures that quantify and depoliticize race, class and gender tensions. As workers struggle to realize social justice agendas, the findings of this study can assist them in mapping out and pinpointing how race, class and gender are depoliticized within the structures, policies and procedures of their agency, the social service community and the wider society. These types of strategies can enhance our capacity to resist oppression and build new structures, relations and identities based on shared struggle and social justice agendas. 


\section{Chapter Two}

\section{$\underline{\text { Literature Review }}$}

\section{Defining the Critical Social Work Literature}

This study investigates everyday practices within a specific genre of social work referred to hereafter as critical social work. Critical social work is part of a cluster of theories which analyze all aspects of social life from an explicitly political perspective. This political perspective intertwines theory and practice in order to produce knowledge aimed at both interpreting the world and changing it. Finding much of its initial inspiration in the work of Marx and others associated with his work and goals, critical theory seeks to understand how subordination and domination operate in society, as well as ways to "demystify rival approaches that obfuscate" (Fraser, 1989: 113) or rationalize oppressive and exploitive relations . Critical theory sees social movements and struggles for social change as "the subjects of its critiques and sees political practice as the ultimate test of the validity of its claims" (Fraser, 1989: 113).

Critical or radical social work theory is a specific genre of critical theory largely developed in the 1960s and 1970s in the Britain, Canada, Australia and the USA. ${ }^{1}$ While arguing for a unity of community, clinical and policy work, the critical social work literature addresses itself mainly to direct practice issues. Included under the broad umbrella of critical social work are radical social work, structural social work, Marxist social work, feminist social work, anti-racist social work, as well as

1 Although not well developed in the literature various forms of socialist or critical social work existed in all these countries prior to the 1960s. See for example the work of Bertha Reynolds and the Rank and File Movement $(1945,1958)$ or some of the activism around settlement houses in Canada and the USA, or social gospel social work in the same countries. Examples of this type of radical work are scattered and not well documented and hence are not included in this problematization. 
post modernist and post-structural social work. Overall, critical social work is often seen as lagging behind other genres of critical theory in a number of areas.

An enduring weakness within all varieties of critical social work is its inability to explicate the interrelations between and within the totality of oppressive social relations. Initially most critical social work was dominated by a class analysis which collapsed all forms of oppression and exploitation under the central relation of class. Later, feminist and anti-racist social work developed a keener analysis of other pivotal axes of oppression such as race and gender. However, although many models have tried, no one model exists which reveals how multi-oppressions interact with, contest, and reinforce each other.

In the following pages I will review the way in which critical social work literature constructs each of race, class and gender as well as how they theorize the inter-relationship, if any, between or among the three. Secondly, I will relate these findings to the way that these literatures formulate key pieces of critical practice in relation to their consiructions of race, class and gender. These specific practices include critical consciousness raising, political action, the use of critical theory and the role of the client's experience of oppression and exploitation. The way in which these facets of practice and theory relate to institutional practices, structures and relations will also be discussed. Although other genres of the critical literature may engage with these notions with greater theoretical sophistication and complexity, this review will address itself only to the critical social work practice literature. $^{2}$

Critical social work literature is epitomized by an analysis of power relations. Liberal and

2 In specific this review will not include genres of the critical literature that are sometimes included within a broader framing of social work literature. These genres include social policy, feminist social theory, anti-racist social theory and various sectors of political economy. 
conservative literatures tend to view power as idiosyncratic, a facet of individual personalities, or the unproblematic backdrop to everyday life. In contrast, within Marxist social work, for example, power is an explicit part of social life with differences in class power constituting the pivot point of the entire analysis. The social work literatures which I have included in the definition of critical social work are those which involve an explicit analysis of power on a social and personal level. Due to its primary focus on the personal or the subjective, I have excluded the following literatures: liberal feminist, multicultural, and empowerment. I will discuss the critical literatures in the following order: radical/structural, feminist, anti-racist, and postmodern/poststructural.

\section{Radical/Structural Social Work}

Radical or structural social work is the largest sector of critical social work in terms of quantity and longevity. Almost without exception, structural/radical social work scholars are white, male academics. In the UK this body of work is known as radical social work (Bailey and Brake, 1975; Brake and Bailey, 1980; Corrigan and Leonard, 1978; Jordan and Parton, 1983; Langan and Lee, 1989; Leonard, 1975; London Edinburgh Weekend Return Group, 1980), in the USA as radical, Marxist or structural social work (Burghardt, 1986, 1982; Galper, 1975; Longres and McLeod, 1986; Reynolds, 1963, 1951, 1946; Wineman, 1984)3 , in Canada as structural social work (Carniol, 1990; 1987, 1979; Moreau, 1989, 1979, n.d.; Moreau and Leonard, 1989; Mullaly, 1993 1995; Mullaly and Keating, 1991; Wharf, 1990), and in Australia as empowerment or structural social work (Rees,

3 Wood and Middleman (1989), also American, have written a book entitled The Structural Approach to Direct Practice in Social Work. However the analysis and model they present is actually the ecological or life model of social work which is not a critical social work theory. Therefore they have not been included in this analysis. 
1991). Beginning in the mid-seventies with Brake and Bailey's work in the UK and Galper's work in the USA, radical social work has had significant influence on mainstream social work (Brake and Bailey, 1980; Galper, 1975).

In an article entitled "Similarities, Differences and Dialectics of Radical Social Work" Mullaly and Keating (1991) summarize the core concepts and agreements among this melange of radical theories. Like Langan and Lee (1989) they argue that most points of agreement exist at higher levels of abstraction. Their nine points of agreement include: 1) a rejection of capitalism, 2) a rejection of liberal reformism, 3) the capitalist state props up capitalism, 4) social welfare as a societal norm is antithetical to capitalism, 5) conventional social work perpetuates social problems, 6) the individual vs. society is a false dichotomy, 7) a socialist/marxist feminist perspective is an epistemological imperative for radical social work, 8) racism rewards white people, perpetuates personal and social injury and reinforces capitalist relations, 9) professionalism is for professionals not for service users and must be viewed with caution or distrust (Mullaly and Keating, 1991). These schoiars locate the major differences of this genre of social work as lying within the model and methodology of politicoeconomic change. They have developed four categories in an attempt to capture these differences: 1) social democracy (fabian socialist), 2) revolutionary Marxism, 3) evolutionary Marxism, and 4) Mullaly's model - the dialectic approach (Mullaly and Keating, 1991; Mullaly, 1993).

Unfortunately, Mullaly and Keating's list of similarities is more of a wish-list for a preferred model of critical social work rather than an accurate reflection of what exists. ${ }^{4}$ My reading of the

4 Mullaly and Keating (1991), like Langan and Lee (1989), include feminist, and anti-racist social work literatures in the category of radical social work. Hence, they can credibly make their claims regarding feminist epistemologies and analyses of race. However, feminist and anti-racist scholars identify themselves as such, for large part, because of the weaknesses and hegemonic tendencies of radical/structural social work. Hence, I have identified these literatures, as they identify themselves, as critical genres which are compatible with, but distinct 
literature did not uncover widespread commitment to feminist ideas or epistemology. Although many authors note that women's experience of oppression and exploitation differs from that of men, an analysis and theorization of this experience is not central to their critique of capitalism (Bailey and Brake, 1975; Brake and Bailey, 1980; Galper, 1975; Leonard and Corrigan, 1978; Longres, 1986). Secondly, most radical literature does not include more than a superficial mention of race or antiracism. Thirdly, radical/structural social work has paid scant attention to theorizing how multiple oppressors such as class, race and gender might overlap, reinforce, contest or contradict each other. Exceptions to this rule include later work by Moreau who recommended a model of Parallel Oppressions. In order to avoid an evaluation of which oppression is most important, Moreau's model simply lines each oppression up alongside the other in a unquantified and unquantifiable manner (Carniol, 1989). Clearly, this model has no capacity to explicate how oppressions interact with each other in various social contexts and experiences. Mullaly (1993) offers perhaps the best model of multiple oppressions. Expanding on the work of Wineman (1984), he argues that axes of opfression are a mesh of criss-crossing oppressions which interact with each other in specific ways at their points of contact (Wineman, 1984: 169-170). Thus a black, lesbian, working class woman experiences the multiple and unique oppressions of this particular conglomerate of oppressors. The experience of a white lesbian or a black straight man would be significantly different as influenced by the cross-hatch of the axes of oppression which impact on each of them. Unfortunately, while Mullaly (1993, 1995) notes that race, class and gender are major oppressive forces, his own work on structural social work analysis includes an in-depth analysis only of class.

These weaknesses are pervasive in the radical/structural social work literature. By focussing

from, the radical/structural literature. 
almost exclusively on class issues, this literature remarginalizes everyone who is not an able-bodied, white, straight, man. For example, early works such as Corrigan and Leonard (1978) or Bailey and Brake (1975) clearly situated class as the central social relation to which all others are secondary. Although Langan and Lee suggest that absences in early radical social work have been supplanted by a wider awareness of the specifics of race and gender as well as the complex relationship between social work and the state, it is difficult to find evidence of this in the literature (Langan and Lee, 1989: $5,10)$. Radical social work can be seen to focus on class relations, the contradictions of capitalist production and a more-or-less dialectic class struggle over the control and ownership of the means of production, and the state. Production is seen as the central relation in which capitalists, the minority, own the means of production and workers, the majority, own nothing but their labour power which they are compelled to sell in order to earn the means of subsistence (Burghardt, 1986; Corrigan and Leonard, 1978; Longres and McLeod, 1986). Hence, the major focus of struggle is working class revolutionary politics (Corrigan and Leonard, 1978; Longres and McLeod, 1986). For social work this means we must be active in the politicization of all aspects of work life, while building support for and of working class struggles (Bailey and Brake, 1975; Corrigan and Leonard, 1978; Jordan and Parton, 1983; Langan and Lee, 1989; Longres, 1986; Reynolds, 1963). In the social work agency, political action takes the form of support for working class struggles. This support requires constructing the broadest possible unity amongst staff -- therapists, social workers, cleaners, support staff, drivers -- and with and between labour unions and other mass movements (Brake and Bailey, 1980; Carniol, 1987; Corrigan and Leonard, 1978; London Edinburgh Weekend Return Group, 1980).

Early radical social work often focussed more on the victimization and oppression of clients 
and workers, than on the myriad of ways they display agency and capacity for collective activism (Bailey and Brake, 1975; Bailey, 1980; Galper, 1975; Mayo, 1975), or the way that we explicitly and implicitly are part of and recreate relations of domination and subordination within the social work milieu. The work of Leonard (1975) and of Mullaly (1993, 1995) bring useful correctives to the preoccupation with the social control aspects of social work and society. They emphasize that social life is dialectic ${ }^{5}$, hence individuals are both the objects of social control, as well as active subjects capable of utilizing their own human agency and capacities to resist oppressive relations (Mullaly, 1993: 143). The re-emphasis on dialectics is a significant advance in radical theory and analysis. Marx's original work emphasized that class is a matter of a dynamic or dialectic relationship between individuals and the means of production. Rigid or deterministic interpretations of Marx, such as much of the early radical social work writings, often lose this pivotal piece of Marx's theory. This results in analyses and practices which are prescriptive, narrow and resist developing in tandem with changes in material conditions. The re-emphasis on dialectics is, probably, the most important aspect of this body of literature. A dialectic analysis is key in the struggle to illuminate how race, class and gender are active in social life, and the facets of these relations that social workers must understand in order to practice in a liberatory ${ }^{6}$ manner.

\section{Feminist Social Work}

Feminist social work theory and practice developed with the second wave of feminist activism

5 Certain terms used in this document attempt to express a dynamic that is difficult to capture using simple language. See Chapter III - Discussion of Terms for a definition of this term.

6 See Footnote 3. 
and academia in the sixties and seventies. Although feminists hail from as many political perspectives as do non-feminists, most feminist social work writings tend to reflect either a socialist/marxist feminist analysis or a liberal feminist analysis. Canadian, British and Australian literature (Baines, Evans, Neysmith, 1993; Dominelli and McLeod, 1989; Fook, 1984; Gilroy, 1990; Hale, 1983; Hudson, 1989; Levine, 1982; Marchant and Wearing, 1986; McLeod in Wilson, 1980; Morgan, 1981; Walker, 1990a, 1990b; Wilson, 1980) tend to reflect the former and with some notable exceptions (Withorn, 1984), American literature represents the latter. As noted earlier, the liberal feminist analysis only very peripherally connects with the goals and definitions of critical theory. Hence, I will limit my examination to socialist/marxist feminist social work literature.

Socialist/Marxist feminist social work, referred to hereafter as feminist social work, attempts to combine the methodologies and analyses of feminist and Marxist traditions. Consciousness raising, or "the demystification of social relations through the collective sharing of individual experiences", as well as the realization of the personal is political, are the two mainstays of critical feminist methodology in both academia and activism (Dominelli and McLeod, 1989: 33). ${ }^{7}$ These two methods tie feminist analysis to women's everyday lived-in experience and place the focus of feminist social action on social relationships,

through the process of becoming aware of the shared similarity of experience and the causes of their misery, women's individual problems become defined as social issues. Consequently, the solutions to these problems are sought in the public rather than in the private domain (Dominelli and McLeod, 1989: 33).

This focus on social relationships extends also to the feminist theory of power. Similar to the marxist

The realization of the personal is political refers to the process of politicizing personal/private aspects of life, as well as using the everyday experience of women as an epistemological basis for political struggle and critical practice. 
or socialist analysis of power, feminist social work sees power as relationship (Wearing, 1986: 34). Unlike a strict Marxist interpretation which sees class as the central relationship of oppression and exploitation, feminist theory adopts an approach which permits the inclusion of at least two axes of oppression. At the level of theory, multi-axes of oppression are not worked out in a simple way and controversy abounds over just how more than one axes of oppression can co-exist, contest, reinforce and/or diminish other axes. In the seventies and eighties many feminist theorists inside and outside of social work adopted a dual systems or capitalism plus patriarchy approach (Sargent, 1981; Hartman, 1981). Others rejected this formulation as awkward and inexact (Harding, 1981; Young, 1981). While appealing in many ways, the dual systems theory, like Marxism itself, had difficulty incorporating and explicating other axes of oppression such as race, or sexual orientation, without resorting to reductionism.

The late eighties and early nineties saw the development of feminist theory that attempted to unite feminist theorists in multiple axes of injustice. The work of feminist sociologists, philosophers, anthropologists and political scientists struggled with ways to understand the intersections, similarities and differences between and among race, class and gender (Bannerji, 1995, 1993; Benhabib, 1994; Butler, 1994; Rebick and Roach, 1996; Young, 1990). In particular the eclipsing of the issues of women of colour was identified as ongoing practices of colonialism, imperialism and racism (Bannerji, 1995, 1993; Davis, 1989; Green, 1993; Razack, 1993). While discussed widely outside of the social work literature, these ideas have been resisted within the social work arena and there is very little evidence of their influence within the feminist social work literature.

In general, most feminist social work literature provides no more than a passing mention of race, and does not incorporate anti-racism as a central arena of practice. Its attempts to explain 
multiple oppressors is, likewise, awkward and unfinished. For example, at the level of practice, Dominelli and McLeod argue that feminism supports egalitarian relations in all aspects of social life, therefore "feminists are also against other social divisions which reflect dominance and subordination such as race, class, heterosexism, ageism and ablebodiedism" (Dominelli and McLeod, 1989: 2). Dominelli and McLeod's formulation permits the possibility of multiple axes analyses and practice. However, this analysis lacks the capacity to explicate relations of dominance and subordination, how they come about, how they interact with each other and with other social forces, and how they manage to continue. Multiple oppressor practice and analyses within the feminist social work literature is not the norm. For the most part, the feminist literature demonstrates an ongoing preoccupation with gender, and to some extent class as it is expressed through gender.

Unlike the other critical social work literatures, feminist social work recognizes that social work is a feminized terrain with women comprising the majority of the paid workers, the unpaid volunteers, the unpaid caregivers in the home and the clients (Baines, Evans and Neysmith, 1993; Dominelli and McLeod, 1989; Fook, 1986; Gilroy, 1990; Levine, 1982; Marchant and Wearing, 1986; Wilson, 1977, 1980; Withom, 1984). Feminist social work refutes constructions of social problems that do not integrate both the so-called public and private spheres of life. To that end, these writers have developed an extensive analysis of the family, caring labour and unpaid work, the community, alternative social work agencies and therapy as sites of social life that depend on and recreate unequal, often oppressive and always gendered social and interpersonal relations (Baines, 1997; Baines, Evans and Neysmith, 1993; Dominelli and McLeod, 1989; Gilroy, 1990; Levine, 1982; Morgan, 1981; Wilson, 1977; 1980; Withorn, 1984).

In addition, feminist social work would be strengthened by an extension of its analysis to how 
both men and women are gendered in this society and how this gendering is crucial to continuing inequality and oppression. Also it needs to develop a clearer understanding of the way that women act in a gendered way to each other just as gender is present in all relationships between men. Finally, this body of theory should develop a greater exploration and problematization of hetero- and homosexuality. Again, both these social relations reinforce and define the other. The perpetuation of the oppressive and exploitive aspects of these social relations is significantly dependent on the other. In summary, for the most part, feminist social work demonstrates a lack of analysis of race and other significant axes of oppression. There is also clear need for further development of how multiaxes of oppression overlap, contest, and mutually reinforce.

\section{Anti-Racist Social Work}

Scholarly work on anti-racist social work is the least developed sector of critical social work literature. This can be attributed to the general marginalization of people of colour within academia and social work, as well the dominance within critical social work of the Marxist analysis. This has meant that the development of a critical analysis of these other forms of oppression took longer, followed other routes, continues to struggle for recognition within critical theory as a whole or all three. Orthodox Marxism, in particular, collapses all forms of oppression under the rubric of class oppression. Just as the struggles around gender are seen within orthodox Marxism to be secondary to class struggle, racism was also seen to be most effectively redressed through the building of class struggle and socialism. Due in part to the perseverance of feminists and anti-racists, Marxist analyses broadened to more explicitly include other vectors of oppression in their analysis and strategies. Regrettably, the anti-racist social work literature is very limited in quantity and somewhat narrow in 
scope. An assessment of the literature leads one to conclude that it would require an active affirmative action project in order to ensure that this key political and social issue is more central to critical social work theory, policy and practice.

Much of the existing anti-racist social work literature is British and hence, unique to England's history of slavery, colonialism, imperialism and present day racism. Some Australian work exists which, while not extensive, is rather promising (Petruchenia and Thorpe, 1990; Petruchenia, 1990). The Canadian literature is very scarce. That which exists deals primarily with First Nations (Howse and Stalwick, 1990), and due to the specific history and condition of First Nations people within Canada, this literature is not generalizable to other people of colour.

American literature is largely clinically oriented, multi-cultural and pluralistic rather than critical and anti-racist, and fairly prescriptive. For example, Davis and Proctor spent several years putting together statistical profiles of the race, class and gender of the average service user and service provider actoss the entire USA (Davis and Proctor, 1989). This quantification of clients and workers also includes a discussion of options for how to proceed with interventions. While one might question whether a statistical profile of the average American client could usefully inform practice in such disparate settings as an inner city New York and in small town Kansas, the biggest problem with the work is its ultimately liberal analysis and practice options.

Davis and Protor promote a conception of anti-racist, anti-sexist, class conscious practice as a series of quantifiable and easily attainable, individual, professional skills. For example, Davis and Proctor provide the following advice on the issue of sexism:

To enhance their demonstration of respect, workers should be diligent to use appropriate titles (for example, Ms. or Mrs.), to ask women (as they routinely ask men) what they do, to refrain from commenting on women's appearance more than men's, and to listen attentively and carefully to what women clients say. Respect is also conveyed by taking client's problems 
seriously. (Davis and Proctor, 1989: 253).

Racism is also seen to be individual acts of ignorance and disrespect rather than structures, relations and systems of subordination and domination. Workers are told that "prompt availability for appointments" combats negative messages to clients of colour and builds trust (Davis and Proctor, 1989: 121). Practitioners should also "greet minority clients with handshakes, proper introductions, and references by titles (Mr., Mrs.) and last name" (Davis and Proctor, 1989: 121). Class is explained as one's socioeconomic status and is also argued to be addressable through a series of rather trite alterations in the behavior and demeanor of the worker. Davis and Proctor's work on race, class and gender, like most of the American social work literature on anti-racism, does not fit the definition of critical theory. Hence, it will not be included in this analysis.

Critical anti-racist social work theory seems to have developed, in part, due to the inability of existing critical theories to explain racism or to elucidate strategies for struggle. While most of the British anti-racist literature maintains a class based analysis, they reject a collapsing of racism into the overall battle for socialism. Instead they seem to favor a dual-system analysis combining race and class (Husband, 1980; Hutchinson-Reis, 1989). A few scholars, such as Shah (1989), incorporate race, class and gender into their analyses; however most omit gender entirely. Writing in Australia, Petruchenia and Thorpe (1990), likewise, attempt the development of a race, class and gender analysis.

Dominelli, in a completely different direction, argues that race is the central contradictory relation in the present socio-economic-political system. She theorizes that the resolution of race contradictions will also result in the resolution of gender and class oppressions (Dominelli, 1988). She argues that in additional to eradicating racism, anti-racist social work can "expose and tackle other 
forms of oppression which are reproduced by and perpetuated through social work" (Dominelli, 1988: 163). This will include ending class and gender inequality through fundamental changes to the political, juridical and social basis of current practice (Dominelli, 1988: 163).

Unlike the other critical literatures, anti-racist work spends a great deal of time attempting to define what anti-racism is and what it is to be anti-racist. Most of the British anti-racist social work literature, for example, provides a detailed and directive road map for the "radical" social work practitioner. This prescriptive quality may emerge from racism's pervasive and subtle ideological qualities so that anti-racist theorists are constantly bombarded with questions around what is racist social work practice, what does it look like, how do we identify it and do things differently? It may also be a quality which exists when theory is very new and forced to justify itself at every turn. Whatever the reason, it sets itself up for easy critique as it dictates absolute solutions rather than engaging people in creative and critical thinking which has the possibility of creating more comprehensive and lasting changes.

In defining itself and racism, anti-racist social work literature argues that work with people of colour must be placed in the context of the history of slavery, colonialism, imperialism and contemporary racism. As Husband notes in regard to racism in the UK,

British racism assumes an inferiority of black in relation to white identity -- the exploitive relations between white Britain and black societies necessarily generated ideologies which legitimated the nature of these relations (slavery, colonialism, imperialism) and permits people to believe that they are tolerant, pleasant, fair, civilized people while oppressing and exploiting others (Husband, 1990: 68). ${ }^{8}$

8 In the UK the term "black" is employed by and for people of colour. In some radical circles it is used more broadly to refer to all those who are not part of the dominant AngloSaxon majority. Race is a very slippery category at best and this is reflected in the anti-racist social work literature as it is not always clear how the term "black" is being used. 
Dominelli sees racism as comprised of three main elements in interaction with each other -individual, institutional and cultural racism (Dominelli, 1988: 7, 8). Individual racism is comprised of discriminatory and prejudgemental attitudes and behaviors. Lacking institutional support these attitudes and behaviors constitute prejudice. Institutional racism is comprised of "customary routines which ration resources and power by excluding racially inferior groups" (Dominelli, 1988: 8-9). Finally, cultural racisms are those values, beliefs and ideas which reinforce and legitimize the superiority of white culture.

Using a Gramscian framing Dominelli argues that in order to maintain dominance the ruling groups and their allies must "capture people's hearts and minds in a common-sensical, seemingly untheorized way which secures their consent to be dominated without being conscious of it" (Dominelli, 1988: 8). The subtle, unarticulated and pervasive nature of such hegemonic ideologies permits most white people to think of racism as the extremist actions of a few violent, neo-Nazis rather than an always present feature of society. Dominelli suggests that the social control and oppression of people of colour occurs through racist social relations. Hence she argues that race rather than class or gender is the central relation for black people, as class and gender are mediated through and by race. Thus a black person's experience of sexism or class oppression is different than that of a white person's (Dominelli, 1988: 11).

Most anti-racist social work literature sees racism, whether at the institutional, cultural or individual level, as experienced through everyday relations and practices. Within the specific context of social welfare policy, service delivery and practice, racism is perpetuated in three major ways through practice that is racist, through social workers using "the authority of office rather than the authority of (the) experience" of the oppressed (Dominelli, 1988: $x$ ), as well as through resisting anti- 
racism. Practice that is racist includes such things as colour-blindness, pathologizing the black family, erasing the history of society as white supremist, colonial, and imperialist, suggesting that black culture is responsible for the racist treatment Black people receive - for example: not learning English, being on welfare, etc., and pathologizing black resistance to everyday racism. Finally, while most social workers identify as non- or anti-racist many resist the implementation of anti-racist policies, practices and strategies (Petruchenia and Thorpe, 1990; Dominelli, 1988; Hutchinson-Reis, 1989).

Dominelli identifies seven ways in which this is done:

1. denial - denying the continuing existence of a problem

2. omission - not seeing anti-racism as relevant to most situations and relating to others as if it did not exist

3. decontextualization - the problem is out there, not in here

4. colour-blind approach - we are all equal here and treat all clients exactly the same

5. dumping approach - it is black people's problem and they should deal with it

6. patronizing - blacks are quaint and cultural while whites are the mainstream and superior

7. avoidance (Dominelli, 1988: 71-72).

Dominelli also provides a detailed list of ways in which social work educators should promote anti-racist education (Dominelli, 1988: 69-70). Reflecting her very strong sense that white people have a different relationship to racism, Dominelli also provides a list of practice directives for white social workers (Dominelli, 1988: 162-163).

Petruchenia and Thorpe identify two sorts of problematic responses to anti-racist work in social work. Based on their community practice experience in Australia these scholars define antiracist welfare practice as a "commitment to identify and challenge racism within ourselves, in others 
and in society" (Petruchenia and Thorpe, 1990: 54). However, they also suggest that non-racistracists and anti-racist-racists often confound and confuse the best efforts of anti-racist practitioners. Non-racist-racists are those who take a neutral stance on racism and thus maintain the status quo by doing nothing to challenge racism. The anti-racist-racist openly campaigns against extremist racist and fascist organizations but does not attempt to challenge institutional racism, or to promote and monitor the implementation of anti-racist strategies in the workplace (Petruchenia, 1990: 55). Part of this assumption is actualized in the notion that white people and white culture have much to offer black people whilst black people and their culture can provide little or nothing in return (Gilroy in Dominelli, 1988: 2). A great deal of social attention is focused on black people and their communities rather than on white people and their practices and power structures. Thus those at the receiving end of racism are blamed and scrutinized instead of the social relations creating power inequalities (Gilroy in Dominelli, 1988: 2).

The anti-racist social work literature provides important correctives to critical theory. In particular, it highlights the importance of critiquing and exposing as racist everyday, commonsense practices and discourses, as well as larger systemic patterns and structures. However, like radical/structural and feminist social work, anti-racist social work requires a multi-axes analysis of exploitation and oppression. This analysis must be able to account for how these vectors overlap, contest, and mutually reinforce. Additionally, anti-racist social work would be strengthened by an analysis of how all people are racialized in advanced capitalist societies just as all men and women are gendered (O'Brien, 1993). These racialized relations are a significant way in which racism is kept in place and recreates itself in new forms under constantly changing social and economic conditions. 


\section{Postmodern and Poststructural Social Work}

Postmodern and poststructural social work are relatively new sectors of critical and mainstream social work theory. Developing in the early nineties, postmodern social work draws on the work of postmodernists such as Baudrillard (1987), Lyotard (in Irving, 1994: 21) and Harvey (1989). While postmodernism and poststructuralism are often used interchangeably, poststructuralists draw on the work of Foucault. ${ }^{9}$ Within social work, these theories have largely been applied to social work knowledge and education (Brown, 1994b; Chambon, 1994; Epstein, 1994, Featherstone and Fawcett, 1994; Gorman, 1993; Irving, 1994; Leonard, 1994; Sands and Nuncio, 1992) with a lesser focus on practice and policy (Gowdy, 1994; Pardeck et al, 1994; Parton, 1994; Pozateck, 1994; Saleeby, 1994). As Sands and Nuccio uncritically point out, much of postmodern practice is compatible with mainstream models of social work such as the ecological perspective (Sands and Nuccio, 1992: 489). Other scholars specifically ally their postmodern analysis with emancipatory projects and the oppressed (Brown, 1994a, 1994b; Gowdy, 1994; Leonard, 1994).

While postmodernists employ a methodology known as deconstruction, and poststructuralists favor Foucault's archaeological methodology, this genre of critical social work tends to combine both methodologies in a kind of post-liberal, post-marxist, post-humanist eclecticism. Some also add a feminist or postmodern feminist analysis to this pot pourri of methods (Featherstone and Fawcett, 1994; Sands and Nuccio, 1992; Brown, 1994a, 1994b). While significant variation exists, the following points comprise the central operating concepts of this genre of social work: ending

9 Michael Foucault was a prolific scholar. Some of his more influential pieces include Discipline and punish: The birth of the prison (1977), The history of sexuality, Volume I: An introduction (1978) and Power/knowledge: Selected interviews and other writings, 1972-1977 $(1972,1975,1976,1977)$. 
dichotomies, avoiding fixed categories, and a shift from consciousness as dependent on social and environmental factors to consciousness as dependent on language and discourse.

Postmodern/structuralist social work theorists are critical of the way in which postEnlightenment or modernist knowledge is largely based on a number of exclusive and exhaustive categories such as paid/unpaid work, private/public, market/family, male/female, Black/White. These false dichotomies are seen to emerge from capitalist, hierarchical (and for some scholars, patriarchal) society and create rigid, hierarchical thinking, as well as oppositional, zero-sum relations which obscure the complexity and fluidity of social life (Sands and Nuccio, 1992; Featherstone and Fawcett, 1994). Within social work such false dichotomies are seen to exist between policy and practice or between personal services and social action (Sands and Nuccio, 1992: 489). Sands and Nuccio argue that social relations are better represented by continuous or holistic knowledge building and practice. In contrast, Featherstone and Fawcett seem to favor historically, temporally and culturally specific and comparative analysis (Featherstone and Fawcett, 1994: 35).

Postmodern/structural social work attempts to avoid fixed or universalizing categories as it sees all definitions as historically contingent and context bound (Sands and Nuccio, 1992: 491). Fixed categories lead to essentialist definitions or attempts to get at the essence or single moment in which a relationship or category originated. While the search of the origins of women's oppression, for example, has proven to be academically interesting it has also served to marginalize and control those who do not fit within the resulting explanatory theories. Those who "fit" such universal, explanatory theories tend to be white, heterosexual, middle class women and those who do not "fit" tend to be women of colour, lesbians and other marginalized groups. Postmodern/structuralists see essentialisms as obscuring the diverse and multiple birth points and influential factors along the way 
as well as the transience of the present form of the oppression or social relation. Creating space for multiple explanations and multiple voices is thought to encourage the flowering of diversity and empowerment of those previously marginalized (Featherstone and Fawcett, 1994; Sands and Nuccio, 1992).

Some postmodernist/structuralist social work scholars are concerned that the notion of a precarious and constantly changing subjectivity allows dominant groups in society to abdicate responsibility. Just as the demands of women and Blacks are gaining some legitimacy we are told that these categories do not exist and that their needs claims are precarious and contingent. Featherstone and Fawcett question whether this allows men and white people "off the hook" by adopting perspectives which are concerned with challenging fixed and reductive notions of power and difference (Featherstone and Fawcett, 1994: 13). Chambon, likewise, questions whether postmodernist diversity has resulted in a plurality of closed and exclusive objects through the creation of a new, multi-voice field of diversity experts and "non-experts", rather than an expansion of the avenues of inquiry and empowerment (Chambon, 1994: 63).

Within the realm of social action and social change many social work and non-social work postmodernist/structuralists advocate an approach loosely known as "acting as if there were subjects" (Valverde, 1991). ${ }^{10}$ In other words, for the purposes of social change and mobilization, activists are permitted to pretend that the discredited, modernist, unitary subject and materialist consciousness (dependent on social and environmental factors) exists. Thus it is possible for diverse populations

10 Most postmodern/structural social work writings implicitly adopt some sort of notion of a unitary subject even while critiquing this modernist notion. Valverde's work is not in the social work realm although it is used by critical social work theorists. I have included a reference to the skilful theoretical argument she has put together around this debate in order to underscore some of the tensions and contradictions within the social work literature. 
to unite in order to struggle for common interests. Some refer to this approach as neohumanism and argue that large scale analyses and political struggle are possible but they must be hisiorically, temporally and culturally specific and comparative rather than universalist (Fraser and Nicholson, 1990 in Featherstone and Fawcett, 1994: 35). ${ }^{11}$ Despite these radical theory attempts to link postmodern/structuralism to macro or collective social change, most of the postmodern/structuralist social work literature focuses primarily on the individual's construction of meaning as detached from larger contexts and social forces (Gorman, 1993; Pozateck, 1994; Pardeck et al, 1994).

Postmodern/structural social work theory provides some useful notions for the critical social work theorist and practitioner. Their avoidance of dichotomies, the emphasis on diversity, and the notion that social relations are constantly shifting provides useful ways to think about social relations such as race, class and gender. Moreover postmodern/structural social work theory places a central focus on the dynamism and changeability of social life. On the other hand, seeking to avoid rigidly objectifying social relations, this literature has no particular way to put multiple oppressors together beyond the immediate. For the most part there is no acknowledgement within this literature of relations such as race, class or gender, or how these facets of social life might interact. However, these points of analyses are not explicitly excluded. Seeking to avoid fixed meanings, this analysis has difficulty avoiding individualistic and pluralistic ways of analyzing injustice and inequality. In addition, the emphasis on multiple voices and transient meanings, identities and language makes it very difficult to determine better from worse interpretations of actions, analyses, strategies and or pieces of social organization.

$"$ For an interesting example of a neohumanist, socialist-feminist approach to see Linda Gordon's (1988) historical study of the way that poor families met their needs and resisted the incursions of child protection services in Boston from $1880-1960$. 


\section{Other Problems}

Pieces of practice which are common to all the genres of critical social work include: critical consciousness raising, critical use of the client's and the community's experience, and political action. For the most part, these pieces of practice reflect certain commonalities in the conceptualizations of consciousness, experience, self determination, ontological vocations, ${ }^{12}$ the role of structures and ideology, as well as analyses of various pieces of social organization such as bureaucracy, hierarchy, and professionalism. Due to the very different histories and the ways in which the various social relations have been organized, as well as politicized, certain notable differences exist. These, in addition to the similarities, are discussed below. The concepts discussed in this next section are central to this thesis as they impact very strongly on how we are able to think about and theorize race, class and gender as a conglomerate. These concepts will be used repeatedly throughout the thesis in discussions of the data and discussions of the shortcomings of our present models for understanding and acting upon issues surronding the triumvariate of race, class and gender.

\section{Consciousness}

Fook notes that "the congruence of socialist and feminist analysis regarding the formation of individual consciousness by social and cultural institutions is well documented" (Fook, 1993: 64). This congruence has emerged as thought on consciousness developed within the various genres of

12 McLaren and Leonard (1993) argue that Freire's work, like the work of many critical practitioners, contains the notion that those who are subordinated have a predisposition to be liberated. They refer to this notion as an ontological vocation, or an inevitability that is located simply in one's "being". Alınough subordinated groups must struggle to achieve this liberation, there is a certain inevitability about it that is located simply in their existence. This sort of premise belies the adaptability and endurance of systems of domination, as well as the way that systems of domination and the strategies that may ultimately defeat them are wholly material practices in which inevitability plays no role. 
critical social work. Early radical/structural social work largely saw the state, social services and bourgeois culture as agents of social control (Bailey and Brake, 1975; Corrigan and Leonard, 1978; Galper, 1975). This produced a conceptualization of consciousness as wholly determined by the structural. Consciousness raising was a process of throwing off false consciousness, or thinking that was in the best interest of the ruling class, in order to see things as they really are. Later radical/structural theorists promoted a view that social life is dialectic hence, individuals are both the objects of social control, as well as active subjects capable of utilizing their own human agency and capacities to resist oppressive relations (Leonard, 1975; Mullaly, 1993: 143).

Still other radical/structural and feminist theorists have adopted a more Gramscian perspective which notes that consciousness is contradictory, containing elements which oppress and elements which have the potential to liberate (Dominelli and McLeod, 1989; London Edinburgh Weekend Return Group, 1980). Hence, the relationship between experience, ideology, critical consciousness and resistance is a complex one in which both the surface of experience and the forces and relations which underlie and organize material experience must be explored.

Postmodern/poststructuralist differ from the other critical social work literatures in their conceptualization of consciousness. Reflecting their rejection of fixed or objective meaning, consciousness is not seen as dependent on social and environmental factors, but on language. Meanings within language rather than being fixed, essential and concrete are multiple, unstable and open to interpretation (Weedon, 1987; Sands and Nuccio, 1992; Featherstone and Fawcett, 1994). Discourses, or bodies of language, as well as texts and readers are situated, not neutral, and provide the context for this interpretation (Sands and Nuccio, 1992: 490). As Foucault notes at any one time multiple perspectives or discourses are present but only a few are heard (Foucault, 1978). 
Consciousness, based on language, is not unitary and purposive as assumed by modernist thinkers. Rather consciousness, like language and meaning, is conflictual and precarious, always changing and changeable (Featherstone and Fawcett, 1994: 4). As Gorman notes it may not change fundamental injustices to know that "you" are socially constructed and historically contingent; however it may change our understanding of these injustices and of ourselves (Gorman, 1993). Postmodern/poststructural social work focuses primarily on the subjective, giving great credence to self-determination and the ontological vocation ${ }^{13}$ of the voiceless to be emancipated through their inclusion in diverse, transient and historically contingent strategies and interventions.

At the level of practice, these conceptions of consciousness do not produce meaningful differences. However, the various genres of critical social work do produce differing conceptualizations and methods of critical consciousness raising. For example, feminist social work theorists argue that disjunctures, or everyday sorts of contradictions exist in the way that ideology, structures and the experiences of women fit together (Dominelli and McLeod, 1989; Fook, 1986; Walker, 1990, 1986). These disjunctures between women's lived-in experience, and ideology are the fissures that provide a place for consciousness raising to enter and begin to expose contradictions, and foster empowerment, oppositional identities and activism. Thus, "although molded by social expectation and structural arrangements, the individual may be able to overcome some restrictions and exercise personal choice" (Fook, 1993: 64). However, critical consciousness is not the inevitable product of the identification of these contradictions. These contradictions are just as likely to be glossed over or explained by the client or community in reactionary or non-political ways as they are to produce social justice activism.

13 See Footnote 12 for a discussion of this term. 
Based on this observation, feminist social work has raised important questions around the limits of consciousness raising and the need for political debate and exchange between client and worker. Although the process is based on an egalitarian exchange of ideas, the worker must clearly impart her standards and understandings of social justice, equality and fairness, rather than unreflectively adopting the stance of the client. Utilizing their conceptualizations of overlap between structures, ideology and consciousness, feminist social work writers have problematized critical consciousness raising including central social work concepts such as self-determination.

Fook, for example, begins by asking how much self-determination does any person really have (Fook, 1993: 144). She observes that there are social, moral and material limitations on the extent to which an individual person can be self-directing. There may also be limitations unique to the people themselves - they may not know what they want, or may choose not to choose. Moreover, when a feminist social worker assists the client in politicizing their world view through consciousness raising, there is no guarantee that this politicization will remain a feminist or radical one. Clients may be reluctant to follow through on radical interpretations of their situation as it may mean major upheavals in their private lives (Fook, 1984: 145). Clients may choose, for example, ultraconservative, liberal, or no activism. There is nothing inherently radical about self-determination. Self determination, like consciousness raising, must be understood as a highly political mechanism, which unless tied to a larger Marxist/socialist feminist analysis and collective action, runs the risk of reactionary application.

In contrast to feminist social work, anti-racist, radical/structural and postmodernist/poststructuralist social work theorists do not make use of feminist critical consciousness raising. Instead, they propose the use of Freire's methodology of conscientizacao, an 
adult education and politicization process involving egalitarian, dialogic exchange between learner and educator (Freire, 1974). Freire's methodology does not differ in any significant way from feminist consciousness raising. Indeed, some authors equate the two (Mullaly, 1993). The most notable difference between the feminist method and Friere's method is that conscientizacao has a great popularity among those suspicious of, or marginalized within, feminist methodology - white men, and male dominated liberation and literacy movements in the third world, sectors of the anti-racist struggle, and various others.

\section{Experience}

Experience has not been a widely debated topic within the radical/structural social work literature. It is a topic more attended to by those who feel that their experience has been systematically marginalized within mainstream and radical/structural social work literature. It has been a hotly debated topic within feminist literature which overlaps with debates within postmodernism/poststucturalism and, to some extent, anti-racist social work.

Largely in reaction to traditional psychiatry, which objectifies the client (usually female) by dictating both diagnosis and treatment, feminist practice has developed a practice axiom that each woman knows what is best for herself. This sense of what is best for oneself is waiting latently to be discovered by the client, with or without the intervention of the worker. With sufficient support and consciousness raising, female clients are presumed to be fully self determining in terms of direction, pace, goals and duration of counselling or interventive services (Brown, 1994a; Burstow, 1992; Greenspan, 1983; Levine, 1982). As noted above, this axiom is primarily aimed at countering the devaluing of women evident in traditional therapies and shoring up women's seriously undermined 
decision making capacities. It simultaneously exudes an ontological vocation, or a rather deterministic and pre-existing imperative to be collectively liberated (McLaren and Leonard, 1993). The notion of an ontological vocation weakens any sort of radical analysis as it lends a sense that emancipation is inevitable rather than something that people must fight for simultaneously on many levels. Moreover, it idealizes and objectifies the experience of people who are oppressed rather than seeing them as people who have as much potential to be reactionary or inactive, as they have to be progressive.

On a slightly different track, Brown uses postmodernism to critique feminist social work's privileging of women's experience as the basis for feminist knowledge and much of clinical practice (Brown, 1994b: 35) ${ }^{14}$ Feminists have privileged women's experience in order to compensate for the exclusion of women's experience from most forms of knowledge, theory, policy and practice. However, Brown argues that standpoint feminists, many liberal feminists and postmodern/structural feminists have failed to understand the ways in which all experience is socially organized and interpreted through ideological frames (Brown, 1994b: 39). She notes the work of Smith (1987; 1990) and of Haug (in Brown, 1994b: 39) who suggest that an individual cannot provide an objective account of herself, rather she subjectively interprets and changes it in the telling. Thus rather than one unitary feminist truth or experience we have many experiences moderated by social, ideological and historical factors. Brown encourages social work practitioners dedicated to emancipatory social change to abandon the authority of experience in favor of understanding and transforming those processes through which women's experiences are put together rather than taking these experiences

14 Anti-racist and radical social work which utilizes Freire's ideas also privileges the experience of the oppressed in knowledge building and directing practice. 
on face value (in Brown, 1994: 39 \& 44).

Anti-racist social work literature on experience reflects some of the same weaknesses as the feminist and the postmodernist literature. For example, the anti-racist, the feminist and the postmodernist literature emphasize the importance of oppressed people interpreting their own needs based on their experience and incorporating this interpretation of needs into radical restructuring of agencies, services and practice. This perspective, like some types of feminism, views the experience of people of colour as a pure realm that is devoid of any sort of ideological or interpretive framings.

As quoted above by Brown, Dorothy E. Smith (1990) has been critical of the notion of experience as an ideological free-zone. She argues that all experience is interpreted through the conceptual and ideological tools available to us in society (Smith, 1990). In order to produce a critical interpretation of racist experience one must have access to critical concepts and tools. Lacking such an anti-oppression or critical analysis one tends to interpret experience through the ideological analytical and interpretive tools provided by mainstream, liberal society. Thus replacing social work interpretation of needs, with experience-based interpretations of clients or communities is no guarantee of more liberatory politics or outcomes.

\section{Political Action}

The genres of critical social work have general agreement on the need for collective and individual political action. While working towards a more or less united vision of an egalitarian and just society, the emphasis of struggle differs in tandem with the major focus of struggle. All genres agree that all aspects of life are politic and must be brought into a larger political struggle. Howe identifies two major approaches within the radical/structural social work camp -- the revolutionaries, 
or those who focus on "collective social and political action to effect structural social change and the redistribution of power and resources", and the consciousness raisers, those who emphasize "the importance of the 'concientizacao' (Freire, 1974) process in facilitating people's awareness of the structural and ideological forces which perpetuate their oppression and subordination" (Howe in Petruchenia and Thorpe, 1990: 12). Various tactics exist within the revolutionary vector including: sabotage and middle-class banditry (Pearson in Jordan and Parton, 1983: 19), ${ }^{15}$ the politicization of ail aspects of life and support for and of working-class struggles (Bailey and Brake, 1975, Brake and Bailey, 1980, Corrigan and Leonard, 1978; Jordan and Parton, 1983; Leonard, 1975), and a Gramscian model of building new relations and structures within, against and outside of existing services (London Edinburgh Weekend Return Group, 1983; Withorn, 1984). Indeed, radical/structural social work's development of political actions is more plenteous than the other genres of critical social work. For example, an articles by Moreau (n.d.) and Leonard (1975) list twenty-two political action practice directives for the radical practitioner. ${ }^{16}$

is Reflecting their skepticism over the limitations of social work within the context of an oppressive, class based, social control society, many authors recommend that practitioners use their professional and middle-class privilege to sabotage and bend rules in favor of clients, ignore management directives and oppose individualism (Pearson in Jordan and Parton, 1983). To this end Bailey and Brake suggest that their goal is not the elimination of case or social work, but the elimination of social work which supports the hegemony (Bailey and Brake, 1975). To that end Leonard (1975) and Moreau (n.d.) suggest the following: inform all clients of the unfair policy of the agency and how to manipulate this policy, self-disclose pertinent insights and experiences so as to lessen social distance, bend rules and turn a blind eye to infractions of agency requirements for clieits, organize clients where possible and work with groups, as well as with individuals and families, tie client into community networks and social change groups, sabotage unreasonable demands from management, refuse to be snowed under by the bureaucracy's demand for documentation, maintain a high level of activity in one's trade union, build concrete links with other social causes and political groups, provide empathy and non-hierarchial relations with co-workers, political allies and clients, as well as challenge sexism, classism, racism and homophobia in all its manifestations.

16 See Footnote 3. Although these recommendations do not appear in any publication in this exact format, I have combined Moreau and Leonard's distinctly similar recommendations for practitioners. 
Feminist social work and radical social work encourage collective action but focus their discussions at the level of consciousness raising and how to best include the experience of the client and community in agency, programme and social change efforts (Dominelli, 1990; Hutchinson-Reis, 1989; Levine, 1982; Marchant and Wearing, 1986). Postmodernist/poststructuralists eschew the provision of suggestions or directives for political action as these decisions are best made by each locality based on indigenous forms of resistance, identity and power (Featherstone and Fawcett, 1994; Sands and Nuccio, 1992).

\section{Bureaucracy, Professionalism and Other Forms of Social Organization}

The feminist social work literature is the most extensive on forms of social organization. Radical structural social work includes a number of arguments which condemn bureaucracy, professionalism, hierarchy, and other forms of social organization (Brake and Bailey, 1980; Carniol, 1987; Mullaly, 1993, 1995; Moreau, 1979). However, there is very little discussion of alternative forms of social organization or social change agencies. Similarly, most of the literature on community work sees it as a preferred site for practice but offer limited critiques of its problem areas (Wharf, 1990).

Those radical/structural social workers who make use of Gramsci advocate an interesting theorization of how to build new services and relations. They argue strongly that while we can always demand more resources "the one thing we cannot ask for is new social relations,..., these we will have to make ourselves" (London Edinburgh Weekend Retum Group, 1983: 132). They suggest that we can start to construct these new relations through the building of a culture of opposition. Building this culture of opposition will involve infusing all aspects of everyday life with oppositional 
practice. In the social work site they advocate the following as a beginning point for building oppositional practice:

1. overcome individualism - act collectively

2. define the problem our way as opposed to the state's or the experts' way

3. define the problem in class terms

4. step outside the brief - bring the totality into view

5. refuse official procedure

6. reject managerial priorities

7. develop alternative organization within struggle

8. reject misleading categories (London Edinburgh Weekend Return Group, 1980: 92-101).

Reflecting the higher level of development of alternative services, the North American and Australian feminist social work literature has developed the most extensive discussion of ways in which bureaucracy, professionalism and other forms of social organization impact on social service users, providers and the community. Building feminist social services is seen as an explicitly political activity spanning the public and private realms and offering new ways of meeting human needs. Withorn (1984), for example, draws on Gramsci's vision of how socialism will be developed. Gramsci argues that the new state will be one that is "generated by the associative experience of the proletarian class" (Forcas, 1988: 87). Gramscians refer to this period of history as prefigurative communism. This period of struggle involves not only "organizing and propaganda" but also "experiences where our minds and emotions could anticipate the goals and new values we hope to achieve someday" (Withorn, 1984: 76). Service provision from "an explicitly political perspective may provide some 
similar insights and the key to maintaining our commitment to experimentation and development of new forms of social organization" (Withorn, 1984: 76). Withorn offers the following five-point programme on creating a political strategy for social work practice:

1. develop public responsibility - raise people's expectations in life, ensure that people know that we have rights and expect more

2. make debureaucratization complete - present quality alternative models and challenge the power of professionals and bureaucracies to dictate service needs and delivery

3. do good work in a debureaucratized setting

4. achieve reciprocity - clients are potential comrades, mutual dependence should be the norm, mutual recognition of skill based on mutual self-disclosure, no division of means from end goal, emphasis on process

5. build an outside constituency - efforts to maintain a daily political practice are practically impossible without outside support, the link with outside movements will permit us to remember where we are going (Withorn, 1984: 221-227).

Adamson, Briskin and McPhail are similarly optimistic about feminist alternative services noting that politicized service delivery raises expectations, is a positive programme not just a critique and helps to build a base of fighting women (Adamson, Briskin and McPhail, 1987: 188). On the other hand, they are also acutely aware of the limitations of feminist services in meeting needs -- the creation of a false optimism that major inequalities can be solved in this essentially unequal social system, the absorption of all of the time of activists to the detriment of other political struggles, and the inability of such services to alter power relations in larger society (Adamson, Briskin, McPhail, 1987: 188).

$\mathrm{Ng}$ (1988) and Morgan (1981) have both written persuasively on the ways in which alternative services are not wholly outside of oppressive social relations, but continue to be shaped and influenced by state and market structures. $\mathrm{Ng}$ argues that this influence occurs, in part, through state 
funding which in turn structures clients, workers and the community through demands for documentation, casenotes, budgeting, audits, and hierarchical workplace relations (Ng, 1988). Morgan agrees naming these processes bureaucratization, individualization and professionalization (Morgan, 1981: 19-20). Concurring with the previous two scholars Walker points out that the challenge for feminist services is to develop strategies for "political action to change the oppressive conditions of women's lives, without being appropriated through our interactions with the ruling apparatus and participation in the relations of ruling" (Walker, 1990: 219).

Many feminist social work scholars adopt a similar approach to radical practice in non-radical settings. While arguing that radical practice and non-radical settings is possible and important, they caution that strategies must be very long term, consistent and goals must be continually reassessed. Fook notes that it is important to adopt a notion of "the 'politics of the unfinished' or a series of related and ongoing changes where the task is never finished although campaigns may culminate" (Fook, 1984: 147). Dominelli and McLeod (1989) are critical of workers who abandon governmentrun services for the less oppressive atmosphere of community and social action agencies. They term this "the drop out solution - avoid social work's short comings by not practicing it" (Dominelli and McLeod, 1989: 102).

Feminist social work scholars such as Baines, Evans and Neysmith (1993) have problematized the construction of community as a site for service delivery. Much of the mainstream literature and even some of the critical literature idealizes the community as a more intimate, responsive and appropriate site for social work practice. Feminists however have noted that devolution to the community usually means increased exploitation and oppression of women in the form of lower pay and insecure jobs, unpaid volunteer work or unpaid caring labour in the home. These services often 
provide less choice and resources to clients and to women rather than "empowerment". Thus, feminist social work is skeptical of mainstream community social service delivery.

Anti-racist social work does not provide discussions of sccial organization beyond the need for anti-racist staff training and organizational change. Quite an extensive anti-racist organizational change literature exists within mainstream and critical social work, as well as within the field of management. While some of it is predicated on notions of racial and social justice (Dominelli, 1990; James, 1996; Thomas, 1987), much of it is based on arguments of profitability (Fernandez, 1991; Hudson Institute, 1991; Karp and Sutton, 1993; Moran and Harris, 1991). For the most part, the management literature has not taken up the anti-sexist or anti-class themes, possibly because these strategies do not impact positively on profits and productivity. In contrast, most of the social justice, anti-racist literature addresses a range of diversity issues in the context of organizational change (Dominelli, 1988; Ferguson, 1996; Thomas, 1987).

While the end goals differ substantially, the social justice and the management literature agree that anti-racist or diversity organizational change is an ongoing and never finished process that involves all aspects of work life and work place culture. They include the importance of individual awareness and changes in how the work place is organized, promoted and perceived. They differ on the need for anti-racist political action and wider social change with the social justice advocates citing this as the most important aspect of avoiding cynicism, despair and the possible recreation of new forms of racist practice (Dominelli, 1988; Thomas, 1987, 1991). Both literatures discuss in some detail the kinds of problems that can arise when diversity or anti-racist organizational change and training go wrong (Karp and Sutton, 1993; Katz 1978, Suderman, 1992). These problems include: changing hiring practices only at the administrative and support staff level, providing only short-term 
training, alienating those in power, endless studying of the problems without any action, no bottomline connection, conflict avoidance leads to slowing stoppage or inadequate programme, undermining the credibility of the change agents, the myth of the happy ending, and, finally, depending on the Executive Director to change everything (Katz, 1978; Karp and Sutton, 1993; Suderman, 1992; Thomas, 1987, 1991).

In contrast to the other genres of critical social work, postmodernist/poststructuralist social work has not produced any significant discussions of social organization. Instead, it tends to limit itself to the realm of subjectivity and the local (Gowdy, 1994; Featherstone and Fawcett, 1994; Pardeck et al, 1994).

\section{Conclusion}

This chapter has reviewed how critical social work literature conceptualizes the intersections, separations and tensions between and among race, class and gender. Overall, the literature provides very few models that assist in thinking about or taking social action around these three pivotal social relations. Various concepts that may aid in the development of more comprehensive theoretical models of race, class and gender relations were also reviewed in this chapter. These concepts included theorizations of consciousness, experience, political action, bureaucracy, professionalism and other forms of social organization. In the following chapters I will make use of these concepts in order to analyze pieces of the data as well as to identify weaknesses in the theorization of and social work practices concerning race, class and gender. 


\section{Chapter Three}

\section{The Problem}

\section{Delineating the Problem}

The critical social work literature contains several problems or "gaps". In short, the problems revolve around critical social work's deficient understanding of race, class and gender as wholly social relations that should not be separated at the level of practice, analysis or theory. Secondly, an incomplete theorization of experience as an ideologically interpreted realm creates the potential for academics and practitioners to pursue reactionary and oppressive strategies based on the experience of marginalized, but not progressive, individuals. Following a brief summary of the inadequacy of critical social work models for understanding multiple subordinations, I discuss various terms that are pivotal to this problem, the methodology and the analysis presented in this thesis. While much of the terminology I use is common to most social science research, some of it is particular to critical theory and some to this project. In elaborating these terms I have borrowed from other literatures and disciplines, in particular sociology.

While some of the critical social work literature recognizes race, class and gender as social relations, most of the literature fails to capture a sense of race, class and gender as relations, that, in concert and in conflict with other socio-economic-political relations, sustain and recreate capitalism and social work's changing place in it. In other words, most of the critical social work literature, in its analysis, theorizing and models of practice, is inadequate to the task of mapping out the ways that race, class and gender are constantly changing, contesting and reinforcing relations of domination and subordination. Instead, most of the critical literature is centrally concerned with providing directives and prescriptions for practice. Prescriptions for practice preclude more dynamic and fluid ways of 
understanding social life. Instead, they reflect a non-relational, static form of social life and power. Moreover, the critical social work literature discusses race, class and gender as if they were and are separate and separable relations. Social work research, direct practice, and the delivery and organization of services replicate and extend these notions so that race, class and gender are experienced and practiced as entirely and markedly different social, economic and political phenomena.

A second important "gap" in the literature involves the theorization of gender. Although an almost exclusively feminized terrain, most social work literature, with the exception of feminist work, fails to include a comprehensive analysis of the way that social work is pivotal to the construction of women as exploited and oppressed as workers, clients, and volunteers within the home, the paid work force, and the political sphere.

Finally, much of the critical literature theorizes consciousness as resulting from both material conditions and experience (Fook, 1986, 1993; Mullaly, 1993; Withorn, 1984). However, a significant sector of the literature, implicitly or explicitly views experience as an ideological free realm from which emancipatory resistance and practices will automatically flow (Gowdy, 1994; Pardek et al, 1994; Levine, 1982; Howse and Stalwick, 1990). This conceptualization ignores the way in which all experience is interpreted by the teller and the listener through ideological frames. Experience is just as likely to be interpreted by either or both parties in an oppressive manner, as in an emancipatory manner.

Indeed, Gramsci might argue that experience is most likely to be interpreted simultaneously as emancipatory and as oppressive. This reflects his notion that consciousness is contradictory and contains pieces that can liberate, and pieces that augment the domination/subordination of ourselves 
and or other groups and individuals. Gramsci noted that ruling ideology often lags behind constantly changing material conditions. Through the study of people's actual material conditions, everyday activities, tentative ideas and practices, it is sometimes possible to see the origins of new, more liberatory social practices and theories (Sassoon, 1987a). Gramsci suggests that liberatory practices and culture

must be based on the embryonic ideas, practices and institutions which are already in evidence in the lives of the vast majority, in the material circumstances of the mass of the population (Sassoon, 1987a: 20).

In Gramscian terms, then, one could argue that the relationship between experience, consciousness and emancipatory resistance is a complex one in which both the surface of experience and the forces and relations which underlie and organize it must be explored. As Brown notes, by neglecting to explore "how we use the category of experience we fail to see how we participate in the 'ideology at work' of existing social relations" (Brown, 1994b: 17). For the purposes of this thesis, I will employ Gramsci's construction of consciousness, and subsequently experience, as fractured and contradictory, containing practices and fledgling ideas that have the potential to build emancipatory practices, structures and hegemonies, or to undermine them through the augmentation of oppressive ideologies and practices.

\section{Discussion of Terms}

\section{Race, Class and Gender}

Rather than static categories or facets of people's existence, "race, class and gender" will be understood as the constantly changing relationships of domination and subordination between individuals and groups of people, and the means of production and reproduction within specific 
historical, material and social formations $(\mathrm{Ng}, 1993 \mathrm{a}: 196)$. It is not possible to talk about or experience race without simultaneously talking about class and gender, or class without drawing in race and gender, or gender without drawing in class and race (Mohanty, 199la). Instead, race, class and gender need to be studied in relation to how dominant groups maintain their hegemony over the means of production and reproduction $(\mathrm{Ng}, 1993 \mathrm{~b}: 196)$.

This use of race, class and gender is meant to provide a sense of oppression as a set of practices and concrete, material activities or, as Eller and Couglan put it, moving words like race and ethnicity from "nouns to verbs, from observable entities to ethnicizing processes" (Eller and Couglan in Hale, 1995: 432). Continuing with the example of ethnicity Hale notes, this process is intended to "take what is given as what actively needs to be explained, namely, how ethnicization emerges in different historical situations" (Hale, 1995: 433). She adds, "ethnicity is an ongoing construction, not a projection of the past" (Hale, 1995: 434). Inserting "class" or "gender" into this sentence provides a sense of the ways that I will be exploring all three relations in this thesis.

However, it is important to note that processes of racializing, gendering, and classing are not pluralist exercises in reducing all oppressions to some level of equivalence. Race, class and gender are unequal, hierarchically organized social relations which are pivotal to the continuation of capitalism, and social work's constantly shifting role within capitalist social, political cultural and economic life. In regards to race and gender, for example, Bannerji notes that we need to remember that "women are differently 'sexed' in a 'raced' society" (Bannerji, 1995: 127). Similarly, "organization by race (or racism) is a fundamental way of forming class in Canada, and that this formation of class is a fully gendered one" (Bannerji, 1995: 52).

In this thesis, white will be regarded as a socially constructed race. Whiteness is generally 
accepted to be the norm in Western societies requiring no particular analysis or study. The focus, instead, is turned on people of colour as those who deviate from this norm. In discussing this omission in regards to women and race, Bannerji argues that it is precisely "because white women are implicitly but fundamentally 'raced' as white and thus a member of the 'master race', that they don't need to be named as such" (Bannerji, 1995: 127). White supremacy, the marginalization of all who are not white and the systemic omission of Western society's histories of colonialism, imperialism and racism mean that

it is almost impossible for European societies as they are to eliminate racism in a thoroughgoing way. Racism is not simply a set of attitudes and practices that they level towards, us, their socially constructed "other", but it is the very principles of self-definition of European/Western societies (Bannerji, 1995: 47).

\section{Other Terms}

Other terms that require clarification include: social organization, institution, structures, ideology, the state, neo-liberalism, practices, types of agencies, clients, progressive social workers and the balancing of fairness, justice and democracy. They are defined, in turn, below:

The term "socially organized" or "social organization" refers to the way that social phenomenon such as bureaucracies are made up of a series of intentional and unintentional activities of human actors. These activities or practices are tied into other phenomena or series of activities, such as professionalism, or documentation, which overlap and produce the various ways in which we experience the material world. While they may appear to be actual things or objects, they are wholly constituted through human activity.

"Practices" refers to ongoing human activity that produces pieces of social organization on a small scale, such as a social work intake, or a large scale such as the field of social work, or a multi- 
level, service, research and policy bureaucracy such as the provincial government's Vocational Rehabilitation Department. I use the term "mechanisms" simply to delineate various pieces of social organization from each other. For example, professionalism is identified as a mechanism of social organization.

The term "state" is used in an everyday sense to refer to the departments, Ministries, and activities of various levels of government. The term "types of agencies" describes in short hand the four main forms of social work agencies in my study. They include: government-run services such as welfare or corrections; government-mandated and funded, but run by a community Board of Directors, agencies such as hospitals or child protection services; community agencies such as settlement houses or community centres which are run by a community Board of Directors and funded by a variety of government and non-government sources; and social change agencies, such as some of the women's shelters or sexual assault services, which are run by a community Board of Directors and funded by a variety of government and non-government sources and pursue an explicitly political agenda in terms of organization, delivery and mandate of the service.

The notion of "institution" is borrowed from Dorothy E. Smith's understanding that it "identif(ies) a complex of relations forming part of the ruling apparatus, organized around a distinctive function" (Smith, 1986: 8), for example, vocational rehabilitation, welfare, or education. Relations of ruling refers to the intersection of institutions organizing and regulating society (Smith, 1987,1990 ). Ruling is a piece of social organization or series of overlapping conglomerates of human activity which take place in various sites throughout society. Examples of sites include government, the market, the home, social work agencies and education facilities. Smith (1990) argues that ruling within these sites is textually mediated, or occurs through and is linked by 
professional, academic and technical texts and documents. As Hick notes, "textually mediated discourse abstracts at a conceptual level the world directly experienced by people" (Hick, 1991: 26). Texts enable relations of ruling to be present in many forms simultaneously in multiple sites. This form of rule is referred by Smith as an extralocal mode of ruling (Smith, 1987: 70).

"Ideology" denotes material practices which conceal more than they reveal. Drawing on the work of Smith, Walker argues that ideology involves various processes of organizing and governing the telling of an event or experience which obscures any other way that we might see this phenomena (Walker, 1986). She notes,

Images, verbal modes, abstracted forms, symbols, documents, are not a direct reflection of everyday experiences but are reproduced for us by experts, academics, intellectuals, media people and so on. Those who produce this ideological material are part of the apparatus of ruling and their work is part of the ruling relations of capitalism (Walker, 1986: 19).

Like Walker, I agree with Smith that ideology has a material base in practical activities. However, unlike Smith, I argue that ideology is a potentially liberatory aspect to building emancipatory cultures and strategies. I adopt a more Gramscian notion that ideology is the medium through which consciousness and meaningfulness operate in everyday life (Gramsci in Lather, 1991: 2). Lather refers to ideology as the stories that a culture tells itself about itself and is something that people inhabit in a daily, material way which can be oppressive, liberatory or both (Lather, 1991:2). Liberatory ideology is apparent in the various practices of critical social workers including their exploration of ideas and practices, their analysis of oppressive forces and the actions they take, individually and collectively, to change the conditions and relations of our lives.

"Neo-liberalism" is a set of political, economic and social policies and practices aimed at consolidating corporate power, and returning social welfare to the responsibility of the family and the market. Optimally, the role of government is to be restricted to that of a tax clearinghouse that 
intervenes in public and economic life only to ensure optimal market conditions for long-and shortterm corporate interests. This form of liberalism is similar to that of the nineteenth century which was based on free, unfettered capitalism (Rebick and Roach, 1996). The Progressive Conservative governments of Ontario and Alberta personify neo-liberal politics, as does the federal Liberal government albeit in a less vinulent, but just as destructive, form. Some of the ways that neoliberalism is played out within the social work arena are discussed in greater detail in Chapter Four, The Context.

"Client" refers to all those who make use of the services of social work agencies or auspices. This term, like many others, is problematic. Its connection with professionalized relationships such as those between lawyers and clients, or accountants and clients belie the involuntary nature of many aspects of the social work relationship. However, other terms such as "consumer" tie into notions of the market and the power assumed to be inherent in purchasing power. This conceptualization is also an inaccurate, and undesirable, depiction of the social work relationship. "Community member" or "programme participant" do not convey the diversity of the social work field which includes clinical situations that do not lend themselves well to this description. "Patient" while used by many clinical social workers offends the sensibilities of most community workers.

Instead, I have chosen to use the term "client" because of, not in spite of, its contested nature. In view of my research question, I am particularly interested in the way this term's association with professionalism gestures at classed, gendered and racialized contradictions. I use this term fully aware of its limitations.

"Progressive social worker" is used throughout this thesis to describe a diversity of social work approaches and identities. In electing to take part in the study, informants indicated their 
willingness to identify with critical theory and practice. This critical theory and practice took a number of forms as did the ways that workers described themselves and this genre of social work. The terms the workers used to describe themselves and their practice included social justice worker, radical social worker, feminist social worker, anti-racist worker, community worker, structural social worker, structural-feminist social worker, Marxist social worker, critical social worker, postmodernist, and anti-oppression social worker. When asked to supply a common name for critical practitioners my informants could not achieve a consensus. Some felt that the title depended on auspice. For example, in the community one would call oneself a social justice or community worker whereas in clinical practice one would call oneself a feminist practitioner or a structural social worker. Others felt that radical social worker was a useful umbrella-like term while others argued that radical was too specific and spoke of a left, labour tradition that alienates certain anti-racist and feminist practitioners. "Progressive social worker" was the least controversial of the umbrella terms and, so, has been adopted for this project.

Throughout this thesis I argue that there are ways to distinguish better critical practice from worse practice. My problematization of experience obviously discards an individual standpoint epistemology as the adjudicator. Within the context of a social relations analysis it is not possible or desirable to use an objective standard. Instead, I have borrowed heavily from Nancy Fraser's discussion of the politics of needs interpretations (Fraser, 1989). She argues that justifying some interpretations as better than others "involves the balancing of procedural and consequentialist considerations" (Fraser, 1989: 182). Process considerations include achieving interpretations "by means of communicative processes that most closely approximate ideals of democracy, equality and faimess" (Fraser, 1989: 182). 
Consequentialist considerations, on the other hand, involve ensuring that "all things being equal, the best interpretations are those that do not disadvantage some groups of people vis-a-vis others" (Fraser, 1989: 162). While obviously not as simple as it sound, Fraser argues that the inclusion of process and consequences must be based on the balancing of democracy and equality. Democracy in this case refers to participatory rather than representative democracy and equality refers to outcome, rather than opportunity. While the standard I use in this thesis is referred to as "equality, faimess and democracy", it is meant to include the broader discussion above.

The terms "liberatory social work" and "emancipatory social work" are used throughout this text. They refer to a form of social work practice that attempts to go beyond the boundaries of antioppressive social work. That is, this form of practice not only works to oppose subordination and domination in all its forms, it simultaneously seeks to build new social relations, identities, cultures and structures. In doing so, liberatory social work works to fundamentally reorder the existing political economy and build towards a just and equal society. This form of practice has tended to be rooted in socialist models of social, political, economic and cultural change, and restructuring. ${ }^{17}$

17 See for example the models of social work and social relations discussed in the work of the London Edinburgh Weekend Return Group (1980) or that of Anne Withorn (1984). 
Chapter Four

The Research Project

\section{Critical Focus}

Habermas argues that there are three types of knowledge building -- technical, interpretive and critical (Habermas, 1971). While the former two are required to address many of the problems facing humankind, critical knowledge is necessary to illuminate the way that power, in the form of domination and subordination, operates within society (Maguire, 1987). This research project employed a critical methodology to investigate the operation of class, race and gender in everyday practice. Carspecken argues that critical methodologists share a common epistemological orientation, rather than a "distinctive, critical, value orientation" (1996: 6). While many critical researchers provide their own definition of a critical epistemology (Carspecken, 1996; Lather, 1991; Maguire, 1987), the following points summarize the critical epistemology on which this thesis is based:

1. Knowledge is not neutral, it is a form of power. In this society power takes the form of relations of domination and subordination that are historically and socially constituted.

2. Relations of subordination and domination are often mediated by social relations of capitalist production and reproduction. However, "oppression has many faces and that focusing on only one at the expense of others (for example, class oppression versus racism) often elides the interconnections among them" (Kinchloe and McLaren in Carspecken, 1996: 4).

3. Social "facts can never be isolated from the domain of values or removed from some form of ideological inscriptions" (Kinchloe and McLaren in Carspecken, 1996: 4).

4. "Mainstream research practices are generally, although most often unwittingly, implicated in the reproduction of systems of class, race and gender oppression" (Kinchloe and McLaren in Carspecken, 1996: 4).

Reflecting the critical epistemology outlined above, this project employed a critical qualitative, quasi-participatory research methodology that guided the setting of the research question, the 
collection of data and the analysis. This epistemology meant that the locus of investigation was not social work practices per se, but material practices in social work. ${ }^{\prime}$ The particular material practices under investigation were racialized, classed and gendered relations of domination and subordination. Dovetailing with the priorities of the epistemological stance outlined above, the goal of this project was the refinement of critical theory in order to change social life, rather than furthering a description of social life (Carspecken, 1996).

\section{Qualitative Research Design}

Due to the small size of the progressive social work population in Toronto and the locus of the research project, a qualitative design was selected. It is generally accepted that qualitative methods have a greater potential to explicate the tie between the immediate setting and the wider social context than do quantitative designs (Borg and Gall, 1989: 407). While influenced by the contributions of many critical researchers, the design borrowed heavily from materialist methodological notions as discussed in the works of Dorothy Smith (1990, 1987), Patti Lather (1991, 1986a, 1986b), Sandra Kirby and Kate McKenna (1989) and Gary Anderson (1989), and participatory research notions as discussed in the works of Patricia Maguire (1993, 1987), Peter Park et al (1993), Bud Hall (1981, 1979, 1975) and Jean McNiff (1988). Materialist methodologies focus on the way that everyday activities and "talk" are organized by and are the organizers of larger social relations of ruling such as race, class and gender. Participatory research designs focus on redistributing knowledge and knowledge making resources from the researcher to the researched.

\footnotetext{
'. This reframing is similar to Geertz' observation that critical anthropologists do not study
} villages, they study in villages (Geertz in Carspecken, 1996: 22). 
These two methods are very compatible and are often melded in research endeavors.

\section{Data Collection: The Entry Points}

\section{Methods and Process}

The data collection was multi-method including in-depth interviews, focus groups and the use of documents as informants or data. The researcher entered the research endeavor as an insider (Kirby and McKenna, 1989; Maguire, 1987). Trained as a structural-feminist social worker and part of the same progressive social work community, the researcher shared common ground with the informants around the question of how to build critical practice and theory. The researcher entered the field as a "knower" with several years of practice experience. Therefore, extensive initial fieldwork aimed at uncovering basic themes was not required by this project. The integrity of the research was not compromised by this insider positioning as the goal of the project was the illumination of processes of defining, interpreting, influencing and transforming social realities, rather than of discovering the existence of an objective social reality.

The understandings and observations of the researcher-as-knower were recorded in a reflexive journal. Bogdan and Biklen note that, in addition to descriptive accounts, researchers require a "more personal account of the course of the inquiry" (1982: 86). They encourage the recording of speculation, feelings, problems, ideas, hunches, impressions, prejudices, plans for future research, and clarifications of unwarranted conclusions or misunderstandings (Bogdan and Biklen, 1982: 86). The point of such a journal is to keep "an accurate record of methods, procedures and evolving analysis" and to use subjective reflections as "a means to a better study, not an end in themselves" (Bogdan and Biklen, 1982: 87). In this study, a reflexive journal was used primarily to record processes, evolving 
analysis and to highlight the operation of the researcher's "conceptual baggage" (Kirby and McKenna, 1989 ) or preconceived notions. As themes and connections emerged from the data, they were compared to the experience and expectations of the researcher. Contradictions with the researcher's experience served to underscore the importance of seeking further data to strengthen or undermine emerging analysis. Member checking, discussion with progressive social workers not involved in the study, and further interviews and focus groups provided this additional information.

Rather than a linear sequence, data collection took place through a process of iteration or "cycling between interpretation and observation (repeatedly reformulating and re-examining revised interpretations in light of further observation or examination of evidence)" (Stiles, 1993: 2). Initially, one focus group of six progressive social workers met for a two hour period to generate practicebased stories in which class, race and-or gender played a central role (see Appendix 1). The discussion in this group was tape recorded and transcribed with the written permission of all participants. A note taker provided a secondary recording source (Bertrand et al, 1992: 202). The tapes were immediately transcribed filling in the blanks in the note taker's minutes and correcting any mistakes. Discussions with the note takers was included in the reflexive journal.

Themes generated in the first focus group were used to modify the discussion guide for the second group who met approximately one week later to discuss similar topics (see Appendix 2). The same recording and transcribing techniques were used for all groups. In an attempt to maintain momentum and relationships established during the initial meeting, the first focus group met a second time approximately two weeks after their first meeting. Discussion moved from requesting stories in which race, class and-or gender were central to asking for descriptions and analysis of how their work differed from that of non-progressive or mainstream social workers (see Appendix 2). 
Informants were then asked to thematically group these stories and reflect on how race, class and gender were part of these themes and stories.

Data collection then moved to two of the nine in-depth interviews with each interview serving to refine the interview guide and process of the next (see Appendixes $3 \& 4$ ). The interviews took approximately one and a half to two hours and were tape recorded and transcribed. Data collection slowed for some time following the birth of my daughter. The second focus group met a second time approximately three months after their first meeting. Discussion focused on stories and observations around the use of various pieces of critical practice such as critical consciousness raising, integrating the client's experience, and collective and individual political action. Focus group members agreed to challenge each other on issues with which they disagreed or to clarify ideas. Even with this explicit agreement the group veered away from discussions that caused or had the potential to cause direct conflict.

All three focus groups had a tendency to avoid all but the mildest disagreements. As soon as conflict arose, group members would intervene and steer the conversation to less contested topics. This resulted in a somewhat superficial analysis of a number of themes and stories, although it also permitted a generally positive and convivial atmosphere in the groups. As will be discussed in greater detail below, the progressive social work community and network is fairly small. Most group members knew each other, or knew of each other. Anonymity was not possible, nor necessarily desirable given the locus of the research project.

Some groups members reported that the focus group was one place that they felt it was safe to explore radical issues and themes. Hence, they had an active interest in avoiding divisiveness and 
discussions that might jeopardize the quality of this safety. ${ }^{2}$ One member noted that the progressive community generally feels itself to be under attack from external sources such as social service funders, the government and mainstream social work. The apparent unity of the focus group was a pleasant reprieve from the conflicts of the wider society. Thus, intra-group conflict was eschewed.

Findings from the focus group reflect this group and community culture and were analyzed in light of these limitations and strengths.

The third interview occurred just prior to a meeting of the focus groups in which preliminary results and themes were presented. Insights gained from the interview were integrated into the feedback meeting. Due to time and interest constraints on the part of informants, the two focus groups were amalgamated into one group for the feedback meeting. Participants were presented with a series of maps or diagrams that depicted very tentative themes, their interconnections, as well as gaps in the data. Informants were asked to comment generally on the diagrams and to pinpoint areas that required further investigation.

I presented the same findings in an undergraduate social work class trained in a branch of progressive social work, namely structural social work. Although not all the students were committed to the structural model of practice, they were all trained in it. The themes and priorities generated by this class did not differ in any significant way from those of the feedback focus group. While their

2 Indeed, I underestimated the need for safety in one of the groups. At the second meeting of one of the groups, the participants demanded and took more time than I had anticipated to renegotiate safety issues. Formal topics renegotiated between participants included seeking reassurance from each other that they would provide confidentiality "what is said here, stays here", and reassurances from me that neither they or their agencies would be identifiable in my final write-up. Confidentiality issues had been addressed in the written package and consent form supplied to each participant, as well as discussed at the first meeting. Safety, obviously, meant more than confidentiality as workers also sought reassurance from each other that no one thought that any of the participants were unprogressive, that their comments were useful, and that they all experienced difficulty being radical in a field that thinks of itself as inherently progressive. 
discussion is not included in the findings their conclusions acted as a form of triangulation or confirmation of the general direction of the findings.

The final six in-depth interviews, for a total of nine, included insights gained at the feedback focus group (see Appendix 9). They occurred in the two weeks following the final focus group meeting.

\section{The Workers}

A snowball sampling method was selected in order to gain access to as many progressive social workers as possible. Due to time and financial constraints the sample was drawn from the Toronto region. The Social Work Education and Action Team (SWEAT), a progressive social work organization, agreed to provide past and present mailing lists to the study. These names were amalgamated with those of other workers known to the researcher and those referred to her by members of the Dorothy Livesay Collective (DLC), a group of progressive doctoral students in the Faculty of Social Work, University of Toronto. Progressive social workers were mailed an information package and letter outlining the research project. ${ }^{3}$ These letters were followed up by phone calls.

As the study progressed various informants provided the names and addresses of other potential participants who were contacted in a similar manner. A total of 26 workers agreed to participate in the research process although for various reasons, most unknown to the researcher, only 21 actually took part. Although it was not a criterion of the study, all participants had university level

3 This package also contained a consent form as approved by the Ethics Committee of the University of Toronto (see Appendices 21 to 25). 
education. The majority had completed graduate education in social work. The participants had attended a number of universities in various parts of the world; the majority, however, had attended programmes in central Canada such as the MSW at Carleton University, University of Toronto or York University. Many informants also had BSW degrees from schools such as Ryerson Polytechnic, York University, the University of St. Thomas, the University of British Columbia, the University of Calgary or McMaster University. Graduate degrees were also pursued in non-social work areas such as the Sociology of Education at the Ontario Institute for Studies in Education.

Clinical, community, policy and research workers took part in this study. As the chart below shows, the workers were employed in a number of agencies including government, quasi-government or government mandated such as child welfare and hospitals, community agenices, private practice and social change agencies. Although no statistics exist on the demographics of the progressive social work community, the composition of the sample did not seem unrepresentative of the gender, race and sexual orientation of the progressive social workers.

\section{The Workers}

Clinical, Community, Policy and Research workers

* $14 \%$ male

$86 \%$ female

* $\quad 29 \%$ people of colour

$71 \%$ white

* $\quad 14 \%$ gay or lesbian

$86 \%$ straight

* $\quad \mathbf{8 0} \%$ graduate degree in social work

$20 \%$ other

$83 \%$ of the people of colour had graduate degrees 
* $\quad 24 \%$ government-run services

$10 \%$ hospitals or child welfare

$28 \%$ community agenices

$28 \%$ social change agencies

$10 \%$ private practice

All informants broadly defined themselves as "progressive", although as discussed in Chapter Two, they used a number of terms to describe their critical orientation. Screening mechanisms were not used as this population is assumed to incorporate great diversity. A number of participants observed that, from time to time, they wondered if they were "radical enough" to be included in the study. One worker dropped out of part of the study for this reason. Others resolved these tensions in ways that were not shared with the researcher. As a number of methodologists note, focus groups are more than an opportunity to report ideas (Anderson, 1989; Chambon, 1994; Morgan, 1988). They are dynamic processes in which the ideas of participants are challenged and subtly or fundamentally altered. This collective process is recognized in the literature as having the intended or unintended side effect of empowerment and consciousness raising (Chambon, 1994). Paralleling the participatory research framing of this study, the consciousness raising process was a desired side effect and one which, according to most of the participants, happened to a greater or lesser degree.

\section{Documents}

Informants were asked, where possible, to supply agency documents that described agency policy and processes, funding agreements and any pivotal studies or position papers. Workers in smaller agencies had no difficulty supplying these documents whereas workers in government bureaucracies and large service centres had no idea how to locate or access such documents. These 
documents were used as evidence, and to supply a greater sense of the context in which progressive practice occurs. ${ }^{4}$ Other funding and policy documents such as the United Way of Greater Toronto's report entitled, Action, Access, Diversity! A Guide to Multicultural/Anti-racist Organizational Change for Social Service Agencies and the Social Planning Council of Metropolitan Toronto's reports on access to health and social services were also used as background materials.

\section{Validity}

Patti Lather argues that in order to meet the needs for credible and resolute research, critical methodologists must ensure rigour "as well as relevance" (1986a: 67). She argues in favor of data credibility checks in order to provide further legitimacy for our findings and a solid base for our theory building. This research project included the following validity measures:

1. Triangulation of Methods, Data Sources and Theories" (Lather, 1986a; Stiles, 1993).

Participatory and materialist methodologies were combined in this project. Data were gathered from twenty-one informants employed and educated in very diverse sites. Documents were used as secondary or contextual source. Finally, data analysis utilized a three-part frame combining feminist, Marxist and postsocialist theories. In addition, as discussed in greater detail below, the data analysis proceeded more or less simultaneously within two different data analysis schemes fracturing the data for later reconstruction (Strauss and Corbin, 1990) and holistic analysis of large passages and stories. These two schemas were later mapped out and provided useful comparators highlighting strengths, weaknesses and new avenues to pursue in data collection and analysis.

2. "Face Validity (established by recycling categories emerging analysis, and conclusion back through

4 I am differentiating my approach with documents from that of Dorothy Smith (1987) and others who study documents as organizers of social relations. While I do not disagree with this conceptualization of documents, it was not pivotal to the answering of $m y$ research question although it would make an excellent follow-up study. 
at least a subsample of respondents)" (Lather, 1986a: 78).

Emerging themes, analysis and conclusions were discussed by the focus groups who agreed to meet together. Focus group members were encouraged to provide feedback and highlight areas for further investigation. These same tentative themes and analysis were discussed by a group of students trained in structural social work practice. Stiles calls this type of validity check engagement with the material or ongoing discussion of interpretations and observations (1993: 2). While the insights and observations of this class were not included in the findings, the dovetailing of their comments and those of my informants acted as an additional data credibility check.

In addition, extensive member checking (Stiles, 1993: 2), or recontacting informants for additional information, occurred around certain categories that were identified as important by these two groups, but continued to have a paucity of data. Confirming the importance of the these themes and their context within the emerging analysis opened up new ways of looking at the data and how they fit into larger analytic schemas.

I had intended to also include catalytic validity (Anderson, 1989; Lather, 1986a; Stiles, 1993), or some discussion of the way that the research process has "led to insight and, ideally, activism on the part of the respondents" (Lather, 1986a: 78). For example, informants observed that in the midst of increased caseloads and work speed ups they rarely have a chance to reflect on their practice. Some of the workers commented that they appreciated the opportunity to talk to other workers about critical social work issues. It, apparently, left them feeling "ready to go out and fight again". Other workers reported feeling troubled after meetings and wondering if their practice and that of others was actually "radical at all". The richness of these data indicates the need for systematic data 
gathering and analysis rather than its inclusion as a validity sidebar to a larger project. The insight and activism prompted by this research project constitutes a research question in and of itself that cannot receive the attention it deserves if subsumed within the larger thesis. Hence, catalytic validity measures are not included in this study.

\section{Analytic Process}

As noted earlier in this discussion, the research process was not a linear one. It followed a process of iteration (Stiles, 1993: 2) or moving back and forth between the data, data gathering, preliminary analysis, reflexive journalling, member checking and theory building. After transcribing the tapes from the focus groups and interviews, these transcripts were read multiple times until themes seemed almost to "fly up like sparks from the page" (Barritt, 1984: 6). These themes were sorted and categorized through a cut and paste method in which similar themes are placed in files for later comparison and analysis. ${ }^{5}$

The data analysis simultaneously built two separate sets of themes and diagrams or maps. One of these schemas emerged from an analysis of the fractured data (Strauss and Corbin, 1990), or data that had been divided into its smallest component elements. As Anderson notes, the constructs informants provide are reconstructions themselves of social reality (1989: 253). Hence, breaking these reconstructions down into component parts can help to illuminate the connections between them as well as the operation of various social forces and relations. These elements were eventually reconstructed at the thematic and then the analytic level to permit analysis of structures, systems,

5 For a more detailed description of this process see Kirby and McKenna (1989). While I did not follow their instructions exactly the general sorting and coding processes were most helpful. 
discourses and power (Carspecken, 1996).

The second analytic schema left the worker's stories intact to provide a more context-rich and holistic approach to the development of themes, and, later, analysis. Moreover, this approach left the voices of the informants more intact as well as the schemas informants utilized to reconstruct, define and influence reality. In my reflexive journal I called this technique a holistic approach to analysis. As Marcus and Fischer note,

wholism involves more than simply documenting those outside forces and macrostructural elements that impinge on the local cultural unity under analysis. A critical wholism recognizes that "the 'outside forces' are an integral part of the construction and constitution of the 'inside', the cultural unity itself, and must be so registered, even at the most intimate levels of cultural process (Marcus and Fischer, 1986: 77).

The intact stories were examined in their entirety for evidence of the organizing activities of larger social forces and relations. The way the stories were put together and discussed individually, as well as within the larger group or the interview, provided a sense of the operation of these themes at the level of progressive social work "talk". Themes and emerging analysis were diagrammed or mapped out and compared to the mapping emerging from the fractured data. Differences in the mappings provided new insights and avenues to pursue in further data collection and analysis.

As mentioned above, at several different points emerging themes and analysis were diagrammed or mapped in order to provide in visual form a schema of relationships between the themes, "holes" in the data and the multiple levels at which reality is organized. Mapping occurred just prior to the focus group in which the preliminary results were reviewed by the informants (see Appendices 12 to 18). Informants at the feedback focus group were provided with a series of preliminary diagrams of how each of the following are organized within the social work milieu: class, race and gender, as well as class and race, race and gender and gender and class, and the constellation 
of the three social relations. As previously discussed they were asked for feedback on strengths and weaknesses of the tentative conclusions, themes and diagrams, as well as other areas requiring investigation.

Throughout the process workers received calls from the researcher seeking clarification of various points, additional data on areas priorized by the feedback focus group and input on new areas and ideas. This member checking was a valuable source of information and support to the researcher, and one in which informants showed infinite patience and good will.

At the termination of the interviewing and focus group processes, specific agency documents as well as broader policy and research documents were examined in order to contextualize and historicize findings. As noted earlier, these documents were examined only as pieces of evidence rather than as organizers of social relations. ${ }^{6}$

Final mappings took place incorporating all the available data (see Appendix 19 and 20). These mappings had a slightly different emphasis than previous mappings as they more closely resembled the process outlined by Dorothy Smith (1986). Smith calls this process making a design

It is a means of extending the analysis for the level of the everyday analyzed as a work process to the expanded social relations in which that work is embedded. A design provides a proximate map, that is, a map of the immediately relevant set of relations. It is constructed to be specifically open "at the other end" where it is tied to the extended relations of the political economy (Smith, 1986: 10).

While previous maps had attempted to capture multiple levels of the operation of the analysis, this design deliberately tied the analysis to larger relations within the structures of cultural valuation and the socioeconomy.

6 See Footnote 4. 


\section{Analytic Framework}

In this study the development of the analytic frame was deliberately left until the end of the project in order to avoid, in as much as is possible, a situation in which the research was theorydriven. A theory-drive project is one that seeks to prove the assumptions found in existing theory rather than to refine, extend or challenge existing theory. While many researchers are critical of theory-driven research (Anderson, 1989; Smith, 1990, 1987; Walker, 1990), Patti Lather offers this warning:

Building empirically grounded theory requires a reciprocal relationship between data and theory. Data must be allowed to generate propositions in a dialectical manner that permits use of a priori theoretical frameworks, but which keeps a particular framework from becoming the container into which the data must be poured (1986b: 267).

The analytic frame described below was developed after the completion of the collection of data, the generation of various diagrams and a certain median level of analysis. During the data collection process, cycling back and forth between the data and critical theory provided many insights as well as many unanswered questions. These insights and unanswered question were later used to generate an analytic frame "tailor made" to meet the specifics of the emerging conclusions and questions. Thus, theory did not act as a "container" for the data, instead, the data, emergent analysis and theory acted in tandem to generate an analytic frame best suited to illuminate the specifics of the data.

The data have been analyzed using a three-part framework which will be discussed in detail below. This multi-level framework employs the following analytic concepts and pieces of larger theories:

1. social relations

2. ideology and consciousness 
3. the politics of culture and socioeconomic politics

\section{Social Relations}

Class, race and gender will be analyzed as social relations that organize the actualities of our everyday lives, as well as larger social structures and systems of domination and subordination. Class, race and gender are regarded as dynamic processes that operate both at the level of discourse, as well as at the level of the material world organizing the day to day experience, consciousness and systems of people. As discussed in some detail in the literature review this conceptualization of class, race and gender draws heavily on the work of Roxana Ng (1993a, 1993b, 1990, 1988), Dorothy Smith (1987, 1990), and Himani Bannerji (1995, 1993).

The social relations approach illuminates the political and contested nature of all aspects of our everyday lives and commonsense practices. Politics are not relegated to one particular sector of social life. Instead they are seen to infuse all aspects of everyday practice, talk and ideas. As the London Edinburgh Weekend Return Group notes, "there is no such thing as a politics-free zone" (1980: 145).

\section{Ideology and Consciousness}

The analysis has made use of Gramsci's conceptualization of consciousness as a contradictory whole containing pieces that are ideological and pieces that have not yet been incorporated into ideology (Sassoon, 1987b). Gramsci noted that ideology often lags behind material conditions and that through the study of people's actual material conditions, practice and tentative ideas about social life, it is sometimes possible to see the origins of new more liberatory social practice and theory 
(Sassoon, 1987b). It is thus possible to discover how ideology works at an everyday level. ${ }^{7}$

Gramsci suggests that liberatory hegemonies and practices "must be based on the embryonic ideas, practices and institutions which are already in evidence in the lives of the vast majority, in the material circumstances of the mass of the population" (Sassoon, 1987b: 20). The analysis will delineate some of these tentative practices and idea, as well as assess their potential to refine critical theory and practice.

\section{The Politics of Culture and Socioeconomic Politics}

Nancy Fraser (1997) argues that the present separation of cultural (recognition) politics and socioeconomic (redistributive) politics weakens the liberatory potential of both strategies. The challenges of the present era require a unification of these social justice models. She points out further that there are two main approaches to recognition and redistributive politics - liberal multicultural/end-state redistribution strategies and radical deconstructive/socialist strategies.

Liberal multicultural strategies favor interventions that provide additional recognition for marginalized, dominated and disrespected identities. Additional recognition is thought to promote a re-evaluation of marginalized populations along more culturally positive lines. They simultaneously promote differentiation among and between groups as the basis for determining who merits such increased cultural positivity. Increased differentiation freezes identities in place and constructs cultures as static rather than constantly changing. This differentiation decreases the probability of developing the solidarity required for broader social change efforts, and closes off possibilities for the

7 A more complete discussion of how the term "ideology" is used in this thesis is included at the end of Chapter Three. 
development of new liberatory identities.

Liberal redistribution strategies tend to focus on problems of end-state maldistribution. Inventions target these only maldistributions rather than their underlying causes. Programmes that focus on end-state inequalities, such as social assistance, tend to recreate class distinctions, inequalities and cultural stigmatization. Thus their impact is to increase cultural injustices such as stigmatization and disrespect, while failing to create socioeconomic equality.

More radical cultural politics call for the deconstruction and destabalization (dedifferentiation) of existing identities and the underlying symbolic-cultural valuation system. Thus, rather than providing additional recognition to a static cultural identity, this approach calls for the transformation of everyone's sense of self to make room for new alliances and coalitions of groups, as well as the emergence of liberatory identities based on a universal human identity. This identity must be based on the deconstruction of dichotomies and the unequal evaluation inscribed within dichotomous identities such as white and Black, men and women, straight and gay.

Socialist redistribution strategies focus on the need to transform the underlying political and economic structures of society. The goal of more egalitarian distributions of power and wealth blurs existing class distinctions and inequalities, and creates reciprocity and solidarity. In effect, they dedifferentiate ${ }^{8}$ populations based on class, and work to transform everyone's access and control over resources within a new, liberatory political economy. Fraser (1997) calls for the unity of radical redistribution and recognition strategies in order to create a politics aimed at building liberatory

8 Fraser (1997) uses this term to emphasis the solidarity, reciprocity, new liberatory identities and alliances possible within an egalitarian distribution of power and resources. Rather than increasing differentiation between groups and classes, socialist redistribution strategies work to decrease differentiation and disparity. 
identities and cultures, as well as democratic and egalitarian access to, and control of the resources of society.

The stories and talk of progressive social workers will be evaluated in terms of the ways these three analytic concepts are played out, omitted or both. The following chapters discuss the context of the study, the findings and the analysis. The critical epistemology described in this chapter is integrated throughout as is a commitment to improving the practice and theory of progressive social workers. 


\section{Chapter Five}

\section{The Context}

\section{The Roots of Social Work}

Since the late nineteenth century, most of Canada has had a mixed social economy (Valverde, 1995). That is, social services were provided by a number of sources including charities, the municipal, provincial or federal states, and social change organizations. These three levels parallel the three roots of social work in Canada namely the charitable-philanthropic, the professionalbureaucrat and the social change activist (Carniol, 1987; Baines, 1990).

While early and later state provision focused on scientific delivery of services, and close accounting of expenditures and interventions, charitable services embodied notions of noblesse oblige or the responsibility of the wealthy to provide some level of subsistence for the indigent. In contrast, the social activist roots of social work stressed social solidarity, the need for social and economic restructuring and the equality of all people. Examples of this type of orientation can be found in some of the early settlement houses, certain union social services and grassroots social work organizations such as The Rank and File (Baines, 1990; Carniol, 1987; Reynolds, 1963; 1951; 1946; Withom, 1986, 1984). These three strands of social work overlapped and contested in many ways through the years, with charities such as the United Way's adoption of more professional and managerial approaches, or social gospel social work's focus on religious and socialist themes in grassroots community development work (Wills, 1992).

\section{The Rise and Decline of the Welfare State}

The end of the second World War witnessed a previously unknown willingness on behalf of 
the federal government to fund and, in some cases, administer or deliver human services. The provision of human services at the federal, provincial and municipal levels expanded through the next few decades reaching its peak level in the 1970s. A major influence on

Canada's welfare state, T. H. Marshall envisioned a network of services and programmes that would provide

the right to a modicum of economic welfare and security, the right to share in full social heritage, to live the life of a civilized being according to the standards prevailing in society (Marshall, 1950: 08).

While Marshall's vision was inspiring, the reality of the welfare state was seen by many to be a strategy by which those with power and privilege could maintain and expand it. Others have argued that rather than a strategy of top down social control, social services represent a contradictory conglomeration of the strengths and weaknesses of the struggles of the working class and capital (London Edinburgh Weekend Return Group, 1980). However, the present organization of social services provides people with "resources we need,... (and) relations we don't" (London Edinburgh Weekend Retum Group, 1980: 42).

In addition to providing much needed, although often paternalistic and oppressive services, from the beginning the welfare state took an active role in organizing unequal gender relations. As Sir William Beveridge noted,

the great majority of married women must be regarded as occupied in work which is vital, though unpaid, without which their husbands could not do their paid work and without which the nation could not continue (Beveridge, 1942: 49).

Beveridge's vision was one of an independent, breadwinning male and a financially dependent, work-in-the-home female. Services for unmarried women, or for women whose male partner could or would not financially support them, reflected similar themes. Many critics have argued that the 
kinds of services available to women have replicated female dependency and constitute a form of state, rather than individual, patriarchy (Sarvasy and Van Allen, 1984).

Concomitant with the expansion of the welfare state in the early seventies, various social change movements developed activist social services. Among these was the feminist movement's development of women's shelters, crisis lines, resource centres and helping networks. These services were thoroughly infused with grassroots political understandings of power, structures, gender and social justice. Echoing the trend witnessed throughout the broader social service community, most of these services have been professionalized and bureaucratized like their state-run counter-parts. Certain activist service agencies continue to exist on the margins of the social service community. They include feminist services for women, the anti-psychiatry services, some ethno-specific services, and grassroots organizations of unemployed workers.

The Canadian state and human services in Canada were also built on racial exclusions. These found their source in colonialism, genocidal and assimilationist policies towards Aboriginal people, slavery and imperialism. Racial exclusions and exploitation have been inscribed in a variety of social policies ranging from sections of the Indian Act, to internment policies during the second World War, to the majority of immigration and education policies, labour laws, housing policies and the shaping of many pieces of social service delivery system (Bolaria and Li, 1988; Henry, 1995; Tator, 1996). While countless studies have documented these realities the white majority have been slow to recognize or redress these injustices. Henry et al (1995) report that racism continues to be a problem that is pervasive at the structural level as evidenced by the continual marginalization and exploitation of people of colour within the labour and housing markets. Other studies such as those undertaken by the Social Planning Council of Metropolitan Toronto (Doyle and Visano, 1987) or the United Way 
of Greater Toronto (1991) document the systemic barriers faced by people of colour and new Canadians seeking health and social services in the Toronto area.

Since the late 1980s, Canadians have seen the election of neoliberal governments across the country. Neoliberal economic policy promotes the restructuring of the economy and the work force in order to reduce government spending and deficits. At the level of social welfare policy, neoliberals encourage the entry of market relations into the realm of human services. Neoliberal policy makers advocate individual responsibility-taking for risk, consumer choice in a privatized market of services and entrepreneurship from service users and service providers alike. Services targeting only the most destitute or "needy" are substituted for broadly accessible or universal services.

The enactment of neoliberal policy has produced record numbers of long-term unemployed, the reduction and termination of many human services and a general increase in human misery and despair. For social workers, neoliberal agendas have resulted in significant job losses, the ever present threat of further cuts to agency funding, reduced benefits and wages, inadequate resources and increased caseloads of desperate clients. The human service sector has become an unsafe and contested terrain in which the fundamentals of how, or if, a society will meet social needs is fought out on a daily basis in the lives of clients and workers.

At present a three-prong struggle exists within the social work arena. Broadly sketched this struggle is between (1) those who wish to reprivatize social services and extend the relations and domination of the market, (2) those who wish to politicize and to restructure social services, agencies and practice towards greater social justice, fairness and equality, and (3) those who wish a return to the "good, old days" of the welfare state. Within this struggle the state acts as the major agent of privatization and extension of market relations to the social work realm. 


\section{Liberalism}

Liberalism is the dominant political philosophy of the capitalist era. In its so-called "leftliberal" form this philosophy favors state intervention to create a level playing field or equality of opportunity. In its neoliberal form it discourages government intervention except to create optimal conditions for the operation of large and small business.

Liberalism, within social work, is experienced as "just what we are all about". Although often couched as feminism, social democracy, humanism or multiculturalism, liberal notions of fairness, opportunity and reform permeate social work agencies, practice models and theory. Liberal ideas and concepts such as equality of opportunity, and interventions aimed at problems of maldistribution of resources undergird the way that social work services and theory construct services, clients, workers as well as larger social problems and solutions. While most social workers may not openly identify themselves politically or theoretically as liberal, they work on a day-to-day basis within this micro and macro world frame.

A central feature of this frame is the notion that social life and the social work endeavor are interpersonal or interactions between individuals rather than wholly political relations, structures and systems. The liberal construction of social work as apolitical is diametrically opposed to critical theory's view of social work as a set of entirely political day-to-day activities and discourses. Liberal processes within the social work milieu that act to depoliticize and diffuse political relations and struggles are, in effect, acts of ruling and forms of racism, sexism and class injustice. The identification of these liberal processes is one of the major findings of this study and is discussed throughout the ensuing chapters. 


\section{Changes in Demographics}

While the demographics of class and gender within the social work milieu have not changed significantly in the past decade, race demographics have. Clients, workers, volunteers and unpaid caregivers in the social work arena continue to be overwhelmingly female, while clients continue to be from working class or declassed elements of the working class or the petit bourgeoisie, small business operators. ${ }^{1}$ While racism has been pervasive in Canada since Euro-contact, changes in immigration have produced new patterns in the racialization of various populations, as well as in racism and anti-racism.

Lowered domestic birth rates, activism for less discriminatory immigration policies, a reduction in immigration from Europe, and increasingly desperate conditions in many third world countries has resulted in a significant changes in Canadian immigration patterns. More immigrants are people of colour and most immigrants settle in one of Canada's major cities. Henry et al. report that in 1961, 90\% of Canada's immigrants came from European countries whereas between 1981 and 1991, this declined to $25 \%$ (1995: 78). In 1986, "racial minorities" accounted for $6.3 \%$, or 1.6 million people in Canada. By 1991 the numbers had increased to $9.6 \%$ or 2.6 million people. Large urban centers are absorbing most of these new immigrants. Henry et al. report that by the year 2001 approximately $50 \%$ of Torontonians and two-fifths of the population of Vancouver will be "racial

I I am using the term declassed in a specific way to signal the way these individuals are organized by their non-relationship to production and paid employment. Many of the so-called poor originally were part of various strata of the working class or small business owners (petit bourgeoisie). These people have lost their employment and move in and out of the paid labour market. Hence, they have no consistent relationship to the means of production. They are however organized by their non-relationship to the means of production, or by their "class", to be cheap labour or part of the reserve army of the unemployed.

According to Rosa Luxemburg, this reserve army "is not merely a special section, a sort of social wastage which grows enormously when the walls of the social order are falling down, but rather an integral part of the social whole" (Water, 1970: 392). 
minorities" (1995: 81). At the micro level these changes have placed accessibility and anti-racist demands on social service agencies and practitioners. At the macro level these changes reflect the legacy of colonialism, the globalization of capital and poverty and the ongoing effects of imperialism.

While some immigrants bring skills and traditions of progressive struggle to Canada with them, other less progressive immigrants and Canadian citizens of colour become politicized when their living conditions and expectations are lowered by structural racism. Demands for improved schooling, more responsive and less prejudicial policing, and more access to government jobs and services have seen the mobilization of major sectors of the immigrant and left communities. While not unified in political outlook or interests, such broad coalitions have experienced varying degrees of success with the local provincial and federal states ${ }^{2}$ as well as with some human services agencies and schools of social work.

Social work, as a whole, has not been at the forefront of those identifying and redressing the social inequality and injustice faced by Canada's racialized groups. Indeed, social work has been slow to integrate anti-racist themes into education, curriculum, practice models and agency priorities. In many cases anti-racist or diversity organizational change has taken place at the initiative and insistence of funding bodies such as the United Way or the Metro level of government in Toronto. For the most part these strategies are individualistic, pluralist strategies rather than strategies aimed at more fundamental and society-wide restructuring.

The context of this study is composed of these four mutually reinforcing processes -- a mixed social economy paralleling the mixed roots of social work practice, the decline of the welfare state

2 For an interesting discussion of the politics of minority resistance against racism in the local state see Stasiulis, D. (1990). 
and, the concomitant rise of neoliberal politics, liberalism as the backdrop to all social work practice and thought, and, finally, changes in the demographics of Canada, particularly changes in immigration patterns. The intersection of these multi-faceted forces has placed pressure on social services and practitioners. The response of a particular group of practitioners acts as the locus for this study. 


\section{Chapter Six}

\section{$\underline{\text { Class }}$}

\section{How Class is Depoliticized}

Within the social work milieu, class is liberalized and formalized. By formalization I am referring to processes and practices which operate in accordance with certain recognizable managerial, hierarchical and bureaucratic forms, and routines. These forms and routines are more than commonsense or professional ways of doing things. They are actual pieces of social organization. These pieces of social organization depoliticize social relations, such as class, by sorting them into conceptual and repetitive ways of doing things that are abstracted from everyday conflicts and needs. This study shows that within the social work milieu, class relations are formalized into union-management relations, as well as through hierarchies, bureaucracies, documentation, professionalism, auspice and hiring practices.

Class is also depoliticized and liberalized through discursive practices. When class is depoliticized through a process that takes the conflictual everyday experiences of people and cycles these experiences through the processes described above, certain ways of talking about class emerge. These ways of talking are rooted in the actual material conditions or processes that organize the work and activities of a social service agency. Like the material relations from which they spring, these ways of talking also act as forces that organize how people think about and act upon issues associated with class relations.

As noted in Chapter III, for the purposes of this thesis class is understood in the Marxist sense of one's relationship to the means of production and reproduction. Marx developed an understanding of class as a relationship with the intention that it be used as an analytical tool to aid in the 
explanation of "structural change in societies characterized by a capitalist mode of production" (Stolzman and Gamberg, 1974: 106). Class, as Marx employed it, was aimed at understanding the dynamics of social conflict, its structural roots and its central contradictions within specific capitalist formations. Hence, Marx's understanding of class is useful for laying "bare the foundations of class inequality" rather than describing specific strata of groups of people (Stolzman and Gamberg, 1974: 110). While Marx did not include reproduction in his formulation of class relations, feminist contributions to this discussion reveal that the productive formation in any society cannot be properly understood without an analysis of the relations of reproduction $(\mathrm{Ng}, 1993 \mathrm{a}, 1993 \mathrm{~b}, \mathrm{Smith}, 1987)$.

My informants' stories about class also reveal how ideology works at the everyday, commonsense level. As Gramsci noted, commonsense is fractured, containing pieces which are ideological and oppressive, and pieces that precede ideology and foreshadow more emancipatory relations. As this section on class underscores, progressive social workers display a complex melange of liberal ideological understandings of class, and radical, transformative practices.

For example, when progressive social workers discussed class as a facet of their everyday work, they employed a liberal stratification analysis, rather than a dynamic or relational understanding of class. However, when the workers spoke of how they were politically active around issues of class, they employed radical practices and understandings of class which acted to destabilize existing class relations, identities and distributions of resources. The stories on class also reveal how liberal ideology infiltrates all levels of social life concealing, organizing and sustaining relations of injustice and subordination.

In this section I will examine mechanisms that formalize, restrict and redirect progressive social work endeavors. These mechanisms include bureaucracy, hierarchy, auspices, 
professionalization, standardization, individualization, documentation, hiring practices and the division of community, clinical and policy practices. Various discursive practices around class will be discussed in the second section. In particular, the following discourses will explore the way that class is understood and practiced by progressive social workers as a descriptive category not a social relation, as well as how this category is translated into notions of the poor and of the middle class as non-antagonistic, static social groupings. The final section of this chapter proceeds with a discussion of some of progressive social work's transformative formulations and applications of class.

\section{Seven Mechanisms that Depoliticize Class Relations}

Overall, the data suggest that there are seven mechanisms that formalize and "cool out" class relations within the social work milieu, while simultaneously shaping the progressive social worker's maneuverability on the work site and the possibility of practicing in an emancipatory manner. I will argue that these ways of organizing social relations are the main ways that class is formalized, depoliticized and distanced from any sense of everyday political struggle. These pieces of social organization are entirely external to the workers, although workers participate in them on an everyday basis. The pieces of social organization that will be discussed in this section are not neutral ways of ordering the work of a social services agency. They are conduits for relations of domination and subordination and as such organize some people to be marginalized, oppressed and exploited while others fill in other more dominant positions in the classed social order.

I will refer to these pieces of social organization as mechanisms. This term signifies the way that these organizers operate largely outside of the control or intentionality of the individual worker, and generally, of the individual agency. Instead, they operate routinely, or mechanistically, to recreate 
the unequal and unjust conditions of the larger society.

These mechanisms are not unique to class. They are also mobilized within social work agencies to depoliticize other socioeconomic and cultural struggles. For example, race was neutralized through specific agency-wide projects aimed at managing diversity. Known as anti-racist or multicultural organizational change programmes, these projects utilized various facets of the mechanisms discussed below to recast vibrant anti-racist political struggles into controlled, standardized, bureaucratized procedures and policies. Similarly, gender was depoliticized through mechanisms such as the professionalization and bureaucratization of anti-sexist struggles. The specific ways that the seven mechanisms below impact on the formulation of race and gender will be explored in greater detail in subsequent chapters.

Although workers were largely unaware of the way that discursive practices around class entered their practice, workers could describe how relations of ruling, in the form of government and state control, entered their work through the ways that their work and work places were organized. While these mechanisms operate in ways that are often assumed by larger society to be effective, efficient and caring, workers expounded on many of the ways these mechanisms formalized, standardized and liberalized their working relations and their work. This was not a simple social control analysis. Workers noted that certain agencies are organized in ways that encourage anticlassist practices and ideas to develop, while workers in all types of agencies resisted these mechanisms of formalization and liberalization. The way that alternative forms of social organization are more or less effective at resisting relations of ruling was also discussed with great clarity.

This analysis of the operation of these mechanisms is not a critique of public provision of human services. It is a critique of the present organization and delivery of those services. 
Progressive social workers were very supportive of public provision and, in contradiction of neoliberal preoccupation with downsizing, they called for the expansion of funding to and support of human services. Some of the lessons drawn from the organization of alternative social services such as some of the feminist women's services or the ethnic-specific services can provide insights as to how public provision might be organized and delivered in a more participatory, emancipatory and explicitly political way.

The next section will discuss these highly political and ideological mechanisms and workers' reflections on them. These seven mechanisms include: 1) bureaucracy and hierarchy, 2) documentation, 3) professionalization, 4) individualization and standardization, 5) the agency's relative distance from the government and state, 6) hiring processes and 7) the community-clinicalpolicy division of labour. In each case I will present the worker's description and analyses, as well as ways that these mechanisms were resisted.

The data suggest that agencies with minimal bureaucratization and hierarchy seemed to have more potential to practice social work in an emancipatory manner and to be open to political challenges from oppressed groups. Rather than simply accepted as the best way to organize social work sites, bureaucratic forms, within the alternative agencies, tended to be imposed externally from the state and other funders. This bureaucracy was negotiated carefully and resisted in conscious and deliberate ways by the workers, the Boards of Directors and the agencies as a whole. These agencies are characterized by horizontal or quasi-horizontal forms of decision making, distribution of power and division of work within the agency. Horizontal structures tend to involve workers and volunteers in setting the general direction of the agency and their own work. In addition, the workers and volunteers often participated in aspects of setting their own work and work practices. The workers 
argued that the broader based, participatory nature of this type of decision making created the possibility of greater openness and responsiveness to new ways of looking at and incorporating political issues and the communities and individuals with which they were associated.

Workers identified the hierarchical organization of most social service agencies as one way that class was expressed in their everyday work lives. Hierarchy in the work organization results in according different positions within most agencies more or less status and power in a bureaucratic chain of command. This power is rarely meaningfully divided between workers and management while clients are almost always excluded. As one worker put it, "our agency is basically very suspicious of frontline workers and consumers." Another worker added that workers were only allowed to sit on committees that have no actual policy making input or power, while clients were not allowed to sit on any committees. As she opined, "the people at the top are fearful of a lot of consumer input."

Workers noted that some community agencies put clients on their Boards of Directors. These clients are fairly consistently patronized and manipulated by non-client Board members. For example, one clinical worker observed that the service users on her Board were either "always right because they are consumers, or always wrong because they are consumers." She continued, "the other Board members seem to have no ability to deal with clients as equals." This example highlights the way that formalized mechanisms for power redistribution can be undermined by individual practices. Although decision making structures have changed, ideological constructions of clients continue to limit and marginalize their input and power. Other workers spoke of more positive experiences with Boards of Directors and management. These experiences occurred within agencies who see themselves, and hence their Boards and management, as part of a social movement or social change strategy, rather 
than as an executive of a bureaucracy. These boards and management teams can be found in agencies with strong social justice mandates and ties to social justice movements, such as some of the feminist or some of the anti-psychiatry service providers. Board members, staff and management of these agencies were recruited for their demonstrated commitment to the cause and their political analysis of the issue.

These agencies represent a diversity of experience and organizational forms. For example, noting that "not everybody comes to work everyday wanting to be the boss", some of these agencies have moved from a non-hierarchical collective model to a division of labour which includes a level of senior management. Mechanisms such as frequent general staff meetings have been put in place to ensure that senior management is answerable to staff, as well as to the Board. Workers provided a number of examples of times they have "called management on their handling of certain issues" and continually monitor senior management's direction and agency development.

It is interesting to note that none of these agencies are unionized. Workers demonstrated a strong identification with management and the Boards, and reported that they do not need a union to represent their interests in any aspect of agency life. This type of agency tended to have a smallish number of staff ranging from two to forty arid seemed to have developed practices which permit a division of labour without the marginalization of worker input and decision making. While a formal hierarchy exists, these agencies maintain a certain capacity for fluid relations between workers and management as well as more of an openness to power issues in general.

The literature has identified documentation as a major way in which the state shapes relations and structures in an agency. ${ }^{l}$ My informants who worked in government bureaucracies found

\footnotetext{
1 For a discussion of see $\mathrm{Ng}$ (1993a and 1993b) and Morgan (1988).
} 
documentation to be the centre piece of their jobs. They argued that they spent more time on their personal computer terminals than they did with the clients. One informant reported that he resists documentation by never writing in sentences. Everything he writes, whether it is letters or applications or memos, is in point form. The same worker noted that management would actually like the workers to do less documenting so that each worker can see considerably more clients. The interaction with each client would be even more rushed, standardized and alienating. Hence, the worker was left wondering if increasing the time he takes with documentation might actually be a more effective way of undermining the government's agenda of increased caseloads and lowered service quality.

Limiting the amount and type of documentation was a central practice of the more permeable and less bureaucratic settings. A number of the agencies put considerable energies into negotiating with funders around limiting documentation and resisting new types of documentation. Workers from the non-government, less bureaucratic agencies agreed that this type of negotiation and ongoing refusal to take on new forms of documentation is an important aspect to maintaining some capacity to organize one's work and the service in a less oppressive way.

Other agencies tried to deconstruct the other aspects of documentation. Some workers, for example, spoke of policies within the agencies surrounding the ownership of documentation. For example, one agency maintains while client files cannot be removed, clients own the contents of the files and can look at them, edit them and contest entries at any time. The worker said that these rules provide useful boundaries for her in how to keep client records respectful, as well as helpful to herself and to the client.

The third mechanism of class formalization and liberalization revolved around 
professionalization. This discussion will initially focus on deprofessionalization before moving on to professionalization. Within the social change agencies the debate around professionalization rotates primarily around deprofessionalization. Deprofessionalization can take many forms. It ranges from the anti-expert, right-wing populism found in some of the self-help movements and sectors of the antipsychiatry movement, to the egalitarian ideals and organizations of some of the anti-psychiatry, the feminist and the ethno-specific womanist organizations. ${ }^{2}$ These agencies tend to focus on the worker being "an expert in the field" while the "client is an expert on herself". Worker acknowledges power differentials which exist in the social work-client relationship and see their roles as that of sharing expertise in the form of knowledge, resources and strategies. The more egalitarian model of deprofessionalism values other forms of knowledge such as experience, volunteer work, and credentials from countries other than Canada. This makes jobs and the agency more accessible to immigrant women, working class women and others marginalized within the education and labour market. Mechanisms such as the ways that agencies organize hiring practices, work processes and policies act as a conduit between the agency and new political struggles and debates.

Right-wing populist deprofessionalism shifts the debate from one of multi-axes of injustice and subordination to a primary focus on the power differentials between professionals and nonprofessionals. The right-wing populist solution is to simply eliminate professionals from the equation. "Commonsense" or everyday ways of thinking and acting are valued more highly than any sort of skill-, academic- or political-based knowledge. Commonsense is seen as neutral, natural, and non-

2 Some women of colour and immigrant women prefer not to use the term feminist because of the tendency to exclude the experience of all women who are not white and middle class. The preferred term is womanist which is thought to convey a strong identification with the liberation struggles of women of colour of all classes. 
ideological. This type of deprofessionalism has resulted in abuses of power in the name of commonsense. For example, a worker could become frustrated with a client and, in a so-called commonsensical way, deny them services. One worker from an organization that in the past could be characterized as right-wing populist, deprofessionalized agency, spoke of the excesses perpetrated against clients by often well-intentioned, anti-professional, staff. Following a major inquiry, her agency has adopted a new quasi-professional approach. This approach is distinctly similar to the egalitarian model used in a number of feminist and womanist agency. The worker reported that it affords greater protection and possibilities for clients, for the movement and for workers.

A debate emerged in one of my focus groups around deprofessionalization as an ideological practice. Worker $\mathrm{M}$ is employed by a anti-professional populist agency. The workers in this discussion question each other in a non-confrontational way about substantive differences in analysis. The issue remained unresolved as the workers chose to change the subject, rather than continue to disagree with the dissenting member.

Worker M: (My agency) in itself is radical and a radical reformulation of power structures.

Worker $\mathrm{N}$ : It is anti-class or is it anti-hierarchy?

Worker O: Its anti-class?!?

Worker M: Its anti-class. It is written into its mandate and some of the objectives....If you are an accountant or a social worker or a doctor in your other life, at the table you will be just a (member). So it is anti-class. It's leave your class or leave your education and just come deal with your anger, for example.

Worker N: I guess I see what you mean,...

Worker P: I think it's anti-professional.

Worker M: It's anti-class, too. 'Cause in the same group a doctor, which is a class and, of course, a profession but it is also a class, will be sitting next to a single mom because they have the same (problem). 
Worker O: But there must be dynamics within that,...

Worker M: For sure, but it's written into the structure that it is this radical structure.

Worker O: But the single mom is maybe not going to feel as heard as the doctor, I don't know, ...

Worker M: Well, the groups don't work for everyone. But then the single moms can just go off and form their own groups, see?

It's set in the structure to be anti-class. That's my thought. And so my work is just so far-out. It's bizarre. It's hard to bring it into a space where you talk to others about (progressive) social work.

This excerpt underscores the lack of clarity some workers have around class as well as around deprofessionalization. Worker $\mathrm{M}$ equates being a doctor with being a class. The professional status of doctor is, in reality, an aspect of one's social strata rather than one's relation to production and reproduction. The worker also fails to see that class and gender relations remain oppressive within this service structure, despite attempts to reorganize services to limit the power of professionals.

Right-wing populist deprofessionalism's singular focus on professionals fails to highlight other types of power relations. The individualism of this form of populism underscores the notion that "all men are equal" and merely need to pull themselves up by their own self-help bootstraps. Hence, populist deprofessionalized agencies have a strong tendency to mirror the oppressive relations of wider society and recreate them in their delivery of services. While differences such as disability, age, or gender may be recognized by such agencies, the power relations inscribed in these differences is not addressed hence, services recreate the injustices of these unequal relations. The embracement of right-wing populist deprofessionalization is another example of how ideology works at an everyday level. Progressive workers displayed confusion and inconsistencies in their analysis of this phenomena. 
Like other acrimonious discussions within my focus groups, this debate around deprofessionalism was left unresolved. The workers preferred to move on to new issues rather than engage in lengthy conflictual discussions. The avoidance of conflict permitted the group to maintain some sense of unity and common ground as progressive social workers.

It is interesting to note that workers found it difficult to discuss class without drawing in other relations of oppression. For example, gender was used by Worker $\mathrm{M}$ to emphasize his argument that class equality is an inherent quality of his agency - "a doctor,... will be sitting next to a single mom". The assumption is that the doctor is male, and most likely white, while the mom is obviously female and poor. This same gendered example was also used by Worker $O$ to highlight her sense that equality has not been created. Both make use of their shared understanding of the exploitation and oppression experienced by single mothers to underscore the points they are making around class inequality.

My data present a complex relationship between progressive social workers and professionalism. While all of my informants opposed the Ontario Association of Social Worker's campaign to legislate and regulate the professional practice of social work, they were not uniform in their sense of how professionalism impacts on their clients, work and practice. For example, a worker in the field of disabilities felt that professionalization of his service has meant that workers are less likely to have unreasonable expectations of clients such as "they should go get a job right away". In contrast, as the following excerpts show, workers in progressive, community-based agencies felt that professionalism was one of the ways that "the government has of distancing us from our clients and community". Another worker noted, "We can do the same work without buying into professionalism and it is important that we not be coopted by the status and prestige that it tries to suck us in with." 
Yet another worker observed, "Social workers just like the power it gives them."

Workers in large, bureaucratic, government agencies argued that professionalization was largely unimportant, helpful or both. In an already professionalized workplace, professionalism acts more as a barrier to those trying to gain access to the jobs, rather than as a tool to discipline and regulate workers within the agency. Hence, my informants belittled the capacity of this ideological mechanism to circumscribe their work on a day-to-day basis. For example, workers, in the professionalized, government bureaucracies, provided many examples of how professionalism is a force that has been in place for so long that it fails to control them in any meaningful way. The workers enjoyed telling stories of sabotaging management directives or disciplinary actions, by releasing substantial quantities of "professional" literature which countered management's position. Failing to gain the upper hand in arguments around professionalism, management in many work places had basically abandoned it as a disciplinary tool.

Workers also used the discourse of professionalism in their fights against the neoliberal agenda of various levels of government. For example, professionalism was helpful as a bulwark with which to resist the general deskilling of jobs, standardization of service, and downsizing of the work force. Workers found that the discourse of professionalism lent itself well to the argument that social workers are better prepared to address the complex and multi-dimensional needs of clients than are clerks and their specialized computerized assessment and client self-assessment packages. Professional staff argue that the "quantification of client needs" through self-administered or clerkadministered computer assessments is "inaccurate, alienating and makes things worse for everybody -clients, workers, secretarial staff". In the context of this particular struggle with management, progressive workers joined with mainstream workers in emphasizing the need for "professional skills" 
and bodies of knowledge which stress the importance of relationships, interaction, empathy and context. Where progressive social workers differed from their mainstream counterparts is on the need to use these skills to build solidarity between themselves and clients in order to build social movements capable of fundamentally restructuring our cultural and socioeconomic systems.

Standardization of the social work intervention, the fourth mechanism of class formalization, dovetails with the introduction of computerized assessment of client needs. Through the standardization of interventions, the potential to develop interventions which are personalized to each client's needs is removed. Further, the possibility of politicizing these plans, a key aspect of progressive social work, is also curtailed. As one worker put it his job seems to be to "fit every client into one model" rather than to fit the model to the client. Another worker observed that the services he provides to clients are so limited and inflexible that it is the equivalent to "shooting straight down the middle and missing everyone". Another worker quipped "one size, fits none".

Working in tandem with documentation and standardization, individualization of social problems dovetails with standardization. Mainstream social work is often critiqued for the way it constructs the individual as wholly responsible for social problems as well as for solutions (Camiol, 1990, 1987, 1979; Dominelli, 1988; Galper, 1975; Mullalv, 1993, 1995). The individualization of social problems is reinforced by a series of social work practices including individual application processes, individual rather than group interviews, and apolitical, therapeutic rather than political, social change interventions. Workers chafed at the way that the brief intervention, a current form of standardization, serves to further consolidate the individualization of social problems. The standardized, or brief, intervention is a carefully calculated and controlled intervention which focuses on providing "the minimum resources necessary to get the job done". These resources include the 
amount of time each worker can spend with a client and the type of services that can be made available to each client. The frugal quantification of client need and rigidity of standardized intervention removes the worker's discretionary powers. Hence, she has little maneuverability to develop alternative, personalized and politicized strategies.

Moreover, this rigid standardization removes the necessity of listening in any detail to a client's experience as there is no way in which this experience can be incorporated. In other words, there is almost nothing the client can tell the worker about her situation that will modify or personalize the intervention plan. The particular details of people's lives are made irrelevant to the assessment and intervention process. The analysis and descriptions of people's lives is constructed for the purposes of ruling, rather than to understand or act on actual problems in people's lives. Dorothy Smith (1990) would call this an ideological circle as it is a process in which "the categories set up to explain a phenomena operate to select and assemble it as 'facts'" (Hick, 1991: 82). The process is circular "because the schema for organizing the particulars is not questioned" and provides the appearance of objectivity and rationality (Hick, 1991: 82).

Like individualization, standardization also ensures that clients do not get an opportunity to connect with other people with similar problems and interests. Initiatives such as group support are viewed by management as uneconomical and therefore discouraged or denied. One worker spoke of proposing a peer support group for his young and isolated clients. His proposal did not even make it past his supervisor who referred to groups as "the frills and indulgences of bygone eras".

Similar to previous mechanisms of quantification and control, standardization and individualization are strongly opposed within the smaller, social action agencies, resisted in the large, bureaucratic community agencies and largely unavoidable in the government-run agencies. Indeed, 
an agency's relative distance from the state in terms of funding, management and mission directly impacts on its potential to develop and nurture social justice agendas and oppositional practices. Agencies which are state-mandated, state-funded and state-run such as Corrections, Social Assistance, Vocational Rehabilitation are very resistant to oppositional ways of thinking and practicing. Although progressives are just as present in this type of agency as in any other, practice is very difficult in these work sites. ${ }^{3}$

A worker in one of these agencies observed that

the challenge becomes what happens when you encounter a client who isn't poor and how that effects how you approach the problems or how you respond to the client. And I've seen people running in circles trying to figure out how to respond to wealthy parents with a kid who has some problems.

Large, bureaucratic, state-mandated and funded community agencies such as the children's aid societies are similarly rigid and affective at limiting the entry of progressive and oppositional practices. The work within these agencies is standardized and individualized, and documentation demands are extensive and regulatory. Indeed, workers experience difficulty in seeing clients in any way other than as deviant and inadequate. ${ }^{+}$

In contrast, the larger multi-service community agencies tend to receive funding from a variety of governmental and non-governmental sources. Their mandates and management are independent of governments. While hierarchical and bureaucratic, these agencies offer services that are generally

3 In his doctoral research Mike Birmingham established that progressive social work thought and practice can be found in all types of social work agencies (Birmingham, 1994). Auspice may influence the way progressive practice is shaped, however it does not determine whether or not progressive practice exists.

4 For an interesting discussion of "neglect" as an ideological practice within children's aid societies see Swift, K (1990). 
aimed at groups, rather than at individual clients, hence they are less likely to be individualized or standardized. While present, documentation is less extensive than in state-run or state-mandated agencies.

Overall, community agencies tend to be more responsive to the changing conditions within their mandated communities than are government-run bureaucracies. The target population of most community agencies is defined by a certain geographic area of the city. However, certain centres are identified with, or they themselves identify with, particular discrete populations such as Central Neighbourhood House's work with low-income people and people who live on the street, or the 519 Centre's work with gay men, lesbians and bisexual people. Some community agencies such as the 519 Centre serve a client population who are defined by a certain facet of their social identities. Others, like Central Neighbourhood House, serve certain social strata within a large geographic area. Hence, it is not middle-class services versus services for the poor that explains why these agencies are more responsive and progressive than government bureaucracies.

The permeability of these community agencies seems to lie more in the construction of the agency's target population. In many ways these target populations are pre-existing, that is, the agencies did not construct them, they were created by social movements and activism. The social construction of identities and interests within various social movements results in populations of people who are more likely to be an already politicized, or politicizable, group. Thus, some community agencies work with self-defined populations who happen to have service needs, rather than with populations that the government or state has defined on the basis of having service needs. Indeed, workers reported that the community centres that are linked to various identifiable social causes or identities, are more likely to be responsive to changes within their communities, new 
demands for service and new populations of clients.

Government bureaucracies and government mandated agencies are less likely to have a politicized, or politicizable, cohesive client population who see themselves as sharing cultural and economic issues in common. The target population of most of these agencies is ostensibly any citizen who requires services. In reality, government and quasi-government agencies serve the poor. As discussed earlier, the poor are not an undifferentiated mass, but a large cross section of the population who rarely see themselves as having interests or identities in common. Hence, they rarely act as any kind of extra-agency force, placing pressure on government agencies to respond to their unmet and changing needs.

Workers also found that within agencies, each programme differs in how progressive and open it is to the community and to political struggles. One worker noted that immigrant services tend to be much more fluid than are programmes for senior citizens. Funding for senior's programmes is at a much higher level and is much more established than are service for immigrants. Another worker added that the recreation programmes in her multi-service agency tend to be very mainstream and apolitical, whereas services for families and children tends to be more progressive. In both these example, the programmes for immigrants and for families wore heavily staffed by workers of colour and served a poorer, immigrant and new Canadian population. The programmes themselves received minimal state funding although the participation rate in many of the programmes was unprecedentedly high. My informants reported that the staff, the clients and the demands on these programmes were all less integrated into the predictable ways of doing things at the agency. The instability of the staff, client demands and programme lent it a degree of flexibility, challenge and runaway potential that the other more established programmes lacked. Moreover, those community centres with politicized 
target populations were more likely to be forced to grapple with new and ongoing demands from programme and community participants. Thus, fluidity while not inevitable, was more likely and more possible. Unfortunately, fluidity tended to also be coupled with low and unstable funding. Agencies that developed in tandem with political movements such as feminist services, womanist services, anti-psychiatry and disability rights groups, usually have a mixed government and non-government funding bases, non- or anti-government management and an explicitly political mandate/missions. Most of these agencies maintain some sort of tie to political movements. These ties may take the form of research support, participation in lobby or activist events, membership in coalitions around specific events or ongoing causes or all of the above. One worker found explicit support from her agency for political activism and added that each staff member is encouraged to sit on at least one community board or coalition as part of their work load. Although her agency felt it could not risk directly confronting the government, another informant at a social change agency was given support from her agency to funnel her protest work through a social change organization. This work included the writing of, and presentation of a very critical brief on proposed government policy changes.

Rather than individualizing and standardizing interventions this type of agency "places individual problems within a political and community context". Intervention plans were reportedly "personalized" or particularized to each client within the larger socio-political context. This is very different from the individualization promoted in state agencies. Responsibility for client problems and for solving them is also socialized, hence the participation of staff in political activism.

Hiring processes was the last of the mechanisms of ruling mentioned by my informants. As mentioned previously, staff within social change agencies are hired for their proven commitment to 
social justice. For example, one of my informants started off as a movement volunteer-activist and was eventually hired to be an intake worker. She lacked professional credentials or academic training. However, her experience in the field, in social activism and her practice-based knowledge were viewed as equivalent to more formalized qualifications. In some social action agencies and for some positions, professional credentials are required in addition to an explicit political analysis and way of working. Some workers combined graduate degrees in social work with histories of activism and a critical analysis in order to meet qualifications for similar job openings.

$\mathrm{Ng}$ (1988) notes that job openings in government-funded agencies must often be filled immediately or the funding and job position could be permanently lost to the agency. However, it is often difficult in conditions of rapid job turnover to hire workers committed to social justice. Hence, workers are often hired simply to fill and retain the job position $(\mathrm{Ng}, 1988)$. Workers from social change agencies noted that the neoliberal economy has produced a large pool of unemployed and underemployed progressive workers. This differs somewhat from the economic conditions which existed at the time of Ng's study. Workers cited many examples of unemployed or underemployed progressive colleagues, particularly women of colour. Thus, my informants observed that there is no difficulty in hiring social justice fighters, the problem is which one to hire.

Workers in the government-run and government-mandated agencies lamented the lack of progressive colleagues and reported having no influence over hiring processes. They emphasized the isolation they feel as one of a very small number of progressive workers within a large, bureaucratic work force. Many felt that supportive colleagues were key to any type of meaningful, collective struggle within their job sites.

Workers in the large, community agencies reported a variety of experiences around the hiring 
of social justice fighters. Progressives working in the agencies based in the more politicized communities often have influence over hiring disproportionate to their actual number within the agency work force. The more flexible work conditions and politicized environment created conditions in which progressives within the agency could unite and develop a left-of-centre strategies for the agency. Hiring was a key plank within these strategies. Again the relatively large pool of qualified, unemployed progressive workers meant that job positions can be filled rapidly without risking the lose of funding noted by $\mathrm{Ng}$ (1988). Although it goes against the trend I have been describing, one worker in a government-mandated agency participated in a similar strategy. Progressive social workers within a fairly conservative work site developed strategies within and outside the job site aimed at hiring more progressive social workers, particularly workers of colour. Progressive workers posed as mainstream applicants for job openings. Progressives on the hiring team were alerted to their applications and fought to have them hired. This strategy resulted in a small but influential block of progressive social workers within a larger, mainstream department. The strategy collapsed when neoliberal government funding cuts resulted first in a hiring freeze, and then the laying off of half of the work force. The progressive block of social workers within this agency continues to exist but finds the current climate of layoffs, work speed-up and human service cutbacks to be very hostile to progressive ways of thinking about or doing practice.

Another countervailing phenomenon was noted by two workers at two very different community agencies. Both commented on the way that administrative staff are not required to meet the same progressive criteria required of other staff in the hiring process. In order to compensate for the fact that administrative staff were paid less and had lower job and life opportunities than professional staff, they were not required to have demonstrated commitment to the social issues of 
the agency. This meant that they were often not interested in dealing with clients in the egalitarian and politically sensitive way that the professional staff felt was appropriate.

A split emerged in both agencies between administrative staff and professional staff around how the reception of clients was handled. Due to lower wages administrative staff tended to have higher turnover rates than professional staff. The result was that "it feels like" newly hired administrative staff were continually being "educated", heavily supervised, and at times disciplined around appropriate ways to deal with "poor" people, "crazy" people, and incoherent clients. My informants reported that they "hate playing the heavy and forcing people to behave in certain ways even when they are being awful to the clients". The resultant animosities between professional and administrative staff were long standing and apparently unresolvable. One worker hoped that through the process of developing an Employment Equity programme for the entire agency administrative staff could be included in a general politicization which they might see as "in their own best interests."

A similar phenomenon was noted in agencies that adopted affirmative action hiring processes. As job turnover tended to be most rapid in the lower pay and lower status jobs, these are the jobs in which the affirmative action hiring first occurred. Again, a split emerged within the staff between the predominantly white professionals and the administrative ctaff who were predominantly women of colour.

While on the surface these phenomena seem similar, below the surface they are somewhat different. The latter is the result of introducing a single policy in an effort to bring about anti-racist change. The anti-racist organizational change literature is full of critiques of this type of single strand strategy (Karp and Sutton, 1993; Thomas, 1987; United Way of Greater Toronto, 1991). An ongoing project examining and changing macro and micro practices and policies within the agency 
is required to bring about any meaningful change. While often well-intentioned, single strand strategies tend to result in an escalation of tensions and often the abandonment of organizational change efforts (Karp and Sutton, 1993). It reflects a liberal strategy of inclusion without allocating the resources necessary to explore and redress underlying systems and structures of inequality and oppression.

The former strategy is a further example of ideological practices in the everyday context. By exempting administrative staff from the requirement that they have a progressive analysis and practice, workers are assuming that administrative work is somehow exempted from the relations of domination and subordination that criss-cross all social relations and interactions. They are further assuming that while social work is political practice, administrative work is not. In effect, the agency objectifies and patronizes the administrative staff by treating them as if their political opinions and practices do not exist. The administrative staff, likewise, objectify and patronize the clients.

The last mechanism which seems to detract from the development of a permeable and political environment is the way in which socio-political issues are divided between agencies. In state-run and state-mandated agencies, clinical, community and policy work are organized into wholly separate agencies. It is not intended that these sections will inform each other around leaky issues and there are no measures in place which could permit this to occur. Indeed workers reported that when they attempted to comment on policy initiatives they were actively dissuaded or disciplined. One worker in the public service who wrote a letter to a newspaper about a social issue was told by his supervisor that "there is a line in the sand and don't cross it again" or disciplinary actions would be swift and irreversible. Many workers choose instead to comment through their unions or anonymously through voluntary organizations. 
In contrast to the state-run and state-mandated agencies, it was much more possible for community agencies to comment on policy issues and to participate in social change activities. Despite this possibility, workers reported that most community agencies did not involve themselves in social policy development and had no ongoing mechanism for such work. One worker noted that whenever she complained to her community agency about social policy issues she was told that in addition to maintaining her existing workload, she should go ahead and write a brief, organize consultations on the brief within the agency and then present to brief to the appropriate level of government. She was to expect no concrete support from management or the Board for this work; however she should feel free to go ahead with it. The worker found this response to be an effective way to dissipate activism around controversial issues without management actually having to refuse to participate in policy debates.

An additional problem that workers cited around the construction of the clinical-communitypolicy division was the way that community programmes kept their various levels of programmes quite separate from each other. For example, counselling programmes were quite separate from recreation programmes which were quite separate from housing programmes which were quite separate from neighbourhood development programmes. Thus the experiences and knowledge about the community which can be gleaned from each programme is not pooled with the others, nor does it inform the programming in other agency sections. Obviously, this important social knowledge also did not filter through to the policy development level.

Social change agencies, in contrast, consciously amalgamate policy, clinical and community activities. While a cerrain division of labour may exist within the agency itself between those who specialize in clinical, community or policy work, the experiences of staff and clients in each area 
informs the other. Moreover, there is overlap between staff in each area. For example, clinical workers in one feminist agency regularly participated in community development in the form of public speaking to high schools, service clubs and corporations. They also provided public workshops throughout the year on a variety of topics relating to the agency's socio-political issue. All staff were asked for input on new policy trends, and lobby efforts as well as how to handle funding trends from the government and other large scale funders such as the United Way. In another social change agency, each worker carried a caseload in addition to sitting on community boards and coalitions, and using agency time to attend public demonstrations.

As previously mentioned, the data show that there are seven mechanisms which contain or enhance progressive worker's capacity to think about and do social work in a more emancipatory way. These mechanisms run up and down a continuum with my informants finding a variety of ways to resist them and carve out small spaces for progressive practice or embrace them and develop multilevel emancipatory ways of intervening. These mechanisms and practices are about the division of power within agencies, and between agencies and major funders. They import relations of ruling into the lives of the client and the worker through control of the service product, the service process and the work environment. Moreover, they are ideological practices which conceal the everyday details and realities of peoples lives, replacing them with formalizing and depoliticized ways of understanding and acting upon social problems.

These mechanisms and resistance to them have been taken up in different ways by different sectors within the social service milieu. In particular, feminist services have organized their agencies in ways that resist and restructuring these mechanisms. This will discussed in greater detail in the section on gender. 


\section{Discursive Practices of that Depoliticize Class}

The seven mechanisms discussed above, in a sense, form a container in which social relations are meant to reside. ${ }^{5}$ Worker's "talk" and understanding of social problems and social relations was based in the way this particular container was put together and served to recreate it in various ways. In other words, depoliticized constructions of class were very much in evidence in the discursive practices of progressive social workers. These abstracted and depoliticized discursive constructions of real people and their relationship to the means of production and reproduction, permitted workers to intervene in the lives of people and their communities as if these discursive practices reflected everyday life rather than ideological reconstructions of everyday events and experiences.

No container is one hundred per cent leak proof. The resistance strategies of progressive social workers evidences the leakiness of certain aspects of the class container. However, the container in which class was restricted, more than that of race or of gender, had very few leaky areas or areas in which a more critical analysis was apparent. The reason for this less leaky quality is discussed in greater detail in later sections.

\section{Class as a Description, Not a Relation}

Although, theoretically, much of progressive social work employs a Marxist notion of class as one's relationship to the means of production and reproduction, ${ }^{6}$ in practice, most progressive

s Thanks to Nancy Fraser (1989) for this metaphor. In an article that has broad application for social work and social activists, Fraser uses the metaphor of leaky, runaway issues, to analyze the politics of needs and needs interpretation.

6 For a more detailed discussion of how class will be used in this thesis please see the discussion earlier in this chapter or the definitions section in Chapter III. 
social workers employed the liberal understanding of class as a question of social stratification. Noted earlier in this chapter, class, like race and gender, is understood as a series of dynamic social processes of domination and subordination. As $\mathrm{Ng}$ notes "when we speak of class, then, we are referring to a process which indicates how people construct and alter their relation to the productive/reproductive forces of society, using whatever means they have at their disposal" (Ng, 1993a: 188). This understanding of class differs significantly from its usual social science usage as a descriptor of various objective criterion of social status such a income level, education, or professional designation.

The following example highlights the way that progressive social workers failed to grasp the way that class is a relationship between people and the forces of production and reproduction. This circumvents the possibility of understanding how class actively organizes domination and subordination in everyday life

I remember taking this course in second year university. It was a sociology of gender issues or something and the professor got mad at us because when we defined class, we talked about who we know, and our education. And she kept on saying, "No, no, no, no, no, no these are elements about class. According to the Marxian analysis your class is if you own the mode of production." If you own something, then you're upper class or whatever.

But, I think that's really limited. I think class is really fluid. I think if I'm not educated, and I don't have the mobility like not much education, and I come across a lot of money, just because I have a lot of money doesn't mean that I am okay. If I become mentally ill, I can still lose everything and become poor with no other kinds of resources. So class is complicated.

While this worker is correct in noting that class is complicated and fluid, she simultaneously adopts commonsense ideological notions of class as income and education indicators rather than processes that "have to do with how people relate to each other through productive and reproductive 
activities" (Ng, 1993a: 188).

This slippage between theory and discursive practices is two-fold. The first element of this slippage is the way that most of social work is strongly saturated with liberal ideology. Thus, wherever critical analysis and practice is not consciously and conscientiously employed, liberalism actively infiltrates and dominates social work discourse. Liberalism is clearly dominating the formulations of class described above.

The second element of this slippage can be found in social work education. Like the rest of social work, academia is strongly saturated with liberalism and, for the most part, teaches a social stratification analysis to social work students. As the example discussed early in this section highlights, in the few cases where a more social relations or Marxist approach is taught, students incorporate this analysis into their practice in a liberal, rather than a critical way. Quite unintentionally progressive social workers employed descriptions of social strata, and particularly of class, rather than a critical, relational analysis.

\section{The Poor and the Middle Class}

Key to the construction of class as a static category of income level, education, and professional status were the ways that workers discussed the poor and the middle class. The poor and the middle class were often juxtaposed in stories giving one the sense that they are the only two classes in society. The poor were not juxtaposed with the very rich or with corporations. Instead, the middle class and the poor were presented as categories of deprivation on the one hand, and of privilege on the other. Deprivation and privilege were not depicted antagonistically, as Marxists might juxtapose the working class and the bourgeoisie as antagonistic players in the system of 
production and reproduction. Instead, while certain individual may move between the middle class and the poor, these groupings are somehow seen as an unchanging and unchangeable feature of society.

This formulation of the poor and the middle class does little to increase our understanding of what is really occurring in society, and how social, political and economic structures organize and sustain subordination and superordination. Instead progressive social workers are implicated in ideological practices of class that move attention away from class conflicts between workers and capitalists and refocus attention on tensions between employed and unemployed sections of the larger working class. In this section I will initially discuss constructions of the poor before moving on to constructions of the middle class and notions of class as a cultural injustice.

\section{The Poor}

Stories around poverty are permeated by a number of themes. These themes include the poor as an undifferentiated mass, as those who have no significant attachment to the paid workforce, the difficulty in discussing class separate from race and gender, and the static sense of poverty as a liberal notion of end-state maldistribution. ${ }^{7}$ I will discuss each of these in turn.

While sometimes identified as criss-crossed by gender and/or race, the poor are generally described as an economically undifferentiated mass. Composed of subgroupings such as the working poor, the elderly, the rural poor, people with disabilities, the poor are, in actuality, a highly differentiated conglomerate of people and interests. Stories around class did not reflect any sense of this economic differentiation. Instead, there seemed to be an unstated assumption that the poor are

\footnotetext{
7 See Footnote 6.
} 
only those people who have no meaningful attachment to the paid work force. In other words, poverty is a euphemism for people on welfare, as well as for other low- or no-income people who have no formal ties to the paid labour market.

Some stories were explicit in identifying poverty, hence class, as an exclusion from the paid work force. These stories were also explicit in defining the solution to this exclusion as the gaining of paid employment. Reflecting the neoliberal reconstruction of welfare from a problem of poverty to a problem of dependency, progressive social workers identified a lack of employment being the remedy required for and of people on welfare. One worker, for example, was adamant that "my clients want admittance to the workforce and can't get it." Lacking this admittance, they "have no choices and will remain poor".

Another worker told a similar story, equating a desire to leave poverty with an understanding of class. The worker noted that class is the relation of subordination best understood by clients because "they are poor and want to change their class". In addition to a sense that the lack of attachment to the workforce is the central problem of people on welfare, this worker's statement captures the sense that class is not a social relation, rather it is a description of a place in society. Attachment to the workforce is thought to propel one out of this place called poverty, and provide choices. The reality is that for most people who have been on welfare, attachment to the paid labour force means continued poverty and lack of choices.

These workers did not problematize the injustice inherent in the existence of classes, nor did they recognize the existence of the working poor. Instead, they promoted a neoliberal ideological story that attachment to the workforce is possible for all people. Further, this attachment ends poverty and powerlessness. This commonsense ideological formulation speaks of individual rather 
than collective solutions and of liberal meritocracies where upward mobility and successfully leaving poverty behind are real possibilities.

At times, it seemed possible for the workers to talk about poverty without drawing in gender or race. At other times gender and race were very present. The following passage displays some of the ways in which stories about poverty draw in aspects of gender and race,

We grew up really poor and we didn't even know it (laughing). We'd get a box of clothes from our neighbor and think "oh, wow, this is great" until we went to a bigger school and it became clear and we knew we were poor (laughing).

So the staff were sitting around talking the other day and the Executive Director said "my mother used to always say 'when you're picking friends, look at their fingernails to see if they are clean'". And I said, "Oh, yeah, then you wouldn't have been able to be friends with me because I just learned to use a nail brush this year and I'm thirty-five." And it was very interesting because other staff said the same thing and two of them are Jewish and grew up very comfortably and one is Black and grew up middle class and here I am Anglo-Saxon and poor as dirt with dirty fingernails and used clothing from the neighbors.

The story below also draws in race and gender. At the same time it reveals an analysis around

the structuring of services for those who are poor as well as the cross-hatching of race and gender,:

I remember one woman who called, a Black woman, and I spoke with her for a quite a long time,..., and she'd been in the criminal system. Now, some agencies say that they won't accept people who have been in the criminal system, although all of them are poor, and in need of support. A lot of the women I see who have been involved in the criminal system have been women from very poor backgrounds and women of colour. So it is a structural thing that we refuse service to poor women who only got into trouble because they were poor women.

This story from a clinical social worker also draws in more than just lack of resources when

discussing poverty. It also identifies gender, social organization and systems:

I work with a lot of very poor women, women who go to food banks in order to feed their families...Definitely, women certainly talk about the difficulty they've experienced in getting into free places for services and accessing services. So we spend a lot of time dealing with these issues because sometimes it's a matter of survival, like "where are you going to get money from, where are you going to get food from, where are you going to sleep tonight?" 
Of course, again, dealing with what I would call systemic classism, talking about the ways in which different systems or structures, the way they, in fact, block women from accessing their services. Or how they, for example, treat women. What happens to them. How they're treated by systems. The kinds of services they get, how they get their services, how they're treated when you get it.

I will return to this theme of structures later in this section as it is an important piece of how progressive social workers construct class. Other stories about poverty did not specifically identify race and gender. A worker offered this explanation for stories about poverty where race and gender are not explicitly present:

One of the ways, in Toronto, class might operate is in terms of proxies. Somebody who is poor is likely to be a person of colour, and disproportionately likely to be a woman, and the sole supporter of her children. So that the way in which class becomes part of our awareness - it's ironic - they say sexism doesn't exist, racism doesn't exist but this is a poor, Black woman who receives welfare benefits and has two kids and, um, that's sort of natural. And it becomes a way in which the class issues is, in a way, both acknowledged and at the same time ignored or giossed over.

An oncology worker concurred, noting that "simultaneously the other two issues are erased, denied also." Commenting further on this proxy theory, a clinical worker noted: "It's a great way to relieve ourselves of responsibility by saying there's nothing we can do about it anyways."

In the following stories and story lines race and gender are not overtly present although they may be by proxy. These stories display empathy and a keen description of the condition of the poor; however they do not move decisively beyond a liberal paradigm. Most workers see the "poor" as blamed for their own poverty and spending most of their time "struggling for survival". A number of workers felt that "most clients are too busy worrying about food and immediate things to think about class other than in a day to day kind of way".

Workers were sensitive to the ways in which being poor "pushes people to the edges of 
society". This marginalization occur even within programmes aimed at the poor. One worker described a programme designed for poor women in which middle-class participants tended to dominate the group, and pass strong judgements on poverty and the poor. The poor women did not make similar judgements on middle-class life and reacted mutely to the onslaughts of their more privileged group members.

Consistent with neoliberal public discourses, distrust and dislike of the poor was a theme that workers observed coming from all sectors of society, including among poor clients. One worker described how most of the poor people with whom she works "are upset to be on welfare and to have to live with other people on welfare". This sentiment was observed to be strongest amongst those who had been poor for the shortest length of time, and due to health crises, had no immediate or long-term likelihood of changing their circumstances.

For the most part, poverty seemed to workers to be an immutable and unchangeable state of being rather than a inevitable result of capitalist society. The following quotes provide a sense of the permanence of poverty --

most of our clients are poor and there is not too much that can be done for them the poverty among our community members is very clear to see and there are no programmes for most of them

there are so many really poor people out there who call in and there is so little that I can do for them

While not reflecting a relational construction of class, workers were explicit that the existence of poverty is unfair and unjust, and although on an agency level, little can be done, on a society-wide basis much can and should be changed. However, this level of analysis reproduces the weaknesses of the analysis of class. The role of corporations, wealthy individuals, and capitalism as a system 
based on class, race and gender inequality are obscured. Instead struggles take place at the agency and the governmental levels. The government and its state are the major targets for change efforts by progressive social workers. Although the present government reflects the interests of corporate capitalism, progressive social workers do not identify capitalism as a problem. Instead they target government spending, and at times, public opinion. This construction of the problem permits the government and the state to act as a buffer zone for corporations and individuals capitalists, obscuring who is actually benefitting from existing class relations. Moreover it provides the sense that changes in policy, rather than radical restructuring of democracy, governance and the public sphere, can produce equality.

While both socialists and liberals might agree that, within the confines of most social agencies and under existing neoliberal government policies, there is little that workers can do to eradicate poverty, the stories presented above seem to reflect an grudging and unwilling acceptance of existing socioeconomic relations. They do not reflect any sense that radical restructuring of our cultural or socioeconomic relations is essential, or central to their practice discourse.

\section{The Middle Class}

Operating in concert with this formulation of class issues as poverty is a similarly vague but all encompassing and undifferentiated notion of the middle class. My informants did not mention any classes other than the poor and the middle class. One could conclude from this that everyone who is not "poor" is comfortably middle class. Within the myriad of stories around middle-classness there were no stories which noted the significant differences between sectors of the middle class such as the working poor or very wealthy, upper-income professionals. Instead, like poverty, middle classness 
was discussed as if it was a unified category which is explicitly linked one's relationship to the paid work force. The major benefit to being middle class is not being poor.

The major problem with the concept of middle class is its ideological capacity to conceal how domination and subordination are organized and structured through productive and distributive systems, as well as through cultural-symbolic systems. Instead, the workers presented an analysis of the middle class which rotated on a liberal notion of an end-state maldistribution of resources such as privilege.

The major problem with being middle class was often described as the privilege that one attains simply by being part of this class. The concept of privilege is, likewise, ideological. It is never quite clear what it means and it is accorded the capacity to stand in place of a more detailed analysis of how power and injustice is operating in the social work milieu.

Although a number of the workers came from working class or poor backgrounds they argued that in becoming a social worker they became middle class --

all the staff are middle class, obviously, we all get middle class pay cheques

we have one working class person on staff, well, she was working class and now she is a professional so she is middle class

I come from a working-class background and although Im now middle class I remember what it was like and use that in my work

This analysis of the middle class rotates on a liberal notion of a maldistribution of resources such as privilege, rather than a focus on changing the systems of production and reproduction that unpin and create unjust distributions of resources. As quoted earlier, Fraser (1997: 25) notes, that liberal strategies shift "attention from the class divisions between workers and capitalists to the division between employed and unemployed fractions of the working class". 
Moreover the liberal preoccupation with issues such as the maldistribution of privilege promote a cultural-symbolic order remedy, namely the recognition and re-valuation of the culture of poor people as a central solution to a problem within the political economy arena, or arena of production and distribution. Thus, the solution to class inequality is seen to rest in a more equitable end-state distribution of privilege and recognition of the culture of poor people, rather than a full scale restructuring of relations of production, reproduction and the symbolic validation structures which generate inequities and injustices. In other words, if middle class people were willing to simply shed some of their privilege and cultural dominance and make some of it available to the poor, injustices would lessen or be fully addressed. Obviously, these solutions are inadequate to the task of redressing the socioeconomic and symbolic injustices surrounding the poor.

\section{Class as a Cultural Injustice}

Some social workers formulated class as an aspect of cultural or symbolic injustices rather than as a socioeconomic or politico-economic injustice. In a society in which stratification and hierarchies are organized, among other things, through one's relationship to production and reproduction, the cultural and symbolic orders reflect and create unjust and hierarchical ways of understanding and representing class. However, this does not mean that the remedy to class injustice lies primarily in the cultural realm. Class injustice cannot be removed through processes of deconstructing identities and symbolic codes and meanings. Nor can liberal cultural strategies of increased recognition for groups subordinated by the class system hope to eradicate class exploitation and oppression. A focus on class as a cultural phenomena, to the exclusion of a focus on class as a process within the relations of production/reproduction, acts ideologically to distract attention from 
the need for fundamental restructuring of the realms of paid and unpaid labour.

The following story underscores class as liberal construction of racialized cultural subordination. As the worker told it, certain lower paid staff, who were people of colour, felt they could not afford the entrance fee to a staff party, and so did not attend. Although unstated we can presume that higher paid staff, presumably white, could afford the entrance fee and did attend. The entrance fee acted as a largely invisible and impassive arbitrator of class and race privilege. As the worker noted, "nobody had a problem with that" and "there was no discussion at an organizational level".

The injustice highlighted in this story is the socioeconomic injustice of marginalization of the people of colour, and the cultural injustice of non-recognition (being rendered invisible) of the exclusion of certain members of staff (Fraser, 1997: 14). The socioeconomic problem is one of maldistribution $^{8}$ and the way that this prevents equal opportunity to participate in agency social events. The cultural problem in this story is one of interpreting the non-participation of lower, paid staff of colour as simply personal choice rather than as a direct result of agency social event and payscale policies.

Other workers told stories that tried to capture a sense of how the cultural, symbolic order marginalizes all those outside of the mythical middle class. These stories display an awareness of the

8 I am using Fraser's (1997) critique of a liberal approach to problems in the socio-economy which she argues lies in a preoccupation with end-state maldistribution of resources rather than in strategies aimed at removing the systems and structures that create and perpetuate socio-economic injustices. While socialist approaches to distribution are epitomized by strategies to restructure systems of production and reproduction that under-pin and create on-going inequality, liberal strategies attempt to affirmatively redistribute goods, services and opportunities within the parameters of existing structures and systems. In effect, liberal redistribution strategies make "surface reallocations again and again" between various sectors of the working class. These strategies shift "attention from the class divisions between workers and capitalists to the division between employed and unemployed fractions of the working class" (Fraser, 1997: 25). These concepts are also discussed in Chapter III. 
role culture and the symbolic order play in marginalizing unemployed sectors of the working class. Simultaneously, these stories reinforce the non-Marxist notion of class critiqued above. My informants provided examples of how the racialized cultural-symbolic order distances people from needed services. For example, one worker told a story of the way that middle class experience was used within social work to marginalize other kinds of standards and experiences. This meant that poor clients "feel that they have to lie as they could be found out and harshly judged by middle-class standards".

Another story concerned a group that the informant rans for new mothers in receipt of welfare. The written materials provided by sponsoring agencies took certain middle-class opportunities around housing, nutrition, education and heterosexuality for granted. These written materials enforced a standard that was not attainable nor necessarily appropriate for her clients. As the informant put it, the materials "have the assumption that everyone is middle class and a denial that people who come to the programme do not have access to those things." The use of these materials in the past had caused her clients to feel hopeless, scrutinized and fearful that they would be found to be inadequate in their capacity to parent.

Workers also told stories emphasizing cultural prartices that differ between middle income people and low income people. For example, a number of my informants observed that middle-class people are far more likely to seek services earlier, to be assertive in seeking services and having their needs met. One worker noted that poor people are only likely to contact her community mental health service when they are "in total crisis". It is almost as if they could not justify to themselves or their families that it was acceptable to seek social work help unless the problem was extreme and "almost out of control". This meant that they require more of the agency's services and more 
complicated and multi-level kinds of assistance by the time they finally come in for help. Middle-class people, on the other hand, were more likely to seek help sooner and to require less agency resources and other kinds of assistance.

\section{Class as a Piece of Social Organization}

There were a couple of exceptions to the non-Marxist understanding of class. One of my informants, in particular, employed class in a way that bespoke an understanding of class as an active relationship between individuals and the socioeconomic systems of society. In formulating class as a relation this worker explicitly linked class to race and gender. She described class as a

piece of social organization,..., the dominant force social organizing most Western capitalist societies is, in fact, capitalism. And it employs, if you like, it employs racist ideology and patriarchy to perpetuate class relations as well as to maximize profit making and gains for capital. It's raison d'etre is to continue itself, to maintain itself, along with patriarchy. So they are not just ideologies, they are part of the structure of power.

Rather than employing terms like poor and middle class, this clinical worker largely used the term "working class" to describe herself and her clients. She noted that she used this explicitly because of its ties to Marxist notions of political economy and class struggle.

The following excerpts highlight the way in which this worker sees class as relational rather than static stratification. With clients this worker stated that she will "frequently use the term working class" and begin to build an analysis around this relation. "I will talk about my experience coming from a working class background and I try to normalize it and not pathologize it. Sort of talk about what seems real from what they are telling me that I can connect to some kind of an analysis." She continues,

So it is not typically that they are going to disagree. It is more that they themselves are not going to actually use the language "working class". They are more likely to say that they were 
poor. That there was not much to go around. Or they may not even say that but you may just start to get a sense. And when you start to get more information you can see that what you actually have is a working class situation.

This worker noted the overlap between class and the way that "it shapes consciousness in a certain way in terms of expectations." She claimed that when her working-class clients talked about "what they can expect of themselves, what they would like and what they feel they are capable of doing there is often much more of a sense of parameters and limitations." This worker argued that "the other thing that people from working-class backgrounds talk about, ... is what they can expect of themselves. What they would like and what they feel they are capable of doing." She noted that "there's a whole series of barriers that... need to be talked about and to be drawn out. And there is a sort of knowledge base of knowing to bring out certain issues of where certain difficulties lie." In short, the worker's goal in social work practice was to work with the client to build a critique of the structures of production and distribution and the cultures these systems produce, while simultaneously strengthening clients in their resistance to these social forces.

Not withstanding the exception discussed above, most progressive social workers formulated class in a liberal manner in which class is two dichotomous categories of poverty and deprivation on the one hand, and middle-classness and privilege on the other. This static description of the conditions of various strata does not help us to analyse class with a view to understanding how production and distribution interact in this society, or how to strategize around the eradication of the social injustices associated with a class-based system. There is nothing inherently liberatory in a stratification analysis. Descriptions of stratification can and often are used to defend class privilege, or justify social programme funding cuts.

In contrast, the relational view of class is an analytical tool that is always associated with 
"elucidating the sources of structural change within the capitalist system" (Balbus in Stolzman and Gamberg, 1974: 106). In other words, class, as a relational concept, is inseparable from "the analysis of the dynamics of social conflict and its structural roots" (Dahrendorf in Stolzman and Gamberg, 1974: 107). Social work sits in a pivotal position within the relations of ruling. It can ally with those who are the objects of oppressive relations, or with those who benefit from the ruling. In order for social work to fulfill its social justice mandate, as outlined in the Social Work Code of Ethics (1994), a relational analysis of class conflict, its structural roots and social change strategies are essential. As the London Edinburgh Weekend Return Group notes, in social services there is "no politics-freezone" (London Edinburgh Weekend Return Group, 1979: 145).

\section{Repoliticizing Class}

The following section discusses liberatory ways that progressive social workers formulated and applied class in everyday practice. While all of these practices simultaneously contain pieces that have the potential to liberate, they also contain pieces that are somewhat liberal, and mask the ways in which domination and subordination are played out within the social work endeavor. The practices examined in this section will be analyzed using the previously discussed three part analytic frame (see Chapter IV). In addition, various pieces of the critical social work literature will be reintroduced in order to place these practices within the context of existing models of progressive practice. The work of Ann Withorn (1984), Maurice Moreau (1989, 1981, 1979) and Bertha Reynolds (1963. 1951, 1946), as well as the international social work contributions of Campfens (1988) are of particular importance to issues surrounding ways to build liberatory practice. 


\section{Structures}

While progressive social workers displayed discursive practices that formulated class in static and categoric ways, in practice they applied a number of concepts which are more dynamic and dialectic. Most of these concepts and their interventive strategies are explicitly associated with the critical social work model. For example, structural social work is centrally concerned with structures and their practices of oppression and subordination (Moreau, 1987, n. d., Carniol, 1987, Mullaly, 1995, 1993). Radical, Marxist, and structural social work have all discussed the importance of working within union organizations (Bailey and Brake, 1975, Burghardt, 1986, 1982; Mullay, 1995 , 1993). When utilizing these interventive strategies progressive social workers were more likely to display a dynamic understanding of class and of the struggle for social justice. When not explicitly employing these critical interventive strategies, the work of progressive social workers did not seem to differ in any meaningful way from mainstream social work.

One of the most common intervention strategies is referred to, in the literature and by progressive practitioners, as structures (Bailey and Brake, 1975; Carniol, 1987, 1990; Fook, 1993; Galper, 1975; Gilroy, 1990; Moreau, n.d., 1979; Moreau and Leonard, 1989; Mullaly, 1993). Structures is a term that is used to describe pieces of social sarvices and larger society which oppress, exploit, victimize and regulate clients, workers, work with clients, and larger social life. Structures seem to run up and down a continuum from larger social relations such as race, class and gender to macro practices such as government policies to micro practices in agencies such as day-to-day documentation, intake procedures, and the layout of office furniture. Generally, structures do not seem to be connected to any particular socioeconomic system, although sometimes they are specifically linked to capitalism. 
While structures is a rather vague and all-encompassing notion, it is also a term which permits progressive social workers to grapple with the way relations of ruling are not just top down control mechanisms. Instead, they seem to signal an understanding that we inhabit social relations in an everyday kind of way. Although sometimes over stressing the victimizing aspects of social relations, the way that structures is used by progressive social workers perhaps points to new ways of understanding and contesting apolitical, non-material notions of social work practice.

Mainstream social workers are criticized for failing "to recognize structures", tending not to "look at power structures within an organization", "seeing issues as client-based not as structural issues". Birmingham's (1994) study of ideology among social workers confirmed that the majority of social workers blame the victim rather than larger social structures. In contrast, progressive social workers place the responsibility for social problems firmly within the realm of social structures. Indeed, none of my informants indicated any tendency toward client blaming. The identification of structures and how they operate in clients' lives assumes a central role in progressive practice. All of my frontline informants routinely suggest to their clients that various structures, such as changes in social policy and public opinion, are the nucleus from which "personal" problems originate. For example, one worker suggested to a seriously depressed client that a $22 \%$ cut to welfare payments that occurred in July of 1995 must have been "very grim" and greatly increased the stress in her life. The client's concurrence and consequent discussion of her day-to-day experience of poverty assisted 
both client and worker in identifying sources of her sadness and despair, as well as ways to begin to resist.

Clinical and community social workers also described strategizing and collaborating with clients around the best ways to cope with and combat micro level agency structures. Particularly in government bureaucracies, clients were discretely assisted in placing and pursuing formal and informal complaints, demanding and receiving their full entitlements, constructing themselves on paper and in person so that they fit the agency's mandate for services, as well as encouraging clients to contact the Premier or their Member of Provincial Parliament with complaints. As one worker noted: "I encourage clients to get mad and then I help clients manipulate the system anyway I can." In the same vein, workers spoke of strategies employed to push pieces of agency organization that structure work with clients, without directly involving or jeopardizing their clients. Such strategies include: advocating on client's behalf, subtly altering, omitting or embellishing certain aspects of documentation, as well as refusing to rush meetings with clients. Some workers also spoke of effectively using the agency mandate and language against the agency to ensure clients get the maximum service possible. One worker spoke of using a hospital's mission statement of "To serve the whole community" to push the facility to develop specific outreach programmes for poor clients and recent immigrants.

In resisting and using structures in the best interests of clients, workers felt that they were stepping outside of social control and regulation roles. In collaboration with clients and other workers, they argued that while they may not be building "a brave new world", they are not unreflectively complicit in the domination of clients. A child and family worker added: 
these systems weren't made by us or for us, and so we need to use them any way that we can - so that we are not part of the problem, we are part of the solution.

The critical social work literature refers to this type of work as the extension of the political realm into the social work realm (Campens, 1989; Mullaly, 1993; Withorn, 1984). It is part of a wider process of politicizing all aspects of everyday life with oppositional practices in order to build a complex, mass movement or movements capable of transforming the totality of oppressive and unequal relations and structures (Withorn, 1984).

Another important set of structural practices included referrals to social action groups for follow up. Although most workers noted that only "about one in 100 clients is open to taking political action on their problems", workers consistently presented the possibility of collective social action as part of their interventions. A crisis worker told this story:

My view is that you tell people as much as you can. Knowledge is power. So I give everyone at least four referrals, whereas my colleagues give out one. I always add in at least one social action group or option so that people can go further if they want to. Sometimes they call me back and ask for more, and sometimes I hear from the social action group that somebody new showed up mentioning my name. I gotta feel pretty good about that.

Nancy Fraser (1997) notes that liberal politics in the era of the postsocialist ${ }^{9}$ promote strategies that differentiate cultures and social classes. In contrast, Fraser argues in favor of a politics of recognition and redistribution that dedifferentiates through the blurring of class distinctions and inequities, the creation of new identities, solidarities and reciprocities, as well as the destablization of the underlying cultural validation structure so that everyone's sense of self is transformed (Fraser,

9 Fraser (1997) argues that we are living in a period that she terms the postsocialist. This period is characterized by "an absence of any credible overarching emancipatory project despite the proliferation of fronts of struggle; a general decoupling of the cultural politics of recognition from the social politics of redistribution; and a decentering of claims for equality in the face of aggressive marketization and sharply rising material inequality" (Fraser, 1997: 3). 
1997: 13-14). As a practice concept, structures is used in a way that blurs the division between worker and client and creates a shared realm of activism and resistance. It gives workers a way to see themselves as situated within an arena of services that can simultaneously help clients, as well as increase the subordination of clients. Moreover, the notion of structures prevents workers from feeling helpless by giving them ways to step outside of oppressive pieces of agency organization in order to build new relations and practices aimed at social justice activism. While these practices do not directly transform cultural and symbolic structures, they destabilize the identity of the worker as the professional provider of apolitical service units, as well as the identity of the client as passive recipient of standardized and stigmatizing services. They help to create a shared realm in which both client and worker are social justice activists and colleagues. Likewise, while practices based on this concept do not transform the underlying political economy, they attempt to reorder the priorities and organization of agencies so that the needs of people are couched within the context of political struggles over resources and identities. The next section discusses a practice concept which operates in a similar manner.

\section{Solidarity-based Social Work}

Closely tied to the concept of structures is the practice and discourse of solidarity, or the worker using her power and privilege to collaborate with clients, and to redistribute resources such as skills, knowledge, and networks in a non-stigmatizing and reciprocal manner. Solidarity social work is not based on a charitable or colonialist model ${ }^{10}$ of top-down help from those who have

to Sharene Razack (1997) is critical of most social work approaches for its missionary or colonialist approach which embodies notions of the inferior and irrational subject who requires paternalistic and authoritarian interventions aimed at moral and rational elevation and direction. 
resources to the deserving poor. Instead it is a more egalitarian model aimed at mobilizing communities around a shared sense of social injustice. As one worker put it, "to say that we don't like the present world order, we are outraged at its injustice and we think there can be a better way to do things." Hence, workers put their "energies alongside those people who are being pushed to the edges". Some workers defined this as "being on the same side as the client", whereas others pointed out that clients can be as "racist, sexist and classist as the rest of us, so we are not always exactly where they are". These workers argued that "you need to develop a smart, not a stupid way, of confronting people and moving them to a better place." When workers described solidarity-based or collaborative social work practice they stressed the class aspects of it, but race and gender are also present as the following discussion indicates.

The practice of solidarity has many aspects. One child and family worker used the term collaborating to describe solidarity social work within the context of the organizing project she facilitates for sole support parents of colour. Collaborating involves sharing resources and decision making rather than the traditional model of worker or agency control over projects and services. In this case, my informant provided supports to the single mothers' project in the form of a place to meet, telephone access, computer skills, knowledge of communitv resources, and agency credibility. The women lead the project and used her skills, contacts and expertise as resources which enabled them to meet their goals of greater social and economic participation for single mothers in the community.

Another community worker noted that with solidarity-based social work, "you have the responsibility to take what scope you have and effect some change within it". This involves being cognizant of the power and possibilities one has, as well as the restrictions experienced by others. 
"Middle class women have more resources to be politically active, we can't judge other's inactivity." In particular she recalled work she had done with immigrant women in the garment industry and noted that

I would not fault the garment workers for not being able to come out to rallies and protests, or if they don't have the analysis that I have. You know, it would be very arrogant of me to expect all of us to share that. I do blame people who judge others, because some people have very limited resources because of whatever circumstances that they find themselves in. But, I do believe that I have a responsibility, because of my resources, to include them, to involve them, and to listen to them.

This worker noted further that while it is important to listen to the experience of others with less resources, and incorporate their experience in solidarity-based social work, "I have some principles that I am not willing to compromise." This means that part of solidarity-based social work is "to have some basic values that you hold on to" and while "you may not change people", certain oppressive practices will not be tolerated. For example, "there is no room for racists in any organization."

Addressing the use of one's scope and power in the social work milieu, a community worker noted that she always responds to sexism or racism when it is raised at community meetings as she recognizes that other community members may feel that they cannot speak up in such a forum. She follows up these challenges with discussions after the meeting with both the individual who voiced the unacceptable content, as well as the objects of his comments. Further, she tries to use her influence in the community to structure meetings with a round of check-ins at the beginning and a round of end-of-meeting evaluations at the end. In this way, all community members will be required to speak during the rounds. This ensures that those who have little or no opportunity to speak publicly can gain some experience, and hopefully find ways to expand their participation.

Personal relations with supervisors are also important conduits of power within agencies, and the benefits one can derive for one's cause and one's client. One worker noted that she knows she 
has the director's ear because she is a nice, white girl with a Masters Degree. She finds it easy to speak up for her causes and it "pisses her off that others can't speak up as easy" because of their less secure personal and professional positionings.

Within agencies privilege was very often associated with aspects of class such as professional versus administrative staff status, management versus frontline workers, as well as level of formal education. These structures of privilege are further stratified by gender and race. Access to postsecondary education, and good, old white boys networks were two factors identified that reinforce existing racially stratified, and gendered, class structures. As one worker noted,

In our field most of us are women, but in the top management, most of them are white men. Not just in ours, but in other centres, there are a lot of white men. And they are part of a kind of like an old boys network. It is very clique-ish, that network. So you look at the ultimate decision makers in social services and they are all men, all white men.

Some workers reported that they likewise have progressive networks which they depend on heavily when hiring occurs within the agency. They turn to these networks to seek progressives who may be willing to apply for job openings. In social change agencies, progressives actually do the hiring and use these networks to ensure that those hired are committed to social justice causes. I will return to this discussion later in this section.

One worker noted that solidarity-based practice is difficult for most social workers as "few people have had the opportunity to unlearn and relearn the racist, sexist and classist social work we learn at most schools of social work". She lamented that the fact that a very small number of her colleagues "have the privilege, and I see it as a real privilege, to work in a place where it is safe to do this stuff -- to take off the lid and really dig in". Part of her solidarity work involved the redistribution of this relearning to colleagues and clients "in ways that made it easy for them to see 
it as in their best interests to unlearn the stuff they learn out there". Another worker strongly agreed and added that coalition building across oppressions is a key aspect to solidarity practices although "few groups have had the opportunity to think through coalition building, as the emphasis has been on building separate groups and movements". This theme will also be returned to later in the chapter on gender.

Like the practice concept of "structures", solidarity social work blurs the distinctions between workers, clients and activists. Based on solidarity and reciprocity, it seeks to politicize and provide services based in a non-stigmatizing and non-differentiating way. The politicization appears to encompass both the worker and the client, hence the identities of both parties have the potential to change and become more open to new ways of being and doing. The critical social work literature is full of discussions of the need for reciprocal and mutual relationships between workers, clients and communities (Campens, 1989; Moreau, 1981, 1979; Reynolds, 1946, 1963; Wineman, 1984; Withorn, 1984). Building on the work of Bertha Reynolds, Ann Withorn (1984) argues that services must embody reciprocity between providers and service users as well as egalitarian agency structures. The data indicate that while workers may not have control over agency structures, they struggle to find ways to practice that reflect solidarity or reciprocity and demands for more egalitarian structures.

Within the solidarity-based practices described above, the workers stressed the importance of using one's privilege or the scope and power inherent in one's location in an agency or the broader society, to affect whatever change is possible. Through this solidarity process the interrogative spotlight is shifted from the practices and emotions of the client to the practices of social agencies, social workers and larger social systems. While my informants asserted that they provide supports to assist clients in dealing with pain and suffering at the individual level, they also spend time with the 
client discussing how they may be able to collaborate in a mutual agenda of social justice. This solidarity process, my informants argued, places clients and workers in the shared space and identities of activists and colleagues, rather than being positioned as expert provider and passive recipient of standardized and stigmatizing services. The critical social work literature stresses the importance of seeing clients as potential comrades and social change agents (Campens, 1989; Mullay, 1993; Withorn, 1989). As Reynolds (1946) and the Rank and File Movement (in Reynolds, 1963: 173-174) argue, social work practice must be allied with the interests of the subordinates classes and groups in society, as well as with the "movements for human betterment".

As demonstrated by the preceding discussion, most of the stories about solidarity social work involved women as workers, volunteers, clients and activists. While ostensively gender neutral, solidarity social work reflects the gendered character of most of social work. I will return to the discussion of solidarity social work in the chapter on gender as it is a key piece of the feminist politicization of frontline practice.

\section{Unions as Tools}

Class was also described in worker's stories as various aspects of how work sites, workers, the work, the target client population and the social issue are defined and organized. A number of workers noted that class relations within the social service workforce "have been largely formalized into union versus management relations". Complaints against management are formalized into grievances that "can take months or years to be resolved". Other issues are addressed through the lengthy and difficult collective bargaining procedures legislated by the state. Mirroring management structures, the hierarchies and bureaucratization of unions generally "cool out and distance most 
workers from any sense of immediacy or social activism". The exclusion of clients from unions highlights the way that workers and clients are positioned antagonistically and presumed to have very different interests. This artificially divides potential allies in social justice struggles. Thus the formalization of union-management relations serves to largely depoliticize, contain and obscure class struggle and class relations in the social work site.

Despite this formalization of class relations, most progressive social workers adopt a stance of critical support for unions. As one worker put it, "at times I have fought against the direction unions take,... but I believe in collective bargaining. Social workers need collective bargaining!" This worker found that union struggles are particularly important to women of colour. Within her agency these women tend to be the lowest paid and the most exploited. Involvement with collective bargaining and organizing struggles has given many of these women "new ways of looking at themselves and their world. It gives them some power, even though the union isn't anywhere near easy to work with, and some clout in the agency."

For other workers experiences like strikes provided important learning grounds around the need to keep close tabs on one's own leadership. Following an acrimonious, province-wide strike many of my informants expressed anger with the way the leadership of their union appeared to be collaborating with management. After walking many cold hours on the picket line, these workers felt that their union was not fighting their issues consistently or creatively. One worker noted, "I have nothing but disgust for the leadership at this point." Another worker noted that both management and the union had "sold them down the river". Despite this, the same worker continues to serve as shop steward, and to fight to strengthen and reform the union. As he noted, and others in the study concurred, "there are lots of problems with unions, lots of problems. They are only as good as the 
people involved, which is why I had to get involved."

Workers reported finding ways to use unions as tools of politicization in larger struggles over policy issues and practice questions. Some workers reported that bringing their unions into local grassroots struggles helped to give these organizations some credibility and financial backing. Unlike many other single cause activist groups, unions have been around for years and will continue to exist in one form or another. Other, more grassroots organizations, cannot count on this lifespan. The longevity of unions was reported to provide an important sense of long-term struggle and stability for less well-resourced, informal community groupings.

Many workers made use of their unions as protective shields for their activism on the job. For example, various workers reported secretly feeding internal management documents to their unions. Most of these documents proposed serious policy and service changes. The unions turned these documents over to social action networks and consumers' groups which used the information to oppose the proposed changes in a more informed and detailed way.

Grievances, likewise, were used strategically by workers to "police" management, to delay implementation of management directives, and to deflect their attention from other fronts where workers need more time to consolidate oppositional strategies. One worker told a story about joining with other workers to grieve accusations and threats of disciplinary action that had been thrown at them around the leaking of a sensitive management-document to the media. This document was aimed at enacting serious cutbacks in client services. The grievance served as warning to management that the staff would not be intimidated or inactive around issues of public concern. It also tied management up in months of grievance procedures thus deflecting them from a singular focus on detecting who leaked the document. Moreover, it provided the media with a follow-up 
story and served to further discredit a cutbacks oriented management team.

Workers cautioned that this is not an easy time for union activism. Recent changes to legislation around organizing unions and collective bargaining polarize an already hostile environment. However, as one worker observed,

people think that now is not a good time to try to get better working conditions or services but we should at least try and collective bargaining is one way we can do it. At least we can go down resisting.

Progressive social workers seem to have developed some ways of working with unions that destabilize bureaucratic forms of union-management conflicts. For example, the way they use grievances to slow or expose the process of service cutbacks creates a form of solidarity between workers and clients which deconstructs notions of unions as the tools only of working people. Some of the focus on using collective bargaining to increase the wages and benefits of low-paid workers, reformulating identities from victim to activist and fighting exploitation, economic marginalization and deprivation speaks of a melding of redistributive and recognition politics. Workers displayed ways to use the formalization of unions as tools to bring stability to social change strategies.

The tactics discussed above dovetail with discussions of unions in the critical social work literature. Mullaly (1993, 1995) stresses the importance nf using unions to promote social justice agendas for workers, clients and the larger community. Other scholars note the importance of outside constituencies in maintaining daily political practice and the role the trade union movement can play in this regard (Withorn, 1984). The analysis and stories of my informants reflects a certain creativity and energy that is not captured in the critical literature's less passionate discussion of union struggles and social work. It also reflects an extension of the political realm into the work place and into dayto-day social work practice. As such it represents "the deprofessionalization of politics and, in 
reverse, the universal politicization of society" (Campfens, 1989: 19).

\section{Summary}

In this chapter I have outlined how progressive social workers formulate and apply class in their everyday discursive and practical activities. The first section identified seven mechanisms which formalize and liberalize class relations in social work agencies. These mechanisms then serve as the basis from which liberal and depoliticizing discursive practices flow. The mechanisms include: 1) bureaucracy and hierarchy, 2) documentation, 3) professionalization, 4) individualization and standardization, 5) the agency's relative distance from the government and state, as well as its relative distance from social change movements, 6) hiring processes and 7) the division between community, clinical and policy practice.

These mechanisms run back and forth along a continuum with workers finding a variety of ways to resist them and carve out small spaces for progressive practice or embrace them and develop multi-level emancipatory ways of intervening. These mechanisms and practices are about the division of power within agencies, and between agencies and major funders. They import relations of ruling into the lives of the client and the worker through control of the service product, the service process and the work environment. Moreover, they are ideological practices which abstract from and conceal the everyday details and realities of peoples lives, replacing them with formalizing and depoliticized ways of understanding and acting upon social problems.

In the second half of this chapter I identified those discursive practices of class which are limited by liberal notions of maldistribution, and/or cultural constructions of class divorced from redistributive themes. Liberal and cultural constructions of class included a sense that class is a static 
category, not a relation; secondly that class is understood as two rather large, mostly static and not necessarily opposed groupings, namely the poor and the middle class.

Progressive social workers bounce back and forth between transformative practices and ideological practices. Their understanding of class as a static system of stratification and their preoccupation with the poor and the middle class are examples of how ideology works at the everyday level. More transformative and deconstructive notions of class were also discussed in this section. These included progressive social workers use of the concept of structures, the use of solidarity-based social work and their use of unions as tools of multi-level struggle. These three pieces of progressive practice reflect reciprocal relations, the possibility for workers and clients to share political struggles as well as a find common ground and identifies as activists. Moreover, they provided the opportunity to blur class distinctions and build new relations and practices which support multi-level transformations in the distributive and symbolic validation structures of society.

These mechanisms and resistance to them have been taken up in different ways by various sectors within the social service milieu. In particular, feminist services have organized their agencies in ways that resist and restructuring these mechanisms. This will discussed in greater detail in next chapter. 


\section{Chapter Seven}

\section{$\underline{\text { Gender }}$}

\section{How Gender is Depoliticized}

The social work milieu is a highly gendered terrain with women making up the majority of paid practitioners, unpaid caregivers, clients, and volunteers. One might safely assume that relations of ruling will reflect a high degree of gender specificity. Clearly, class does not exist separately from gender, and gender does not exist separately from class. They have been separated in this thesis for analytic purposes. As analyzed in the previous chapter, class containment processes within social work were gender blind. That is, they did not account for the different responses to, and patterns of women's relationship to the means of production and reproduction.

This chapter introduces the gender specific piece to this discussion. Gender is formulated and applied within progressive social work in ways that are somewhat different than class. As discussed in the last chapter, rather than an analytic category which has potential to mobilize social change actions, class has been neutralized through mechanisms that formalize and depoliticize it, as well as through the liberal discursive practices that flow from these structures. This chapter will show that gender's emancipatory potential has been dissipated through the same mechanisms, as well as through two additional mechanisms, namely therapeutism, and women's committees. Initially, in this chapter, I look at these main processes that neutralize gender and make anti-sexism difficult to practice. I then move on to a discussion of how progressive social workers mobilize gender in ways that tie into professionalism, liberalism and neoliberalism. The last sections of this chapter considers some of the transformative ways that feminists have experimented with organizing services and pieces of practice. 


\section{Women's Committees}

In the preceding chapter on class, I analyzed the way that class has been formalized through various processes such as management-union relations, bureaucracy, hierarchy and documentation. The establishment of work place and union women's committees acts as a similar type of process in the formalization of gender relations. A number of workers reported that their agencies or their unions have long standing women's committees which are mandated to address so-called "women's issues". At one time these separate committees played a crucial politicization role in the struggle for gender justice equality. Women's committees that exist at this point however, seem to be a way that gender tensions can be dissipated and held in check.

A policy worker noted that the development of separate women's committees has been both an emancipatory and a containment strategy. As a grassroots initiative, many women's committees have worked avidly for significant changes in women's programming, wages, hiring patterns, and promotion as well as policy concerning sexual harassment, family responsibility leaves and flexible work hours. Organizing separately, as women, has been an important way to maintain a focus on gender inequality, rather than having the issue diluted and diffused over broader themes. However, a lot of gender activism has proven to be too narrow to speak to the issues of most women, especially women of colour and poor women. A number of workers noted that these committees were often criticized for being inactive, unable to achieve anything, or interested only in white women's issues.

The narrowness of the mandate of many women's committees and of the agencies themselves has made it difficult for these groups to make significant gains. The scope of women's committees tends to be restricted to minor changes within the agency. Most committees can make recommendations but have no policy making or implementing capacities. In addition, some women's 
committees recreate the agency's structures of privilege and inequality. Women's committees were accused, often correctly, of being "narrow, and self promoting" rather than broad and multi-issue. The narrow construction of interests was usually associated with "white women's issues" and, not surprisingly, white women are seen to be the primary beneficiaries of any gains initiated by these committees. Workers noted that some women's committees are viewed with hostility by activists of colour and with skepticism by many progressives. Thus the narrow construction of women's interests as well as the narrowness of the committees effectively siphons off and redirects conflict.

Another depoliticizing and ideological aspect of women's committees is the way they often relieve the rest of the agency from doing anything about sexism. Even inactive committees play this role as management and workers can point to the dormant group and claim that there is no interest in women's issues. As one worker quipped, "our women's committee has been around since the late seventies, and most people don't mind a bit that it hasn't done a thing for the last decade or so".

Ironically, one worker noted that when not attached to specific work places, women organizing separately as women have been quite successful at intc grating diverse, multi-level social justice strategies. As an example, she pointed to the National Action Committee on the Status of Women (NAC), as a leading force in the development of new forms of multi-issue, social justice coalitions that simultaneously work to address internal diversity issues. In part, this has been due to NAC's efforts to meld various sectors of the women's novement together despite their different histories and origins. ${ }^{1}$ This worker argued that work site women's committees and anti-racism movements have much to learn from NAC's work in this new area.

1 For a discussion of the role the state has played in developing and exacerbating differences within the women's movement, see for example Carty and Brand (1993). 


\section{Discursive Practices of Sexism Is Not/No Longer an Issue}

While most workers observed that during the latter part of the seventies and most the 1980s, sexism was an issue that was discussed in many social work agencies, it has been moved out of the spotlight during the 1990s. As noted by Walker (1990), the institutional absorption processes associated with the receipt of state and United Way funding has resulted in the intentional and unintentional professionalization and bureaucratization of many anti-sexist services. Dovetailing with this cooptation was the introduction of demands from first the community and then funders for multicultural or anti-racist organizational change. These organizational change strategies placed issues of cultural and racial inclusion and access at the centre of many agencies' agendas and, intentionally or unintentionally, moved women's issues back to the margins of the social service arena. The one main exception to this marginalization of anti-sexist services has been the centrality of antiviolence work within the gender discourses of social work. This section will explore the gender discourse that has become dominant since the introduction of multicultural organizational change programmes. The next section will discuss the centrality of male violence in the formulation of gender while the following chapter, Race, will further discuss organizational change programmes and the discourses associated with this mechanism of depoliticization.

The major set of gender discourses in social services radiates from the denial that sexism continues to exist within the social work milieu. Progressive social workers told stories of encountering this containment strategy in its many forms in their day-to-day work. Resisting these discourses proved to be difficult and largely unsuccessful. The denial that sexism is a problem rotates on the notion that sexism is no longer an issue, although it may have been a problem in the unenlightened past. This construction of the issue provides a pleasing sense of forward momentum 
and resolution of pesky social problems. It relieves the agency and practitioners from the responsibility of taking any action on the issue.

The sexism is not/no longer an issue discourse takes many forms. Some workers reported that colleagues and management acted "completely blank" when sexism was mentioned. That is, they did not argue or get angry or engage in anyway with the topic. They simply acted as if they did not hear or understand what was being spoken of. A government worker summarizes,

Some of the staff were having a meeting a few weeks ago about some problems they're having around...being the lowest part of the food chain. I said that I thought it had a lot to do with power and sexism, and everybody just looked at me like I had two heads. And then went back to what they'd been talking about. They just don't get it and don't want to.

An adjunct to the sexism-is-not-a-problem discourse was experienced by a number of progressive social workers. They reported that co-workers and management referred to discussion of sexism as divisive. Therefore, the person who raises the issue is explicitly or tacitly ostracized. One worker noted that the attitude at her workplace when she brings up sexism is one of "oh, that's nice-and-happening, dear, and now, shut up, kind of thing". Another worker had his executive director say to him, "Look,...I am not a feminist and don't want to be a feminist and will never be a feminist so if you want to fit in here, like -- give up on it."

A worker in a quasi-government agency commented that the sexism experienced by clients is invisible to most of her co-workers. ${ }^{2}$ Most of her co-workers agreed that sexism exists to some extent in the larger society. However, they did not recognize that their agency and personal practices recreated sexism and oppression in a number of ways. Whenever she pointed out different aspects

2 For an interesting discussion of how gender is constructed through service provision see Krane (1985). 
of sexism, her co-workers responded with denial and hostility directed towards her and towards the clients. The passage below highlights this dynamic:

Worker 1: I see my role at this point is to sensitize some of my co-workers...I say okay, you could also see this differently. And, if you saw it differently, you might not see your client as resistant as you think, or has good reasons to be. So, I find the hardest people to work with are not the families, but the people that I work with at the agency.

Worker 2: Oooh, they must hate you...

\section{GROUP LAUGHTER}

Worker 1: Yes, ... I'm building up, building up momentum and conflict simultaneously.

Gender injustice can also be contained by the agency's construction of the client population, or of the "community". One worker, in a well-established multi-service agency, noted that $80 \%$ of the agency's clients are women and that women's inequality is "very clear to see", "especially women's greater poverty". However, the agency has never had a programme specifically for women and it is very difficult to talk about sexism in her workplace.

She claimed her agency's construction of social problems and programmatic responses to social problems does not include "a mechanism for beginning to talk about anti-sexist or womenspecific programming". The aim of the agency programming, she explained, is the development and strengthening of that which the agency sees as "community". Community development was thought to occur when people were pulled together who were perceived by the agency management to have interests in common. These interests-in-common have tended to be aspects of life such as age, language, recreational interest or geographic location. The worker claimed that to propose that gender be seen as a common interest is to be seen as "unrealistic", "out of touch" with the true issues 
of the community, "divisive of the real community", and wasting everyone's time and resources.

Another way of framing the sexism is not/no longer an issue discourse was found in the widespread claim that sexism was resolved years ago. This discourse is an especially clear example of how ideology operates at the everyday commonsense level. It requires no substantiation in the experiences of real people. Instead, it operates very smoothly to obscure the gender inequality that is part of every social service agency. In this framing of the postfeminist discourse, the predominantly female, social services work force was pointed to as proof of the lack of sexism. The presence of women equals gender justice.

A worker in an agency with a predominantly male workforce noted that this same discourse also works in reverse. She was told that gender was not an issue at her agency because there are almost no women in the agency and hence no potential for sexism. In this case absence equals gender justice. In the latter case, sexism is something that women introduce to an agency through their presence, and in the former case it is something that they remove through their presence. In both cases, sexism is a problem that is connected to women, not to men, social organization or systems. In both cases, despite individual and group experience to the contrary, sexism is not a problem for the agency or anyone connected to it.

It is interesting to note that the construction of class reflected a sense that class injustice is a problem of the poor, not of the rich, or of the structure of capitalism. The same formula is employed in the construction of gender. Sexism is a problem for women, not for men, or for the structures of capitalism and patriarchy. The chapter on race will also show that race is constructed as a problem for people of colour, not of whites, or for the structures of a racialized and gendered capitalism. 
Contrary to this construction of the postsexist era, the predominantly female work force in most social service agencies has nothing to do with anti-sexist organizational change. Women are not hired affirmatively within social work agencies. They simply make up the majority of workers who are trained and willing to take on social service jobs. Affirmative action hiring strategies have, in the past, been aimed at men in order to give the profession greater credibility (Moffat, 1995). They were "officially" abandoned during the second wave of feminism in the 1960s and 1970s, when feminists demanded a re-evaluation of male privilege within the profession. Men continue to make up the majority of workers in elite sectors such as academia and management.

Workers reported that another way of employing the post-sexism theme was an inclusion or multi-oppression strategy. Workers were told that to focus only on one oppression, such as sexism, was outdated and insensitive. Instead, workers were told that is important to look at the myriad of ways in which people are "oppressed". This framing of multiple oppressions reflected a pluralist, liberal analysis and made no differentiation between or among social relations. All oppressions were seen to be similar to each other, to the point where differences basically became meaningless. One worker commented that, in her agency she has been told that it is important to "incorporate everything in one's practice, not just one aspect. We're past criticisms of feminism, so we don't really do it at all".

Workers reported the sense that gender has been dealt with for long enough and that either it has "been wrapped up and solved" or that "it is just a fact of life, so let's move on". Many workers reported that their agencies tend to adopt pet issues for a season or two and then put them aside to take up new issues. The old issues are seen as "been done" and, although nothing significant has changed within the agency or society, there is a need to move on to a new issue. One worker noted 
that it was not just a "post-feminist era" in his agency, it was a "post-anything era" -- "last year it was senior citizens, the year before that was multi-culturalism and the year before that it was singles".

This postfeminist, "so many causes, so little time" discourse reflects certain funding arrangements. Many funders target their dollars for new programmes or programme expansion at certain populations. The United Way, for example, often directs pilot programme funding at target populations which it believes are under serviced. Agencies that adopt these same priorities tend to improve their chances of maintaining or increasing their United Way funding quotient. Resisting these funding priorities would be contrary to the logic and conceptual practices of management. Hence, most managers will organize the services of their agency, and their respective discourses in accordance with the priorities of the funders.

The construction of gender as sexism is no longer an issue isolates those who continue to fight for gender justice. Workers noted that explicitly feminist service agencies are seen by the mainstream of social work as "a bit shrill", "unrealistic" and "on the margins". In contrast, the professionalized, mainstreamed women's services were seen as part of "the extended family of social services". This acceptance of professionalized women's services was seen as contingent on the understanding that gender injustice is "no more of a problem than any other issue". These discursive practices highlight another aspect of how ideology around gender works at an everyday level. These discourses require no substantiation within the realities of women's lives; instead they transform the details of everyday experience into "objective", professional and managerial discourse. Through these discursive practices, sexism is reduced from a major social relation of oppression to one more element within a larger pluralist hodge-podge of professional and managerial issues and problems of modern society. A mental health worker commented that during the present period of neoliberal governments 
it has become increasingly difficult to address sexism within social service networks and coalitions. Many individuals within these networks see the only "enemy" as the provincial government, and call for "the maximum unity in fighting these cuts". Unity means that there can be no discussion of internal problems such as sexism within social services and the networks themselves. "All the enemies are external" and issues like sexism must wait until the greater battle against the cuts is successful. She said that there is a sense that all inequality comes from the government and that there is no point in discussing sexism or other oppressions because everyone in the networks is equal and committed to equality. Social change organizations are not exempt from the operation of ideology. The construction of unity, of "the enemy", of "the battle" and of where "inequality comes from" are all examples of how sexist ideology works in a commonsense way within this particular environment. Although these constructions are mobilized by people committed to social justice, they nevertheless serve to replace the "actual" with conceptual schemas and discourses that organize and coordinate gendered relations in conjunction with other matrix of relations of ruling. In this way these discursive practices are ideological as well as actual pieces of the way that gendered social relations are organized into the system of capitalism.

Progressive social workers were critical of the postfeminist, post-sexism discursive practices around gender, but somewhat vague on why sexism remains an issue within the social work environment and what is to be done. Many snorted derisively or nodded appreciatively when sexismis-not/no-longer-an-issue stories were told. It was almost as if we all knew this story line so nothing more needed to be said. When I urged workers to explore this story line in greater detail they usually began to discuss gender in terms of the male violence experienced by clients. 


\section{Constructing Male Violence: Professionalism and Therapy}

Progressive social workers inadvertently make use of professionalized constructions of gender when they discussed male violence and the client-survivor. Within social work, professionalism is a series of practices and logic, or ways of thinking and acting upon issues, which, as Mullaly notes, are for the benefit of the professional, not of the client (Mullaly and Keating, 1991). These practices and logic remake society-wide male violence into individualized, psychological problems that are amenable to the kinds of skills and knowledge possessed by mainstream social work. In other words, rather than starting with the experience of women who are survivors of violence and build solutions from this entry point, professionalism reshapes women's experience of violence to fit the kinds of solutions that social workers already provide. Thus, male violence is constructed as an issue requiring professional, clinical skills of assessment, diagnosis and counseiling, rather than the comprehensive restructuring of society including income redistribution, the provision of social housing and the eradication of all forms of violence. Moreover, male violence is remade as an apolitical phenomenon that is wholly outside of the political arena.

Professionalized, therapeutic responses to male violence maintain a central and pivotal position in the construction of gender. Rather than a series of overlapping complex issues that require fundamental restructuring of socioeconomic and cultural relations, gender is contained and reformulated as a fairly straightforward psychological problem. This problem is one that is amenable to existing social work interventions, namely counselling, therapy and support.

Although there were notable exceptions, when asked directly about how gender is part of their work, most progressive social workers mentioned male violence against women. Even workers who do not specialize in work around violence issues identified this piece as central to the construction 
of gender in social work. Progressive social workers noted that "almost every client has been abused by every male they came in contact with through their childhood" and that "all the females and most of the males have been sexually assaulted at some point". They continued, "the kind of sexual abuse that goes on within programmes and within families is horrendous. It is absolutely shocking what some people have to put up with." A mental health worker observed, "if you open up the subject, pretty well every woman has a story to tell about violence." A community worker was adamant that woman are violated a gazillion times more than men. And the violence is systemic. So that, if a woman is hurt in a violent way and then goes for redress to the civil proceedings or the criminal proceedings, then, there is systemic violence in those institutions as well.

Progressive social worker's mobilization of class was strongly concerned with notions of the poor and of welfare, and various programmatic and/or solidarity measures that could be taken. The concept of violence seemed to play a similar role in the formulation of gender. Like poverty, violence is seen as an unjust, but very present and possibly permanent facet of a gendered society. Like poverty, violence is such a backdrop of everyday life that it is partially invisible. Violence, like poverty, is constructed by most progressive social workers as a problem of the oppressed group, not of the oppressors. In other words, just as poverty is a problem of the poor and not of the rich, male violence is a problem of women, not of men. The locus of intervention and analysis, in both cases, is the oppressed group. In both cases, a large, complex problem is remade into a small problem that can be tackled within the small arena of professional social work practice. No other arena of struggle is suggested and no other solutions are considered.

Interventions aimed at the oppressed group obscure what is really going on to create and sustain these relations. Further, it enforces a certain way of proceeding with the problem that cools out conflict and makes the problem amenaible to conventional social work interventions such as 
counselling, client education and group work. The following quote outlines some of the tensions in this construction. The worker is employed in a clinical capacity in a larger community agency:

The clients I work with are some of the most sexist people I've ever met in my life. They really kind of embody 1950 s roles for males and females.

And most of the guys are abusive to their girlfriends - they beat on them, curse at them and emotionally abuse them, psychological abuse, you name it. The way I handle it is to do a differences exercise and this builds a group dynamic and gets past some of it.

Most of the women have been raped and I find the more open to this I am the more I find out and the more I can help them deal with some of these issues and being raped and dealing with the home life and stuff.

An analysis of this not atypical discussion of violence illuminates ideological and professionalization processes. The worker started off discussing clients of both sexes and identifying both genders as participants in sexist gender roles. She clearly attributed violence to the men in the group, but then aimed her first intervention at building a sense of cohesion among the clients despite the existence obviously abusive relationships. She is signalling to the clients that the immediate relations of sexism and violence are not a problem. The issues are thus cooled out and distanced from immediate experience.

The men, who, the worker notes, are perpetrators of abuse, are not the targets of any antisexist intervention. The men are not encouraged to take responsibility for their practices of domination or to stop them. Instead, their abuse and other practices of domination are made invisible and they are brought into the cohesion of group experience through a carefully designed group exercise.

Given that the worker's first intervention was aimed at getting past male violence and sexism through a cohesion building group exercise, it is unlikely that her notion of helping women deal with male violence was emancipatory on any level. As the passage below highlights, this worker's exercise 
does not explore everyday relations of domination and subordination. Its primary goal seems to be to cool out conflict and permit the work of the agency to proceed.

DB: Is the differences exercise primarily pluralist or does it have a power piece to it?

Worker G: It is mostly pluralist but I try to say every now and again, now who seems to have more power here.

The process this informant describes makes male violence amenable to conventional, clinical social work interventions such as assessment and group work rather than taking it to a more politicized level of practice. It invites the clients to understand male violence within the context of pluralist differences between people. Finally, it encourages clients to think of male violence as something to be dealt with therapeutically after the fact rather than as a relation to address in day-today relations. In her professional, day-to-day practice, this informatn is actively promoting ideological and professionalized constructions of violence and of gender.

In this, as in other stories around violence, instead of being terrorized or galvanized to action by the pervasiveness of male violence, many progressive social workers applied a professional framework to the problem. This "cooled out" and distanced male violence from the average worker by constructing it as a client issue, not an issue that most women experience. Within this framing of the issue, should female social workers experience male violence, they become in construct and in practice, clients seeking and needing service. Thus, the issue is made less intense and impersonal. It is made amenable to professional and technical interventions and controls.

Progressive social workers accurately theorized male violence as a piece of gender relations. However, this piece of gender relations was often taken up by progressive workers in an apolitical, professionalized manner which obscured the way that violence is the implicit and explicit backdrop 
to everyone's everyday lives. This construction of clients and violence operates both at the ideological level which distracts attention from what is really going on, and at the structural level as actual pieces of the way our everyday experiences, our social services and our professions are socially organized.

The process of professionalization takes the struggle against male violence out of the political arena, and recasts it as an individual problem which requires a therapeutic response. While counselling may be part of the supports required by survivors of male violence, the unequal organization of the paid labour market, and the unpaid domestic realm, as well as the lack of social housing, childcare and other support services are, perhaps, more important in providing women with the means to escape violent situations. As Rebick and Roach note,

Violence against women is connected to women's inequality in society. There needs to be a broader understanding that women need more options, more social, political and especially economic power, to be able to leave violent situations. It's inequality that makes women vulnerable to violence (1996: 125$)$.

These authors also observe that men, as well as society as a whole, must stop colluding with male violence and build a society based on non-aggression and equality.

The social work construction of male violence as an apolitical, individualized phenomenon, places it wholly outside of transformative relations. Moreover, violence against women is positioned as if it were the totality of gendered inequity and injustice. This encapsulement of gender in the issue of violence is a way that the anti-sexist scruggle is contained. In essence, the wider field of unjust and unequal gender relations is made invisible and all anti-sexist efforts are focused on this one piece of the broader problem.

While the counselling techniques used with survivors of violence may reflect liberatory constructions of women, the way that the issue is contained by its professionalized and neutralized 
framing removes its capacity to change relations of gender dominance and subordination. Hence, like some of the other pieces of practice examined in this thesis, this formulation of gender is not transformative or progressive.

\section{The Invisibility of Relations of Reproduction}

Gender, as formulated by many progressive social workers, assists in eclipsing some of the biggest pieces of women's lives, namely unpaid reproductive labour. The unequal division and status of reproductive labour such as house work, child care, elder care and care of a spouse were notably missing from the way most progressive social workers mobilized gender and anti-sexism. As Barritt (1984) notes, gaps in the data speak loudly and also require analysis. This section will explore this absence in the data as well as the ways that relations of reproduction are organized within the social work milieu. Social workers employed in explicitly feminist services were an exception to this rule as were some other workers. These exceptions will be discussed in detail later in this section.

Most progressive social workers seemed to formulate the private realm of the family as an arena where needs and practice were depoliticized. This is not to say that needs within this realm were unrecognized. Rather, needs were incorporated as issues and problems which are amenable to professional social work interventions instead of being incorporated as highly contested, politicized and politicizable issues which have the potential to radically redistribute justice and equality.

For example, most workers were reluctant to intervene in the unequal division of caring labour in the families of clients. Some informants felt that they were being radical to simply observe to female clients that their male partners performed very little reproductive labour. One worker said that although an unequal division of domestic labour is apparent in all her cases she "never mention(s) 
it unless the mother does first". Another worker noted that within her service mothers are made responsible for almost every aspect of their child's life, but given the narrowness of the agency mandate and inadequacy of resources, there is nothing that she or her agency believe that they can do about it. Hence, they just "try to be kind about it". This reluctance to intervene in the unequal relations of the reproductive realm and sense of the futility of interventions reflects a passive acceptance of existing inequalities, and the way social services reinforce them.

The private aspect of this realm, as well as the realm itself, are wholly ideological notions. Privacy acts in two ways in the domestic realm. First, it permits the unequal and gendered relations of reproduction to appear to be the individual choices of women, rather than longitudinal patterns of exploitation and oppression. Secondly, it permitted progressive social workers to avoid recognizing or acting upon the injustices in this realm.

The following passage reveals the way the ideology of privacy operated in one of the focus groups. Some workers were only comfortable discussing non-domestic sphere male-female relations. In this scenario, the group had been discussing sexism in social work. Following this exchange the topic of discussion returned to issues of bureaucracy and funding cuts.

Worker X: One thing that strikes me with some of the mainstream social workers is how separate their work lives are from personal lives... But it amazes me how people can step into two different worlds so seemingly easily?

Like I know lots of women who are good on issues at work and then end up with Tory partners, like really conservative, sexist, abusive guys. Like just how they apply gender in one context of their lives and are so blind to it in another?

Worker Y: I don't know if it is so much stuff like that for me. I don't think we can judge or make everything look like left versus right all the time.

Worker Z: Well, not that we're not all full of hypocrisies all the time, but how can you fight sexism at work and put up with a creep in your relationship? It's something women 
do all the time, sometimes it is so blatant and right out there,...

Worker Y: Oh, I don't know. I don't know if that's the issue we're really talking about here.... Can I make a quick point? I want to go back to something we were saying before about funding,...

In other discussions, workers noted that many female social workers experienced male domination in their "private" lives. However, they managed to keep the realm of work and domestic life quite separate. Many of my informants noted with disbelief the number of female workers who are progressive on the job, but have husbands or partners who are blatantly sexist and or abusive to them. "Compartmentalization" was the term workers gave to this process of tolerating male domination at home, but fighting injustice on the job. Again, while noting that this is a problem, workers accepted the situation with the same type of resignation with which they accepted poverty.

Violence and the threat of violence in the private realm also has an oppressive and controlling impact on women's work life. The privacy of the domestic realm constructs violence as a form of intimate and secret suffering. As noted in the preceding section, when violence comes to the attention of those in the human services sector, it is recast from private suffering into a professional issue requiring clinical intervention. The example below highlights what can occur when violence or the threat of violence in the private realm infiltrates the public realm in a way that is not amendable to clinical intervention. The ideological strength of the concept of privacy serves to depoliticize and neutralize analysis and action.

While organizing a work-related political campaign, a worker was told repeatedly by female colleagues that, while they supported the campaign, they could not receive any political mail at home or their "husband(s) would kill (them)". These women were serious in not wanting their husbands to know of their political activities or sympathies. This story underscores the way that relations of 
male domination in the domestic realm infiltrate and curtail activities in the paid work realm. My informant felt that this story was about the privilege she has to be politically active at work and at home. She did not think that the story was also about the political issues raised by the unequal and potentially violent home lives of her co-workers, and the way these oppressions shaped everyone's work lives.

Although this worker was prepared to be politically active on other injustices in the work place, she did not identify the aforementioned male dominance as a political issue that merited social action campaigning. The ideology of the private sphere of home and hearth operated in a commonsense way to screen relations of male domination from political scrutiny and action. In other words, my informant and her timid co-workers collaborated in constructing injustice and abuse in the home as a private, individual affair, while other kinds of injustices in the work place were public and actionable. The privacy of the so-called private sphere remains private in part because we collaborate in making it that way.

Gender and one's relationship to various means of reproduction also operate within social work as mechanisms that sort out and reinforce what kinds of skills and capacities each gender is to develop and promote. In other words, men's and women's relationship to reproduction in larger society is reflected and recreated in the way that social services are constructed, and the roles that men and women are accorded within these services, and the value coded into these roles. Paralleling their role within the domestic sphere, male social workers are generally employed in areas where caring skills are not central skills. Instead skills such as organization, research and leadership are valued in the male job preserves of management, policy, and academia. Women, in contrast, are employed in positions where caring skills are in high demand, namely, frontline clinical and 
community practice.

Some of the gendering of the social services work force is determined by personal preferences, which are also shaped by social forces. However, most of this pattern is determined by the skills and potential that employers believe to be embodied by each gender. For example, one of my informants complained that he is always sent the most obstreperous and violent clients because as a male he is thought to be "better able to handle them". In his job site, male workers are hired and valued for this particular role. My informant resented the way that this streaming under-develops his skills of caring and nurturing, while over-developing his crisis and containment skills. He pointed out that this same pattern of streaming means that female workers do not have opportunities to use or develop their crisis and containment skills. Instead they are sent clients who are thought of to be in need of nurturing and empathy. The female workers are assumed to have nurturing skills by virtue of their gender. Thus, each gender is provided with opportunities to develop those skills which they are believed to already have, and denied opportunities to develop skills which the opposite gender is assumed to embody.

Another informant, working in one of the few male-dominated sectors of social work, noted that caring and empathy skills are not rewarded at his work site. Instead workers are expected to display a certain air of control, authority and, at times, "tough love". When my informant displayed caring and nurturing skills on the job he was called a "bleeding heart". Co-workers would joke, "oh, here comes Deng, 'gush', 'gush', 'gush' - what's the feeling of the day?" Thus, although ostensively gender neutral, the kinds of skills that are sought out, rewarded and developed in certain jobs recreate male and female relations to the reproductive work of caring. Even where men are present in caring 
social work roles, they are present differently than women. ${ }^{3}$

Fraser argues that gender equality in the domestic realm, and indeed, in all areas of social life, requires the deconstruction of "breadwinning and caregiving", "domestic privatism" and bureaucratized, institutional public services, and the "wholesale reconstruction of the institution of gender" (Fraser, 1997: 61). This will involve a shift in everyone's identities so that all workers are caregivers and all caregivers are workers. It also demands a restructuring of the paid and unpaid work worlds as well as the realm of human services in order to blur the cultural juxtaposition of workerism versus caregiving. The restructuring of the private realm must be accompanied by a concomitant restructuring of civil society so that carework becomes a democratic, self-managed social activity of those with and without kin-based caregiving responsibilities (Fraser, 1997: 62). ${ }^{4}$ In short, paralleling the broad cross section of socioeconomic and cultural changes necessary to eradicate male violence and female victimization (Walker, 1990), Fraser calls for the deconstruction of existing unequal, gendered identities within the private and the public realms, as well as the redistribution of paid and unpaid work between women, men and public providers.

Not all progressive workers failed to include and politicize the domestic realm. The following analysis arose during my final focus group where my preliminary results were discussed by the group. The worker is addressing the topic of reproductive labour,

When people talk about gender and about how social workers work in their practice, there

3 For a full discussion of women, social work and reproduction see Baines, Evans and Neysmith (1993).

4 This theme has also been discussed within other sectors of the feminist literature such as women and the state, and women and caring labour. See for example Baines, Evans and Neysmith (1993). 
is a kind of absence of talking about how women's lives are outside the agency. There is really kind of a void. I find it really frustrating.

Some women who are really good feminists will talk like there's nothing that happens except the agency. Like, there isn't a whole world of inequality beyond that. And women's access to good jobs and being able to keep good jobs has nothing to do with the worlds outside of the agency. Like the fact they may have children, and that they have to care for them, so that they won't have as much time to get as many credentials or as much experience as men. So, they have to take more time off to care for sick kids, and then they don't get the promotion. It all seems to have been erased somehow.

Other progressive workers demonstrated a strong willingness to intervene in both the private and public spheres of women's lives. A community counsellor in an activist feminist agency reported that her work with women involved

looking at the larger context, looking at how different systems...the education system, religious system, medical system, have historically not always very well met the needs of women. And so, we do try to talk about systemic sexism, how that impacts on women in the workforce, on it impacts on them in the home and so on.

The same worker observed,

We do the same thing when we go out and we do our workshops or educationals or presentations.

Some workers placed gender at the forefront of their work with men, as well as with women.

A health care worker reported integrating gender inequality themes into work with men "it's always there...it is always choosing how and when and when, gauging when to take something to the next step." One tactic she uses is plastering her work environment with feminist posters and talking casually to male and female clients about the topics they raise. This worker notes that sexism is part of her "everyday life" which includes working in "a female-, but not feminist-dominated work place" and living with a man, having a son and having a daughter, "it's part of the lens which through I look all the time. So, I wouldn't know how to put it aside it I wanted to." Another worker adds,

It (gender) is everything I do all the time, everywhere -- at work, at home, with the Board, 
with my staff, with my supervisor, with my landlord, with my friends and with my lover (if I had one, but that's another story), with my computer, my vacuum, my pencil and my garden hose.

Thus some progressive social workers integrated an analysis of paid and unpaid labour and their own experience of struggle within the private and the public realms into their formulation of gender.

The invisibility within the progressive social worker's analysis of gender and of the relations of reproduction reflects the neoliberal social economy. Within this social economy all people are workers first and foremost, and parents incidently. Those workers who are parents must absorb their own risk and responsibility for making the choice to become parents (Rose, 1994). Special services for supports within the economy or public sector are not desirable as this undermines the utility maximizing capacities of individuals. Instead, women should purchase services through the market or turn to the private family for supports. Within this model there is no shifting of caregiving to either the state or to men. Women's attachment to the work force is seen to be a matter of choice with no acknowledgement of conditions of exploitation, marginalization or deprivation. Women's experience with these forms of economic injustice are erased and disparaged. Those women who cannot make it in the private markets are interpreted hostilely as aliens. Thus, the neoliberal social economy sets the stage for and expansion in both socioeconomic and cultural symbolic injustices (Fraser, 1997).

Fraser argues that the opposition between breadwinning and caregiving is one the principal undergirdings of the current gender order (Fraser, 1997: 61). Progressive social work's lack of engagement with the themes and issue emanating from the reproductive realm re-emphasizes the opposition between the paid and unpaid work realms, as well as the different value accorded to each. As such, it plays into the neoliberal agenda and weakens efforts to deconstruct gender and pursue 
strategies of social justice.

\section{Importing Market Relations: Private Practice Feminist Therapy}

An interesting phenomenon of the 1990 s is the growth of private practice social workers. These workers free lance and are not attached to any particular agency. Most private practitioners are therapists and charge a fee for their services. The provision of individual or group therapy by progressive private practitioners, in particular feminist practitioners, is a controversial mode of progressive social work. While most private practitioners enthusiastically embrace private market relations with their clients, many feminist therapists try to balance precariously between the relations of the private market and their collectivist and egalitarian principles.

Private practice feminist therapy is a particularly rich example of some of interlocking of class, race and gender. I have placed it within this chapter because of its primary identification with issues of gender. However, its placement within the neoliberal private market draws feminist therapy into a complex web of class relations, structures and ideological practices. While arguably private practice feminist therapy has provided important and much needed services to many women as well as providing a creative space for the practice and development of critical social work, its tenuous and controversial embracement of private market relations makes it vulnerable to many of the same inequalities and injustices it deplores. This section primarily analyses private practice feminist social work's importation of market relations to the social sphere. ${ }^{5}$

Private practice places the worker in an isolated work environment lacking in supports,

5 A more complete evaluation of some of the benefits of private practice feminist therapy can be found in the work of Brown (1994b) or Kalotay and Reynolds (1991). 
supervision and accountability mechanisms outside of those of the market place. In order to combat the problems associated with isolation and to promote feminist therapy, some feminist practitioners have chosen to affiliate with a feminist referral service. In Toronto, the feminist referral service has undergone significant struggles around race, class and other relations of oppression. Workers told stories of the major changes which have occurred within this agency in terms of "very self consciously" making the service accessible to, inclusive of and representing the interests of women of colour, poor women, lesbians and women with disabilities. This involved serious changes in the composition of their Board, their staff, their referral lists and the ways in which they promoted their service to women. One worker noted that "it was a huge issue of political fighting around issues of representation". She added,

I would say now that (the agency) is one of the most self-conscious organizations in the city. When I say that, I mean, what was once a traditional white, middle-class agency became very self-conscious of the politics of inclusion and representation.

The agency continues to expand this work through newsletters, "a gazillion of workshops", discussion groups and the standards it maintains for the feminist counsellors on its computerized referral list. The agency insists on a number of firm principles for the therapists it lists. These include a clear analysis of power and oppressions, accessibility, a sliding-scale of fees and the provision of a certain amount of free counselling.

Indeed, the feminist referral service has become more rigid in its enforcement of requirements around the provision of free services because so many therapists failed to do so, or would do so only with pressure from the service and the client. While obviously well-intentioned, the provision of a certain amount of free counselling, and charging fees based on a sliding scales are examples of liberal strategies aimed at end-state maldistribution. That is, they address the outcome of a system based 
on inequalities rather than addressing underlying structural inequalities (Fraser, 1997). Moreover, the existence of fees represents a barrier to many who will not seek out services if they believe they cost money. Private therapy is therefore accessible to those for which the paying of fees is not a barrier. Hence, like other liberal end-state redistribution projects, this feminist referral service's fee structure reproduces hierarchies within the social service community.

One of my informants was of the opinion that fees do not play the same role in limiting access that they do in other sections of human service provision. She argued that women seeking feminist therapy in the private market are not like the average consumer. They are more informed consumers who have previous experience with the medical model or mainstream counselling and have found these services to be oppressive or inadequate to their needs. These women are actively seeking an alternative therapy provider. My informant also observed that "contrary to popular belief many working-class women go to private practice feminist therapists". Like doctors and psychiatrists, most private practitioners would prefer to have their services billable and reimbursed by the Ontario Health Insurance Programme (OHIP). Lacking this option, feminist therapists argue that they are doing the best they can within a flawed system.

Free of the restrictions of state- or mainstream-funders, agency structures, and Boards of Directors and supervisors, private practice feminist therapists have had the flexibility to experiment with alternative constructions of clients and services. Within the private practice milieu clients are "encouraged to see themselves as informed consumers" who have a myriad of choices available around type of service, length of service, issues to be worked on and who to work with, and in what way. This differs significantly from state-run and state-mandated agencies where clients are assigned to a worker, and have little or no possibility to change workers or to negotiate anything about how 
the servicing will occur.

Beyond this surface level of service, the consumer role is not a powerful one within a market that is dominated by the provider. The only real power the client has is to terminate, or threaten to terminate the relationship with the therapist and or complain about the inadequacy of the service to whomever would care to hear. This does not provide immediate solutions to problems within the service. It places all the onus on the consumer to extend considerable energy for dubious results. It means that the client is quite likely going to be without a service she feels she needs.

Moreover, this construction of the client as consumer is consistent with neoliberal ideology and socioeconomic restructuring. The neoliberal restructuring of the human services sector reflects liberal theory's preference for the unrestricted private market and general suspicion of government provision (Rose, 1994). Under neoliberal governance in Canada, and particularly Ontario, human services are in the process of being spun off from the state through privatization and cutbacks and/or regulated by a series of practices utilized in the private market. Entrepreneurial initiative, competition and the marketing of service providers are practices which are being introduced to services which previously operated on notions of accessibility, flat grant funding, service as a right of citizenship and social solidarity (Rose, 1992). Under neoliberal governance, the service user is, likewise, reconstituted as an enterprising consumer who is best served when exercising the neoclassical economic practices of free choice within an unrestricted market, and utility maximization. The enterprising consumer is held fully responsible for the well being and advancement of herself and her family, with the government taking no responsibility beyond the development of optimal market conditions. Consumer choice becomes a matter of risk avoidance, calculations and strategizing around the best way to meet present and future needs. 
Private practice therapy lends itself well to the neoliberal society. Feminist therapy becomes another consumer choice which assists clients in taking individual responsibility for their own choices and satisfactions, and as Rose puts it, "subjects of their own narratives" (Rose, 1994). Many scholars warn that therapy is not a neutral way of organizing how certain needs will be addressed. In fact, many see therapeutism as operating comfortably within neoliberal agendas of private solutions and individual risk (Epstein, 1993; Parton, 1994; Rose, 1993, 1994). Epstein, for example, argues that therapeutism acts as a major transhistorical, scientifically objective and apolitical means for interpreting needs, changing undesirable behaviors and creating people capable of living and working in late capitalist society (Epstein, 1993). It pivots on the notion that personality is more amenable to, and a more appropriate terrain for change, than are social conditions such as poverty and sexism. "Therapeutism", Epstein warns, "pervades the public mind" shaping and depoliticizing needs, social policy and lives. Indeed, it is difficult to think of the impact of socioeconomic problems on individuals, without invoking some aspect of therapeutic discourses.

Feminist therapy rose, in large part, as an alternative to the oppressive aspects of mainstream psychiatry and psychology. However, it failed to break out of therapeutism's narrow parameters and constructions of social problems. The private practitioner's exclusive focus on therapy, and on recreating a woman's relationship to her inner self is limited in its capacity to redress the multi-levels of political, social and economic inequality in women's lives. Many feminist therapists claim that their presence within the therapeutic milieu is in itself a political act. They argue that the majority of therapy patients are women and without feminist therapists in the market, most women would have no alternative other than oppressive, male-supremist services. While this argument may have some legitimacy, it does not explain why most feminist therapists do not try to politicize the entire social 
service delivery arena rather than limiting their political work to the thin strand occupied by private therapy.

Some private practitioners, such as one of my informants, feel that feminist therapists should not limit their politics to the clinical realm. She argued that feminist therapists must also be active in community development and mass movement politics. A minority within the feminist therapy community, she noted that social change must occur at many levels including "the structural", in order to alleviate women's suffering and oppression. This worker argued, further, that many feminist therapists would rather work in the public or quasi-public sector, however due to neoliberal government downsizing these opportunities do not exist. Cuts to funding for women's services has decreased the number of free or low cost services available to women. Women are encouraged by the government, and other neo-liberal bodies, to turn to the private market to have their needs met. Hence, a demand has been constructed through years of therapeutism, funding cuts and neo-liberal ideology. My informant pointed out that while it is not their first choices, many feminist practitioners, lacking other employment possibilities, have responded to this demand and turned to private practice.

Other feminist therapists report that they actually preferred to work in private practice because of its lack of restrictions on their work. These practitioners value the flexible work hours and the possibility to practice free of disapproving supervisors and colleagues. Thus, rather than being the victims of human service funding cuts, these practitioners actively seek out private practice opportunities. In essence, they act in tandem with the neo-liberal notion that the best place to find therapy is in the private market. Moreover, rather than a liberatory practice, private practice feminist therapy is just another consumer choice within a competitive private market of therapists and experts. In moving away from collective and activist feminist solutions, feminist therapy can be seen to be 
mirroring the neoliberal drift away from universal, solidaritistic solutions and towards individualized, private service solutions. Positioned within the neoliberal private market, feminist therapy participates in the commodification of feminism as a therapeutic service rather than, and separate from, emancipatory collective struggles.

\section{Repoliticizing Gender}

While the discursive and other day-to-day practices discussed thus far, indicate that progressive social workers have difficulty mobilizing gender in ways that are emancipatory, other examples exist which embody more transformative possibilities. The feminized terrain of social work has provided a fertile working ground for the development of services and practices which are organized with one foot inside the relations of ruling, and one foot outside. While conflictual and vulnerable to power struggles, these practices exhibit potential to create new kinds of helping relationships based on equality and mutuality while simultaneously developing "contestatory political and public spaces" for human service delivery (Yeatman, 1994: ix).

\section{Feminist Pieces of Social Organization}

Feminist social services have existed since the nineteenth century in many countries. The present complement of services delivered by feminists with an explicitly feminist mandate, model of service and analysis developed to fill the gaps in the welfare state. Wendy Weeks argues that the Australian welfare state was built on notions of the breadwinning, independent, citizen-male and the financially dependent, stay-at-home caregiver female, as well as the "colonization, dominating and marginalized ethnicities" (Weeks, 1994: 304). This highly gendered and racialized model of services 
failed to meet the needs of most women. Feminist women's services, based on women centred analyses of needs and ways of working, developed to fill this void.

Feminist services operate on principles and practices that differ significantly from the mainstream. These differences are summarized in Week's ten themes of feminist women's services:

1. A feminist or woman-centred analysis of needs

2. The provision of women's safe space and women workers is an organizational as well as a service delivery principle

3. The centrality of women service-users and participants

4. Ensuring a respectful response to all women, avoiding victim-blaming

5. Supporting women's control over their decisions

6. Recognition of and response to women's over-representation in poverty and low-income groups

7. Empowering approaches in practice

8. Accessibility

9. Responding to the special needs of women

10. Aiming at excellence, quality and relevance (Weeks, 1994: 305)

While Australia's explicitly feminist services are more plentiful than are those in Canada, they follow a similar overall trajectory.

A number of explicitly feminist services exist in Toronto at this time; however, this small sector of the social service community is vulnerable to neoliberal restructuring. ${ }^{6}$ Whereas liberal

6 By explicitly feminist or feminist women's services, I am referring to those services that incorporate an analysis of gendered forms of power into their mandate and the organization of their service delivery. I am attempting to differentiate feminist women's services from those provided by the state or community agencies that lack a power analysis and practice. 
governments were more or less willing to permit these services to function on the periphery of the social services community providing services to those who could not or would not find their way in the mainstream services, neoliberal politicians have voiced their direct opposition to the politicized service sector. Not long after the election of the Conservative provincial government, Diane Cunningham, Ontario Minister for the Status of Women, told a gathering of women's groups that services that are publicly critical of the government's policies will be audited and shut down (Morrow, 1996). This story circulated rapidly through the social services community, causing many workers and agencies to fear for the continued existence of progressive social work and services. Subsequent cuts in funding to women's shelters, crisis lines, resources centres, clearing houses and clinics resulted in decreased service and life options for women.

As mentioned previously, explicitly feminist services in the post-feminist era tend to be somewhat isolated from the mainstream social service community. The relative isolation of feminist women's services, coupled with their activist roots, analysis and ties, has permitted these agencies to experiment with alternative and emancipatory ways of organizing services, work, the workers and the clients. Many lessons can be drawn from the explicitly feminist services that have a much broader application. This section will discuss some of the ways that feminist women's services have grappled with issues such as paid and unpaid labour, bureaucracy, hierarchy, anti-oppression organizational change strategies, ties to social movements and resistance to standardization and documentation.

One of the major ways that a power analysis has been incorporated into feminist women's services has been the organization of the paid and unpaid work of the agency. Feminist services have experimented with alternate ways of organizing the work, the work force and the clients. At one time, the feminist model of service delivery was thought to be epitomized by the non-hierarchical 
collective. Collectives avoided hierarchical and bureaucratic division of labour and status through processes such as the rotation of collective members through all agency positions and tasks. Workers, activists and volunteers took turns carrying out administrative, janitorial, community development and counselling duties. Thus, no single person became ghettoized in a low-skill job, or privileged within a supervisory or management role.

The work force was also organized to reduce hierarchy between paid staff, unpaid staff and clients. Volunteers often became paid staff, and paid staff who moved on to other jobs often returned to the agency as activists and service volunteers. Clients were encouraged to become agency or women's movement volunteers. Thus, a significant degree of fluidity of tasks and of job status was built into the way the agencies were organized. These horizontal structures ensured formal equality between and among those who did the work of the agency. However, inequalities such as class, ability, race, and sexual orientation were not addressed by these frameworks. The early collectives also experienced a great deal of difficulty with other sorts of unfair expressions of power between and among collective members. A number of agencies were plagued with infighting and bitterness as a result of ongoing power struggles around political and personality issues. As one worker put it, "everyone has their own story about horror collectives."

These types of conflicts sent feminist services in two major directions. The first was to continue to struggle with the non-hierarchical collective structure and attempt to res slve some of these problems. The second was to adopt some form of hierarchy in order to avoid certain kinds of conflict. Both employed formal and informal mechanisms in order to address the conflicts, and to permit their services to move forward.

Many feminist and womanist services continue to be organized into non-hierarchical 
collectives as this structure as many activists see collectives as very compatible with feminist/womanist, anti-racist, anti-class, anti-homophobic, anti-ablist analysis and goals. As a worker in a newly formed ethno-specific, womanist non-hierarchical collective observed,

Social justice and race, class and gender are all clearly laid out in our mandate. Our big challenge is how to really operate as a non-hierarchical collective with two paid staff and a bunch of volunteers. It's not easy but we all believe it is the best way we can work together.

Another worker identified the stability of the work force in her collective and "shared ideals" as part of the reason for why her particular collective continues to function despite the dissolution of most other collectives. This stability is seen to be the result of two elements. This first is a very stable funding source. The second is a unionized work force who have been able to secure better wages, benefits and working conditions in a field that is notorious for low pay and poor benefits. Stable funding and unionization meant that there was very little turnover among the staff and long term goals and strategies can be developed. This worker noted that conflicts, typical of most feminist collectives, had "all been worked out years ago". New conflicts seemed to be viewed as resolvable challenges rather than deep cleavages or problems for the staff. Low staff turnover created certain contradictions for the collective and the community. Most of the staff in this agency were white in a community which had, over the years, become almost totally composed of people of colour. Although new staff were hired on an affirmative action basis, the low staff turnover meant that introducing more women of colour to the collective was a decidedly slow process.

In other feminist collectives, formal mechanisms such as Harassment Grievance Procedures and Mediation Procedures were introduced in order to formally address conflicts around social inequalities and abuses of the power. One worker noted that Harassment Procedures do not always clear up conflict. These procedures can and are used to exacerbate situations where power is being 
abused

I've seen some horrible messes here with murky charges of discrimination, harassment, prejudice. Yuk! I saw some horrible messes up at (my last job) with lesbians accusing other lesbians of harassment, and then turning on the Harassment Grievance Officer and also accusing her of sexual harassment. The whole collective ground to a standstill.

Another worker who had experienced a similar situation observed that tying up an agency with multiple levels of Harassment charges and Mediation sessions discredits the agency in the eyes of the public and of the feminist community: "it can be used as a very clever weapon against progressive people and progressive agencies to stall their work." The first worker noted that she has "shifted and changed from believing every charge of sexual harassment,... and to a much more cautious approach,...seeing it as something that requires much more in-depth investigation, understanding and analysis". She continued,

People may say that something is harassment when it is really just somebody getting back at somebody else and wanting the power and control. Power and control may not be part of larger social relations, they may just be about interpersonal power struggles. But, we hand people a way to legitimate their power tripping by handing them Harassment Procedures and Mediation processes. I think that a radical analysis of power, not just of things like class and homophobia, can help us understand the dynamic.

The worker lamented the fact that no one seems to have done this kind of power analysis work although many acknowledge a need for it in order to make Harassment and Mediation Policies more just.

In significant part, due to the conflictual nature of many collectives, some feminist services have experimented with various forms of hierarchical divisions of labour. In one agency, two levels of workers exist -- a management level and a worker/volunteer level. The management level has "final responsibility" for the agency while the worker level performs clinical, community and social policy tasks. The worker noted that "not everyone wants to come to work to be the boss", although 
"no one wants to be dictated to". The staff in her agency have attempted to strike a balance which they call "working cooperatively" rather than working collectively.

In this particular feminist agency, staff and volunteers "expect to be part of the processes" of hiring, policy development, funding and setting furture directions for the agency. She termed the sorts of decisions that management is expected to share with the staff, a "mixed bag", and observed that she could not "set out all the examples of what has to be brought back". This "mixed bag" provides the staff and volunteers with a significant degree of latitude and flexibility to speak on issues that may not immediately appear to be in their purview. "We want to know what is coming down the pike, we don't want just to be told what's what." She emphasized that the management team has often been "called on certain things that they haven't brought back often enough to the staff". When asked about non-hierarchical collectives the worker replied that the women in her work place did not believe that there is only one feminist model that works in all settings and for all causes.

This agency, as well as the others discussed above, have an unambiguous policy regarding the hil ing of women committed to feminism. These standards are laid out in the agency manual, in job descriptions and advertisements, as well as discussed during job interviews. Applicants must have an anti-sexist, anti-racist analysis that is integrated into their practice. They must be committed to working cooperatively/collectively and have at least a year's experience working in feminist services. Certain job positions also require specific legal, counselling or language skills although, all workers, regardless of credential, tend to think of themselves as resources rather than professionals. The goal of the hiring criteria is the inclusion of feminist/womanist immigrant women, women of colour and poor women who may not have formal education or credentials but have equivalent bodies of knowledge and expertise. Thus, a certain degree of flexibility is built into the hiring processes 
ensuring that new bodies of knowledge make their way into the agency.

This greater accessibility of these agencies to immigrant women, women of colour and poor women has helped to challenge the predominantly white, feminist analysis and approach of such agencies. A number of feminist agencies have undergone far reaching changes in their anti-racist, inclusive and representative practices. Known as anti-racist or anti-oppression organizational change, these strategies involve comprehensive, multi-level, participatory reorganization and reordering of the agency. While many agencies have initiated these organizational change plans, few have developed the ongoing projects that most anti-racist change activists see as necessary to the building of anti-oppressive agencies and practices (Karp and Sutton, 1993; Thomas, 1987; United Way of Greater Toronto, 1991).

Usually in response to internal as well as external demands from activists of all types, women of colour, women with disabilities, lesbians, immigrant women, First Nations women and poor women, changes have occurred in the ways services are delivered, structured and promoted, as well as changes in staff composition, Board composition and priorities of the agencies. Often this involved "huge political battles" and a "lot of upheaval and bitterness". Just as often, feminist agencies "changed dramatically" in more collegial and harmonious ways.

One worker spoke of the work her agency has done, over the past four years, around antioppressive organizational change. She noted that the workers and volunteers have "gone out to different communities, to different organizations within communities and talked about our work and how we might work together". New programmes have been started and existing ones changed in order to include the needs of a more diverse group of women. Staff hiring has focussed on hiring women of colour, women with disabilities and immigrant women. All staff openings in the past four 
years have been filled exclusively by women from these groups. In addition the board, previously white and upper income, has changed so that it is representative of the different groups of women within Toronto. Board recruitment has focussed on "bringing in women from communities which have been systematically marginalized in society". The worker summarized:

We've been doing quite well, this organization has changed dramatically over the last five or six years and we are much more responsive to the grassroots level, to women from those communities which have not historically found mainstream feminism to meet their needs. There were reasons why we were a white, middle-class agency for a number of years -namely that's who founded us more than a decade ago, but we have overhauled ourselves to become inclusive of the needs of most women in Toronto today.

Many agencies have experimented with new and controversial anti-oppressive practices. One worker spoke of a quasi-quota or affirmative action system that has been set up in her agency to ensure access to women who are not part of the traditionally white clientele. When counselling spaces become vacant, the agency tries to "make those spaces available to women of colour or immigrant women before we give them to white women." A worker from another social change agency noted that her poor, white client had difficulty understanding the affirmative action waiting list. The client questioned why she as an psychiatrized, poor, single parent should have to wait for assistance, while more privileged women of colour may not. The worker, herself a woman of colour, commented that it is

easier for middle class and rich people of all colours to give up privilege, as they can look for services elsewhere. Whereas for poor people, they have fewer options and are often much more desperate. So things like the waiting list are hard for them to understand or support.

This story highlights the limitations of anti-racist and anti-oppression organizational change. In the end, even the boldest of these strategies embraces a liberal, multi-cultural model in which injustice is redressed through organizational changes within one agency, rather than through 
restructuring of the underlying political economy and symbolic cultural evaluation system of the broader society. Hence, these changes often increase rigid identities and static notions of culture, class and gender while simultaneously creating new hierarchies and stigmatizations, and undermining social solidarity and mutuality.

Despite these weaknesses, it is interesting to note that while a number of workers told stories about anti-oppression organizational change none of these agencies had gone as far in this process as had the explicitly feminist agencies. Anti-racist challenges and organizational change strategies have gained a substantial foothold in explicitly feminist agencies. Some of this compatibility seems to emerge from the way that anti-oppression organizational changes can be integrated with a feminist analysis, and with social justice goals of these agencies. The sense of an ongoing project against larger structures and immediate practices is common to both analyses, as is a commitment to political activism and socioeconomic change.

Another reason for this apparent compatibility may lie in the tie between explicitly feminist services and social change groups. Anti-racist struggles within the women's movement are more advanced and acute than in other social movements, and this is to some extent replicated within antiracist struggles in the feminist services sector. Differing from government bureaucracies or large multi-service community centres, feminist services have a certain volunteer and analytic base within the activist feminist and women's communities. These ties to the activist community makes feminist services broadly accountable to a more informed and politicized population. The fluidity between the movement and the services acts as a conduit of the new ideas and practices taking shape at the level of political activism. In effect, the feminist services are more permeable to, and permeated by the everyday struggles of social change groups. Moreover, this ongoing back and forth between the 
social movements and some feminist agencies represents an example of "politics of the unfinished" in which services and practice must value their contestatory nature and resist a tendency to become static, permanent and impregnable (Yeatman, 1994).

Other aspects of the feminist agencies which provide them with greater openness to social justice issues includes their resistance to processes such as individualization, standardization, documentation, and the community-clinical-policy split within social work practice. One worker summarized her agency's position in regards to standardization and individuation, "it's hands off from the government, no one dictates to us what we do. Our work is decided with each woman depending on what she wants and where she is at". Another worker added, "there is no point to working in a feminist agency if you are handcuffed to the way the funders want you to work." She observed that the lack of standardization in her job lets her learn from the community and clients as to what they need and to build the necessary service plans and activism together.

Feminist agencies resisted mechanisms of professionalization and liberalization in a variety of ways, with more or less success. Around funding, one of the agencies has delegated negotiations with funders to a particular team of workers. The task of these workers was to use their extensive knowledge of how to write funding proposals, and how to negotiate with various funding bodies in order to minimize the impact of state processes on service delivery. As one worker pointed out, these specialized volunteers act as a "buffer zone" between the funders and the workers and activists which served to "protect us at our level".

Part of this protection included negotiations and strategies around documentation. The same worker spoke of a deliberate strategy by the agency to resist documentation requirements from funders. In particular the agency effectively resisted a funder-imposed computer software package. 
The software package was to be used by all workers on a daily basis to gather statistics. This statistics gathering would take up a considerable amount of each worker's time and alter their interactions with clients. Instead the agency devised its own very lengthy but basically meaningless form for the funders. Negotiations over which format to use took so long and were so complicated that eventually the funders exempted the agency from statistics gathering pending the development of new statistics gathering tools. Thus far they have not received any such data gathering package. Other workers reported less success at limiting the impact of documentation, although they were well aware of the way that it cut into the time they had for other activities and shaped their interactions with clients.

Feminist services have had significant success in resisting a split between community, clinical and policy practice. One worker felt that a tie to mass movements, such as the feminist movement, was an important factor in maintaining a focus on the ways in which feminist practice is inherently political and needs to be worked at the clinical, community and policy levels simultaneously. Another worker agreed noting that while she is the only staff member who consistently sits on organizing committees for mass demonstrations, she inevitably sees staff, volunteers and board members at these events. Further she noted that these events provide a sense of the context of feminist practices as it helps to remind them "what it's all about and what we are up against". Most of the explicitly feminist agencies maintained formal or informal ties with some sections of the larger women's movement.

Feminists have experimented with ways to make the feminized terrain of social work more responsive to women's needs and more transformative of their oppressions. It is interesting to note that the new forms of organization discussed in this section are gender neutral. That is, they could be applied to feminist or non-feminist agencies, to work with men or with women. They have 
developed within the feminist agencies, in part, because of the explicitly political mandate of these agencies and their commitment to fundamentally restructure society along more socially just lines. They represent important new ways to advance an emancipatory programme, while simultaneously resisting existing forms of regulating and depoliticizing social work practice.

\section{Politicizing Direct Intervention}

One of the most notable contributions of feminist practice has been the politicization of social work. As one worker noted, "it is just the extension of the personal is political." The personal is political is, of course, a long-standing slogan of the women's movement. The words attempt to capture the dynamic of conflict in areas traditionally thought of as apolitical. In particular, personal life has been recast as a political zone, and a key site in which women's inequality is socially organized.

Social work has traditionally been thought of as a charitable or a reform project, and largely apolitical (Camiol, 1987; Mullaly, 1993). Feminists have used the slogan, the personal is political, as a basis for injecting power relations and analysis into the totality of social work. They have had considerable success in the area of social work known as direct intervention. Combining community and clinical practice, direct intervention is characterized by work with communities, groups, families and individuals in which the worker intervenes in the environment to meet needs and develop social change strategies.

As discussed in the chapter on class, progressive social worker use the concept of structures and the practice of solidarity in ways that increase reciprocity, blur class distinctions and transform everyone's sense of self within the social work relationship. As such the concept of structures and 
the practice of solidarity contained transformative possibilities. Many of the stories described in the class chapter were put forward by feminist social workers. These two techniques were strongly embraced and widely practice by feminist social workers in my study.

A third set of potentially transformative practices they discussed focussed on communication. Almost all direct intervention work involves communication in one form or another. Feminist social workers were very interested in the way that interpersonal communication is always a political process. This political process can mask and reinforce existing inequalities, or become part of a social change strategy. Critical consciousness raising (CCR) was the political communication process most discussed by feminist workers. CCR is an analysis of communication as a process of dialogue around the power politics and social relations involved in the personal situations of clients. This technique does not differ in any meaningful way from Frierian consientizacao, or dialogic communication. Indeed, the biggest difference between CCR and the Frierian technique is who is using it. CCR is used more by feminists, while consiensitacion is used by adult educators and third world development workers. In essence, $\mathrm{CCR}$ is a gender neutral technique that has been successfully developed and used by feminist practitioners and activists.

Feminist workers listed different aspects of CCR. One of these was alignment or nonneutrality in all communications with clients. Workers felt that there was no such thing as neutral practice or communication. One clinical worker reported, and other workers agreed, that to be neutral "would feel dishonest". She argued that "it's important that women coming in to see me have a right to know where I stand and how I feel." She added that she stresses to clients that her politicized view of the social world is "not the basis for our working together", although it is a piece of how their work will be done together. Two other workers pointed out that "neutrality is status 
quo" and hence, recreates inequalities.

A another large piece of CCR is "naming things", or trying to expose some of the relations that exist below the surface of everyday life. Workers commented on the importance of "making things explicit". Of particular importance to working with women, is the posing of direct questions about the women's experience with male violence, racism and or poverty. When these questions are not asked, one worker pointed out, "women will not mention them". Instead, women will often provide vague complaints which mask some of the real problems in their lives. These vague complaints include such things as "feeling blue", "having a hard time coping" or "falling apart".

A private practitioner noted that

sometimes when you are in an oppressed or marginalized group the things you are thinking about yourself are not always in your best interest. They are being shaped by the forces that are oppressive to you. So, we don't just take it at face value. We do have to take it apart, deconstruct it and look at it and see are there pieces of that we want to hang onto and are there pieces of that we don't want to hang onto.

After naming an issue, contextualizing it, providing verbal reassurance and support, most wurkers moved on to seeking concrete supports for dealing with the problem. It was seen as unethical practice to simply reveal to clients the sources of their oppression. Resources must be mobilized to assist women in everyday life. Workers noted that analysis of the more complex aspects of the oppressive relations generally occurred once supportive resources were located. Where appropriate resources do not exist, workers agreed that while it is difficult, "it is your responsibility to try and organize them." Workers were not very clear on how one might go about the organizing of new resources although most of them liked the idea a lot.

A health care worker noted that it is always a case of "choosing when and where", and not going in with a "bulldozer" but also "never missing an opportunity" to reveal to people some of the 
ways their world is organized to obscure the real sources of their suffering. She added that this consciousness raising must be coupled with a sense that "we are outraged that these injustices" and that we believe the world could be a more just place. This worker argued that tying clients into collective political action is essential to lessen their sense of futility and provide a sense of "shared causes" or solidarity.

One worker referred to this type of CCR as paralleling work. The exploitation and experience of the client is paralleled to other social relations of exploitation and oppression. She spoke of an instance where she and a white client were in a store. The client, a survivor of incest and wife-assault, began to disparage people of colour. The worker intervened by tying the client's struggle against male domination to people of colour's struggles against white supremacy. Initially angered by this comparison, the client agreed to discuss the issues, and cease her behavior in the short term. Later this woman began to make links between her own struggle for dignity and survival, the tyranny of racism and sexism, and who benefits from the divisions between people.

A clinical worker noted that often CCR is easier when she "makes it more personal". In other words, she shares pieces of her own life experience and politicization to help clients reframe their problems, the sources and potential solutions. Another tactic suggested by a clinical worker was to make very general statements like

what you're talking about sounds very much like the kinds of stories that most women tell me. If we take a closer look I think we can figure out how much is really unique to you and your situation, and how much is part of sexism and how this society treats women.

However, she noted that if she is working with somebody who is coming from a feminist position or "really absorbing it quickly" she proceeds much more explicitly. "It is all a matter of gauging what is going to work so that people don't tune you out and hear nothing." She adds that "most of the time 
women's reactions are very positive. They feel they had been affirmed, that somebody finally understood." This worker also stressed the importance of linking clients to "others in the same position, fighting the same fight".

Feminist workers reported that an important aspect of CCR is "making links" between the client's experience, the client's own oppressions and other oppressions. This helps the client understand how her situation is part of a broader socio-economic system of power relations. CCR without political action and linkages to other oppressions was seen to be "useless" and "potentially damaging". Political awareness with no possibility of positive change can increase a client's sense of despair and powerlessness. Hence, workers used a wide variety of techniques to encourage collective action and mutual action from and with clients. These techniques included referrals to social action groups, invitations for clients to attend public meetings or events with the worker, introductions to social activists and the development of local, participatory actions around client issues and problems. While most of these social action groups and activities were aimed at reform efforts, the struggles provide the opportunity to develop new types of identities and relationships, as well as an extension of political and public spaces (Yeatman, 1994: ix). These elements are integral to the development of the kinds of consensus, relations and moiilizations necessary to comprehensively restructure the political economy and cultural valuation systems of any society.

CCR was a process that was used by feminist workers in many direct intervention sites. Although therapeutism shapes social work as largely individual and apolitical, the feminized terrain of social services has provided a fertile environment for the development of this type of resistance and politicization strategy. This type of strategy is, to a large extent, outside of the relations of ruling as it attempts to make oppressive relations explicit and build solidarity among those who are oppressed. 


\section{Summary}

Gender was examined in this section as a series of liberal, neo-liberal, formal, therapeutic, and professional ideological practices. Gender struggles were seen to be depoliticized through a discourse that gender is not or no longer an issue, the construction of male violence as a problem of "clients", the invisibility of relations of reproduction, the creation of separate women's committees, and the development of private practice feminist therapy.

The structures and practices of feminist services were seen to epitomize ways that social work can be practiced in a more transformative manner. These agencies have experimented with various ways to organize services that resist bureaucracy, hierarchy, individualization, and demands for documentation. Moreover, feminist practitioners in many different sites made use of politicization techniques such as critical consciousness raising to help clients identify the structural and political levels of their personal problems and build resistance and collectivity. 


\section{Chapter Eight}

\section{Race}

\section{How Race is Depoliticized}

Race was the relation that progressive social workers spoke of in the greatest volume, detail, and intensity. It was also the social relation that the workers thought of as the most contested within social work. They reported that there was more attention paid to, and more activity within and around their agencies about, race/anti-racism than around class or gender. Simultaneously, they felt that there was not enough activity around, or attention to, race/anti-racism.

Like class and gender, an active race discourse exists in Toronto. However, as $\mathrm{Ng}$ (1997) notes, it is not clear whether this is an anti-racist discourse or simply a race discourse. Bannerji observes that social relations of ruling must be historicized as colonialism and imperialism, and hence argues that anti-racist discourse and activism must take the form of "revolutionary feminist antiimperialism" (1993: xviii). ${ }^{1}$ The mainstream social work discourse on race is not concerned with these themes. As the data will demonstrate, the conventional social work discourse on race is largely preoccupied with ways to integrate people of colour into the existing social service community with minimal adjustment of that community. Mohanty (1993) calls this the additive approach. "Diverse" people, that is, people of colour, are recruited to introduce "difference" to an organization, while the work of that agency goes on as usual. In effect there is no "shifting (of) the normative culture versus subcultures paradigm" (Mohanty, 1993: 56).

Bannerji (1993) is drawing on the work of Chandra Mohanty (1991a, 1991b) and Dorothy E. Smith $(1987,1990)$ to develop a understanding of racism that is materialist, feminist and directed to restructuring of the political economic and cultural systems. 
As established in previous chapters, class is neutralized in the social work milieu through processes of formalization and liberalization, and gender was neutralized through

formalization, liberalization, professionalization and therapeutism. Race is neutralized through these same formalization and liberalization mechanisms as well as through an additional process particular to the kinds of pressures that the anti-racist movement has placed on mainstream institutions. Broadly speaking, the anti-racist movement in Toronto has demanded inclusion, representation and equality. ${ }^{2}$ Within the social work milieu these demands have been picked up as questions of access to services for marginalized people and sensitivity within services to the concerns and cultures of these same populations.

For most of the social services community, question of access and cultural sensitivity have been introduced to social work agencies through a series of processes associated with managerial projects for organizational change. That is, race/anti-racism has been integrated into the existing organization of social services through a process which translates politicized demands and identities into neutral, routine agency policies and management systems. Through these managerial projects, race/anti-racism is abstracted from its conflictual everyday society-wide context and recast as an issue which can be professionally managed. This management takes the form of recasting society-wide political struggles as interpersonal disagreements and conflicts, and standardizing the behaviors and responses of the agency to such disagreements. These managerial responses also involve the commodification of those individuals seen to embody race and diversity, and a general "proliferation of discourses of pluralism" (Mohanty, 1993: 57).

2 The anti-racist movement is not monolithic, nor does it speak with one voice. Various sectors of the movement place greater emphasis on social justice and restructuring, while others simply want admission to the present system. See Stasiulus, 1990 for a more extensive discussion. 
My data show that systems for managing race included the establishment of advisory boards and committees, the extension of mainstream services through the provision of services in languages other than English, and the introduction of affirmative action hiring policy, harassment policies and organizational change strategies. The data also reveal the operation of pluralist discourses that reflect and legitimate the strategies outlined above. Discourses of pluralism validate the notion that all differences are basically the same and fairly benign. Hence, they are amenable to straightforward, commonsense managerial responses. In this case, race is abstracted from its historical context of colonialism and contemporary context of imperialism and recast as an issue of access. The issue of access lines up along side other issues of special interest groups as no more or less important.

Within the discourses of pluralism, other axes of oppression such as gender are similarly recast as just another point to be factored into inclusion tactics and strategies. As noted repeatedly, class is not included in these types of managerial plans at all, except as a facet of culture. For example, representatives of "the poor" or of a specific community or housing project may be asked to sit on a hospital or community advisory board thus ensuring that the voices of those living the culture of poverty are represented.

Later in this chapter I will discuss some of the main aspects of the race discourse that is dominant within the social work realm. In brief, the race discourse is pluralistic and non-racist rather than politicized and anti-racist. ${ }^{3}$ This pluralism privileges race over other axes of social injustice. However, it is important to note that this privileging does not mean that race is dealt with in a way

3 Roxana $\mathrm{Ng}$ (1997) differentiates between non-racist and anti-racist discourses. Non-racist discourses use strategies such as inclusion and representation to address the injustices associated with colonialism, imperialism and racism. Anti-racism attempts to address and fundamentally reorganize those structures and systems that socially organize racism and white dominance. 
that creates greater justice. Instead, the data show that this privileging acts as a lever with which to dislodge and marginalize other axes of subordination, in particular gender. In other words, this pluralist discourse and the managerial projects associated with it, privilege race without empowering anti-racist projects. Simultaneously, this centrality of the race discourse acts to undercut the emancipatory force of other anti-subordination discourses. Thus, not only is race/antiracism depoliticized and joins other depoliticized relations within the discourses of pluralism (Mohanty, 1993: 57), it is also employed within social service agencies as a discourse that curtails political action and debate on other axes of subordination thus ensuring that emancipatory discourses remain securely restrained within the boundaries of pluralist, depoliticized difference.

My informants reported that the particular form this discourse takes within social services is the theme of race is "in" and other issues are "out". The stories and observations of my informants around these themes will be presented in greater detail later in this chapter. The first section of this chapter will discuss the management systems and processes that formalize and depoliticize race/antiracism, and its complementary discourse. The second section will discuss the relatively new phenomena of neoliberal discursive practices around race, while the third section will focus on fledgling practices that foreshadow more emancipatory ways for social work to engage with this important social relation.

\section{Funders and Organizational Change Programmes}

The anti-racist struggle itself is not entirely new, although the broader base of people giving attention and energy to the struggle is new. Much of the focus on race in the social services vector emanates from the demands of funders. As noted earlier, social service funders attempt to influence 
the direction of agencies by identifying key issues that they believe agencies should address. New and continued funding are often contingent on agencies developing a focus on these issue areas. As funders such as the United Way or the Metro Toronto government funding body change their priorities, the agencies follow suit.

For example, a major funding body in the Toronto social services scene, the United Way of Greater Toronto (UW), adopted a multicultural and anti-racist policy in 1991. Arguing that Toronto had become a more "diverse" city as a result of immigration from "non-traditional source areas", namely Asia, Latin America and the West Indies" (United Way of Greater Toronto, 1991: 2), the UW policy required the enactment of organization change programmes in all its member agencies. This organizational change was aimed at the development of services to assist member agencies in improving access, cultural sensitivity, the elimination of systemic barriers, the promotion of attitudinal change, as well as the development of appropriate policies and procedures and communication strategies reflecting "positive and balanced portrayal(s) of racial, cultural and linguistic groups" (United Way of Greater Toronto, 1991: 5). In order to receive funding, the UW continues to demand that member agencies document the ways that they are engaging or plan to be engaging in multicultural and anti-racist organizational change.

There are several problems with multicultural and anti-racist organizational change programmes. Foremost among these is the way that they transform social justice struggles into manageable, quantifiable, standardized procedures and policies. As Mohanty notes, these programmes imply that diversity "(a euphemism for people of colour)... will be out of control unless it is managed" (1993: 55) (brackets in the original). Through anti-oppression organizational change programmes the managerial language and practices of corporations are brought into everyday social 
work practices. These managerial practices professionalize, standardize, individualize, and commodify race within the social work milieu. Mohanty notes that these everyday processes are part of the "Race Industry" (Mohanty, 1993: 45) or the construction of race within the broader society (Mohanty, 1993: 57). Organizational change programmes are clearly part of how ideology around race operates at the commonsense level.

Overlapping with managerial depoliticization processes is the construction of diversity as liberal pluralism, that is, all differences are seen as benign. Within the pluralist schema, problems in end-state distribution are seen as legitimate claims for strategies aimed at enhancing opportunity. This liberal framing of social problems and their solutions recasts systemic racism as limited access, lack of language services and under representation on boards of directors, and among staff and volunteers. Organizational change programmes take the type of problems and develop opportunity enhancing techniques and procedures such as affirmative action, inclusion, proportional representation and multiculturalism.

While organizational change programmes state that systemic barriers must be removed, their interventions are aimed at managing conflict, rather than "addressing economic exploitation" (Mohanty, 1993: 56), and understanding "the, struggles of racial minorities against imperial, colonial and neocolonial experiences" (Rezai-Rashti, 1995: 8). The liberal model of organizational change urges a positive re-evaluation of marginalized cultures without historically examining why these cultures were and are marginalized. That is, whose interests are and have been served by the hierarchical valuation of racial and ethnic groups.

In other words, liberal redistribution strategies attempt to redress racial injustice through efforts to ensure that people of colour get a fair share of the jobs and services, "while leaving 
unchanged the nature and number of those jobs and places" (Fraser, 1997: 30). It also includes the effort to assure people of colour respect while leaving intact the "black-white code" on which white supremacy is based (Fraser, 1997: 30). Moreover, within anti-racist organizational change programmes, race and culture are frozen into existing identities and the relations that underlie them, rather than changing the identities of dominant and subordinate cultures so as to make room for new regropments, struggles, positive identities and liberatory cultures (Fraser, 1997; Yeatman, 1994).

It is interesting to note that class issues generally are not part of the organizational change agenda. When class issues do arise they are incorporated into existing union-management structures or human resource management procedures such as pay scales. Diversity and anti-racist organizational change is, for the most part, focused on the containment of people of colour and other identifiable "minorities" such as people with disabilities.

Gender, likewise, is generally incorporated within organizational change programmes as just another aspect of diversity to be managed, and "not a very important one at that". The theme of managing diversity will be returned to throughout this section. The subsections will discuss specific ways that multicultural and organizational change have been picked up by the various agencies.

Many argue, and rightfully so, that anti-racist and multicultural organizational change strategies are, at least, inclusion strategies. Without these strategies, most people of colour and other marginalized groups would have even less access to much needed jobs and services. Even flawed organizational strategies are seen to open up certain opportunities for larger social change and justice. These arguments are valid and in no way contradict the analysis presented earlier in this section. However, while organizational change strategies to some extent challenge white exclusivity and supremacy, they do not dislodge existing systems of dominantion and subordination based on 
racialized meanings and lodged in the political economy of agencies, funders and larger society. It remains to be seen how far even the best anti-racist organizational change projects can proceed without simultaneously removing the bureaucracy, hierarchy, standardization, individualization and professionalization that mediate and organize unequal relations of race, class and gender. As long as organizational change plans leave these mechanisms of ruling in place they have little potential to repoliticize or fundamentally alter race, class and gender injustices. Instead, these organizational change plans act as reforms within the existing systems of inequality rather than as reforms to these systems. Further research is required to investigate ways that organizational change projects can be used as tools to further struggles for social justice rather than as tools to incorporate, depoliticize and co-opt anti-racist and multi-"ism" social groupings and movements.

\section{Race Is "In" and Other Issues Are "Out"}

As mentioned earlier, workers observed that race is talked about in their agencies more often than other social relations and is integrated into various policies and practices. This section will look at the discursive practices unique to the discourse of race in the social work community in Toronto. Workers reported a strong sense within their agencies that "race is in". Workers argued that being an "in" issue does not necessarily mean that anti-racism is being addressed in a positive way. One worker noted that

to say that racism is getting talked about, it is. But getting talked about, in ways that suggest that, to even say the word is offensive. It's not that in talking about it, there's an actual change that's happening, or that people are benefitting. Quite the opposite.

Another worker strongly added, 
it would be stupid for agencies at this point to ignore race, and they really can't unless they try very, very hard. But this doesn't mean that it is being picked up and pushed forward in a radical way. In lots of ways anti-racism seems to just get co-opted and corrupted and controlled by "the powers that be".

To most workers, it appeared that race was the "in" issue within the context of sexism being the "out" issue. Workers noted, "sexism gets no air time, racism is the big topic these days", "at this point we're dealing mostly with race, sexism is passe", "race is the scariest to deal with for most people, gender has been around longer - people are used to it" and "I think a tension that is quite present in most of social work right now is that gender is not in vogue like race is."

Racism being in and sexism being out was also present in the way that some clients constructed their problems. One worker provided a story of how a white client saw her situation as race-based although this did not do much to illuminate the sources of her problems:

She thinks that everything her father does that she doesn't like is because her father is white. She is politically progressive and sees everything in racialized terms so her all of her father's problems are about being white.

And it is this whole new form of socially categorizing which is actually quite inadequate. She is making vast generalizations about quote "whites"... she is really just trying to find a way to explain things that is actually not addressing her experience of her father's inadequacy and what really might be producing those quote "inadequacies".

Like other progressive practitioners, this worker noted gender dimensions to the client's problems, "There is probably way more gender stuff going on there than anything else".

A mental health worker, a white woman, provided an example of how issues are seen as being about race even when other relations are fairly central:

A few weeks ago a client came in and said "I don't want a Black worker". And he was talking to a Black worker and she said she couldn't deal with it, and asked me to intervene. So I went and challenged him on it. And we had this big discussion about racism, and as a white, male, how does he think he can say that stuff. And it was quite useful. 
In peer supervision, later, people only wanted to talk about the race aspects, and whether I handled it the right way, and not about how we, as women, felt about confronting a big, angry guy.

The worker went on to question class, race and gender issues embedded and overlapping in the situation:

He wasn't the least bit intimidated that we were workers and we're supposed to have all this institutional power behind us. Would he have reacted that way to a Black man? I don't know but I don't think so. And would he have agreed to have the same big discussion with my Black friend instead of me -- I really don't know but I don't really think so.

Progressive social workers were troubled by the tension between race and gender. They felt that race merited a high level of activism, however they felt frustrated by the way it was difficult to concomitantly focus any attention on gender. Progressive workers found very few opportunities for discussing or practicing in a way that combined the two. A clinical worker offered this explanation:

I wonder if this is because of liberalism; our institutions haven't figured out quite yet how to incorporate race the way they've incorporated gender. So they dealt with gender. They can pretend that it's all cleaned up. It's gone away. But race -- they're still grappling with."

A tension exists between pluralist constructions of multiculturalism, and the centrality of race to the diversity discourse. Within a purely pluralist construction of diversity

gender would be just one more axes of difference. Instead, it is the difference which is juxtaposed to race - race can only be in if gender is out. Gender, not class or disability or some other social relation, is targeted in this equation. It is as if two social relations cannot share the spotlight. Hence, gender must be dislodged.

This tension most likely arises out of gender's centrality to social work. As discussed in the chapter on gender, social work is a gendered milieu with women making up the majority of the paid workers, clients, unpaid activists and volunteers, caregivers within families. A gender discourse has 
been quite central within social work although this discourse is not an anti-sexist one. ${ }^{4}$ In effect, the race discourse could not become dominant within the social work milieu without first dislodging the centrality of the gender discourse. In other words, gender must be abstracted from its everyday reality as pivotal to every social work interaction and recast as no more important than any other difference in order to permit race to assume a central position. Thus, the "race is in" discourse contains an explicit or implicit message that "gender is out".

As an example of a countertendency in the data, while most workers noted the contentious relationship between gender and race, one worker argued that gender is out of the spotlight because women have gained significant equality. She used the example of harassment policy. This informant argued that notable differences exist in the way that racial harassment and sexual harassment complaints are dealt with in her organization. When racial harassment complaints are made, management seeks a conciliatory response such as "well, maybe he needs some education on the issue', or 'it's a personality conflict', or 'maybe he just misunderstood". In contrast, with sexual harassment complaints, "there's no discussion. Everyone know that it's inappropriate and it contravenes policy." She attributes this difference to the significant gains that women have made within her organization and "a certain degree of comfort now, or at least, willingness, openness to dealing with gender." As further evidence of the gains made in gender equality, this worker pointed to the content of inter-worker arguments during anti-oppression training sessions in her work place. Generally, she found that critical practitioners had to "struggl(e) and ha(ve) long fights and discussions around definitions of race, which we don't have to do around gender."

4 See for example, Birmingham's study of ideology among Ontario social workers. This study revealed the contradictory findings of a generally progressive outlook on gender, as well as strong support for blaming the victim (1994: $174 \& 180$ ). 
The works of June Jordan, Angela Davis, Chandra Mohanty, bell hooks, Himani Bannerji and others have documented the ways that women of colour have been excluded and remarginalized by the practices of many feminists. Discussions in the gender chapter underscored the ways that women's committees and other forums have constructed gender in a formalistic and liberal way that reconstructed existing class and race injustices. The primary beneficiaries of any changes in policies or practices were individual women, usually white. This same sort of relation is operating in this scenario. However, there are aspects of this relationship that are specific to the historical, sociocultural and political context of social work agencies in this era.

Within the social work milieu, gender is neutralized through processes that liberalize, professionalize, formalize and construct people as clients requiring therapeutic responses. Thus although shared definitions of gender within social work agencies may appear substantive and liberatory, these concepts are translated into practice in ways that rob them of any political or social justice capacity. Within the aforementioned agency training sessions, social workers may discuss gender in ways that sound very progressive. The process of abstracting the gender "talk" of workers and recreating it as a series of formalized, standardized policies and procedures robs this "talk" of dynamism and any capacity to enact more than superficial changes.

As a more recent political struggle, anti-racism has not been incorporated into social work practices for as long, or as effectively. At this particular point in history, the struggle to contain and resist anti-racist ideas is taking place throughout the social work milieu and, as the worker noted above, it is the subject of bitter conflict between staff members. In contrast, gender, as a more "contained" issue, demands little in the way of day-to-day changes from workers, and hence is largely passively accepted and incorporated by the majority of practitioners. This does not mean that gender 
equality exists, although in certain sites greater gender equality may be the case. It merely means that race is the subject of a more contested and fluid discourse with concomitant possibilities and liabilities.

In discussing the discourse of "race is in", a number of workers noted that it is easier to work with clients around race/anti-racism, than with co-workers or management. Some of this work is collaborative - working with clients to identify racism in their own lives, in practice, in the agency or in the wider community and to confront and change things. Some of this work is confrontational - making clients aware that racism is not acceptable and working with them to change behavior and attitudes. Workers found that they were more likely to receive support from co-workers when confronting racist clients, than when confronting racist co-workers or management. One worker summed it up thus,

it's a doubled-edged sword really. Other workers in my agency will back me in opposing racism in clients. But (they) don't want to discuss anti-racist policy for the agency. This is, I think, because it (racism) is easier to work with when it comes from the outside. Partly because it is so blatant and coming from people in a less powerful position.

Similarly, a number of workers felt that it was harder to confront co-workers around racism due to a lack of collegial and management support as well as a general depoliticized work environment. Lacking collegial support, workers found that any confrontation of management and larger systems tended to be difficult and intimidating. Indeed, workers identified the lack of collegial support as the strongest detractor in their attempts to practice anti-racism on the job.

The liberalism of the social work environment lends itself to individual rather than systemic solutions. Hence, it is not surprising that change efforts aimed at individual clients receive the support of co-workers. The professionalism of the social work environment acts similarly to deflect 
and rechannel demands that workers confront their own racism. Professionalized anti-racism is framed as a need for skill and knowledge development rather than oppositional practices, analyses and demands for cultural and socioeconomic change. Discourses such as "cultural competency", "negotiating intercultural conflicts", and "prejudice reduction" recast anti-racism as discrete and measurable pieces of knowledge that professionals can acquire in workshops, agency training sessions and special courses.

The professionalism of the work site also means that social workers tend to equate their interests and those of management and rather than to see managers and directors in class or political terms. Workers who identify with professionalism are reluctant to enter into oppositional relationships with management, preferring instead to work through the system for gradual change. Operating from outside of the liberal relations of professionalism and individualism, progressive social workers do not find a receptive audience amongst co-workers or management.

\section{Hiring}

Mohanty (1993) notes that the tokenism of affirmative action hiring turns people of colour into commodities that organizations hire to represent the minority position. The minority positions themselves are also commodities that the organizations promote as additional services or attractions. This add-on nature does nothing to disrupt the everyday ideological and unequal practices of the organizations. Instead it manages conflict and deflates demands for greater racial justice.

A community worker noted that affirmative action hiring has occurred within her agency. However, most people of colour have been hired on a part-time basis while permanent jobs continue to be held by white workers. This is partly a function of the neo-liberal job market in which funding 
for full-time jobs is increasingly rare. As a side effect of this tight job market, many people remain in jobs which they would prefer to leave if they could find employment elsewhere. This low staff turnover means that jobs are not available to be filled affirmatively. Workers holding the existing fulltime jobs tend to be white as, historically in Toronto, it is white people who have access to the education and professional training required by social service employers.

Another worker noted that hiring within her agency is based on affirmative action. This hiring policy has resulted in a situation where the majority of the administrative staff are women of colour, while professional staff remain largely white. Salaries and opportunities are lower in administrative positions, hence there is much faster staff turnover. This has meant that administrative positions have been available to be filled affirmatively. However, when administrative positions are filled affirmatively, the class divisions between administrative and professional staff are further exacerbated by race. As discussed in the chapter on gender, a number of examples exist in which affirmative action hiring strategies have resulted in racial splits between a predominantly white, professional staff and an administrative staff who are mainly women of colour.

The organizational change literature identifies this types of conflict as resulting from single policy strategies rather than comprehensive, multi-level, participatory, ongoing organizational change strategies (Karp and Sutton, 1993; Thomas, 1987; United Way of Greater Toronto, 1991). Others would argue that it is the liberal focus on end-state maldistribution of privilege and opportunity that recreates the existing hierarchies, inequalities and stimgas (Fraser, 1997). Organizational change plans generally employ static notions of cultural and racial differences which freeze identities and political possibilities while leaving underlying structures of socioeconomic, cultural and symbolic validation systems unacknowledged and unaddressed. Hence, they not only fail to meet the criteria 
of building lasting social justice, they also act as everyday, commonsense ideological social work practices.

A process takes place that Dorothy Smith calls the three tricks of ideological representation (in Hick, 1989: 24). First, organizational change plans or single policy strategies separate ideas from people's everyday activities and experience. This could involve, for example, separating the idea that the agency is fair and equitable from the workers' first hand observations that their agency is all-white. Secondly, various connections, which have little basis in people's everyday realities, are made between the aforementioned ideas and other ideas which may or may not be similar in nature. These connections are then represented as commonsense and natural. To continue with our example, affirmative action hiring policy is presented as the commonsense way to further develop an already fair and equitable agency. Here equality is connected to hiring practices. In reality, equality has very little to do with hiring and most people know this although they tolerate the inequities and oppression that are inherent in the being hired and not being hired processes of our society. Hiring practices are intensely political activities that organize our lives in numerable classed, raced and gendered ways. Hiring is really about who gets a job and an income and who does not. However, the inequities of hiring processes are remade as fair and commonsense within the language and processes of professionalism and management. Thus, within this example, we can see connections being made between ideas that have very little in common but are presented as natural and matter-of-fact.

The third ideological trick occurs when "(t)hese ideas are then attributed back to actual people" (Hick, 1989: 24). To continue with this example, ongoing racial inequities in the agency can be attributed to people of colour, their lack of skills or motivation, rather than the injustices inscribed in macro and micro cultural and socioeconomic structures. As Hick notes "ideology splits concepts 
from practices, thereby becoming a substitute for relations as experienced by the participants" (Hick, 1989: 24).

Some of the contradictions of liberal, multicultural organizational change are underscored in the segment below. The worker, part of a large multi-service agency involved in a United Way organizational change plan, noted that existing race hierarchies are modified by hiring processes, but not fundamentally altered. Instead, class hierarchies and the marginalization and stigmatization of community activists are recreated.

Community agencies seem to be getting much better at hiring people of colour who are the same race; ethnicity as the community. What they are not getting any better at is hiring from the community (emphasis in original). That is, hiring people, who have lots of life wisdom and skills and experience but maybe they are too political, and have years of conflicts in the community, and with the agencies, and probably lack formal education and credentials.

I think we're going to address one kind of problem, like the lack of people of colour in social work jobs, but recreate the marginalization of poor people, especially politically active poor people of colour.

A number of workers noted that affirmative action policies often focus on the hiring of racial/ethnic groups in the same proportions as they are represented in the community. However, as workers noted, this is not a simple process on any level. Access to higher education and professional training has meant that there are fewer people of colour who have attained the required credentials for social work jobs. Workers were very concerned around this point noting that "racism is not only in ourselves and our agencies, it is also in larger structures of post-secondary education, who has the money to go, who had the family motivation to go, and so on and so on".

\section{Multi-"ism" Strategies}

In part as a response to community, funder and worker demands for anti-racist organizational 
change, a number of agencies have developed what my informants called multi-"ism" strategies. These multi-"ism" strategies rotate mostly around notions of inclusion and representation, which as one clinical worker put it, involves management "inviting everyone to the table while giving no one any power". She continues,

it's easy for us to kid ourselves that inclusion is actually a radical maneuver when in fact it's no more than what traditionally has always been done to marginalize people.

A number of workers spoke of multi-"ism" Advisory Committees that are mandated to address agendas set by senior management. The workers noted that "these committees are not given any real decision making or policy making power", nor do they have much latitude for setting priorities or defining the issues that are to be addressed. Indeed, the committees seem to be quite tightly controlled from above and provide little opportunity for client or community needs to be aired or addressed. At one quasi-government agency, management selected and appointed all the "community representatives" on such a multi-"ism" committee. A member of the management team at the agency chaired the committee and assigned a staff person to take minutes. The chairperson provided a pre-set agenda to the committee for every meeting and was reluctant to take agenda items from the floor. The tone of the discussion at the meetings tended to be "very professionalized which makes it almost impossible for anyone other than the professionals to participate." My informant observed that the multi-"ism" committee provided the "illusion of community involvement" but actually represented "the same old thing" with agency management and its depoliticizing approach to issues.

Further, according to my informants, although these committees are defined as inclusive they tend to emphasize a certain framing of race and ethnicity issues at the expense of class and gender. This means that the class-based and gendered issues of most clients of colour are actually excluded 
as "most of the visible minorities, well, most of the people on our committee are very privileged people." Similarly, although women often sit on the committees, equal gender relations are rarely an issue, as one worker noted, "men clearly dominate in terms of who gets heard, whose ideas get taken forward and who influences decision making." One public servant blamed the sexism in this situation on the way that white women have "owned" the anti-sexism issue in her work place and have not made any substantial steps towards equality. Thus, she argued gender inequality has been recreated within the new multi-"ism" advisory committees.

Another worker noted that often the privileged person or people of colour who sit(s) on advisory committees "plays the role of protecting the organization from the challenges around the need for more profound change." She noted that working "within minority communities to cut through that dynamic is difficult,... it's not valued. It's certainly dangerous."

Like other components of the liberal paradigm, multicultural organizational change programmes, multi-"ism" committees are detached from socioeconomic injustices as well as projects that deconstruct the identities of the dominators and the subordinated. Moreover, multi-ism committees reproduce existing racial hierarchies by failing to connect strategies to analyses of how oppressions came to be. The failure to place race relations in the context of imperialism, colonialism and systemic domination is a form of neocolonial practice. This practice erases both the causes and the real impact of imperialism, colonialism and domination, thereby setting the stage for their continued invisible but omnipresent operation within the racialized structures of the social service community.

Mohanty refers to the way that select individuals are hired or promoted within universities in order for these institutions to attract funding, students and community legitimacy as the 
"commodification and personalization of race" (1993: 57). Members of marginalized populations who sit on most multi-"ism" committees are similarly commodified. The agencies use these individuals as commodities, or objects that can be traded upon in order to retain and expand agency funding. To use strictly Marxist terms, the exchange-value of these individuals lies in the credibility they lend to agencies seeking continued United Way and metropolitan government funding.

In Toronto, the metropolitan level of government as well the United Way require the participation of funded agencies in anti-racist organizational change programmes (United Way of Greater Toronto, 1991). ${ }^{5}$ Agencies must document the changes they have made and intend to make around issues of inclusiveness, access and representation of marginalized populations. For many agencies, the existence of multi-"ism" advisory committees and the presence of people of colour on these committees is central to retaining existing funding leveis, and essential for gaining funding for new programmes. Thus, representatives on multi-"ism" committees become objects whose value to the agency is located in the way that their presence within the agency can be exchanged for a positive evaluation from funders, and hence ongoing agency funding.

Differentiating between multi-"ism" Anti-Racism committees and the multi-"ism" committees discussed above, a number of my informants spoke enthusiastically of the transformative possibilities of multi-"ism" Anti-Racism committees. These committees differ significantly from the multi-"ism" strategies described above. These differences and the politic.ll possibilities they open up will be discussed in greater detail later in this chapter.

5 A discussion of the liberalism of most anti-racist organizational change programmes is included in several sections of this thesis. See for example, Chapter II or Chapter VIII and various sections of this chapter. 


\section{Access and Language}

Access is another inclusion strategy which can be seen to contain or depoliticize struggles around race and ethnicity. Many human services have been found to be inaccessible to any number of marginalized populations. While access is a highly political concept, the liberal framing of access enervates its social justice capacities. Within a pluralist, liberal framing of multicultural work, accessibility has come to be understood, in significant part, as an issue of language. The addition of some language services is the kind of concrete, quantifiable, apolitical action that is compatible with managerial responses to social inequality. Many agencies have developed policies around the provision of services in languages other than English and point to these policies as evidence of a commitment to anti-racism and multiculturalism.

Workers complained that agencies are not obliged to provide consistent multi-programme language services in order to promote themselves as having language access. There are no community or professional standards to which they must adhere and no accountability mechanisms. Workers told stories of agencies listing themselves as providing services in various languages when in fact, at one time, they had a worker or a volunteer who spoke a language other than English. This individual was unlikely to have skills in more than one area of the agency and may no longer be associated with the agency. Other agencies claimed to provide language access when the most they have done is translate a few brochures or pamphlets. A worker added this complication to the translating of such documents:

No one ever thinks of illiteracy in other language groups. Most of our information is translated by professionals. And it's just not very well translated into accessible language for the actual people we are serving, who are not professionals, and often not well educated.

Another worker noted that access is usually thought to exist if an agency has an occasional 
recreational programme run by a worker who speaks more than one language. She notes that it is not enough to have one or two workers who speak a language other than English. An agency must take a multi-level approach to language and accessibility. She used the example of an elderly client who comes in and is depressed because of family problems around money, guardianship orders and social isolation. A number of specialized workers and services are required in this scenario to meet the specific needs of the client including a counsellor, a lawyer, a community worker and various social programmes and projects. The agency must provide or have access to a wide range of workers who speak the client's language. Otherwise the client will not receive service in certain areas or she will receive inferior service. Thus the non-English speaking client is constructed as a person whom the agency thinks of as "okay for them to fall through the cracks."

One worker told a story of how language can act as a proxy for race and class. She noted that recent cuts to her services were framed as cuts to French language services. While not supporting cuts to services for French speaking people of any race, almost all the people who use her French language programme are recent immigrants of colour. Thus, the cuts are denying service to a very poor and racially marginalized population.

A worker at a telephone crisis line observed that although the service was meant to be accessible to all citizens, there were very few people of colour or people for whom English is a second language who called. Thus, the service was de facto a service for English speaking whites. She said that although some of her colleagues shared her concerns, they feared that efforts to make the service more accessible to other language and racial groups would draw too much attention to the service. In the present neo-liberal funding climate, workers fear that drawing attention to the agency may result in major funding cuts from the provincial government, and the loss of the service 
for everyone. The threat of cuts, not the actual cuts themselves, thus deters anti-racist work and maintains the status quo. Further, it causes workers to curtail their own political inclinations and activities so that they become implicated in maintaining a predominantly white social service.

Agencies have picked up on language in a number of ways, most of them are fairly narrow and inadequate. Language, obviously, is only one aspect of accessibility to services. Defined in a more comprehensive and politicized way, my informants were optimistic that access could be used in radical as well as status quo kinds of ways. Real access occurs, as one worker noted,

when communities feel that they truly have a space. They truly feel that they have some ownership over the centre,... it is not just a matter that we have that language here. But it is that sense of being part of the centre.

This involves

mak(ing) organizations change to an extent that you would allow that to happen. Because it takes some courage, it takes some risk to say, yeah, I am willing to share this space, and, at least at a services level, share decision making with my consumers.

In this worker's opinion real access rarely occurs as most clients

still don't have access to decision making. Because, it is ultimately a (social service community) controlled by staff - the senior management who also happen to be white males -- not even by the Boards which can be somewhat more representative of the communities.

She noted that "if power sharing is not there for consumers" it is even more difficult for minority clients who have obvious barriers of language and culture.

While workers were adamant that access does not equal language, service provision in languages other than English is seen to be a necessary but not sufficient element of making a service fully available to all citizens. It was agreed that an agency must provide services in more than English or "it is a service just for whites". Language was seen to be progressive facet of service provision when it is an agency or a "management decision around why these clients are seen as valued, why is 
their language valued and why is it not okay for them to fall through the cracks." However, most service provision in languages other than English were unlikely to be part of a political framing such as that listed above.

Some workers targeted their access strategies at the development of new services for marginalized racial and ethnic groups. Although spanning a number of approaches to social problems, these agencies are generically referred to as ethno-specific services. One of my informants had been heavily involved with a the development of a womanist, ethno-specific agency that attempted to reflect "the diversity of sexual orientation, religion, class, ability and region" within one of Toronto's racialized communities. The mandate of this fledgling organization stated that it is "working against systemic discrimination and violence and striving to understand how this is translated into diverse individual experiences". It stated further that it "recognize(d) that our individual experiences are linked to broader social, political and economic realities".

The following discussion reveals some of the tensions around this agency's formulation and application of race. The agency operates as a non-hierarchical collective and has developed a mandate that makes use of a social relations model of oppressions. In its policy documents, it uses terms like class, race and gender in an explicitly political and relational way. However when interacting with its target population, agency members used the language and practices of the community.

DB: The collective that you work with, would it describe itself as feminist-anti-racist or antiracist-feminist?

Worker Q: We would call ourselves feminist, but I don't know if we would call ourselves a feminist collective just because of the way of that label, and the way it has been identified with white-feminism. We'd call ourselves woman-centred.

I don't think that we say anti-racist either, but we definitely lean towards anti-racism in our 
communities, but that's not the language that is used in our communities, you know?

Worker R: Yeah, that kind of academic language isn't really used. When you are working in the community you do anti-racism, but you don't really label it as such.

Worker Q: I think people could deal with it if we said anti-racist, but it would be difficult because it is not like they use those words,...

While this story does not go far enough to permit an assessment of how a social relations analysis and mandate were put into practice, the interaction outlined above highlights the difficulty this agency is having around putting theory into practice. Workers who use the language of the community, and thus the practices of the community often find that their work has been, depoliticized, or politicized in a neoliberal way. While there are ways to work progressively using the language and practices of a community, this form of intervention is very difficult. It must be dialogic in the Frierian sense of a mutual communication process between people that must illuminate oppression in order to change it (Friere, 1974). That is, one cannot uncritically incorporate the language and practices of the community into one's work or one may be inadvertently reconstructing oppressive relations. Instead, the use of the language and practices of a community must involve an exchange of ideas in which an end goal of emancipatory politics is explicit. Any form of dialogism is a difficult balancing act and one that requires an understanding of how to decode ideology in everyday interactions and practices, as well as how to foster oppositional ways of practice that anticipate new, egalitarian relations. The data here do not permit further exploration of these themes. However, progressive social workers need to constantly ask themselves how their practice is critical. One way to do this is to differentiate it from mainstream practice.

When asked why women would seek their service, as opposed to a mainstream service, one worker replied: 
They are looking for service that is really sensitive to what they've been through. They would get the understanding through talking to us that we have been through similar experiences. And, the resources we are aware of might be a little different and more sensitive than what a mainstream agency could do. Also, the ways we have of getting things done would be more familiar and comforting to them.

While a fuller discussion with the worker might highlight the way that this agency provides services in an emancipatory way, there is nothing in this passage that marks this organization or its services as progressive. Sensitivity may be a code word for a kind of practice that embodies antiracist practices specific to this community. However, it is not possible to determine this from the passage. Instead, the passage appears to be an example of the slippage between critical theory and critical practice which permits the entry of liberal ideology and practice. Hence, one ends up with a social relations analysis and an empathetic but liberal social service agency. This example underscores the pervasiveness of liberal ideology and the way that progressive workers import it into progressive agencies in everyday kinds of ways.

\section{Other Pluralist Policies}

Several workers spoke of various race policies that had simultaneously made things better and worse. There were two main problems identified with most race policy. The first problem arose from the way that most race policy was not explicitly anti-racist. Instead, race policy is often called multicultural, ethno-cultural, cultural competence or ethno-racial, aboriginal access policy. A community worker noted that the word anti-racism is almost never included, and that this "reflects the comfort level and interest and commitment to actually doing something about this." These policies formally state goals around access to services, and commitment to equal treatment and the removal of sources of discrimination or prejudicial treatment. One worker noted that despite the 
strong sounding language, "these policies do not have the power or the intent to address systemic barriers". Instead they seem to reflect what Mohanty calls the "proliferation of discourses of pluralism" (1993: 57). Differences are stripped of their political and contested natures and remade as benign and static attributes which can be accommodated within existing managerial and social service delivery systems.

One worker used her agency's General Harassment Policy as an example of a non-systemic but very principled sounding policy. She noted that harassment policies "outline the kinds of behaviors that are inappropriate in the workplace, but mostly extreme kinds of behaviors like name calling or physical harassment." These kinds of policies are complainant-driven and largely after-thefact kinds of responses. They offer no particular preventive measures and do not alter micro or macro social relations in any discernible way.

Another worker added that the adjudication of harassment policies in many organizations is somewhat less than credible. The worker noted that in a number of agencies the Executive Directors, who are all white men, adjudicate the harassment complaints. This adjudication process is seen as quite intimidating by most of the workers, volunteers and clients. Policies, such as the Harassment Grievance Procedures mentioned above, act as ideological processes which recreate relations of domination and intimidation as manageable, interpersonal conflicts. The Harassment Grievance processes abstracts from people's everyday experiences of racial injustice and remakes them as individual complaints to which management can respond in standardized and individualized ways.

The second major problem associated with race policy was the way it is atomatized, rather than integrated. Workers complained that policies addressing race are not well coordinated with each other and are very rarely integrated with other kinds of equality policies. These unintegrated policies 
construct oppressive relations as very separate kinds of problems to which management will respond in very specific kinds of ways.

The now defunct provincial Employment Equity Policy (EEP) was seen as somewhat of an exception to this norm. Introduced in 1993 by the New Democratic government, the EEP included a multi-facet process for reviewing the recruitment, retention, promotion and experience of four target populations -- women, First Nations people, people with disabilities and people of colour. Unfortunately, the Employment Equity Policy was revoked following the election of a conservative government in June of 1995 . For the most part EE plans were never implemented. Some workers felt that in the hands of progressives, this policy had the potential for major restructuring and equality building within agencies. Other workers felt that the policy did not go far enough. Positive uses of the EE will be discussed further in the next section.

Some workers felt that the EEP simply recreated existing hierarchies and cleavages within and between the four target groups. For example, one worker of colour was concerned by the way that the EE people of colour caucus at her work place began to be critical of the advances made by people with disabilities. She commented,

there needs to be some work looking at the fact that there are people of colour among people with disabilities, that there needs to be specific programmes to deal with the particular barriers and oppressions facing people with disabilities. And we need to try and have a conversation in which we are not competing with each other for what little resources (our agency) makes available.

She argued further that white women, the most privileged of the four target groups "were the major beneficiaries" of EE, while the other target groups had difficulty throughout the EE process.

As noted earlier in this section, a growing body of writing exists that documents the marginalization and exclusion of women of colour within struggles for women's equality. Moreover, 
women's committees have generally constructed the struggle for gender equality in ways that promote the interests of white women over those of women of colour. The EE process repeated the practice of constructing the interests of target groups as separate. This separateness means that intergroup competition and lack of solidarity, noted by my informant, was almost inevitable. Similarly, white women, as the largest and possibly most powerful, target group may have benefitted more quickly and directly than other populations.

Women's presence within the social services work force differs from that of other target groups. They have been present as low pay, low status frontline workers since the beginning of social work as an enterprise. The presence of large numbers of women in the social work field has nothing to do with affirmative action. As noted in the previous chapter, men, were for a time, hired affirmatively to counteract $\mathrm{t}$.uge numbers and low status accorded to a predominantly female field. Affirmative action strategies for women now focus on their promotion to, and retention in, positions of authority. Equal representation of men and women in management and director positions would require the promotion of large numbers of women. In order for women to fill these positions in the same proportion that they are present in the entire field of social work, some where around $80 \%$ of management would have to be female. Although white women were the most likely beneficiaries of Employment Equity strategies, equitable gender proportions have most definitely not been achieved in the upper echelons of social work management and academia. In essence, I am arguing that not withstanding the gains made by some white women within EE plans, gender parity is a long way off.

As this example underscores, most EE plans leave target populations scrambling and bickering over apparently scarce resources within the confines of the existing race, class and gender order and 
the ways that these conflicts are played out in social services. The way that caregiving and service provision is gender coded and socially organized is not questioned. Instead, a pluralistic and professionalized notion of organizational change is introduced to existing bureaucratically structured human services. Existing hierarchies and injustices receive superficial attention and reforms through a process of separating the goals and processes of EE from the lived conditions of social service workers.

Interestingly, while most of my informants were quite aware of larger policy debates in society, very few of them had more than a very superficial sense of what sorts of agency policies existed around race, class or gender. Somehow, agency policies were quite peripheral to how battles around equality actually occurred at the front lines of agencies. Instead workers felt that they were encouraged to focus on client-change efforts, ignoring the need for larger structural changes.

The workers in the larger, government and quasi-governmental agencies, in particular, had no sense of what the policies were, or how to access them. One worker commented that she thinks it is not unintentional that workers know little about agency anti-discrimination types of policies. Although she is not sure that she would trust or make use of such policies should she be able to access them, she is quite sure that management does not want these issues of equality to frame everyday work and interventions. As she put it, "the whole notion of those kinds of things being infused and policy being encouraged is just heavily erased."

Workers in the smaller, social action agencies tended, in contrast, to be very aware of their agencies policies and often made use of them in various ways. I will expand on this later in this chapter. 
Neoliberalism and Race: White Backlash

The repeal of Employment Equity by the Ontario provincial government in June of 1995 was just one of a number of measures aimed at ensuring that white people, and white men in particular, would not lose their positions of privilege in society. Although this phenomenon is mostly about white men, workers called this phenomenon "white backlash" not white, male backlash. Its degendered character conceals who benefits from this backlash. White women have a contradictory relationship to white backlash. Some may actually see it as in their own interests. They may benefit from the reinforcement of white privilege although this privilege is often gendered and receipt of benefit is not equal. In addition, the gender interests of most white women are antagonistic to this political force.

White backlash pivots on the notion that people of colour and women have made it impossible for white men to get ahead in the world. As evidence of the lack of evidence to support the claim of white, male marginalization, a worker told a story around several senior positions she has been tracking within the human service community. The last eight job openings have all gone to white males. She notes,

There is such a serious backlash that white men are rallying to protect their privilege even though they are not losing it one bit. Mostly what is being talked about is this assault on white people and there is no recognition of the generations of inequity in the opposite way.

Adding a gender dimension to the discussion, a community clinical worker compared white backlash to the increase in male violence against women:

men and boys are acting out now towards women the way that white Canadians are acting out towards people of colour,..., I think it is white men's fear that they're losing control, that they're no longer in charge. I think it's the same fear that white people have. Who has the power and control. 
Although most workers felt that white backlash rotated on the notion of dominating all those who are not white and male, a countertendency in the data was found in the stories of a policy worker. This worker argued that white backlash is aimed only at people of colour. He was very adamant that opposition to $\mathrm{EE}$ was aimed at people of colour not at women or people with disabilities. He did not mention the fourth EE target group, First Nations people in his analysis. Expanding on his position, the worker reported that a number of his white male colleagues informed him that they voted for the Conservative Party in the last provincial election precisely because of its promise to cancel Employment Equity. These white men, who work in an almost totally male job category, told him that they "wanted to keep their jobs white." He observed further that they did not say that they wanted to keep women, or people with disabilities out of their jobs, although these two groups are not part of the work force in their area of work.

This experience definitely points to white men actively working to preserve their privilege. However, their failure to mention other EE target groups does not indicate their support for these populations. It points to the way that these populations do not present the same kind of threat to their privilege as do people of colour, and presumably men of colour. Despite years in the work force, women have obviously been kept out of this white, male job category and are clearly not seen as a threat. They, like people with disabilities and First Nations people, are irrelevant to the conflict. It is the way that other men could take these jobs that is threatening. White supremacy overlaps with male dominance in the paid labour force to present a scenario in which the interests of men of colour are seen as standing in opposition to those of white men. A large part of this conflict lies in the way that liberal, multicultural strategies construct interests, social change and the distribution of resources. This will be discussed further throughout this section. 
A worker in a predominantly male work site reported that the most difficult clients for him to work with are white men. He claimed that they do not want to see any relation of oppression or inequality in society, and prefer to see their own problems in individualized terms as if they have no connection to other types of suffering or injustice. The worker felt that he has minimal success in alleviating the discomfort of these clients although most of them seem to successfully negotiate services and return to "normal, social functioning". He pointed to this relative success as evidence of the way that the "system still works for white men, even if they don't want to believe it".

A worker in a government-run service noted that the white men he works with often blame people of colour for taking away jobs from them. He tells his clients that he "won't listen to that kind of bull shit. And you and me need to have a long talk about the government and capitalism so that you can see who is really jerking you around." This worker reports that with minimal critical consciousness raising, his white clients of both genders demonstrate a grasp of how class works in their lives. They are less able to incorporate progressive notions of race and of gender. Most of his clients are struggling for admittance or readmittance to the middle class and to middle-class culture. These goals do not seem to be threatened by an understanding of class injustice: however they seem to be incompatible with more than "a superficial and very liberal way of looking at sexism and racism."

For most white men, their narrowly constructed interests would not be met by a social system in which they lose their privileged cultural and socioeconomic position. Liberal strategies aimed at increasing the value and opportunities accorded to subordinate groups necessarily means that these scarce resources are not as availabie to dominant groups. These strategies set groups up in opposition to each other competing over limited resources and recreating hierarchies and inequalities. 
Deconstructing existing male/female binary opposite identities, and the socioeconomic system that coordinates the power inscribed in these identities formulates interests in a way that incorporates social justice for all (Fraser, 1997). However, at this time deconstruction and socialism are not the way that most white men understand or act upon their interests, hence their resistance to anti-sexist and anti-racist strategies.

Demonstrating some of the ways that white supremacy, the consort of white backlash, works in other social agencies, a number of workers commented that their agencies believe that they do not have a racism problem because they have an all white clientele and staff. They deny, however, that white people are the target population of their agency, claiming instead to be accessible and available to all. Some agencies will go so far as to claim that they want to serve people of colour and new Canadians although these people just do not want to take advantage of their services.

While less prevalent, this equation can work in the opposite way as well, where agencies claim to be free of racial strife because they have a number of workers and clients of colour. This is similar to the construction of gender equality where it was possible for either women's presence or absence in an agency to indicate the lack of sexism. Again, like sexism, racism is seen to be a problem which is imported into an otherwise non-conflictual environment by the oppressed group. The dominant group, either white people or men, are not the bearers of, or participants in oppressive relations.

A similar but slightly different phenomenon was seen to exist in various agencies that provided some level of service to people of colour or recent immigrants. Although the majority of clients continue to be white people, the agency comes to be perceived by most clients and by the larger social service community to be a service for minorities. The small number of clients of colour are perceived as being the majority and often as "taking over". Once an agency has such a label it is often used even 
more extensively by those minorities as people come from farther and farther away in order to receive services in their language and where they are more comfortable. One worker observed that this phenomenon seems to relieve other agencies of providing accessible services to minority groups.

\section{Repoliticizing Race}

In this section I will look at six aspects of the struggle around race - progressive social worker's formulation of race, multi-"ism" anti-racism, just standards, "racism needs its moment", and agency structures and mechanisms that build anti-racism. None of these practices embody formulations or practices that are one hundred per cent liberatory. Instead, they reflect the Gramscian notion of contradictory wholes. While they are largely liberatory, they also reflect liberal ideological practices and formulations. In balance, they provide insights into how liberatory practice and social relations might be nurtured and how ideology might be decoded and lose some of its power to legitimate inequality and injustice.

Worker's Formulations of Race: Static, Relational, Racisms, as well as Colonialism and Globalization

Workers varied in their formulations of race. Some employed a static, biological definition, others a more historical, social relations model and others an anti-pluralist notion of racisms. Reflecting a certain stream of thought in the race debate, a number of progressive social workers employed discourses that draw on static notions of biological determinism. A few informants noted, for example, that "your race can't change although your class can". There are several weaknesses in this conceptualization. At this point in human history there are no biological differences which can be said to be clearly attributable to any specific "race" of people. Instead, observable and 
unobservable "differences" are accorded varying value in complex and constantly changing structures of meaning and power. As Hale notes, "ethnicity is an ongoing construction, not a projection of the past" (Hale, 1995: 434). McCameron and Crichlow add the following observation:

racial difference is the product of human interests, needs, desires, strategies, capacities, forms of organization and forms of mobilization. And that these dynamic variables which articulate themselves in the form of grounded social constructs such as identity, inequality, and so forth, are subject to change, contradiction, variability, and revision within historically specific and determinate contexts. We maintain that "race" is a social, historical and variable category (McCarthy and Crichlow, 1993: xvi).

Most progressive social workers employed a formulation of race that embodies a sense of it

as a social relationship of power.

Part of the issue around race is the way that very superficial differences get worked up and understood to be very socially meaningful, which is not the same as being respectful of people's cultural backgrounds or histories or opposing their oppression. Race is treated like this absolute kind of category, but when you take the politics out of it, the power stuff, what does it really mean?

Workers also talked about race as if it were historically and socially constructed, and as if it had both longitudinal patterns and immediate impact that can change suddenly and abruptly from past constructions. ${ }^{6}$ Some of the notions underpinning Bannerji's (1993: xviii) ${ }^{7}$ observation that relations of ruling require historicizing as colonialism and imperialism, are captured in the quote below:

The First Nations people I work with mostly live on the streets in the west end of downtown. Many of them grew up in the city and have a kind of back and forth relationship with some

- McCameron and Crichlow note that racism involves both long-term patterns as well as ongoing reconstructions. They refer to Stuart Hall's notion of "continuities" of racialization, or "patterns of racial exclusion" (in McCameron and Crichlow, 1993: xv), as well as the ever-shifting contemporary constructions and practices of race and identity.

7 As noted earlier, Bannerji (1993) is drawing on the work of Chandra Mohanty (1991a, 1991b) and Dorothy E. Smith $(1987,1990)$ to develop a understanding of racism that is materialist, feminist and directed to the restructuring of political economic and cultural systems. 
of the Elders we are in touch with. Especially some of the people in their forties, because of their experience with residential schools, don't want much to do with the elders and the kind of First Nations culture that they represent.

We work with people where they are at, and try to see the world from their point of view, without closing our eyes to the way our society treats Native people and the way our clients live this everyday whether they talk to us about it or not.

Although the dominant discourse in social work is that of a singular racism which all people and groups of people experience in the same way, workers told stories which contained a sense that racism might be better understood as racisms. ${ }^{8}$ That is, different racial and ethnic groups are thought of by dominant groups, as well as by many subordinate groups, to pose certain specific kinds of threats to society. These racialized patterns are very present within social service agencies. The specificity of these racisms complicate one's understanding of racism, how it/they operate(s) and how to build oppositional practice. It is not enough to have a universal notion of racism. One also needs a sense of the current constructions of various racialized populations, how they are oppressed within social services and how to deconstruct the various levels of ideology that work to conceal what is really going on. The stories below capture some of the ways that racism takes different form in the everyday world.

One worker reported that the agency she works for is generally perceived to be serving Asians although its target population is the entire community. Often she gets phone calls complaining about the agency's alleged discrimination in favor of Asians. She reported that she received calls from white people, from non-Asian people of colour, and from new Canadians who perceived Asians to be a group that is taking over the agency and society as a whole. Other people of colour were also the

8 This conceptualization draws on ideas raised by Roxana $\mathrm{Ng}$ during a consultation meeting (1997). 
targets of various complaints; however the way that they are complained about differs significantly from the construction of Asian people as "taking over". While the agency workers resist reacting to these complaints, they feel pressure to prove that Asian people are not controlling the agency and not receiving all the best services.

Another worker told a story about the power of racialization within specific marginalized cultures. A young, white client told his worker that he liked "Blacks, but not Pakistanis". Within the client's youth culture Black men were perceived to be "cool", "macho" and "in control". In essence, within the client's specific culture, Black men were thought of as more powerful and dominant. His disparagement of Pakistani people was linked to explicit racial hierarchies and the power associated with various racial stereotypes within youth culture.

In a similar vein, a clinical worker spoke about "sweeping, positive sounding racist statements that still deny services to clients". In particular she noted that in her agency, Italian clients are thought to have supportive families who will ultimately step in and "take care of" family members with problems. As a result of this racialized construction of Italian clients, follow-up care was not offered to clients or planned for them although it was standard for other clients.

Another worker provided a clear example of the operation of racist systems and ideology at the level of everyday practice. Other workers in my informant's agency denied that racism was a factor in problems facing Black or Indo-Asian clients. These workers did believe that poverty was a problem for Blacks and Indo-Asian clients although they denied any connection could exist between racism and poverty. While prepared to provide Black and Indo-Asian clients with referrals to poverty services, these workers felt that these referrals were "an act of futility". Black and Indo-Asian clients were expected to be unresponsive and unmotivated. Hence, although follow-up services may have 
been planned and offered to Black and Indo-Asian clients, the clients were not expected to follow through with these plans or benefit from them. Lowered expectations for, and of, certain racialized groups was translated into lower levels of energy and creativity that workers are prepared to put into interventions and plans. Thus, while not directly denied services, clients were marginalized within them, and set up for failure. Although workers would deny it, this marginalization is a direct result of racist expectations of and practices around Black and Indo-Asian clients.

The same worker noted that the boys she works with were more likely to make racist comments in therapy groups than are girls. Further, males of colour made the greatest number of racist comments and most frequently although youth from different racial-ethnic groups have very different ideas about who is their greatest enemy. When the worker told this story during a focus group she was contradicted by another worker who was adamant that oppressed people understand oppressions better than any one else, hence she must be mistaken. The second worker felt that there is only one type of racism and it emanates from white people. As was typical of direct conflicts within my focus groups, the first worker shrugged, gave up talking, and the discussion moved on to other topics.

Later in the same focus group, a research worker built on some of the ideas the clinician was pursuing in the above excerpts. She pointed out that culture is often used to justify denying services to certain groups. For example, she told a story about government officials justifying the lack of nursing homes on Reserves as based on the fact that "Aboriginal people prefer to take care of their own elderly". A third worker noted that a similar argument has been made around services for the disabled in Aboriginal communities. The phrase she and her First Nations clients hear when advocating for services for the disabled is "it is simply not in their culture to seek help outside the 
family". A private practice worker added that lack of funding for ethno-specific services for assaulted women has been legitimized on distinctly similar grounds. Various ethnic groups are said to prefer to deal with male violence within the family, or without calling in outsiders. Thus, services and funding for services was argued to be neither appropriate nor necessary.

Workers were also very aware of the role that Canada and other industrialized countries have played in colonialism, neocolonialism and imperialism. This lent my informants a greater capacity to historicize and politicize the day-to-day experience of recent immigrants, clients of colour and Aboriginal people. For example, one worker noted that her agency does not have a single worker who is Aboriginal although the agency works with a significant number of First Nations people. She noted that this is "so terrible in this day and age" but so typical of agencies that require professional credentials, rather than recognizing the validity of forms of knowledge such as experience as indicators of potential for good social work practice.

Another worker commented on the way that many of the immigrant families from rural North African backgrounds with whom she works are pleased with the concrete services she can access for them. However, they simultaneously feel a sense of loss for the way that these same types of supports were provided for by extended family and friends, and the feelings of reciprocity and community that this engendered. Some of these clients have observed to her that family-based services are being displaced and destroyed in the armed conflicts in their homeland. The worker noted that the wars and changes in service provision are all part of the legacy of colonialism and the impacts of "third world debt crises, restructuring and the globalization of capitalism."

In sum, in this section I have reviewed the ways that race is formulated in the stories of progressive social workers. Progressive social worker's formulations of race were more sophisticated 
and relational than were their formulations of gender or of class. As noted earlier, the anti-racism discourse is more prevalent and urgent in the social services environment than the class or the gender discourse. The race discourse throughout Toronto is quite fluid and political. As workers noted, it has not been as restrained, bureaucratized and coopted as have class and gender. Progressive social workers were also aware of how different their anti-racist practices were from those of mainstream of social work. As one worker noted,

The last time I was in this room, I was thinking of all of us and how we have this little language all our own. And we're all kind of snide about this anti-racist thing (GROUP LAUGHS) even though the things we want to do bears little resemblance to what most of social work is doing.

The discussions of progressive social workers around race demonstrated the ongoing conflictual and political nature of this discourse. With class and with gender, progressive workers mobilized static and liberal notions of these social relations in their talk. However, when they made use of radical social work intervention techniques such as solidarity-based social work, or critical consciousness raising, progressive social workers mobilized class and gender in more transformative ways. With race, most progressive workers seemed able to mobilize race in transformative ways in both their talk as well as within radical practice techniques. Subsequent sections of this chapter discuss these radical practice techniques and the concomitant transformative constructions of race more thoroughly.

\section{Multi-"ism" Anti-Racist Work}

A number of workers told stories about anti-racist work which placed a priority on addressing issues of systemic, structural and interpersonal racism, while simultaneously addressing other axes of subordination. The most prevalent form for this multi-"ism" anti-racist work was broad-based 
coalitions or committees. Workers noted that generally these committees have little real decision making power but "a great deal of influence". Building on lessons learned within women's and class struggles, these coalitions/committees were structured to facilitate participation from people identified with oppressions. Some of these inclusive structures included affirmative action mechanisms such as affirmative action speaker's lists, rotation of chairing and minute taking, as well as check-in and evaluation rounds aimed at ensuring that everyone had an opportunity to talk and to learn public speaking skills.

Some pieces of multi-"ism" anti-racist work took as their mandate "all issues included in the Human Rights Code". The workers noted that tying their work to larger pieces of legislation provided them with added credibility at their agencies, as well as an external constraint to which they could make the agency accountable. Other workers used the Landlord Tenant Act, Employment Equity or other pieces of federal or provincial legislation as standards to which their agencies should adhere or exceed. Other workers commented that it may not be wise to tie agency change strategies to the Human Rights Code, as it may face the same repeal as have other pieces of progressive social policy.

One community worker spoke of the multi-"ism" anti-racism committee in her agency. The committee was mandated to respond to issues beyond the agency, within agency processes, as well as between staff members, between staff and clients and between clients. This committee was initiated by an influential person in the agency, and although it has no direct policy making capacity, it has managed to make significant gains. Most recently this anti-racism committee won same-sex spousal benefits for staff. Despite what many would see as enviable gains, progressive social workers in this agency displayed frustration with the committee and felt that it needed an even broader 
mandate, client participation in the committee, and direct policy and priority setting power.

One of the weaknesses of the committee was its lack of attention to sexism. Echoing the racism is in and gender is out trend noted earlier, sexism was the least likely issue for the multi-"ism" anti-racism committee to address. Committee members noted that "gender has not be adequately addressed in our agency" and argued that it was an issue that fell within their mandate. Earlier discussions pointed to racist practices within the anti-sexist struggle. This example points out the way that anti-racist struggles can operate in a gender-blind way that makes it difficult to ally with struggles against sexism. Although committed to multi-injustice coalition work, anti-sexist themes are erased or marginalized within this committee. The work of this committee displays the ways that consciousness, as well as practice, is ideological and contradictory. Both consciousness and practice contain pieces that are ideological and pieces that point the way to more progressive ways of doing and thinking about social life. The committee energetically pursued both race and same-sex spousal issues, an example of progressive ways of uniting two very different sorts of issues. Gender, however, was not addressed by the committee although workers believes that it fell within their mandate. Thus, within the work of this multi-"ism" anti-racist committee progressive and regressive ideological practices and ways of thinking about issues form a contradictory whole. As noted in other examples, race is often juxtaposed to gender. The two are presented as being unable to inhabit the same politic space. The construction of this apparent incompatibility and its associated tensions will be discussed in greater detail in Chapter Ten, The Dyads.

Another worker spoke of a core committee she has set up to recommend and oversee the implementation of anti-racist organizational change within her agency. This anti-racist committee had a mandate to deal with issues of race, gender, disability, sexual orientation and class. She has 
recruited members from management, as well as "the frontlines and administrative staff...to ensure that, in terms of class, there's representation and the power to do something." She also recruited white people and people of colour, as well as equal proportions of men and women. She noted that we're not doing so hot on making sure that people with disabilities are there. But the bottom line is it's a fairly diverse group. And it's a group that has had to hash out the dynamics of the group around its decision making, as well as how to implement change.

She hoped that processes that have been set up to address their mandate issues will be fluid enough to apply to future issues and anti-oppression challenges, although she noted that on-going vigilance and changes in the processes are always necessary. For example, it became apparent that despite a strategy of rotating the minute taking each meeting, it was only women who were volunteering to take on this task, and the subsequent "reproductive labour" of writing up and sending around minutes. The issue was addressed at length within the committee. As the worker commented, "it meant that they had to deal with gender issues up front in the context of doing anti-racism."

Although this example of multi-"ism" anti-racist work sounds promising the worker was adamant that

it sounds great but the reality is that it's one hell of a nasty, messy process. Management and unions used it as a lightening rod for unfinished business between management and the unions. Conflicts between the genders get played out again and again, as in the minute taking. White managers and white union stewards, mostly all men, acted in solidarity and managed to stall for a long, long time anti-racist staff education. Each for their own particular reasons.

It's a mess, it's nasty. There is no easy way to do this. But if there is enough support at the top, and we have an exceptional senior manager supporting this -- she makes very strong statements at staff meetings supporting this. And, there's also an equal amount of work being done at the bottom of the organization among those of us who have the most at stake in something actually changing - with that combination I think it could actually eventually see multi-level and hopefully sustainable, anti-racist, multi-"ism" change. 
A further difficulty encountered with the building of multi-"ism" anti-racist committees was a theme of "no one wants to be in the power position, everyone wants to be part of the oppressed". One worker observed, "people resist owning the power that they have and constantly want to be part of the subordinated group." One worker told a story about a white female co-worker who said, "I don't like this term white privilege because as a woman, I don't have any." My informant noted that

to look at her lack of power as a woman, but her real power as a white person was difficult for her to do, to separate. I think unless she's able to do that, her ability to ally with people of colour is seriously limited.

Further, the worker felt that the woman "just didn't like inclusion" and was attacking it in indirect ways although "she's struggling" and continues to be a strong supporter of the multi-"ism" anti-racist committee in her work place.

A crisis worker argued that a tactic for addressing this "everyone wants to be oppressed theme "is to "shatter race, class and gender categories,... to see them more as the how of it not so much as the who and the what". Using this tactic, workers can begin to map out how oppressions work in their everyday worlds, rather than identifying who is oppressing who and all the in-fighting and divisiveness this can cause. This tactic dovetails with Fraser's (1997) notion of deconstructing everyone's identities in order to restructure the power inherent in the current cultural order. It also shares similarities with Smith's (1987) institutional ethnographic method which urges the development of knowledge for those who are outside of the relations of ruling, rather than knowledge about them. Smith argues that understanding how injustice operates at the everyday level must start from people's everyday lived experiences and draw out the day-to-day operation of larger social relations within commonplace spheres. 
A number of workers told stories about anti-racist work that simultaneously politicized other social justice issues. One worker spoke of her feminist agency's struggle to become self-conscious and critical about race issues. This struggle resulted in the entire agency concomitantly becoming much stricter in terms of practices and standards around class issues, issues of disability and issues of sexual orientation. While the Board and staff had for some time discussed the importance of integrating class, disability and sexual orientation into their analysis and work, the impetus of antiracist programming provided the "kick in the butt" needed to review structures, practices and philosophies around power and multiple oppressors. The worker noted,

for a long time we felt that we were not addressing class and race very well. But we didn't do anything except worry about it. Now we are doing a better, although far from perfect, job of it. But, we're scared that we'll fall back into our old bad habits or complacency or that a new issue will come along and we'll be last on the band wagon or even fail to do anything about it.

In an attempt to avoid this inertia, the agency has adopted "a framework for the ongoing monitoring of power issues and different ways of working with power". Some of the permeability features built into this framework included ongoing connections with other feminist and womanist services, as well as with the activist women's movement. This iteration or back and forth between the community, activists and the agency was thought to ground the agency in the realities of everyday lives and struggles rather than formalizing and distancing relations to the community.

As discussed earlier, workers spoke of how they have used pieces of provincial or federal legislation to further anti-racist strategies. Despite the cancellation of the Employment Equity legislation, one worker reported that her agency has agreed to continue with its EE plan. The worker reported that because there was "an openness" within her organization for doing something around anti-racism and other oppressions, she volunteered to reactivate an "anti-discrimination committee 
which had been set up but really hadn't done anything". She felt that in an agency that "hadn't really done any work on this issue at all in any formal way, it was a nice sort of concrete, task-centered, way into the whole issue." The development of an EE plan would provide my informant and other activists with a sense of where "the agency was at" in terms of anti-oppression practices and was "less threatening" to co-workers than "saying, okay, we are going to examine how you relate to your (clients) and look for ways in which racism may be part of the way that you interact with your (clients)." In addition to the four target groups - women, people of colour, First Nations people and people with disabilities - the committee decided to add a fifth group -- gay men, lesbians and bisexuals. Her agency agreed to permit her to work on the EE plan one day per week and go through the formal EE programme in its entirety including

the workforce survey, the examination of all your employment systems, looking for the way in which bias might be part of recruitment, everything, job description, job postings, selection, retention, promotion, training, everything that happens in the organization. And doing focus groups and individual consultations with workers.

After a year of intense work the report is almost ready. The worker noted that committee members and those close to the committee have "really learned a lot and changed our sense of who we are as individuals and as an agency". For my informant and the committee the next big challenge was how to implement organizational change in a way that would help people see multi-"ism" antiracist "change as in their own best interests". This broad definition of interests differs significantly from the way the interests of dominant and subordinate groups are presently constructed. It is compatible with Fraser's (1997) notion of deconstructing and shifting everyone's identities in order to make space for further transformations, regroupments and deconstructions. Thus, interests also are deconstructed, realigned and then deconstructed again. The fluid nature of this on-going process leaves the way open for the development of new kinds of plurality with out the dominant and 
subordinate stratifying of existing identities and interests.

Despite the new identities and interests possible in the process described above, even the most aggressive implementation of EE programmes has significant limitations. Like the other multi-"ism" anti-racist strategies, EE work is largely an affirmative or liberal project addressing end-state maldistribution of opportunities within a single agency rather than restructuring those systems and institutions that cause injustice and inequality. While the inclusion of people of colour and other marginalized groups brought about by organizational change projects is important, without a fundamental reordering of the socioeconomic and cultural structures of an agency and of society, marginalized groups can expect to be coopted to the liberal purposes, priorities and systems of the existing agency and society-wide culture.

The real potential in these organizational change strategies lies in their capacity to create space for new and critical ways of thinking about and structuring our everyday work. Some of the feminist services are rich exemplars of the new vistas of thought, practice and political struggle that have been created, in part, through critical engagement with anti-racist organizational change projects. These new structures and relations developed within the struggles around and within these organizational change projects, in turn, help to create the potential for the growth in a wider oppositional culture and liberatory social life. Gramsci noted that the building of socialism is likely to emerge from day-today oppositional practices and structures (Forcas, 1988: 431). Through their capacity to explain social life and reflect the hopes and interests of people, these oppositional practices, relations and structures have the potential to gain greater credibility than, and eventually undermine the legitimacy of, the structures and relations of society's dominant groups. As the London Edinburgh Weekend 
Return Group (1980) notes, one thing we cannot demand is new relations. These we must make for ourselves (London Edinburgh Weekend Return Group, 1980: 83).

\section{$\underline{\text { Race Needs Its Moment }}$}

Among progressive social workers there was a strong sense that race needs to have attention focussed on it for a certain period of time in order to fundamentally reconstruct theory and practice. Although workers favored a "multi-oppression analysis", they felt that it would not be wise to work in tandem with discourses of pluralism that seek to have race reduced to just another benign difference. They argued that it is crucial to have a period of time in which the primary focus of political strategies and battles is on anti-racism. As a research worker argued,

I'm disturbed by the notion that we can wrap racism up in the next little while and move on. Women certainly do not feel that sexism has been all wrapped up and resolved although it is difficult to have anyone see it as an issue any more. We can't let this happen to race.

Another worker added that she is

wary of statements like we should just develop an anti-oppression analysis, because we end up with white men still in power, or all-white women's groups treating all the oppressions as the same, as opposed to focusing on the specific "ism". The result is that nothing really changes because nobody actually looks at the dynamics of power or the way the system and individuals work together to exclude certain people. And nothing changes.

A number of my informants held the position that unless race/racism is targeted for a period of time, it risks losing the momentum and politicization it has achieved thus far. A policy worker noted,

it's important to maintain a focus on race for awhile in order to put the systems under a microscope and actually change the way the system functions. I think that in that process, the key is to maintain race as the focus, while the challenges of people with other identities need to be heard as part of the change process. It's not easy and I'm not pretending like I have all the answers. 
Using her own experience as a microcosm of wider social relations, a worker of colour noted that her "primary site of subjugation is race." She felt that she could take advantage of the gains made thus far by feminist struggles within social work, and felt uncomfortable but protected by the class privilege she receives as a result of being a social worker. Race/racism, however, continued to be the way that she was outside the mainstream white culture both at work and in society. It was the only aspect of her being on which she received rude comments, non-compliance and resistance from clients. While this informant favored a multi-oppression approach, she felt that it was important that anti-racism not be seen as less important than other oppressions. Since race has only recently been politicized within social work, she saw it as premature to move away from a comprehensive overhaul of social work practice, theory and education systems.

While on the surface the strategy of maintaining a central focus on race/racism seems to privilege race/racism within the web of social relations, and invoke static constructions of identities and difference, this strategy needs to be placed within the historical context of social work in order to understand them fully. Despite its purported ties to the community, social work has been slow to engage with issues of race, racism, and diversity. Most schools of social work, social service agencies and models of practice continue to operate in race-blind ways. In reality, the race/anti-racism issue has not been in the social work discourse for more than five or six years (Doyle and Visano, 1987; Tator, 1996; United Way of Greater Toronto, 1991). In order to expand and exploit the potential within the contested and less congealed set of discourses surrounding race/racism, progressive social workers have been struggling to develop ways to resist the full scale, liberal cooptation of the issue. One plank in this multi-level strategy has been to work to extend the more fluid and contested condition of race/anti-racism in hopes of building multi-issue transformative practices. 
Arguably maintaining a focus on race/racism for a period of time reflects a strategic increase in differentiation rather than a politics of dedifferentiation and deconstruction that this thesis has argued is necessitated by existing social and economic conditions. However, this strategy is not antagonistic to deconstructive and socialist politics, nor does it preclude their development. The increases in differentiation within this strategy are framed as time limited in order to make the most of the political possibilities present in the more fluid quality of the race/anti-racist struggle at this time. In addition, these highly politicized strategies resist the larger ideological practices of cooptation, liberalism and depoliticization. As such they are another important tactic in a larger long-term emancipatory project and help to extend a critical debate and a critical public space in which these issues can be worked out. If race/racism are pushed out of the political agenda of social work and broader social discourse, their potential to act as any kind of an emancipatory force is dissipated. These two factors, the time-limited nature of the strategy and its combative and politicized stance work to ensure that race/racism remain an openly contested and fluid issue. It is this contested and fluid nature of the issue that provide the potential for coalition with other struggles and the possibility of longer term strategies of deconstruction and socialism.

\section{Experience and Just Principles}

A number of workers felt that at certain points, sectors of the women's movement committed a set of serious strategic and theoretical errors. This involved according the experience of each woman with the same value, rather than maintaining mechanisms to determine better from worse claims and ideas. When all experience is viewed as equally valid, it is difficult to determine why racist women's experience is less important than that of women who are racially oppressed. In short, when 
a social movement is based upon experience, the movement has no basis from which to determine better from worse experience, or to develop better, rather than worse, political programmes and strategies.

A number of anti-racist-feminists have consciously and critically imported these lessons into the anti-racist struggle. This has resulted in a different construction of the experience of the client. As one worker noted,

there is no such thing as pure experience, if you will. When we talk about our experience we almost always reconstruct it in ideological ways that quite frankly are not always in our own or other's best interests.

Building on this, a number of my informants felt that the anti-racist struggles must base their work on a negotiated balance between the experience of those who are oppressed, and principles of equality, and social justice. Some of the anti-racist struggles within social work have incorporated a notion of just principles from which to operate. As one worker notes,

I believe that all consumers should know their rights. They should know what the policies that are impacting them and what it is that the government is doing,... I have the responsibility to let them know and to include them and to make sure that their voices are heard and they collectively can take action to change that.

But if someone wants to come up and make comments or statements, or suggest actions that will compromise my principles be it race, or gender, or class - I will not compromise. Any organization has to have some basic values that you hold on to, but you also, with those values, have to be inclusive and flexible and all that. But, I don't think there is room for racists, for example, in any organization.

A worker in a social movement agency agreed. She observed that, in the past, her agency had based their interventions on the experiences of the clients. This resulted in a number of problems including a number of acts of discrimination and oppression committed by clients against other clients. The most common form of discrimination and oppression was against people of colour. As the worker phrased it, "people who have been oppressed for a long time may duplicate that oppression 
in any number of ways. This is not okay." Through a long period of internal struggle and a complete change of senior management, the agency now operates from clearly articulated principles of social justice. Staff are responsible for ensuring that these principles are adhered to even where they contradict the experience or desires of clients. Maintaining a framework incorporating notions of absolute and negotiated standards of social justice, the agency believes that it does a better job of providing politicized and anti-oppressive services.

While the discussion above focuses on community examples, clinical workers also have found ways to infuse anti-racist principles into their everyday practices as these quotes demonstrate; "it is patronizing not to challenge patients who are being racist in the waiting room", "although it depends on the relationship you have and how you use yourself as a change agent, it is important to confront clients who are being racist and let them know that it is not okay. You have to find a way to do this that invites change", "you have to set the standard and let clients know that you think that racism is something that oppresses people and makes their lives worse", and "you can't use people's illness as an excuse for racist behavior."

The discussion in this section shows the way that many of my informants integrated a critical evaluation of experience with a notion of minimum just principles. While the use of universal standards of social justice is not unproblematic, ${ }^{9}$ workers struggled with ways to ground universal standards in the experience of their clients, while not making this experience act as the ultimate adjudicator of justice.

9 Universal values have been critiqued for the way that they are based on a white, middleclass, male construction of needs, desires and capacities. This construction marginalizes the experience of all those who do not meet this standard. 
Race and Pieces of Social Organization

While workers could list numerous practices and ways of reorganizing work places in ways that were anti-racist, my informants could not identify specific ways of organizing agencies that were identifiably anti-racist. As discussed earlier, feminist ways of organizing services have developed forms such as the non-hierarchical collectives or cooperatives, and quasi-horizontal managementworker structures. However, my informants could not identify any specific anti-racist structures that are not generally identified as liberal, feminist or socialist structures. The following excerpt provides a possible explanation for this gap in the data:

DB: We had quite a bit of discussion (in the groups) around how feminist structures permit us to work in a different way and remain open to issues like race and class and other progressive strategies. But there doesn't seem to be such a thing as an anti-racist structure and I wonder how this came about?

Worker F: What would an anti-racist structure look like?

Worker G: I don't know but, at some point there must have been a question around what would a feminist structure look like and now we all think that we know what a feminist structure is.

Worker H: It's interesting, because although we have some important work being done around anti-racism, we don't have anything that we would say is an anti-racist structure. Like, we have policies and hiring and affirmative action.

Maybe there is some kind of way in which the race issue isn't owned by progressives or antiracists, so that it can very easily be coopted into liberalism. Maybe race needs to be attached to gender or something in order to maintain a radical character. And so that's why we don't organize anti-racist agencies independently.

Anti-racism, in some of its more critical forms, demonstrates a certain capacity to merge with other oppressions without undermining the importance of either axes of social justice. Rather, it appears that both axes may be strengthened by this association. In particular, within the social work milieu feminist work and anti-racist work seem to have dovetailed. All of the workers from feminist 
women's services reported multi-level anti-racist organizational change programmes, a struggle to put just standards into their work, the use of multi-"ism" anti-racist committees, and ongoing critiques of the structures, systems and culture of racism. This thorough-going change was not observable to the same degree in the other agencies.

On the whole, in the non-feminist agencies, the more bureaucratic the services, the less likely it was for workers to report the development of critical forms of anti-racist practice. Also, the more fluid the organization and the closer the tie to social activism, the more likely it was that agencies were infiltrated by, responsive to and responsible for anti-racist organizational and practice changes. Thus, while progressive social workers were found in all types of human service agencies and structures, progressive forms of anti-racist organizational change were most likely to be found in feminist, social action agencies.

\section{$\underline{\text { Summary }}$}

In this chapter I explored some of the ways that race is neutralized within the social work milieu through ideological processes of liberalization, professionalization and integration into management systems. Within these management systems race is translated from a conflictual social relation into a static set of standardized, depoliticized, routine agency procedures and policies. These policies and procedures individualize problems and responses within the context of "a general proliferation of discourses of pluralism" (Mohanty, 1993: 57). The review of processes for managing race included a discourse that race is "in" and other issues are "out", the establishment of multi-"ism" advisory boards and committees, the extension of mainstream services through the provision of services in languages other than English, and the introduction of affirmative action hiring policy, 
Harassment policies and organizational change strategies.

Some transformative ways of formulating and applying race were also examined including multi-"ism" anti-racist work, refusing pluralism, maintaining just standards, and agency structures and mechanisms in which anti-racism is more likely to flourish. While these practices represented a fractured whole of liberatory and ideological constructions, they are useful examples of how to deconstruct the racialized ideological constructions of everyday practice as well as how to build emancipatory identities, relations and practices. 


\section{Chapter Nine}

\section{Dyads: Class and Gender; Race and Gender, Race and Class}

While my data indicate certain dyads among class, race and gender, for the most part workers do not formulate or apply race, class and gender in dyads. Race, class and gender are largely understood and mobilized as separate entities. The occasional dyadic story in the data highlights some of the contradictions and tensions between and among these social relations. In this section the few dyadic stories present in my data will be analyzed in an attempt to shed light on the relationship among, and between race, class and gender.

\section{Class and Gender}

There were no stories in my data that the workers felt were specifically about the class and gender dyad. Workers' stories did not discuss class and gender working in tandem or antagonistically. Class and gender are each depoliticized in ways that construct them as static categories. The static and naturalistic construction of these categories effectively prevents an understanding of the way that other social relations overlap, reinforce, contest and undermine each other within social life. For example, class is formulated as a series of indicators around education, income, and professional status, not as a constantly changing relationship to the means of production and reproduction. Education and income indicators are concrete, measurable, discrete and contained. They do not encourage questions around injustice and how to create social change as might result from a more dynamic understanding of class. 
Likewise, gender is understood as no longer an issue except for clients who are victims of male violence. Again, this is a discrete category with self-evident, therapeutic, professional solutions that do not leak into larger or overlapping issues of social restructuring and equality. Although social work is a wholly gendered arena, and class is the backdrop to every piece of social work practice, these two relations meld into the back ground rather than standing out as antagonistic or complimentary relations. They are simply the assumed, but invisible back drop to all stories and all interactions in the social work milieu.

\section{$\underline{\text { Race and Gender }}$}

The data show that race and gender are coupled in the social work milieu more often than the other dyads. As discussed in previous chapters, a race discourse, although not necessarily an antiracist discourse, is prevalent in the field of social work. Gender is also a very present part of every social work interaction as the majority of the clients, workers, volunteers and unpaid caregivers are womeit. Hence, one might expect race and gender to be the dominant dyad within the stories of progressive social workers. While a certain amount of data exists in this area of the study, there was not sufficient data to mark it as a dominant theme. The two exceptions to this trend include the struggles feminist services have engaged in concerning anti-racism and mutli-"ism" organizational change and the conflictual coupling of race and gender as noted in previous discussions of "race is in and gender is out".

As noted earlier, an antagonistic coupling of race and gender was identified by a number of workers who reported a strong sense that within their agencies, racism is "in" only within the context of sexism being "out" or no longer an issue. Workers received comments and actions from 
management and co-workers to this effect when they attempted to raise race and gender issues in tandem, and or when they attempted to raise gender issues at all. The following story demonstrates how the discourse of "sexism is not/no longer" an issue operates in a complex manner in conjunction with a liberal, psychologically based discourse on race. In a story discussed earlier in terms of the existence of multiple rather than singular racisms, a white, male worker who worked with a client who stated that he disliked "Pakistanis, but not Blacks". The worker's response merits noting. Having a good relationship with this young man, the worker spent considerable time discussing racism with him. Utilizing a feminist therapy technique known as self-disclosure, the worker told the client, "Hey, Im racist too, but I am struggling with it." Another white male worker in the focus group pointed out that he also used this technique from time to time in racially contentious situations.

When asked whether they would use this same technique around gender or around sexual orientation - "hey, Im sexist too, but I am struggling with it" - they both were very clear that they would not. Both had difficulty explaining why they would not, and were adamant that the use of this technique did not constitute white bonding or an implicit assumption that they were not sexist or homophobic. While other members of the group disagreed with these workers' self-assessment, like other conflicts in my focus groups, the discussion was dropped and turned to other less contentious issues.

The two men in the above example are making use of a confessional, psychologically- based race discourse. This liberal, individualized story line argues that everyone is racist, and the solution to this prejudice is education and awareness. Individuals need not feel culpable, or demand systemic changes. They need only admit their shortcomings, develop an awareness of racial conflict, behavior and attitudes, and use their new "unlearning" to reduce racial tensions (Mohanty, 1993: 53). The 
analysis remains at the level of attitudes, understandable and excusable personal failings, individual change, and universal human psychological make-up. Mohanty argues that this type of discourse removes the historical and social context that have organized existing dominant and subordinate groups. Moreover, it equates individual, psychological understandings of power with "ideological and structural understandings of power and domination" (Mohanty, 1993: 54).

In the example above, an admission of fallibility and racism acted as a psychological bridge or bond between themselves and their, presumably white, clients. It invited clients to join with their social workers in admitting to attitudinal weaknesses, and move forward together as flawed but honest people. The analysis never leaves the level of the personal and the individual and the psychological. As previously mentioned, strategies for addressing psychological and attitudinal weaknesses include awareness and sensitivity training, therapy or both. These strategies avoid interventions that connect the personal with the political, and with collective social change activities.

As previous chapters show, class was discussed by progressive social workers as a static, quantitative, descriptor of one's socioeconomic standing vis-a-vis the rest of society. Sexism was discussed also as a static, quantitative descriptor of the existence of women who are victims of violence, and hence in need of social work counselling. This psychological, confessional race story line also renders it static, quantitative and descriptive. For example, one may have more bad attitudes than others, and hence a greater need for sensitivity training. These static, quantitative descriptors make the individual responsible for changing the system while implying a certain inevitability to the existence of these forms of inequality or injustice. A similar discourse of acceptable bigotry does not exist in social work around sexism or homophobia. As previously discussed, the dominant social work discourse around gender focusses on sexism is no longer, or is not, an issue. Progressive social 
workers counter this discourse by arguing that sexism continues to be an issue in terms of male violence. This discourse does not lend itself to the same admission of personal failings and need for sensitivity-training. Male social workers, for example, are unlikely to confess to being violent or potentially violent. Most female social workers are unlikely to admit to being victims of violence. Instead, most male social workers would inject themselves into this construction of gender only as caring professionals. We can conclude, then, that the current social work discourses on gender do not lend themselves to the liberal, confessional approach.

In the example discussed above the male workers did not feel comfortable admitting to homophobia or heterosexism. Although important to an understanding of gender and oppression, this study has not explored heterosexism, homophobia or sexuality as axes of social injustice and subordination. Therefore, my data fail to illuminate this relation in any significant way. Heterosexuality and homosexuality operate as an unequal, but mutually reinforcing dichotomy. Discourses of heterosexuality and homophobia are pieces of social organization that marginalize and subordinate all sexualities that differ from their central pivot point.

At present issues surrounding sexual orientation remain largely invisible within social work. If included at all, it tends to be seen as another benign, pluralist difference with which men are assumed to be more uncomfortable than women. When an issue is promoted as a pluralist difference, there is no need to adopt a confessional stance, or to invite clients to do likewise. Therapeutic interventions are, also, not necessary. Just as one would not bother saying, "hey, I don't like people with finger nail polish, but I am struggling with it", my male informants saw no benefit to admitting to a bigotry that is largely eclipsed, and that they are supposed to understand only as one benign difference out of many. 
This example underscores differences in the way that race, gender and sexual orientation are organized and politically contained within the social services milieu. Within the gendered milieu of social work, gender is contained through a process of direct denial that sexism is a problem. Racism, in this case, is made amenable to the therapeutic techniques of social work by constructing this relation of social injustice as an attitude or a piece of human psychology. Finally, homophobia is largely eclipsed and denied within the context of benign pluralism. Thus, each of race, gender and sexual orientation are depoliticized in ways that are specific to the way that it is present throughout the field of social work.

Another story in my data also coupled race and gender at the attitudinal level. Clinical and community workers argued that males are more likely to be overtly racist in their talk and body language than are females. My informants did not say that women are less racist than are men, only that they are not as observably racist. There was some disagreement among my informants as to whether males of colour were more likely to be more racist than white males. Due to the very polite and non-contentious tone of the focus groups in which this issue was raised, the dispute was dropped rather than discussed at any length or resolved.

In many ways this story is as much about sexism and male dominance in the public sphere as it is about race. Men articulate their ideas and opinions with greater ease in public than do women. Men are also listened to more attentively and thought to be more intelligent and rational in their thought and speech (Tanen, 1990). The workers who told these stories equivocated on whether they actually thought that women were less racist or spoke up less often and with less vehemence. Women may appear less racist, as they voice their opinions in public less often; however there is no evidence to suggest that they actually are less racist. It may be more accurate to say that women are racist in 
a different ways than are men, particularly when men dominate communication in a social work setting. This story demonstrates the way that gender organizes men and women to behave and communicate differently in social work settings. These differing styles of behavior are interpreted in gendered and racialized ways that lead some workers to conclude that women are less racist than men.

Reflecting a similar relationship between men and race, my informants discussed the neoliberal, white backlash against the politics, policies and practices that provide for greater equality for marginalized groups. My informants used the term white backlash, although this backlash is actually male, as well as white. As discussed in greater detail in the Race chapter, this backlash is a reassertion of white, male privilege. The gendered character of this backlash is made invisible in this phrasing while its racialized character is not. Within this wording, white backlash takes on an androgenous character although it is actually male, and men are the primary beneficiaries.

Androgenous categories tend to assert male interests while positioning themselves as neutral. Androgenous constructions assume that the interests of white men are the interests of all people. White women are subsumed into this androgenous category although their interests are generally antagonistic to this backlash. The reinforcement of white privilege may benefit some white women although this benefit has a gendered character in which males derive greater benefit. Further, some white women support white backlash despite the way that the male part of this backlash is antagonistic to them. Thus, it is important to note that white women, as a group, have an ambiguous or contradictory relationship to the backlash. Through this discourse white males are recentred as the dominant group in society whose interests are understood to be the most important. All other groups are remarginalized although in different ways and to different degrees. 
The occlusion of maleness within the white backlash is an ideological practice within the neoliberal ideological battle. White interests are constructed as unified although they are clearly split and antagonistic along gender lines. White women implicitly share the responsibility for this backlash although they receive ambiguous benefit.

Previous chapters discussed feminist social service agencies and their activities around antiracist and anti-oppression organizational change. As noted in those earlier discussions, my informants argued and my experience would concur, that the feminist agencies were more engaged with antiracist struggles than were the other social change agencies or the mainstream social service agencies. I have concluded elsewhere in this thesis that this engagement with anti-racist struggles results largely from the ongoing ties many feminist agencies have with sections of the activist women's movement. These ties act as a conduit of politicization and social change. Moreover, they provide accountability and ethics mechanisms through which the agencies can remain connected with and part of emerging socio-economico-cultural struggles for social justice. Thus, a more positive coupling of race and gender themes within the social work arena can be seen to arise from the coupling of social services and mass social activism. While these examples did not provide a model of how to think about and act on race and gender issues per se they provided rich ground for further research and theoretical work.

\section{$\underline{\text { Race and Class }}$}

Race and class was a less prevalent dyad in the stories of workers. Workers told only two stories that specifically focused on the race and class dyad. The first story concerned a race discourse that is currently popular. A community worker observed that one's class can change, although one's race cannot. Other workers disagreed, pointing out that while one's race does not change, the power, 
identity and resources associated with the social construction of one's race changes in both the immediate and long term. Another worker added that race is "an entirely social construction" although it is widely experienced and understood as biologically based.

Critical race theorists McCameron and Crichlow would concur with this statement. They argue that it is

misleading to talk of race as an "it". "It" is not a thing, a reified object that can be tracked and measured as if it were a simple biological entity (McCameron and Crichlow, 1993: vii).

They, in turn, quote another group of critical race theorists, "Race is a set of fully social relations" (Omi and Winant in McCameron and Crichlow, 1993: vii). All four of these analysts also stress the importance of understanding the material effects of race, or the way that race is practiced and experienced in everyday life.

It appears that the first worker formulated race as a unchanging, and uncontested condition, namely biology, while class was constructed as a more dynamic relationship. However, later comments revealed that she did not formulate class as one's relationship to the ever-changing and changeable means of production and reproduction. Instead, she made use of the construction of class as a descriptive category comprised of various indicators such as education, professional status, and income level. Thus, for this worker, although class was not seen to have a biological basis, it was also constructed as a non-analytic category rather than a wholly social force that organizes systems, institutions and social life.

The worker has adopted constructions of race, and of class, that do not illuminate the way that they operate within social work or larger society. Descriptive and biologically based constructions of class, and of race respectively, play into pluralist notions of benign difference, and the multicultural and end-state redistributive solutions favored by liberalism. These ideological 
constructions limit the analysis and the solutions one can pursue. As the discussion in previous chapters has shown, this limitation is partial rather than total, for like most progressive social workers, concrete critical social work practices are often ahead of, or outside of, ideological practices and formulations.

The second race and class story, in my data, concerns the way that clients and secondary support services are organized by larger social institutions and structures. A mental health worker noted that clients are streamed by race and class long before they are referred to her service. Most of the agency's referrals come from formal psychiatric services such as psychiatric hospitals. Although ostensibly accessible to all, various groups of people make use of main stream psychiatric services while others do not. Within the groups that make use of psychiatric services, there are further divisions between those who seek services directly from more elite services such as the Clarke Institute for Psychiatry, and those who are involved with chronic care facilities. A further division exists between those who make use of local hospitals, general practitioners and family doctors, and those who make use of psychiatric systems. A final division exists between people who do not make use of any sector of the medical or psychiatric system when experiencing mental health problems. Instead, they make use of extended family and friends.

According to my informant, the less formal the service, the less likely it is that clients are aware of her social change agency. Also, the more informal the service, the more likely it is that the client is poor, and a new Canadian or immigrant. Thus, larger processes of streaming and sorting people with mental health problems through the formal and informal psychiatric and medical systems ultimately decides who is referred to community support agencies and who is not.

The medical system acts as an institution in the sense that Smith uses institution to "identify 
a complex of relations forming part of the ruling apparatus, organized around a distinctive function" (Smith, 1986: 8). As an institution, medicine is concerned with organizing understandings of, access to and experience of health and non-health (illness, frailty, dying, disease, some aspects of disability). By exerting its control over health and non-health, the medical institution is simultaneously organized and organizes aspects of race and of class. The health/non-health system creates and reinforces class and race hierarchies through the way it organizes access, resources and experiences. The purported neutrality of the medical institution conceals its organizing and ruling activities.

The trickle down effect from the medical institution, in turn, organizes many of the race and class aspects of the community agencies with which it is associated. Thus, by situating itself as an agency that accepts clients through the referral system of the formal psychiatric and medical systems, this worker's agency ends up serving a predominantly white, middle class client population.

In this section two examples of the race and class dyad were examined. The first example discussed the widespread race discourse that views race as biologically based. The second story traced the way that clients are streamed by race and class long before they are ever referred to an alternative service agency. Both examples highlighted the ideological way that these relations are taken up in social work, and the ways that social workers are implicated in ideological practices and relations of ruling.

\section{Summary}

Within progressive social workers' formulations and applications of race, class and gender, dyadic relationships receive little attention. Certain tensions exist between race and gender, and to a lesser extent, between race and class. The absence of stories around class and gender highlights the 
effectiveness and specificity of the depoliticization of these social relations. The scant attention paid to dyads, as well as to the way that they are examples of ideological practices, will be explored further in the concluding chapter. 


\section{Chapter Ten}

\section{Race, Class and Gender}

\section{Introduction}

As discussed earlier in this thesis, my informants stories highlighted the way that it is difficult to talk about one facet of the race, class and gender triumvariate without speaking of the others directly or indirectly. For example, one informant asserted that the racialized and gendered character of stories concerning class are present by proxy if not explicitly dilineated. She pointed to the example of people in receipt of welfare who are often assumed to be female, single parents of colour. Thus, one can be clearly understood to be speaking of class, race and gender within most popular as well as professional social work discourse, without continually specifying the race and gender aspects of certain classed categories of people.

Overall, my informants agreed that race, class and gender are part of every social work intervention, policy and programme, they tend to be taught, analyzed and practiced as three distinct entities. My informants concluded further that notions of the inseparability or the intersections of these oppressions is not common discourse or practice in the field of social work in Toronto. Where the trio of race, class and gender is included in social work practice or analysis, it is generally used pluralistically. Within a pluralist use of race, class and gender, all social relations are seen to operate in basically the same way and to have similar impact on all individuals. The pluralist model does not provide insight into how power is played out through social relations, nor does it provide any sense of how such relations maintain and recreate inequalities and injustices. Moreover, within the pluralist analysis race, class and gender are thought of as concrete, measurable, differences that have some kind of a naturalistic, rather than a socially constructed basis. 
The data indicated that the notion of race, class and gender as social relations between and among people, and as systems and structures that organize our lives has not entered the social work milieu in any significant way. Progressive tactics and strategies around this triumvirate are tentative and not well developed. They are contested only at the margins of social work.

In this section I will address the question of how workers formulate and apply race, class and gender in everyday practice. The first part of my argument will demonstrate the multiple layers of analysis required to understand how race, class and gender are constructed within social work. To this end, I explore a story involving a client's reaction to a progressive agency's affirmative action strategy. Secondly, I look at the ways that progressive social workers talked about how race, class and gender intersect, and/or are separable or inseparable, the way the workers formulated and applied the concept of oppressions, the way that other social workers pretended that they already know "all about race, class and gender". The workers suggested various frameworks for understanding and working progressively with race, class and gender. These will be examined in the last section.

\section{The Multilayers of Race, Class and Gender}

When asked how race, class and gender are central or marginal to their practice, workers had a difficult time producing stories. In part this is due to the way that race, class and gender are formulated and mobilized in practice and theory as separate and separable categories. It is also due to the complex ways these social relations organize and are organized within everyday life. The following excerpt demonstrates the multiple layers of analysis required to reveal the ways that progressive social workers mobilized race, class and gender within everyday practice. 
Although this excerpt was discussed earlier as an example of some of the tensions surrounding feminist pieces of service delivery, the multiple layers and richness of this story merits further analysis. When asked how her clients understand racism, sexism and classism, a community worker told the following story. The story concerned a feminist woman's service that keeps an informal affirmative action waiting list based on race. All services are free-of-charge hence, agency clients tend to be from lower income backgrounds. The worker noted that her white client had difficulty understanding this loss of privilege and questioned why she as a poor, psychiatrized, Canadian-born single parent should have to wait for services while "immigrant" women did not. My informant, a woman of colour, observed that it is difficult for marginalized people to forgo the small bits of privilege that may be accorded by their positions within social, cultural and economic hierarchies. In effect, she argued, those women who have access to other resources, and hence other ways to have their needs met, lose little or nothing within this process of ostensively giving up privilege. Thus, it is less difficult for "middle class and rich" people to lend support to this type of strategy of giving up privilege.

In discussions with her client, my informant explained the historical disadvantage experienced by women of colour as the reason for the affirmative action waiting list. The client claimed to have "nothing against immigrants" but did not believe that she should be made to wait for service while others did not. The worker clarified that the waiting list was for all women of colour, not just recent immigrants, and that even if the client "didn't like it, that was the way things are".

There are a number of layers that require analysis. I will provide this analysis as I more or less "walk through" the story as presented above. The client asserts, in effect, that Canadian citizenship should provide her with some privilege within a larger system in which she has few resources, very little power and a large number of unmet needs. Citizenship, in her formulation, is equated with 
whiteness. The affirmative action part of the waiting list is interpreted as an unfair advantage given to immigrant women, who are assumed to not be white. Canadian women of colour are eclipsed by her analysis, as are white immigrants. In short, the client provides a subtle, white supremist, racialist argument against the affirmative action waiting list couched within an apparently neutral, and nonracial argument around citizenship.

In a well-intentioned attempt to understand how the client feels, the informants analysed how class played itself out in this scenario. She knew that only a woman with no other options, that is, a poor woman, would put her name on any waiting list. Anyone with other options for service would most likely make use of them. The worker argued that because of the desperate nature of their needs, people with few resources have a difficult time supporting projects that redistribute resources from them, to others with even fewer resources. Within her argument it is clear that the worker made use of a materialist construction of privilege as connected to one's position within systems of resource distribution. However, it is not clear whether she also understood privilege as connected to hierarchical structures of meaning and cultural valuation.

The worker argued that privilege or resources are easier to forgo for those with more resources/privilege. Hence, mechanisms of redistribution, such as the affirmative action waiting list, find more support from such as those individuals with more privilege and resources. This analysis recognized the role that unequal distribution of resources plays in the formation of consciousness. The worker does not simply excuse the racist piece of her client's understanding or consciousness about this issue. Instead she engaged her in a dialogue about the reasons for the affirmative action waiting list. The worker used critical consciousness raising and historicizes racism in Canada and places the discussion of the affirmative action list in this context. She discussed the issues with the 
client as an equal and adheres to just standards by agreeing to disagree with the client's continued opposition.

This example reveals some of the limitations to emancipatory practice when working within the context of a liberal or neoliberal society. More over it exemplifies many of the contradictions inherent in attempting to address one axis of injustice separate from others. In the context of plenty, affirmative action lists do not deprive desperate people from much needed services. However, in the context of neoliberalism, priorizing who can get access to a socially constructed scarcity of services is a difficult balancing act that create new marginalizations.

The agency, in this example, attempted to redress historical race injustices through the introduction of an informal affirmative action waiting list. Unfortunately this strategy adds up to nothing more than a liberal, cultural recognition and redistribution scheme (Fraser, 1997). The scheme is liberal in the area of redistribution as it recreates existing class distinctions and stigmas rather than reducing them, creating reciprocity and solidarity and transforming the underiying political economic structure (Fraser, 1997: 24). While the access to services for women of colour expands, the underlying structures that create poverty for some and more privileged socioeconomic positions for others remain unaddressed. Moreover, the marginalization of poor, white women is increased through this strategy.

The strategy can also be seen to be liberal in the area of cultural valuation as it provides greater recognition of women of colour as a marginalized group thus increasing the differentiation of various racialized and class groups of women. Liberal strategies such as the affirmative action waiting list tend to freeze existing, fixed racialized identities and close off opportunities for new ways of working in coalition with other oppressed groups. A more comprehensive and radical approach 
to cultural valuation and systems of meaning would focus on ways to destabilize existing identities of all marginalized groups in order to make room for new liberatory human identities as well as new alliances and social change groupings (Fraser, 1997: 24). Accompanied by strategies to simultaneously deconstruct binary codes such as black/white, woman/man and native/colonalizer, this destabilizing of existing identities and symbolic systems is aimed not at the creation of new forms of pluralism but rather at forms of justice that incorporate an end to structures of cultural and socioeconomic domination and subordination.

Despite the wishes of many progressive social workers, it is not possible to restructure the wider cultural valuation and socioeconomic systems through the building of socialism in one agency. Nor is it possible to address one axis of subordination separate from others without recreating new injustices. This example underscores the contradictions of trying to build single issue redistribution strategies in one agency and coupling them with liberal, cultural recognition schemes. However, within the context of a neoliberal society, most agencies have few options for building social justice and even fewer resources. As discussed in earlier chapters, the most important contribution of social change agencies is the cultural, political and intellectual space they create for the development of critical thought, critical practice and new forms of social relations. These discursive and material practices help to build the types of oppositional structures, culture and institutions necessary to undermine the legitimacy and credibility of existing socioeconomic and cultural systems.

In sum, the preceding story is about how race, class and gender is formulated and mobilized by workers, clients and social change agencies. It reveals the multiple levels of analysis necessary to understand what is really going on. Workers often seemed frustrated and confused when asked about how class, race and gender were central or marginal to their practice. They were more confident in 
telling stories about how they do progressive practice. This example demonstrated the complex ways that race, class and gender are part of everyday practice and helps to explain why workers experienced difficulty in talking about these embedded and overlapping relations in a direct way.

\section{No Consensus: Intersecting. Separable or Inseparable Relations}

Workers noted that within social work practice, as well as within social work analyses, services are constructed consistent with the notion that race, class and gender are separable. For example, welfare workers pointed out that income support is a service which intervenes at the level of class, not of race or of gender. Workers in the area of violence noted that their services intervene at the level of gender, and not of class or race, while those employed in services for immigrants found their services to be constructed around race despite the fact that many of the issues they dealt with were also about class and gender. Indeed, the preceding chapters are full of stories in which progressive social workers formulated and applied race, class and gender as separate entities.

Workers produced stories on either side of the question of race, class and gender as separate or inseparable. There was a general consensus that at the level of personal experience race, class and gender are inseparable. For example, one worker felt that the women she works with cannot separate race, class and gender in their everyday lives -- "it's all the same kind of survival story". Another worker noted that race, class and gender are all different "types of oppression but it's the same kind of dynamic at work. It's the same shit and abuse that people have to put up with, it just comes out with different words." A third worker pointed out that he can't separate his work into race, class and gender. 
I just do my work. I don't think the labels. I just do my shit - I don't say, "oh, now I need my feminist side and little bit of my class side and, oh, now I need my anti-racist side and some feminism". You can't walk on eggshells, you just got to keep your eyes on social justice and think critical and get on with it.

While agreeing that at a personal level or at the level of experience class, race and gender are inseparable, some workers argued that at the structural level, race, class and gender are separable and must be redressed in ways that are unique to them. One worker observed that if the "analysis and strategies for creating racial, sexual and class equality could be easily transferred it would be clear that they were the same". She pointed to the example of the feminist movement where more than a decade of activism by white women "left women of colour behind". It is only through many struggles within the movement that the issues of women of colour, and of racism, have begun to be addressed in significant ways. If race and gender are "inseparable and distinctly similar then these struggles would not have been necessary or so hard. But they are not the same!"

A clinical worker provided a story in which the construction of race, class and gender as separate entities is present in an agency committed to an inter-sectionist analysis. A counsellor noted that her social change agency sees race, class and gender as intersecting pieces of capitalism. However, within the construction of service delivery, race, class and gender have been formulated as static, and separable pieces of clients' lives and identities.

This construction of the client began with the intake process. During the initial screening, the agency ensured that clients were referred to workers who are seen to be similar to them rather than to have differences. For example, a woman of colour would be referred to a female worker of colour. My informant noted that she rarely saw clients who were not the same race, class, sexual orientation and ability as herself. While she was not opposed to the idea that some women may prefer to work with workers with whom they feel they share certain similarities, she believes that the issue is more 
complex than embodied by the referral system.

In an effort to become inclusive and representative of race, class, gender, disability and sexual orientation, this agency did not produce interventions aimed at deconstructing how multiple oppressors interact with each other, or at redressing the social and individual injustices of these interactions. Instead, they have produced a new way of sorting clients based on certain superficial and static constructions of differences and identity. The politics of identity are elevated over social and political analysis thus closing off spaces that could be used to develop transformative identities and regroupment.

Although agreeing that women deserved choices around counsellors, my informant argued that it is critical analysis and not identity that is the key to liberatory practice. Within the Fraser schema of recognition versus redistributive strategies, this agency's use of race, class and gender is a liberal, recognition approach. The agency put certain referral and intake procedures in place that increase the value accorded to certain facets of race, class and gender, namely identity as it is presently constructed along those axes. This enhanced valuation increases differentiation among groups, and distance between groups. As such it creates identities that are antagonistic to the kind of relations required to transform the underlying political and economic structures of society. A more progressive alternative might be intake and referral systems that embrace client choice in the assignment of counsellors on axes of identity, as well as axes of critical analysis. In this way, the agency systems may create some of the conditions necessary for deconstructing and destabilizing the "underlying cultural-valuation structure... transforming everyone's sense of self" (Fraser, 1997: 24).

Another worker provided an example that exposes social work's preoccupation with client populations as an example of ideological practices. Within social work academia, as well as in 
practice, clients tend to be defined as discrete populations based on diagnosis, age or sector of the service system. Services are organized in accordance with this division of clients. Although these systems of client definition organize the lives of clients along various permutations of the race, class and gender constellations, most of the social work community accepts these definitions as real, rather than social categories of people.

A mental health worker cited a useful example of the way that these ostensibly natural and neutral client populations act to distance certain people from needed services while facilitating the involvement of others. The worker observed that, while mental health services are thought to be accessible to all, many mental health practitioners refuse to work with women who have been in the criminal justice system. She argued further that though the criminal justice system purports to be neutral in regards to race, class and gender, the majority of the women she works with in the criminal justice system are poor women of colour or poor Aboriginal women. While these women are streamed by alledged criminal behavior, or by what is known in the professional jargon as "social work population", they are actually streamed and organized by race, class and gender. At the level of everyday social work practice, these women are defined as a distinct client population, namely as ex-inmates, and are subsequently denied services based on this racialized, classing practice.

Other workers reported formulating race, class and gender as separate, but intersecting forces. These forces are thought to intersect at different points to create varying experiences of dominance and subordination. In social work agencies, the way that racism operates will not only be influenced by relations of class and gender, but also by the unique ways in which those relations are played out in that specific site. One worker provided the example of his young clients who are often treated in prejudicial ways depending on their address, gender, and race. Geographic location acts as a proxy 
for class and the way it is criss-crossed by race and gender. Youth from Scarborough or some of the housing projects in downtown Toronto are instantly presumed to be poor, deeply troubled, and probably criminal. If the clients are youth of colour, this adds a further presumption of deviancy. When class and gender factors intersect with race, the young person is assumed to be even more deviant and in need of anti-crime counselling and support. Hence, the intersections of race, class and gender largely determine what sort of interventions the client receives from the agency.

A research worker agreed with the notion of race, class and gender as separate but intersecting. She argued that we need to develop ongoing projects in race, class and gender to determine how they intersect and manifest in our work, our agencies, our profession and our society, "it's all about power over, and we need to figure out how that is done in general and in specific."

Most of the workers recognized the difference between the level of the experience of social injustice, and the structural forces that actively organize our experience and social relations. Some of these themes are developed further in the discussion of frameworks for working with race, class and gender. They remain, like much of the progressive social work practice and theorizing around race, class and gender, in the very tentative stages with one foot lodged firmly at the level of experience, and the other perched awkwardly at the level of how to explain things in a dynamic but coherent way.

\section{Oppressions and Cultural Approaches}

Some workers favored the notion that race, class and gender can best be understood and mobilized in practice as a conglomerate known as "oppressions". They argued that the intersectionist approach and the inseparable approach produce race, class and gender as a single, static concept 
rather than as a multi-faceted, dynamic one

I call it race-class-gender. People say it off their tongues just like one word and understand it as one thing, which is very worrisome. Because race, class and gender are not the same, and they also erase other things like sexuality and geography and things like that. I think by naming it race-class-and-gender we try to uncomplicate something that is necessarily complicated. And what we do is flatten out people's lives. I don't think that our job as social workers is to flatten out people's lives.

One worker argued that "it might be better to think of things as oppressions and our practice as antioppression practice." At the same time she feels that it is important to hang on to "what race, class and gender could mean. And what it does mean".

While her formulation was somewhat vague and intangible, the worker is trying to describe a fluid construction of difference and experience. She captures a sense of the complexity of race, class and gender, but fails to articulate the way that these relations organize our lives in hierarchical ways. This type of analysis is fairly prevalent among progressive social workers who favor a postmodemist approach to race, class and gender. The strength of this analysis lies in its commitment to deconstruct identities, concepts, practices and ideology.

The weaknesses of this "oppressions"/postmodern approach are two-fold. The first lies in its preoccupation with standing back and analysing social work practice, rather than actively reconstructing our everyday practices. Deconstructing identity, practice and concepts can become pluralist and defeatist exercises when they are not attached to concrete, collective and individual change efforts. The intellectualism of many adherents of postmodemism encourages abstract analysis that divorces intellectual pursuits from everyday practice and experience.

This worker, for example, eloquently described many ways that race, class and gender can, and should be deconstructed within social work theory. At the level of everyday practice, the same 
worker stated that she never discusses class, race or gender with a client unless they first raise the topic with her. A social worker's role, she noted, is not critical consciousness raising. She argued that people have consciousness and do not require that someone else "raise" it for them. Instead, the social worker's role is two-fold. One role focuses on "naming where people are at, and normalizing that sometimes... making them feel a bit less lonely". The second role focuses on "get(ting) out of people's way". As thus articulated, the role of a postmodernist social worker does not differ from that of a liberal social worker. Practice has not been politicized or contested, and the experience of the client remains unproblematized.

The worker provided an example of what she called a postmodern approach to social work. This example reveals ways that her interventions were a depoliticizing force. Her example involved a story about gendered caregiving. My informant asserted that caring work is gendered. However, she argued that should an unpaid, female caregiver initiate discussion around the injustice of this division of labour, the social worker's role is to sympathize with the women about the lack of reproductive labour undertaken by men. Sometimes this worker will initiate a family meeting in order to emphasize to the parents that "that they both need to work together". In certain situations, this worker provided referrals to the women for support groups for caregivers, and helped the women to feel that they were not alone. The worker noted:

I don't just assume it is gendered. It may not be or it may be wrapped up in all sorts of other things. It may be racialized or it may be that it is what she enjoys or whatever, who knows...Sometimes it is just a matter of reframing it and seeing where she sits with it.

The sort of practice described above does not differ in any significant way from mainstream, liberal social work practice. The ways that our lives are socially and hierarchically organized through gender are not illuminated, and neither the client nor the worker develops any sense of how to 
politicize and resist these forms of social injustice and subordination. Instead, oppressive relations of gendered caregiving are glossed over and legitimated within the "naming" and "normalizing" practices of this worker. The slippage between postmodernist theorizing of the social work endeavor and actual social work practice reveals the way that liberalism creeps into the gaps in our everyday practice and undermines our efforts to practice in new and liberatory ways.

The second weakness of the postmodern approach to social work is the formulation of class as just another aspect of identity rather than as a change-centred analysis of one's relationship to the means of production and reproduction. When class is seen as just another aspect of identity, emancipatory strategies tend to de-emphasize the need to restructure the political economy. Instead, consistent with the most of the postmodern social work literature (Gowdy, 1994; Pardeck et al, 1994; Parton, 1994; Pozateck, 1994; Sands and Nuccio, 1992) my data indicate that progressive postmodern social workers emphasize cultural change strategies.

In their more emancipatory form, cultural politics strategies promote the destablization of identities and dedifferentiation of groups. In their liberal form, cultural recognition strategies emphasize the need for increased valuation of existing identities and promote group differentiation. When detached from analyses that emphasize restructuring of the political economy, cultural strategies are formulated as if "the problematic of cultural difference had nothing to do with that of social equality" (Fraser, 1997: 5). Hence, the cultural strategies described by my informants fail to promote projects that have the capacity to critique and to change the multiple levels of dominance and subordination in society.

Although not a postmodernist, another worker argued that anti-oppressive practice is the model that is most likely to produce a liberatory race, class and gender practice. She noted that race, 
class and gender "have different ramifications but they all become an experience of oppression." Another worker questioned the widespread use of the word oppression noting that it can be used in a number of ways most of which are no longer progressive. For example, many workers and some social work theorists use oppression

in a terrible way -- very victimizing. Like, the "oppressed people". It is a language of "othering" that robs the individual of any choices or power or possibility of political action.

Other informants disagreed with the all encompassing anti-oppressive model, stating that it is dangerous to make specific relations such as race, class and gender "too broad. Then everything becomes the same, buried, covered up and impossible to act on."

In short, based on my data, the postmodernist approach provides some important critiques and an extensive capacity to deconstruct identities, concepts and theory. However, as operationalized by my informants, the postmodernist approach has a number of shortcoming and fails to unite theory and practice, as well as recognition and redistribution themes. Various informants agreed that antioppressive practice may be a useful framing for liberatory social work. However, as described by my informants, it is not sufficiently developed to evaluate in any meaningful way.

\section{Political Correctness and Pretending We Already Know}

Most workers were critical of the lack of formal, informal, and/or professional education about progressive practice. In particular workers were concerned that race, class and gender are not included, for the most part, in formal social work education. When they are included it is rarely from a progressive perspective or as overlapping aspects of social life. Lacking formal opportunities to learn progressive practice, workers turned to informal and self-directed learning. Most workers felt 
ill-prepared to translate critical theory into practice around race, class and gender. Hence, they found self-directed learning through reading to be frustrating and incomplete.

Workers agreed that they needed more opportunities to study and understand how race, class and gender are part of our world and of our practice. One worker called this process "unlearning and relearning" that which has been taught to us throughout our lives in multiple forums. "Opportunities for this type of learning are so rare" she argued that

it is a privilege to be in a place where its been okay and safe and supportive to take the lid off stuff, and unlearn what you need to and learn new things. It's a huge task.

This same worker said that one of the greatest difficulties in dealing with race, class and gender in everyday practice is the way that most workers pretend that they already know how to deal with race, class and gender. As she put it,

there is this feeling that we are supposed to already be there so we have to pretend that we are. In our heart of hearts we know that we're not, because we hear our own thoughts, and know that they are racist and sexist. But we are so afraid of that leaking out that, I think, we run scared from it.

When people refuse to engage in discussion or debate around a topic it is impossible to make any changes around it. The worker noted that this phenomenon is different from pretending that race, class and gender do not exist as issues. Instead, it operates more as a shared assumption that we all know that this is a problem but there is nothing to be gained by discussion. While the first worker attributed this stance of pretending that we already know to resisting the hard work associated with unlearning, a lack of opportunities and resources makes relearning inaccessible to most. Another worker argued that the culture of political correctness has caused many workers to censor themselves for fear of criticism from others. This self-censorship inhibits the development of keener analyses and social change strategies by limiting debate and the generation of alternatives and ideas. 
It also acts as a form of pretending that we are all in agreement on an issue and know everything there is know.

Political correctness is commonly thought to be a phenomenon of the late 80 s and early 90 s where those deemed to be speaking or acting in a way that oppresses others are sharply reproved or disciplined. While political correctness was largely an invention of the right in an attempt to curtail the growing diversity and progressive politics on American campuses (Matsuda, Lawrence, Delgado and Crenshaw, 1993), it also infiltrated progressive politics in certain ways. Political correctness was taken up by many in a superficial way and used as a power tactic to dominate political discussions. It was also used to analyse interpersonal politics in minute detail to the exclusion of other power relations and issues. Some progressive social workers reported a sense of "getting beat up" verbally when they attempted to participate in politically correct debates around race, class, gender, disability and sexual orientation. Some workers reported leaving social activism for a certain period of time as the preoccupation with micro personal relations made it difficult to get anything accomplished and was personally demoralizing.

The absence of opportunities to unlearn and relearn, resistance to the work of unlearning, and the culture of political correctness are not mutually exclusive. In many ways they play into each other. Sectors of the social justice community may have inadvertently played into this condition by demanding that workers meet standards of political correctness when resources to do so did not exist. Lacking opportunities and fear of reprieval creates an environment in which even workers committed to social justice may pretend to have a knowledge and skill base that they do not possess and have little likelihood of acquiring.

Rather than placing responsibility on social work institutions to change their practices, this 
formula makes the individual worker responsible for things "that take years to unlearn and relearn". As such it is a formula that is more compatible with neo-liberalism's political ideology of making the individual responsible, than with a progressive agenda which dialectically balances the responsibility of society and the individual.

Political correctness and pretending to already know are examples of ideological practices. As one worker noted "we live in society that benefits from the fact that most people have no idea that race, class and gender are ways in which we are controlled and oppressed". Both political correctness and pretending to already know shut down debate and possibilities for exchange of ideas, and explorations of more emancipatory ways to practice. They are actual concrete ways that workers avoid, and ensure that others avoid, engaging with critical analyses of our social world.

\section{Frameworks for Working with Race, Class and Gender}

While my informants agreed that race, class and gender are part of every social interaction and construction, most had difficulty producing stories about how race, class and gender overlap, contest, mutually reinforce and recreate themselves. When asked to supply stories on how race, class and gender are put together in practice, some workers argued that everything is raced, classed and gendered. While indisputable, this overgeneralizing does not help us to understand how these relations are ones of dominance and subordination. A number of workers focussed on how race, class and gender operate within their job sites and the social issues their agencies are mandated to address. In addition to the need to understand race, class and gender in one's specific work site, many workers argued that the kinds of problems which draw people into social work's purview are never unidimensional. Hence, there is a need to understand larger patterns of race, class and gender beyond 
the job site.

Some workers found that it was easier to talk about theoretical models than to discuss race, class and gender in everyday practice. My informants generated a number of frameworks, and pieces of frameworks for understanding race, class and gender. The most promising frameworks involved processes of understanding how race, class and gender operate within specific sites, as well as how they operate within longitudinal pattems and practices in larger society. Other frameworks were less tied into practice and workers had few suggestions around how to operationalize them.

A number of workers commented that race, class and gender in everyday practice are "necessarily complicated" and that we are wrong to try to uncomplicate them and make them simple. "There are no firm absolutist answers,... there is too much of a tendency to essentialize social groups, and over-generalize; over-homogenize them." Instead we need to develop a sense that "critical social analysis and community social action skills are what social work is all about". "Community agitation and organizing are integral to radical (progressive) social work and to understanding race, class and gender." Rather than developing a static notion of what oppressions are about, workers argued that practitioners should expect to spend their entire careers collectively defining and redefining race, class and gender and engaging with them from a community action and social justice frame. Site specific analyses must go hand in glove with larger social analyses. As a clinical worker put it, we must "focus on the how of race, class and gender and not so much the what and the who". This will provide us with the potential to map out how social relations such as race, class and gender are manifest in our daily practice and interactions while not separating them from larger social struggles.

A community worker argued that struggles to map out how to combat longitudinal patterns of oppression and exploitation must take place within an understanding of capitalism as "the dominant 
form of social organization". As such capitalism "requires and stands up on other oppressions in order to continue itself". A clinical worker agreed and argued further that "race, class and gender are not just ideologies, they are part of the power structure and are used and abused to advance the system of capitalism."

Bringing this analysis back down to the level of everyday practice, a health care worker argued that it is very important that we be aware that

we live in a society that works so hard to make it (race, class and gender oppression) invisible in a systemic way. It might acknowledge individual acts but it sure goes out of its way to deny any kind of institutionalized oppression.

Hence it is pivotal to progressive practice that we accept that "everything is structured by race, class and gender". Another worker argued that racism, sexism and class exploitation must be dialectically challenged in "our hearts and our minds but also in our institutions, the media, the government, the state, everywhere". Thus in every social work interaction we should not ask "will I encounter race, class and gender? But, how will I encounter race, class and gender, and how will I handle it?"

Incorporating the previously discussed notion of just standards, progressive practitioners must make it clear in their practice that existing race, class and gender structures are "unfair and unjust". This injustice takes the form of dominance and subordination in which "superiority and inferiority is simply assumed". Moreover, there is a "process of internalization of this superiority and inferiority depending on where you are within race, class and gender clusters." These processes of internalization are important for all to throw off as part of a multi-level strugg!e for equality and fairness. In particular, it is essential that dominant groups "give up their dominance and privilege". Rather than focus exclusively on the experience of the oppressed, some workers stressed the importance of understanding how those with "more power get it, sustain it and expand it". 
However, most groups are afraid to become involved in such as process as "we have no models for egalitarian relations. We have no models except one up and one down". Another worker quoted Audre Lourde (1990) noting that "we have no knowledge of how to have relationships across distance". Acknowledging the confusion experienced when trying to understand how to work within the context of multiple oppressions, some of my informants disagreed with Lourde's sentiments, arguing that we do have models for relationships across distance. These models are based in collective social action and include intervention schemas such as solidarity with people in oppressed social groups, using one's privilege to make social change, and finding ways to develop and maintain just standards within multi-perspective struggles. One worker used the example of her struggle to create reciprocal, solidarity-based practices based on principles of social justice. The worker, in this example, was a manager in a social service agency. As part of her role on the management team, she fought for higher wages, benefits and better working conditions for her staff, the majority of whom are poor, immigrant women of colour. She strongly supports their right to unionize despite the difficulties this would pose for herself and the other managers. She argued further that she supports her staff in social justice struggles in any way that she can. This example highlights the work of a manager collaborating with less privileged workers on a social justice agenda, using her privilege to create more space for this struggle, as well as redistributing her skills, resources and knowledge to an oppressed group.

\section{Summary}

The data and analysis above show that progressive social workers did not agree around how to understand how class, race and gender operate within the everyday practice of social work. This 
chapter looked at various stories that revealed the multiple layers necessary to gain insight into how race, class and gender organize and are organized by agencies, experience and structures. This chapter also looked at postmodern and anti-oppressive approaches. While promising in its capacity to deconstruct concepts, theory and identities, the postmodernist approaches discussed in my data were weak in the area of practice, divorced recognition strategies from redistribution strategies and theory from practice. Anti-oppressive practice is not sufficiently developed enough to evaluate in any meaningful way.

This chapter also discussed various discourses that deter the unlearning and relearning necessary in the development of critical consciousness around race, class and gender. Discourses of pretending to already know, and of political correctness were shown to act as an ideological buffer zone closing down debate and engagement with anti-racist, anti-sexist and class conscious practices. Finally, finding it easier to discuss frameworks than actual examples of race, class and gender, workers generated some promising ways of uniting longitudinal patterns of dominance and subordination with the need to understand how these relations organize our specific social work sites and practices. 


\section{Chapter Eleven}

\section{$\underline{\text { Conclusion }}$}

This thesis explored the way that progressive social workers formulate race, class and gender in everyday social work practice. Of particular interest were those pieces of practice that are closely identified with progressive social work, namely critical consciousness raising, individual and collective political action, integrating the experience of the client and the use of critical theory. It was expected that forms of social organization such as bureaucracy, hierarchy, documentation, and professionalism would constrain and modify this formulation in various ways. Further it was expected that social work agencies that are less hierarchical, and bureaucratic, less closely associated with professionalism, and formalized documentation, and more closely tied to the goals and social change struggles of mass movements would display more politicized and fluid ways of formulating race, class and gender in everyday practice.

The data show that liberalism is omnipresent and that, although committed to social justice, the practice of progressive social workers often reflected liberal rather than critical constructs and strategies. In other words, the practice of progressive social workers was often ideological in that it employed liberal constructs that conceal the ways that relations such as class, race and gender operate within our day to day activities, our social work agencies and the larger society to create and maintain systems of domination and subordination. Indeed, when critical practice techniques were not consciously and conscientiously employed, progressive social workers often unintentionally recreated rather than redressed oppression. 
Broadly speaking, race, class and gender discursive and non-discursive practices were liberalized through various processes of depoliticization. Depoliticization of social relations is one of the ways that domination and subordination are maintained in this society. Depoliticized social relations become merely benign markers of difference and diversity rather than processes through which a racially stratified, patriarchal, capitalist society regenerates and perpetuates itself. In addition to the work place related processes listed above -- hierarchical organization, bureaucracy, professionalism, and documentation -- the depoliticization of race, class and gender relations was evident the ways that my informants "talked" about their everyday lives and everyday social work practice.

A second major finding arises from the construction of race, class and gender within the social work milieu as very separate and separable phenomenon. Although significant commonalities exist, race, class and gender are depoliticized and neutralized within the social work arena in ways that are specific to how each of race, class and gender are organized within the relations of domination and subordination particular to the social work endeavor. This study revealed some of the ways that this depoliticization occurs within the everyday talk of social workers, as well as the way that services, the workers, the work and the agencies are organized.

Thirdly, progressive workers were fairly familiar with various critical theories on race, class and gender and could discuss them quite articulately. They also very poignantly described various mechanisms of social organization that made it more difficult to practice progressive, politicized, antioppressive social work practice. This meant that it was difficult to think about or act upon class/classism, race/racism and gender/sexism in a politicized or progressive way within their work and work sites. The data show that the use specific practice techniques associated with the critical 
model of social work enabled workers to talk about and act upon racism, classism and sexism in more liberatory and politicized ways. These techniques included critical consciousness raising, politica! organizing, solidarity, advocacy and other interventions.

However, a gap exists between the formal theory of progressive social workers and the way that they talked about class, race and gender in their practice. While the workers could talk about critical theory and could provide examples from their work which displayed the operationalization of various pieces of critical theory, at the level of practice theory or integrating a critical analysis into how they talked about their work, the workers tended to employ liberal or quasi-liberal notions of race, class and gender.

In short, the workers provided interesting descriptions and analyses of the operation of various mechanisms (for example, bureaucracy, standardization, and professionalization) that make it difficult for them to practice social work in a critical way. They then proved the validity of their claims by describing race, class and gender in static, quantitative and descriptive ways. Specifically, class was described in terms of poverty, gender in terms of violence and race in terms of access and language. Race was the only relation that was analyzed in somewhat relational terms. The other two were mainly utilized in a descriptive rather than a relational manner. Only within specific tactics of critical social work practice such as critical consciousness raising, or solidarity-based social work was it possible to glimpse a more fluid, mutual and political way of formulating race, class and gender. In sum, the findings in this thesis reveal the following:

1. This thesis shows "how" formulations and applications of race, class and gender are rendered as neutral, undynamic descriptors, that is, the processes through which liberalization 
and depoliticization occurs are delineated and discussed.

2. The findings and analysis also identify weak areas in the formulations and applications of progressive social workers. In particular, formulations of race, class and gender tend to be descriptions of various aspects of social strata rather than a change-directed social relations analysis. Additionally, these formulations incorporate aspects of pluralism, professionalism and therapeutism.

3. This thesis pinpoints processes that assist progressive social workers in critical practice and critical theorizing of race, class and gender. These processes include: critical consciousness raising, integrating the client's experience, solidarity-based interventions, using unions as tools, as well as other individual and collective political actions (these practices are listed on page 283).

4. The findings and analysis of this study highlight areas that critical practitioners and educators should focus on in order to enhance the development of critical theory and practice, namely integrating a social relations understanding of class, race and gender, developing ways to identify and decode ideology, developing ways to map out "how" class, race and gender organize agencies, clients and workers, as well as refining and extending our practice of critical consciousness raising, integrating the client's experience, solidarity-based interventions and other individual and collective political actions. 
5. The study found that agencies more closely tied to participatory, democratic mass movements for social change tended to reflect a more politicized and fluid construction of race, class and gender. Further, they experimented to a greater extent with new, less hierarchical and more political ways of providing services, organizing the work of the agency and organizing relations between and among workers and clients. The tie to the mass movements seem to provide an avenue through which the highly changeable and contested issues of race, class and gender could enter the agency and continuously be part of the emerging discourse and practice. Social work practitioners, clients and educators who are seeking ways to provide liberatory services need to find new ways of working with and through social change movements and causes.

\section{Race, Class and Gender Are Depoliticized Differently}

Race, class and gender were depoliticized or removed from arenas of political struggle and contestation in two major ways. The first way can loosely be termed processes. Depoliticization took place through various concrete processes associated with the ways that the work of the agency, the workers and the clients were organized. Race, class and gender were also depoliticized through various processes set up to address or resolve the specific issues of race, class and gender such as women's committees or multicultural organizational change strategies. The second form in which depoliticization occurred was through various discourses and discursive practices within the specific agencies and the larger social work milieu. In everyday life one cannot actually separate processes from discourses, however for the purposes of this analysis they will be viewed as overlapping, 
mutually reinforcing but separate phenomenon. These two forms of race, class and gender depoliticization will be discussed in turn below.

As discussed throughout this thesis, race, class and gender were found to be depoliticized through the ways that social work agencies, the work, the workers and the clients were organized. These depoliticization processes are referred to throughout this thesis as mechanisms. While these mechanisms were mobilized slightly differently around each of class, race and gender, there were seven mechanisms that were found to consistently neutralize race, class and gender within the social work milieu. These seven mechanisms included bureaucracy and hierarchy, documentation, professionalization, individualization and standardization, the relative distance from the government and the state, and the hiring or professionals. In addition to these seven mechanisms, each of race, class and gender was depoliticized through mechanisms specific to it and the power relations surrounding it.

The seven mechanisms "cooled out" issues and distanced them from their conflictual and everyday impacts and messiness. Instead, race, class and gender conflicts were managed and contained through recognizable and replicable, standardized processes and policies. Race, in particular, was the focal point for a number of organizational shange strategies that ensured that antiracism is incorporated into the existing way that this society constructs, organizes and meets human needs. While individual agencies may involve themselves in a comprehensive anti-racist overhaul of their services and policies, the larger patterns of how human services are organized and how needs are meet remain unchanged.

In addition to the impact of the seven mechanisms mentioned above, race, class and gender were each depoliticized through mechanisms specific to their location within larger structures and 
systems. ${ }^{1}$ Reflecting its pivotal position in the continuance of capitalist formations, processes associated with class were concerned with depoliticizing the specific relations of production and reproduction. For example, on of the major process politicizing class was the formalization of unionmanagement relations. Bureaucratic and legal processes such as Grievance Procedures, and Collective Bargaining serve to distance the average worker from the immediacy of the struggle over class inequality and exploitation. Despite this formalization many progressive workers reported creative and innovative ways to use this contradictory, social movement/bureaucratic, tool of ruling in social justice struggles.

Gender struggles were likewise "cooled out" through formal and bureaucratic mechanisms such as management-mandated women's committees. These committees acted as a pressure release valve for the gender struggles within the agency and were blamed for doing nothing as well as for promoting a narrow definition of women's interests. The social work milieu was also found to have developed various ways of depoliticizing gender struggles that reflect the specific terrain that is understood to belong to social work. In particular, processes such as therapy were found to have a distinctly gendered character and used in specific ways to depoliticize the multiple levels of women's subordinated position in society. In particular, the data showed that therapy and professionalism dovetailed in the way that workers formulated male violence. The focus of intervention was not on men and the need to end their violence, as well as the necessity of a wide range of equality-directed policies and services for women including pay and employment equity, affirmative action hiring, training and promotion, universal childcare, social housing and shelters for women who are assaulted.

1 These findings are consistent with those found in other critical ethnographies of social service agencies. Very clear discussion are found, for example, in $\mathrm{Ng}$ (1988) or Walker (1990). 
Instead, the focus was on the construction of survivors of male violence as clients in need of professional therapy.

Gender and therapeutism also dovetailed with the neoliberal emphasis on service provision through the private market. When women seek feminist services, one of their main options is private practice feminist therapy. While these feminist practitioners unquestionably provide a more supportive and analytically critical alternative to conventional private therapy, their positioning in the private market imports market relations and market-based inequalities into the social work realm. Moreover, in failing to problematize all aspects of therapy, it is reinforced as a, or perhaps, the solution to women's social problems. ${ }^{2}$

As mentioned above, race was depoliticized through funder requirements for anti-racist or diversity organizational change programmes. Through various changes in policies, the development of multi-"ism" advisory committees, and other pluralist policies, anti-racism was bureaucratized and recreated as a individual issue rather than a set of social relations of subordination and domination. Although many informants argued that anti-racist discourse and processes have not been fully coopted to reactionary agendas, there is a great deal of evidence to suggest that organizational change projects can as a major liberalizing and enervating force within this political struggle for social justice.

As a tri-relation constellation, race, class and gender were not found to be part of the public or the professional discourse in social work. Not surprisingly, this study found no specific depoliticization strategies aimed at this trio. Instead, the way that these three social relations are

2 For a discussion of some of the ways that feminist social work theory has failed to problematize key aspects of the long-term, individual therapy model see Baines (1997). 
constantly operated on and formulated as distinctly separate serves as its own depoliticization and containment strategy. Progressive social workers formulated and mobilized race, class and gender as largely separate and separable entities. As yet, there seems to be only very tentative and fledgling ways to think about this triumvirate in conjunction with each other. The next sections will develop these provisional ideas further.

The second major depoliticization theme involved the way that progressive workers and other participants in the social work scene "talked" about race, class and gender. This "talk" featured various pieces of analysis, theory and description, as well as some obvious gaps or holes in the discussion, description, analysis and theory. In large part this talk or discourse is rooted in the material relations or day-to-day organization of people's actions and activities. The discourse, for the most part, is reflective of, and reflected in, the structures of the agency, the social service community and wider society.

Progressive social workers reported that they resisted the post feminist, popular discourse of "sexism is not/no longer an issue". Progressive social workers simultaneously participated in a gender discourse that equated anti-sexism with therapeutic and professionalized ways of addressing male violence. This framing of anti-sexism as professional therapy obscures more comprehensive solutions to widespread male violence as well as erasing the many other ways that sexism is part of the social work arena. The talk of progressive social workers failed to incorporate any sense of realms outside of the arena of paid work and their associated gendered injustices. Thus, the workers were complicit in discourses that remove key areas of women's subordination from the political agenda. These key areas include women's subordination within the relations of reproduction, the domestic realm and unpaid caring labour. 
Workers were less likely to formulate race in ideological ways in their talk. The one exception to this was found in some worker's formulation of race as biologically-based, rather than socially constructed with material effects. On the positive side, progressive social workers accurately identified and resisted depoliticizing discourses focussing on race being the "in" issue while other issues are "out", as well as various pluralist themes and white, male backlash.

\section{Race, Class and Gender in Praxis}

Progressive social workers had two main strengths when it came to critical practice. First, they displayed a clear understanding of how the organization of their work and their agencies curtailed the potential for critical practice. Secondly, when telling stories about the way that they utilized pieces of practice such as critical consciousness raising or solidarity-based social work, progressive social workers put social relations and political struggle together in liberatory and exciting ways. However, as the discussion above emphasizes, at the level of everyday talk and critical analysis, progressive social workers had difficulty critically theorizing how race, class and gender were part of their practice. Instead, liberal constructs and theory dominated the way they talked about and theorized race, class and gender. In their "talk", progressive social workers lacked good, critical working definitions of race, class and gender, as well as ways to identify and decode ideological practices.

In short, workers often practiced social work in a critical manner, although they talked about race, class and gender in a liberal manner. Within practice or praxis, progressive social workers formulated race, class and gender in ways that were critical on a number of levels.

Firstly, the explicitly critical practice pieces of progressive social workers embody an 
extension of the public sphere into the bureaucratized and depoliticized realm of human services. This extension of the public is, in effect, the opening of new contestatory politicized spaces where needs and demands can be developed and negotiated (Yeatman, 1994: ix). Moreover it is a site where the kind of relations and strategies required to restructure the political economy and the symbolic-cultural valuation systems can and are being developed. For example, progressive clinicians referred clients to social action groups and community development groups in which they were active participants. This type of practice reveals the linkages between clinical and community work, between the personal and the political, and the shared interests and social justice agenda of both professionals and clients. Moreover, it helps to politicize clinical interventions and link them to larger social issues and structures. Thus, the clinical social work site becomes a place in which political issues are identified and debated, new types of relations between workers and clients are forged based on mutuality and collaboration, and new identities for workers and clients are possible and tentative systems of meaning can be explored.

Secondly, these critical pieces of practice and their corresponding formulations and applications embrace aspects of the classic questions raised by critical theory, namely, social structure, power, culture and human agency (Carspecken, 1996: 3). For example, as part of solidarity-based social work, progressive social workers consciously manipulated the privilege that saturates their professional positions within hierarchical bureaucracies. They facilitated clients efforts at individual and collective activism, they redistributed resources such as agency policy manuals and how to use them, agency materials and information, access to networks of service providers, and referrals to social action groups, they altered documentation and they advocated on behalf of clients and themselves at all levels of the agency, funders, the government and wider society. These 
manipulations and political actions represent an engagement with and resistance to present structural, power and cultural forms, as wel! as relations that prefigure more political egalitarian and participatory ways to organize social services and social life.

Finally, when utilizing the intervention techniques of critical practice, progressive social workers often met Fraser's (1997) theorization of the politics demanded by our present time, namely the unity of the politics of culture (deconstruction) with the politics of socioeconomic restructuring (redistribution). As one might expect, these formulations and critical practices did not explicitly identify deconstruction and socioeconomic restructuring. Instead they were operationalized as mutuality, collaboration, dialogue, solidarity, or sharing power. For example, in some cases, in order to protect clients from possible management retaliation, workers advocated on behalf of their clients without their clients express permission. In other cases, the same workers openly organized in collaboration with clients to oppose management or government changes to services and levels of benefits. These kinds of tactics reflected a level of fluidity and creativity as well as a sense of shared interests in a social justice agenda. As such, they foreshadow the development of new ways of understanding one's self and others within a struggle for restructuring systems of distribution (levels of benefits and services) as well as recognition (new group and individual identities and systems of meaning).

As discussed throughout this thesis, Gramsci argued that consciousness is a contradictory whole, containing pieces of ideology and material practices that have not yet been incorporated by ideology (Sassoon, 1987b). The practices of progressive social workers form this kind of contradictory whole. Their praxis, or theory in action, reveals a certain understanding of the themes of critical theory that workers had difficulty expressing when asked to theorize about race, class and 
gender. The findings and analysis in this chapter show that progressive social workers often incorporated ideological and liberal notions into their practices. These weaknesses existed alongside the critical praxes described below. Together they formed the contradictory whole that constitutes frontline, everyday progressive social work.

The list below adumbrates the pieces of progressive practice that facilitated critical race, class, gender social work praxis. These practices were present in stories workers told about each of these axes of subordination. That is, class did not produce more critical praxis than did race, or race more than gender. Some of the praxes, such as feminist pieces of social organization, have a closer association with worker's formulations of gender although the same type of stories were also told when discussing class and race. The practices themselves are discussed and analyzed in greater detail in the preceding chapters. However, as described in the section above, these practices contain promise in terms of the critical space they create within social work, their multilevel engagement with classic critical themes and the way they, often tentatively and awkwardly, unite aspects of the politics of culture and the politics of redistribution. 


\section{CRITICAL PRAXES}

1. structures

2. solidarity-based social work - using privilege

3. unions as tools

4. feminist pieces and practices of social organization - ways of organizing agencies and services

5. critical consciousness raising

6. multi-"ism" anti-racist work

7. race needs its moment

8. balancing experience and justice

9. racisms

10. negotiating professionalism, documentation, bureaucracy, hierarchy, individualization, standardization and hiring social justice fighters

11. frameworks for working with race, class and gender that stress the strategies above and "how" of race, class and gender operate within specific agencies as well as broader society 


\section{Recommendations and Ongoing Questions}

This study has identified a number of areas that require further critical analysis and operationalization. Weaknesses in how race, class and gender were formulated and applied were explored in each Chapter. Recommendations for how to redress some of the weaknesses are discussed below as are questions that require further investigation.

Further study and practice development is needed around the topic of the everyday operation of ideology. Progressive social workers require ways to identify and decode ideology in their everyday practices and those of the broader social work milieu. Training social workers as critical grassroots intellectuals and community activists rather than as technicians may provide part of the solution to the problem. ${ }^{3}$ Dorothy Smith's (1987) methodology of starting from the entry point of people's experience and mapping out how larger social relations organize our everyday lives is another approach that is compatible with this goal. Tentative and substantive pieces of these approaches could be seen in the stories and strategies of progressive social workers when they discussed frameworks for working with class, race and gender. While an important linkage must be maintained between critical theory and critical practice, these strategies must be based in the everyday details and realities of frontline social workers and their clients. For, as Langan and Lee point out, theoretical differences and weaknesses of critical social work will be resolved not through theorizing, but through practice and political struggle (1989: 10).

Innovative and critical ways of delivering services and developing practice was seen to be

\footnotetext{
3 I am drawing on the ideas of Goli Rezai-Rashti who focuses on the development of the
} critical, anti-racist pedagogy in everyday practice. See Rezai-Rashti (1995). 
more possible within those agencies that maintained ties to social change movements and activities. These ties seem to ensure that the agency maintained a certain degree of openness to new ways of contesting and combatting social injustices. For example, these agencies developed more comprehensive, multi-"ism" and political anti-racist organizational changes projects than had other types of agencies. This tie between services and mass movements can be seen to strengthen both (Baines, 1990). They are an important avenue for progressive social workers, clients and educators to pursue in the development of emancipatory practice, service delivery and social movements.

This study has noted some of the shifts within the social services community and client population resulting from the imposition of neoliberal economic and social policies. These policies are characterized by an erosion of social protections, the marketizing of social relations, the globalization of capitalism and "worsening of the life chances of millions" (Fraser, 1997: 3). Statements like those from the Ontario Minister for the Status of Women, Diane Cunningham, that women's services that publicly opposed government cutbacks would be audited and closed down, reveal the coercive agenda of neoliberal governments. It is no coincidence that existing cuts and job losses, increased caseloads and desperate clients create an atmosphere in which there is little time or energy to develop alternative and liberatory practices. Thus, within the Toronto social work milieu, neoliberalism has explicitly and implicitly reduced the possibilities for critical ways of thinking about and acting on social problems. Further research and experimentation is necessary to reveal how these restricted possibilities are impacting on the practice and theory development of progressive social workers. Progressive social workers need to continue to develop new ways to resist and restructure the policies and practices promoted by neoliberalism. The practices listed in Chart One earlier in this chapter may be a start in this direction. 
Further study is needed to reveal how class is rendered largely invisible in the social work endeavor. Workers must find new ways to deformalize and repoliticize class. Class is largely missing from the promising work of multi-"ism" anti-racist committees, Employment Equity Plans and antiracist organizational change programmes. It has been incorporated into structures such as bureaucracy, hierarchies and individualization so successfully that it is invisible within the social work arena except as the suffering of the very poor.

Class needs to be understood and applied in practice as a strategic relation that illuminates structural relations of production and reproduction within this capitalist formation. Strategies must not lose site of a focus on the dismantling of capitalism. Thus, the target of our interventions will remain on capitalist restructuring rather than on assisting clients to gain entry to the middle class or to adjust to poverty.

The depoliticization and repoliticization of gender also merits continued investigation and practice development. Within the context of progressive social work practice, work with survivors of male violence needs to be reframed in political terms. Workers must focus on broad-based socioeconomic and cultural demands in addition to progressive counselling interventions and political actions. Women require access to decent housing, good jobs, universal daycare, affirmative action training, education and hiring. A shift is also necessary at the cultural-symbolic level of society within systems of meaning that reinforce male and other forms of social violence, as well as female tolerance of it and dependency on males. Deconstructive strategies that focus on shifting everyone's sense of self, of gender and of agency in the world are required. In part, the binary opposition between male and female, and their associations with independence and dependence, and violence and passivity need to be restructured in more egalitarian and socially just ways. 
Part of the destabilization of gendered violence also requires a deconstruction of the binary opposition of female caregiving and male workerism. Progressive social workers need to develop ways to understand the ways that one's relationship to reproduction organizes longitudinal, unequal gendered, classed and racialized relations. Rather than acting in complicity with the erasure of the relations of reproduction and the idealization of the domestic realm, progressive workers need to find ways to expand notions of the public and the political to include these arenas of struggle.

Progressive social workers also need to be cautious of market and therapeutic approaches to social problems. While feminist counsellors and other political therapy practitioners provide important services to many, this pieces of service are only one small fraction of the solutions to women's suffering and inequality. The expansion of feminist therapy within the private market weakens rather than strengthens ties to broad-based social solutions and struggle. The dovetailing of private practice feminist therapy with the neoliberal emphasis on private market solutions further destabilizes public provision and collective solutions. Private practice feminist therapy is a rich area for further research as it operates at the conflux of the market, gender relations, psychology and feminism. Thus, many of the important issues facing critical practitioners overlap in this one area.

While progressive social workers have seized many of the political opportunities presented by the fluid and contested nature of the race/anti-racism discourse, in order to build more than just liberal reforms, strategies must integrate political economy (redistributive) and gender equality demands. Further they would do well to expand the mandate of multi-"ism" anti-racism committees so that race, class, gender and other axes of social injustice can be incorporated, perhaps awkwardly and in contradictory ways, into everyday liberatory praxis. In order to tie struggles for racial justice to the attainment and redistribution of real power, activists must learn from the lessons of other social 
movements that were coopted and dissipated through mechanisms that formalized, bureaucratized and liberalized their efforts. Part of this formalization and depoliticization process was possible because of the way that the interests of various groups were narrowly constructed. Hence, broad based, multi-issue support was not possible. Many of the anti-racist strategies already incorporate other axes of oppression. Progressive social workers must develop ways to expand these struggles while not diluting them to the point that they lose site of the end goal of restructuring the cultural and socioeconomic systems of this capitalist formation. Progressive social workers also need to continue to resist the ways that gender is sublimated to the "new" discourse of anti-racism.

Finally, progressive social workers need to find ways to formulate and apply race, class and gender in ways that reflect an understanding of these forces as social relations. Placing these forces within the context of socioeconomic and political struggle seems to help workers understand the dynamism of these relations, as well as the ways in which this understanding must be directed towards ongoing struggles for socialism and deconstruction. Placing a priority on the expansion and propagation of critical praxis seems the likeliest way of building this important genre of social work practice. 


\section{APPENDIX 1 \\ DISCUSSION GUDE - FOCUS GROUP A, SESSION 1}

\section{OVERVIEW}

1. What does it mean to be a radical practitioner?

What are the challenges of radical practice?

2. How do you understand the relationship, if any, between race, class and gender?

3. What does class/anti-classist social work mean to you?

4. What does gender/anti-sexist social work mean to you?

5. a) What does race/anti-racist social work mean to you?

Can we assume that there is always a class, a gender and a race issue involved in all our work?

5. b) How, if at all, is your work organized around race, class and or gender (official policies, operationalized policies, supervision, documentation, budgeting, work place relations, etc.)?

6. What happens when you attempt anti-racist, anti-sexist, anti-classist work? Can anyone provide a scenario or example of this?

7. Do you use any of the following components in your everyday practice -- critical consciousness raising, incorporating and politicizing the experience of the client, collective or individual political action, critical theory?

8. Is there component of the race, class, gender cluster that is easier to work with in your everyday practice? Which is it and how do you explain this?

9. If we were to say that critical consciousness raising, collective or individual political action, critical 
theory and incorporating and politicizing the experience of the client are all central components of radical social work practice, how would you see them as organized around race, class and gender?

10. Do practices organized around race conflict with, reinforce, undermine or in any way strengthen practices around class? around gender? If so, how? 
APPENDIX 2

\section{DISCUSSION GUIDE - FOCUS GROUP B, SESSION 1}

\section{OVERVIEW}

1. How are race, class and gender present in your work?

2. Is one of the "isms" easier to work in your workplace?

Do colleagues find one easier to work with? Can you provide an example?

Do clients find one easier to work with? Can you provide an example?

Do clients find one easier to understand? Why?

Do colleagues find one easier to understand? Why?

3. What does class/anti-classist social work mean to you?

4. What does gender/anti-sexist social work mean to you?

5. a) What does race/anti-racist social work mean to you?

Can we assume that there is always a class, a gender and a race issue involved in all our work?

5. b) How, if at all, is your work organized around race, class and or gender (official policies, operationalized policies, supervision, documentation, budgeting, work place relations, etc.)?

6. What happens when you attempt anti-racist, anti-sexist, anti-classist work? Can anyone provide a scenario or example of this?

7. Do you use any of the following components in your everyday practice -- critical consciousness raising, incorporating and politicizing the experience of the client, collective or individual political action, critical theory? 
8. Is there component of the race, class, gender cluster that is easier to work with in your everyday practice? Which is it and how do you explain this?

9. If we were to say that critical consciousness raising, collective or individual political action, critical theory and incorporating and politicizing the experience of the client are all central components of radical social work practice, how would you see them as organized around race, class and gender?

10. Do practices organized around race conflict with, reinforce, undermine or in any way strengthen practices around class? around gender? If so, how? 


\section{APPENDIX 3}

\section{INTERVIEW GUIDE - INTERVIEW A}

Generate a detailed profile of how the person's work, work organization and work practices are organized around race, class and gender, as well as a) the worker's understanding and mobilization of race, class and gender, and b) the worker's radical practices, and theory around the same.

1. Is there component of the race, class, gender cluster that is easier to work with in your everyday practice? Which is it and how do you explain this?

2. How, if at all, is your work organized around race, class and gender?

3. How do you understand the relationship, if any, between race, class and gender?

4. Can you provide an example of a time when you used critical consciousness raising on the job?

- How did race, class and gender fit into this?

5. Can you provide an example of a time when you used political struggle -- individual or collective - on the job?

- How did race, class and gender fit into this?

6. Can you provide an example of critically integrating the client's experience?

- How did race, class and gender fit into this?

7.a) What are the official policies of your work places regarding race, class and gender? (eg. sexial harassment, affirmative action, employment equity, organizational change, etc.)

7. b) How are these policies operationalized in work organization, supervision, documentation, budgeting, and workplace relations? 
8. How is race, class and gender formulated and mobilized in the various component parts of direct practice (please use examples where possible):

- needs assessment

- developing a (case) plan

- referrals

- counselling and support work with individuals, families, and groups

- crisis work

- networking

- staff meetings and administrative work

- follow-up work

- documentation

- consciousness raising

- political action 


\section{APPENDIX 4}

\section{INTERVIEW GUIDE - INTERVIEW B}

Generate a detailed profile of how the person's work, work organization and work practices are organized around race, class and gender, as well as a) the worker's understanding and mobilization of race, class and gender, and b) the worker's

radical practices, and theory around the same.

1. a) How do you understand the relationship, if any, between race, class and gender?

1. b) How do your client understand this relationship, if any?

2. Do you use any of the following components of practice?

- critical consciousness raising? Example? How did anti-racism, anti-sexism, or class struggle fit into this?

- critical theory? Example? How did anti-racism, anti-sexism, or class struggle fit into this?

- critical analysis of experience? Example? How did anti-racism, anti-sexism, or class struggle fit into this?

- collective or individual political action? Example? How did anti-racism, anti-sexism, or class struggle fit into this?

3. How is anti-racism, class consciousness and anti-sexism formulated and mobilized in the various component parts of direct practice (please use examples where possible):

- needs assessment

- developing a (case) plan

- referrals

- counselling and support work with individuals, families, and groups

- crisis work

4. What does class/anti-classist social work mean to you?

5. What does gender/anti-sexist social work mean to you?

6. What does race/anti-racist social work mean to you? 
7. Do practices organized around anti-racism conflict or reinforce or undermine practices around anti-sexism? around class struggle? Please give examples. 


\section{APPENDIX 5}

\section{DISCUSSION GUIDE - FOCUS GROUP A, SESSION 2}

Thanks to everyone. The initial results of the data analysis are fascination. I won't really have anything pulled together until the third meeting.

There are no right or wrong answers - a few people from both groups have told me that they were afraid the we weren't quite getting into the issues. However, it is important to remember that research groups are different than social action or community or support or therapy groups. They are intended to generate themes, ideas, unexpected insights and result. Hence they may, at times, feel inconclusive or frustrating to those of us who are used to tying up all lose ends in our attempts to mobilize people to change the world. Let me reassure you, that from my perspective, everything is going great.

How do other people feel? Would people consider a fourth meeting?

Go 'round on how people are feeling, any new aches and pains, the best fight back activity they have heard of recently, etc.

1. Think of a good mainstream social worker either in your agency or in another. How does your work around race, class and gender differ from theirs? BRAINSTORM ON BLACK BOARD

2. Where your work does not differ from theirs, why not, what is going on? Where your work do differ from theirs, what is going on?

3. Do you use any of the following components of practice?

- critical consciousness raising? Example?

- critical theory? Example?

- critical analysis of experience? Example?

- collective or individual political action? Example?

How are race, class and/or gender part of them? Example?

4. Can a worker of another, more privileged race, class and/or gender, such as a middle class, white woman, actually do good critical practice with clients or community from less privileged class, race, and gender locations? Why and why not? 


\section{APPENDIX 6}

\section{DISCUSSION GUIDE - FOCUS GROUP B, SESSION 2}

Thanks to everyone. The initial results of the data analysis are fascination. I won't really have anything pulled together until the third meeting.

There are no right or wrong answers - a few people from both groups have told me that they were afraid the we weren't quite getting into the issues. However, it is important to remember that research groups are different than social action or community or support or therapy groups. They are intended to generate themes, ideas, unexpected insights and result. Hence they may, at times, feel inconclusive or frustrating to those of us who are used to tying up all lose ends in our attempts to mobilize people to change the world. Let me reassure you, that from my perspective, everything is going great.

How do other people feel? Would people consider a fourth meeting?

Go 'round on how people are feeling, any new aches and pains, the best fight back activity they have heard of recently, etc.

I'm going to ask people to provide practice examples of various components of practice that have been identified as central to radical practice.

Is it okay with people if we give feedback to each other tonight on the examples we discuss? I hope that we can clarify some things and deepen each other's analysis. Okay?

1. Can anyone provide an example of critically integrating the client's experience into practice/

- What did it look like?

- When would you use it and when wouldn't you use it?

2. Can anyone give an example of when they used critical consciousness raising on the job with a client, other staff, supervisor, etc.?

3. Can anyone provide an example of political struggle on the job -- collective or individual?

- When would you use it and when wouldn't you? 


\section{APPENDIX 7}

\section{DISCUSSION GUIDE - FOCUS GROUP C, SESSION 1}

1. Explain that this is everyone's opportunity to comment on how things have gone so far and on the themes that are being generated by the data. Recap the research question, where I am going next with the research and what the collection process has been so far.

2. Walk through the diagrams. Ask people to comment anywhere that something does not make sense or where something resonates for them.

Stress that I am not married to this - it is preliminary. Out of respect for their data, $I$ have not discarded anything. This means $I$ have huge amounts of data and a number of possible dead ends that I am still pursuing.

3. Highlight gaps in the data and ask people what they make of them (listed on the bottom of each diagram). 


\section{APPENDIX 8}

\section{INTERVIEW GUIDE - INTERVIEW C}

1. How do you work with on your job?

$$
\text { - race - class - gender }
$$

2. How does your agency address Advisory Boards)

? (eg. Harassment Policy, Anti-racism Committees,

$$
\text { - race - class - gender }
$$

3. If you were to talk to a community group about race, class and gender, what would you say? Can you give me an example?

4. In what ways are still marginalized within your agency?

$$
\text { - race -- class - gender -- the three together }
$$

5. What kinds of things do you think can be done about this?
a) agency wide
b) society wide
c) interpersonally

6. If someone were to tell you that race, class and gender are inseparable, how would you respond? How would you explain it to a community meeting or to a client?

7. If someone were to complain to you that gender seerns to be taking a back seat to race, and that class is never addressed, how would you address this? 


\section{APPENDIX 9}

\section{INTERVIEW GUIDE - INTERVIEWS D, E, F, G, H, I}

Vary the order of questions 1,2 and 3 depending on the central mandate and clientele of the agency.

1. How is gender central to your work?

2. How is race central to your work?

3. How is class central to your work?

4. How does your agency address race, class and gender at a structural level -- hiring, harassment policy, anti-discrimination committees, organizational change, etc.?

5. If someone were to tell you that race, class and gender are inseparable, how would you respond?

6. Can you give me an example of involving race, class and/or gender?

- critical consciousness raising

- experience of the client

- political action (individual or collective)

7. When wouldn't you use race, class or gender in your work and why? 


\section{APPENDIX 10 - THEMES - FOCUS GROUP A-1}

\section{Group A - Tuesday, October 17}

\section{POSSIBLE INSTITUTIONAL THEMES SHAPING ANTI-RACIST, ANTI-SEXIST, ANTI- \\ CLASSIST PRACTICE}

mandate of agency

target population

population you end up with

relationship with supervisor

technological organization of work eg. phone hooked up to computer whicil records length of calls

many class/gender/class issues that are not acknowledged because we work by ourselves; also provides opportunity to do own radical px with minimal scrutiny

caseload - size and composition

funding cuts and threats of funding cuts

lack of support from colleagues

contract vs. full-time employment

have a certain maneuverability with short-term positions that will never go full-time as can resist pressures to work faster or less generously and no one will waste time correcting you

new workers vs. established workers (veterans)

young workers vs. mature, established workers

crisis work positions (usually temporary) vs. long term caseloads

part-time (eg. 7 hors/wk) vs. full-time caseloads

non-English vs. English speaking caseloads

multi-service vs. single service agency (in multi different sections of the agency deal with $r, g$, and/or c more or less well, also depends on the history of that section eg. recreation -- also workers tend to deal with ethnic issues in a divided way)

with a family to support vs. no dependents 
sole supporter and female vs. no dependents, male or female

for emergency welfare, most of the callers are white - why aren't the others calling; I have a fear that if we make this service too accessible the government will find out and cut it

\section{WHAT RAD SOCIAL WORKERS DO}

manipulate the policy/legislation/mandate of agency

build the union **

try to convince others that silence won't help

overextend themselves in community networking ${ }^{* *}$; sometimes seen to lack focus due to the largeness of their work and how they interpret agency mandate

see the biggest obstacles to client service and progressive px as fear and resignation

when a worker takes initiatives; gets stuck with all the work eg. position papers, lobbying, etc.; can stretch agency's position in these pieces of work but not produce a truly radical analysis

go beyond job description

talk up activism to co-workers

often seen by co-workers as the nicest to clients, as the most generous, as the worker they would like to have if they were a client - I say, what's holding you back

build client self-esteem

recognize privileged position (have the CEO's ear, have an MSW, am white, am middle class, as a woman have less privilege)

use the language of management against them eg. their mandates for service, turn political issues and lack of resources issues into management/administrative issues

ignore pressure for faster service units, faster phone calls, less referrals

autonomous work conditions provides great maneuverability for own work but have no control over or input into what other workers do

wish we had more support from co-workers; that's why I go to SWEAT 
many class/gender/class issues that are not acknowledged because we work by ourselves

don't get challenged to grow at work; one of 2 progressive social workers

always wanted a progressive supervisor with millions of years in the field to teach me and support me and show me everything, its never happened

\section{CLASS}

not just how much money people have, also class background, many clients are middle or upper income in background who are now very poor

who uses which service

- declassed clients - ex psychiatric as well as rehab clients with disabilities (eg. engineers) - understand class in a certain way because once had more privilege

- class is one of the isms that can change, unlike gender and race, although race changes with social construction, also sexual orientation changes

\section{RACE, CLASS, GENDER}

\section{CULTURE IS AN ISSUE, TOO: SOME CULTURES USE FAMILY NOT INSTITUTES}

- how did we miss the low-income people who need our service?

staff tend to be white and privileged for the most part

- staff without a degree, with a family to support can take far less risks

- started unionization recently, other at work could take risks, some workers didn't want their husbands to know

- class is one of the isms that can change, unlike $g$ and $r$, although $r$ changes with social construction, also sexual orientation changes

- a feminist collective has a clear mandate to be anti-racist, anti-sexist, anti-classist but has the bigger problem of how to get any funding, how to manage a collective, how to get the work done and have accountability 
- workers are harassed on the job or threatened with violence due to sexual orientation, gender or race; management does not back them up

-home workers are racially harassed in isolated environments; management does not support them

- can't use their illness as an excuse for racism and sexism

-lecturing at people for 2 minutes before they hang up doesn't work

- humour sometimes helps; throw in a sentence like you can't generalize

- when the white worker says she can't work with black clients this is the real problem; this is real power to harm ; addressed issue directly with worker and now feel like snitch if went to supervisor; believe that supervisor and whole office knows and nothing is done; just avoids this person but feels it is not enough

\section{RACE}

- language is a huge issue in terms of who uses which services

\section{- CULTURE IS AN ISSUE, TOO: SOME CULTURES USE FAMILY NOT INSTITUTES}

- for emergency welfare, most of the callers are white - why aren't the others calling; I have a fear that if we make this service too accessible the government will find out and cut it

when the white worker says she can't work with black clients this is the real problem; this is real power to harm ; addressed issue directly with worker and now feel like snitch if went to supervisor; believe that supervisor and whole office knows and nothing is done; just avoids this person but feels it is not enough 


\section{APPENDIX 11 - THEMES - FOCUS GROUP - B-1}

\section{FOCUS GROUP B - WED. OCT. 25 - 7-9PM}

\section{POSSIBLE GENERAL THEMES}

- large separation between workers and clients

- need to redistribute power

- need for staff composition to reflect composition of community

-need for client input mechanisms and control over services

- also for workers who communicate clients' concerns to be taken seriously, not marginalized or silenced

- need for open communication between staff within an agency

- context of work structures possibilities for anti- racism, classism, sexism work for radical practice

- medical model

- prison/corrections model

- self help model

- radical legal model

- community centre model/multi-service centre model

- Harris cutbacks and threats of layoffs

\section{RACE IS EXPRESSED THROUGH}

- absence of a population - within clients, staff, community

- due to immigration policies of Canada

- due to hiring policy of agency

- access issues

- language - service provision in language other than English

- tensions/relationships between tenants

- international work and support of international organizations

- pits prisoners against each other (divide and rule) 
-race gets more air time than other isms; kids get hassled by police

- Executive Director, a man, identifies if harassment has occurred

- predominantly clients of therapy are white, women of colour's sentences do not mandate counselling; the crimes they are convicted of are not seen to warrant it

- the view that women's issues have been deal with and we have now moved onto race issues

- split between administrative staff (women of color) and professional staff (white, well educated, professional women)

- larger systemic problem of access to education and the middle class - ie, who has the education and credentials to get the jobs and who does not

\section{GENDER expressed as}

- predominantly female staff at many agencies tho usually not feminist staff or administration

- sexual violence issues

- cover/overt support for same sex relationships (this would never be the case in male services

- experience of mother vs. father in caring and advocacy for disabled child

- nouveau fathers (very involved with the child fathers)

- predominantly but not exclusively it seems that mothers do disability rights work

- the view that women's issues have been deal with and we have now moved onto race issues

- gender is a dirty word

- the supervisor says she is not and never will be a feminist so just give it up

- Executive Director, a man, identifies if harassment has occurred

- same sex benefits for workers have just been approved in a multi-service agency

- support staff tend to be predominantly female and paid considerably less

- when certain addresses appear, the kid is going to get more hassle and harsher legal treatment from 
the cops

$-90 \%$ of clients in juvenile corrections are male

\section{CLASS}

-separation between clients and workers

- no route of input for clients

- little to no route of input for workers

- workers who attempt input on behalf of clients are marginalized or silenced like the clients are or perhaps in a new way exclusive to impertinent staff

- staff is all middle class, not all well educated in self help movement, multi service centre, all well educated in legal clinic, youth corrections, disability policy centre

- who gets education and who does not (access to education)

- regional disparity in who gets services and who does not

- we the enlightened self-helpers will teach you what to do

- provide a differences workshop and add in a power piece (ie. do you notice any particular group who has more power than others??)

- policy and research focus on ending legislated poverty

- when certain addresses appear the kid is going to get more hassle and harsher legal treatment from the cops

- everyone who comes in for service is poor so becomes irrelevant or lost in the whole scenario

\section{ALL ISMS}

- provide a differences workshop and add in a power piece (ie. do you notice any particular group who has more power than others??)

-amazed at how often isms intersect for clients and they have no sense of how one or the other plays out separate from the rest

- age, in juvenile corrections kids get treated poorly due to powerlessness of adolescents 


\section{WHAT IS NEEDED TO DO RADICAL SOCIAL WORK}

job stability

long term job

union

collective work structure

non-hierarchical structures

collegial support and understanding

consumer/worker input at all points in $\mathrm{px}$, administration, policy

funding that will not be pulled or threatened

Dept of Health outlawing advocacy work, the backbone of rad social work, how can we do our practice?????

recognition of power dynamics of age, education, experience, staff territorialism, legal mandates (eg. only MSWs can work with crisis callers)

find allies or comrades

progressive education in order to educate and support us in our work

need outside system to support our progressive goals in therapy

need whole structure of society to change

more time in the day

functional hierarchies where they are needed and appropriate (eg. everyone can't travel to all the conferences)

functional divisions of labour

small victories celebrated

horizontal restructuring of agency (possibly not a collective as there are horror stories) 
APPENDIX 12

\section{PRELIMINARY RESULTS DIAGRAM - RACE}

\section{STRUCTURES}

(Institutional/

Agency)

Access

3

Hiring

6

Policy

5

Anti-Racism

Committees 3

Agency Divide and Conquer Strategies 4
PRACTICE

(Worker)

Critical Consciousness

Raising 15

Compartmentalization 1 Who Takes the Risks 6

Doing Anti-Racism 11

Theory/Practice Split 2
LIVED

(Client)

NOTABLY ABSENT

- Government cuts

- Anti - racist structures

- Unions 
APPENDIX 13

\section{PRELIMINARY RESULTS DIAGRAM - CLASS}

\section{STRUCTURES \\ (Institutional/ \\ Agency) \\ Room to Initiate} Change 2

Hiring Practices

4

Unions

11

No Accountability

Systems 3
PRACTICE

(Worker)

Informal Relationship

to Supervisor 5

Threat of Job

Loss 1
LIVED

(Client)

Becoming Poor

10

Distrust of the

Poor 6

Poverty and

Disability 6
Who Articulates

Demands 9

Government Cuts 5

NOTABLY ABSENT

- Class is not an issue

- Critical consciousness raising

- Doing anti-class work

- egalitarian structures 
APPENDIX 14

\section{PRELIMINARY RESULTS DIAGRAM - GENDER}

PRACTICE

(Worker)
LIVED

(Client)

Motherwork 4 an issue 8

Work

Organization

2

Unions 3

(Institutional/

Agency)

Unions 3

Abuse/Violence

Progressive

Strategies

3

Feminist

Structures

2

Compartmentalization

1

\begin{abstract}
Abuse/
Violence 6
\end{abstract}

Youth 4

Sexual

Orientation

3

Government Cuts 4

\section{NOTABLY ABSENT}

- Hiring

- Critical consciousness raising

- Dolng anti -sexism

- Access

- Women's inequality in the unpaid realm 
APPENDIX 15

PRELIMINARY RESULTS DIAGRAM - RACE AND CLASS

STRUCTURES

(Institutional/

Agency)

\section{Access}

4

Education and

Hiring 5

Consumer Power

4

\section{PRACTICE}

(Worker)
LIVED

(Client)
Non - Pluralist

Work 1

Changeability of Class;

Not Race 3 
APPENDIX 16

PRELIMINARY RESULTS DIAGRAM - CLASS AND GENDER

STRUCTURES

(Institutional/

Agency)

Structures -

General 1
PRACTICE

(Worker)
Middle

Class

Hegemony 1

LIVED

(Client) 
APPENDIX 17

PRELIMINARY RESULTS DIAGRAM - GENDER AND RACE

STRUCTURES

(Institutional/

Agency)

Structures -

General 3
PRACTICE

(Worker)
LIVED

(Client)

Men 3

Gender is over;

Race is in 6

Harassment 3

Doing Anti -Sexist, Anti-Racism 3 
APPENDIX 18

\section{PRELIMINARY RESULTS DIAGRAM - RACE, CLASS AND GENDER}

STRUCTURES
(Institutional/
Agency)
Recreating
Privilege
21
Critical
Structures
30
Policy
6

Critique of
Mainstream
Structures
14

\section{PRACTICE}

(Worker)

LIVED

$\frac{\text { (Client) }}{\text { (C) }}$

Doing C,R,G

Work 26

Critical Consciousness

Raising 44

Critical Clinical

Work 23

Theory/Practice

Split 10

Experience

10

Research 11

Alignment 9

Burnout 8

Inseparable Three 14 
APPENDIX 19 - MAPPING - PART ONE

LEVEL ONE

POTENTIAL FOR OPPRESSIVE PRACTICE

\section{SIX MECHANISMS OF RULING}

1. Hiring those available

2. Individualization of Service

3. Standardization of Service

4. Agency Type - govt, quasi-govt or private

5. Target Populations - apolitical population

6. Clinical/Policy/Community Split

Threat of Privatizing and Privatizing

BUREA UCRACY

HIERARCHY

DOCUMENTATION

PROFESSIONALIZATION

Resisting Privatization Agendas

\section{SIX MECHANISMS THAT ENCOURAGE RADICAL PRACTICE}

1. Hiring social justice fighters

2. Collectivizing Service - political and social context

3. Non-standardized Service - personalized, fluid, contextual

4. Agency Type - non-govt or social change

5. Politicized target population

6. No clinical/policy/community split

POTENTIAL FOR ANTI-OPPRESSIVE PRACTICE 
EACH AGENCY'S DEGREE OF ENTRY INTO THE MARKET

\section{GENDER CONTAINMENT}

sexism is not/no longer an issue women's committees reproduction invisible

GENDER IN THE MOMENT'S STRUGGLE critical clinical personal is political reproduction is an issue agency structures agency organizational changes violence as a multiple demand multi - "ism" anti-racism

\section{RACE'S MOMENT}

(a moment can be liberatory and/or containing) just standards multi - "ism" anti-racism committees race needs it's moment external policies - Human Rights, Landlord Tenant, etc.

\section{CLASS CONTAINMENT}

union vs. management formalized

middle class hegemony

"the" poor

services we need/the relations we don't professionalization

RACE CONTAINMENT ethnospecific agencies access

language presence $=$ real change racism doesn't exist hiring

Harassment policies multi - "ism" committees gender is over/race is in white male hegemony cultural competence

\footnotetext{
professionalization
}

CLASS IN THE MOMENT'S STRUGGLE multi- "ism" anti-racism deprofessionalization solidarity social work using privilege 
APPENDIX 19 - MAPPING - PART THREE

JOB LOSS

BURN OUT

CUTS

EMANCIPATORY

POSSIBILITIES

(race, class and gender work) 
APPENDIX 20 - FINAL MAPPING - PART ONE

\section{CONTEXT:}

\section{NEOLIBERALISM}

DECLINE OF THE WELFARE STATE

ROOTS OF SOCIAL WORK

CHANGES IN DEMOGRAPHICS

\section{CLASS DN THE MOMENT'S STRUGGLE}

- messy notions of class

- structures

- solidarity \& using privilege

- unions as tools

$$
\begin{aligned}
& \text { - collective bargaining } \\
& \text { - collective action }
\end{aligned}
$$

- private practice as outside/inside

$$
\text { - sliding scale/free services }
$$

\section{CLASS CONTANMENT}

- union v. management formalization, depoliticization

- "the" poor naturalized

- middle class hegemony - recreating privilege/rights

- no redistribution of power

- cuts

- job loss and threats of job loss

- burnout

SIX MECHANISMS OF RULING/EMANCIPATORY POSSIBILITIES

(return to these in each subsequent section)

1. bureaucracy and hierarchy vs. horizontal and less bureaucratic

2. documentation vs. negotiated documentation

3. individualization/standardization vs. context, collectivisation and personalization

4. agency type - mandate, management, who runs it, target population

5. community-clinical-policy split vs. no split

6. hiring - professionals vs. social action fighters 
APPENDIX 20 - PART ONE - CONTINUED

\section{GENDER CONTAINMENT}

- sexism is not/no longer an issue

- the development of separate women's movements, committees

(( no development of women specific services and the invisibility of reproductive work))

\section{GENDER IN THE MOMENT'S STRUGGLE}

- personal is political/gender inequality is the context/still the issue

- unpaid reproductive work

- violence

- poverty

- agency overhaul a) inclusion and representation

b) affirmative action hiring, spots, board

- affirmative action referral sources

- critical clinical

- horizontal

- expert not professional

- development of feminist services

- no clinical-community-policy split

- debureaucratization

\section{RACE CONTAINMENT}

Liberal Strategies

- access

- language

- presence = change

- multi-"ism" strategies

- Advisory Committees

- inclusion

- skills \& empathy

- cultural competence

- ethno-cultural

- Policies

- Employment Equity - white women benefit

- ethnic not anti-racist

- not integrated

Non-Liberal

- white hegemony

- naming an agency ethno-specific when it isn't

((no hiring, Human Rights Code, Landlord Tenant Act)) 


\section{APPENDIX 20 - PART ONE - CONTINUED}

\section{RACE'S MQMENT}

- just standards

- multi-"ism" Anti-Racism Committee

- Political Culture/Climate; Political Correctness

- Race Needs Its Moment

- ethnospecific agency

- Policy

$$
\begin{aligned}
& \text { - hiring } \\
& \text { - Human Rights Code } \\
& \text { - Landlord Tenant Act } \\
& \text { - Access/Language } \\
& \text { - Employment Equity }
\end{aligned}
$$

EMANCIPATORY POSSIBLITIES

HOW RACE, CLASS AND GENDER MAY WORK TOGETHER:

- how political action, theory, critical consciousness raising and the experience of the client go together - possibilities for conceptual practices

- six mechanisms which nourish everyday anti-racist, class struggle, anti-sexist practice 
APPENDIX 20 - FINAL MAPPING - PART TWO

NEOLIBERALISM

DECLINE OF THE WELFARE STATE

ROOTS OF SOCIAL WORK

CHANGES IN DEMOGRAPHICS

CLASS CONTANMENT

SIX MECHANISMS OF RULING/EMANCIPATORY POSSIBILITIES

GENDER CONTANMIENT

RACE_CONTAINMENT

RACE'S MOMENT

(a moment may simultaneously be emancipatory and containing)

GENDER N THE MOMENT'S STRUGGLE

CLASS IN THE MOMENT'S STRUGGLE

EMANCIPATORY POSSIBILITIES

HOW RACE, CLASS AND GENDER MAY WORK TOGETHER 
APPENDIX 21

RESEARCH PROTOCOL - ETHICS SUBMISSION

\section{TITLE OF RESEARCH: RACE, CLASS AND GENDER IN THE EVERYDAY AND CONCEPTUAL PRACTICES OF RADICAL SOCLAL WORK}

\section{INVESTIGATOR: DONNA BAINES - (416) 923-3049}

\section{SUMMARY:}

This thesis is a multi-method critical ethnography which investigates the formulation and mobilization of race, class and gender in the direct practice of those social workers who self-identify as radical practitioners. Methodologically, the investigation will be strongly influenced by Dorothy Smith's $(1990,1987,1986)$ institutional ethnography and themes from participatory research. Data collection will take the form of focus groups, in-depth interviews and textual analysis.

Interview and focus group guides will be pre-tested with fully informed and consenting volunteers. Data collection will occur through the taping of sessions as well as through detailed note taking. Two focus groups of 6 to 8 participants, a note-taker and a moderator, are to run concurrently through the fall of 1995 . These groups will meet three times to discuss their direct social work practice in reference to themes of race, class and gender. The third session will act as a feedback loop for early data analysis and theory building.

Interviews of 1 to 2 hours in duration will take place with 8 to 10 radical social workers ( 1 interview per worker) through the winter of 1996. 


\section{SUBJECTS:}

The sample for this thesis will consist entirely of those social workers who self-identify as radical practitioners (feminist social workers, anti-racist social workers, marxist social workers, structural social workers). Primarily they will be approached through the voluntary organizations with which they are affiliated (SWEAT, The Dorothy Livesay Collective, etc.) and/or through social workers known to these individuals (snowball sampling). As a member of both the above-mentioned groups the researcher has been warmly invited to present at meetings of both associations. The researcher is seeking 6 to 8 participants for two separate focus groups to run concurrently for a total of 12 to 16 participants. In addition, 8 to 10 participants of the focus groups will be recruited to participate in in-depth interviews.

After hearing a brief presentation from the researcher and reading the information sheet, as professional, competent adults, these social workers will choose whether or not to be involved in the study. This is not a vulnerable population but a group of professional colleagues.

It will be stressed that as research participants they have the right to leave the project at any time, the right to speak off the record and the right to have part of their tape or all their tape erased.

\section{RISK/BENEFIT:}

There are no risks for those individuals who choose not to participate in the study. Risks for both the focus group and the interview participants are minimal but somewhat different. As the researcher I will ensure that the focus group participants receive complete anonymity in any and all data collection and analysis. In addition group participants will be asked to provide the same to each other although this cannot be enforced or guaranteed by the researcher. Participants run a slight risk 
of having their identities or ideas revealed to others beyond the group. However, as these are topics which these workers normally discuss and debate in the course of their work and social lives, the risk is minimal.

The same vulnerability will not exist in the interviews although the subjects in both the focus groups and interviews may at some point feel that they wish to retract something they have said, to delete all the data they have supplied, or to withdraw entirely from the research process. These options will be clearly and repeatedly explained to participants. In addition, participants may feel judged or critiqued by the interview/focus group questions or the discussion of other participants. It will be stressed that the goal of the focus groups and interviews is to gather the richest possible data and no judgement or critique is implied or intended at any point. The researcher will make herself available to debrief or provide reassurance to anyone who appears to be upset or made uncomfortable by the research process. Participants who speak off the record or leave the study may feel anxious as to the opinions of other participants continuing in the study. The researcher will provide reassurances and take the responsibility of establishing and maintaining a non-judgmental group orientation.

Benefits include opportunities to discuss contemporary and controversial issues in the presence of like-minded peers, to network with other radical social workers, and to build one's analysis and practice around crucial social work issues. The third meeting of the focus groups will include a discussion of preliminary findings and data analysis, as well as a chance to discuss possible strategies and future actions. This may well prove beneficial to those continuing to work and practice in this area.

In sum, the risks are minimal and not above and beyond what professionals might expect in 
everyday practice and social life. Benefits, on the other hand, are both direct in the form of networking and indirect in the form of possibilities to collectively develop one's own theoretical and practice base.

\section{METHOD FOR OBTAINING CONSENT:}

Two means of obtaining consent will be utilized. Individual or group presentations will be made by the researcher explaining the research project, the risks and benefits, confidentiality issues and their rights as research subjects. Group presentations will be made to SWEAT and to the Dorothy Livesay Collective. Individual presentations will be made to those social workers who are known to the researcher or the groups but not in attendance at these meetings. All questions will be fully answered. This will be followed up by an information sheet explaining the project, subject's rights, etc. to those individuals who express interest in participating. A consent form will be provided to each potential participant for review. Once the participant and the researcher are assured that the consent form and the project are fully understood the consent form will be signed and collected by the researcher. Other potential participants may wish to wait and mail in or provide the consent form to the researcher at a further date.

\section{CONFIDENTIALITY:}

The researcher will ensure that the names and identities of the participants are never revealed in any form. Moreover, work places and any other potentially identifying information will never be revealed. All tapes, notes and transcripts are to be kept in a locked file cabinet drawer in the researcher's office. There is only one other individual who has access to this office and this individual 
does not have a key to the researcher's file cabinet nor any motive to seek out this information or material. These materials will be destroyed at the end of the thesis project which is projected to be Summer 1997. 


\section{APPENDLX 22}

\section{CONSENT FORM - FOCUS GROUPS}

\section{TITLE OF RESEARCH: RACE, CLASS AND GENDER IN THE EVERYDAY AND CONCEPTUAL PRACTICES OF RADICAL SOCIAL WORK}

\section{ENVESTIGATOR: DONNA BAINES - (416) 923-3049}

I acknowledge that the research procedures described on the attached form and of which I have a copy, have been explained to me and that any questions that I have asked have been answered to my satisfaction. I also understand the benefits of joining the research study. The possible risks and discomforts have been explained to me. I know that I may ask now, or in the future, any questions I have about the study or the research procedures. I have been assured that records relating to me will be kept confidential and that no information will be released or printed that would disclose my personal identity without my permission. I have agreed to have the focus group tape-recorded but if I wish to withdraw my tape from the study at any time, I may do so. I may also choose to speak off-the-record at any time during the focus group.

I understand that my participation in this study is completely voluntary and that it is my decision whether or not to participate. I further understand that I am free to withdraw my participation from the study at any time.

I hereby consent to participate.

Name and Date

Signature

Witness and Date

Contact Donna Baines at (416) 923-3049 for information on the project. 
APPENDIX 23

INFORMATION SHEET - FOCUS GROUPS

TITLE OF RESEARCH: RACE, CLASS AND GENDER IN THE EVERYDAY AND CONCEPTUAL PRACTICES OF RADICAL SOCIAL WORK

\author{
INVESTIGATOR: DONNA BAINES - (416) 923-3049
}

\title{
1. THE STUDY
}

I am bolking for social workers who identify themselves as radical social workers (structural, feminist, anti-racist, marxist, post-structural, etc.) to be part of a focus group for a research project I am working on as part of $m y$ Ph.D in Social Work at the University of Toronto.

The focus groups will consist of 6 to 8 radical social workers, meet 3 times over the fall and winter of 1995/6. The sessions will be approximately 2 hours in length during which time we will discuss broad issues around our everyday practice and use of race, class and gender. Focus groups will be tape-recorded and notes will be taken.

2. RISKS AND BENEFITS There are various benefits and risks associated with participation in this research project. Benefits include an opportunity to discuss and organize one's thoughts around important issues that there never seems to be enough time on the job to analyze. In addition this study will provide you with an opportunity to network with like-minded social workers, explore innovative and exciting ideas and practices as well as identify problems in practice and theory and generate new alternatives and strategies.

Risks and discomforts include the possibility that either the questions presented by the researcher or the discussion of the participants may be seen as challenging, critical or judgmental. The goal of the focus groups and interviews is to gather the richest possible data and no judgement or critique is intended.

As the researcher I will ensure that the focus group participants receive complete anonymity in any and all data collection and analysis. Group participants will be asked to provide the same to each other, however this cannot be enforced in any meaningful way. Participants run a slight risk of having their identities or ideas revealed to others beyond the group. As these are topics which most radical social workers normally discuss and debate in the course of our work and social lives, the risk is minimal. It is important that focus group participants are very clear that they should not provide information that could, in any way, harm them or jeopardize themselves, their clients or their agency. 
APPENDIX 24

\section{CONSENT FORM - INTERVIEW}

TITLE OF RESEARCH: RACE, CLASS AND GENDER IN THE EVERYDAY AND CONCEPTUAL PRACTICES OF RADICAL SOCIAL WORK

\section{INVESTIGATOR: DONNA BANES - (416) 923-3049}

I acknowledge that the research procedures described on the attached form and of which I have a copy, have been explained to me and that any questions that I have asked have been answered to my satisfaction. I also understand the benefits of joining the research study. The possible risks and discomforts have been explained to me. I know that I may ask now, or in the future, any questions I have about the study or the research procedures. I have been assured that records relating to me will be kept confidential and that no information will be released or printed that would disclose my personal identity without my permission. I have agreed to have the interview tape-recorded but if I wish to withdraw my tape from the study at any time, I may do so. I may also choose to speak offthe-record at any time during the interview.

I understand that my participation in this study is completely voluntary and that it is my decision whether or not to participate. I further understand that I am free to withdraw my participation from the study at any time.

I hereby consent to participate.

Name and Date

Signature

Witness and Date

Contact Donna Baines at (416) 923-3049 for information on the research. 
APPENDIX 25

INFORMATION SHEET - INTERVIEW

\section{TITLE OF RESEARCH: RACE, CLASS AND GENDER IN THE EVERYDAY AND CONCEPTUAL PRACTICES OF RADICAL SOCLAL WORK}

INVESTIGATOR: DONNA BAINES - (416) 923-3049

\section{THE STUDY}

I am looking for social workers who identify themselves as radical social workers (structural, feminist, anti-racist, marrist, post-structural, etc.) to participate in an interview for a research project I am working on as part of $m y$ Ph.D in Social Work at the University of Toronto.

The interviews will take approximately one and a half to two hours. The interviews will discuss broad issues around our everyday practice and use of race, class and gender. All interviews will be conducted by myself. They will be tape-recorded and notes will be taken.

2. RISKS AND BENEFITS There are various benefits and ricks associated with participation in this research project. Benefits include an opportunity to discuss and organize one's thoughts around important issues that there never seems to be enough time on the job to analyze.

Risks and discomforts include the possibility that either the questions presented by the researcher or the discussion during the interview may be seen as challenging, critical or judgmental. The goal of the interviews is to gather the richest possible data and no judgement or critique is intended.

As the researcher I will ensure that interview participants receive complete anonymity in any and all data collection and analysis. It is important that participants are very clear that they should not provide information that could, in any way, harm them or jeopardize themselves, their clients or their agency. 


\section{BIBLIOGRAPHY}

Adamson, N., L. Briskin, and M. McPhail. (1988). Feminist organizing for change. Toronto: Oxford University Press.

Albert, M., L. Cagan, N. Chomsky, R. Hahnel, M. King, L. Sargent and H. Sklar. (1986). Liberating theory. Boston: South End Press.

Andersen, G.L. (1989). Critical ethnography in education: Origins, current status and new directions. Review of Educational Research. Fall, Vol. 59, No. 3: 249-270.

Bailey, B. and M. Brake. (1975). Introduction: Social work in the welfare state. In B. Bailey and M. Brake (Eds.), Radical social work. (pp. )New York: Pantheon Books.

Baines, D. (1997). Feminist social work in the inner city: challenges of race, class and gender. Affilia, Journal of Women and Social Work. Voume 12, Numner 3: 297-317.

Baines, D. (1990). Mass movement social work: Lessons in structures, relations and struggles. Unpublished master's project, Carleton University, Ottawa, Ontario.

Baines, C. T., P. M. Evans and S. Neysmith, (1993). Caring: Its impact on the lives of women. In C.T. Baines, P.M. Evans, and S. Neysmith, (Eds.) Women's caring. Feminist perspetives on social welfare. (pp. 11-35). Toronto: McClelland and Stewart.

Bannerji, H. (1995). Thinking through. Essays on feminism, Marxism and anti-racism. Toronto: Women's Press.

Banneri, H. (1993). Returning the gaze: An introduction. In Bannerji, H. (Ed.) Returning the gaze: Essays on racism, feminism and politics. (pp. xii-xxiv) Toronto: Sister Vision Press.

Barritt, L. (1984). Analyzing phenomenological descriptions.

Phenomenology and Pedagogy. Vol. 2, Number 1: 12-23.

Baudrillard, J. (1987). The ecstacy of communication. New York: Semiotext.

Benhabib, S. (1994). Feminism and the question of postmodernism. In Benhabibi, S. , J. Butler D. Comell and N. Fraser (Eds.) Feminist contentions: A philosophical exchange. New York: Routledge.

Bertrand, J. T., J. E. Brown, and Ward, V.M. (1992). Techniques for analyzing focus group data. Evaluation Review. Vol. 6, No. 2: 198-209.

Beveridge, Sir William. (1942). Social insurance and allied services. New York: The 
Macmillan Company.

Birmingham, M. (1994). The political ideology of social work in Ontario. Unpublished doctoral thesis, University of Toronto, Toronto, Ontario.

Bogdan, R. C. and S. K. Biklen. (1982). Qualitative Research from Education: An introduction to theory and methods. Toronto: Allyn and Bacon, Inc.

Borg, W. R. and Gall, M. D. (1989). Educational research. An introduction (fifth edition). New York and London: Longman.

Bolaria, B. and P. S. Li. (1988). Racial oppression in Canada. (Second Edition) (pp. 1325). Toronto: Garamond Press.

Brake, M. and B. Bailey. (1980). Contributions to a radical practice in social work. In M. Brake and B. Bailey (Eds.), Radical social work and practice. (pp. 7-25) London: Ed Arnold.

Brown, C. (1994a). Feminist postmodernism and the challenge of diversity.

In A. Chambon and A. Irving (Eds.) Essays on postmodernism and social work. (pp. 35-48). Toronto: Canadian Scholar's Press.

Brown, C. (1994b). Feminist therapy in the postmodern era: Epistemological and practical contributions to the women's movement. Unpublished Comprehensive Paper, University of Toronto, Toronto, Ontario.

Butler, J. (1994). Contingent foundations: Feminism and the question of 'postmodernism'. In Benhabibi, S. , J. Butler D. Comell and N. Fraser (Eds.) Feminist contentions: A philosophical exchange. New York: Routledge.

Burbach, R. (1997). The rise of postmodern marxism: Or virtually existing socialisms. Union for Radical Political Economics Newsletter, 28. Number 2, 4-11.

Burghardt, S. (1986). Marxist theory and social work. Social work treatment. In F. Turner (Ed.), Social work treatment. New York: Free Press.

Burghardt, S. (1982). The other side of organizing. Resolving the personal dilemmas and political demands of daily practice. Vermont: Schenkman Books, Inc.

Burstow, B. (1992). Radical feminist therapy: working in the context of violence. Newbury Park, California: Sage Publications.

Campfens, H. (1988). Forces shaping the new social work in Latin America. Canadian Social Work Review. Volume 5, Winter: 9-27. 
Canadian Association of Social Work. (1994). Code of Ethics. Ottawa: self-published.

Carniol, B. (1990). Structural social work: Maurice Moreau's challenge to social work practice. Journal of Progressive Human Services. Vol.1, No. 4: 1-25.

Carniol, B. (1987). Case critical. The dilemma of social work in Canada. Toronto: Between the Lines.

Carniol B. (1979). A critical approach in social work. Canadian Jounal of Social Work Education, 5. 1: 95-111.

Carspecken, P. F. (1996). Critical ethnography in education research. New York and London: Routlege.

Carty, L. and D. Brand (1993) Visible minority women: A creation of the Canadian state. In Bannerii, H. (Ed.) Returning the gaze: Essays on racism, feminism and politics. (pp. xii-xxiv) Toronto: Sister Vision Press.

Chambon, A. S. (1994). Postmodernity and social work discourse(s): notes on the changing language of a Profession." In A.S. Chambon and A. Irving (Eds.), Essays on postmodernism and social work. Toronto: Canadian Scholars' Press Inc.

Collins, B.G. (1986). "Defining feminist social work." Social Work. 31, 3:214-219.

Corrigan, P. and P. Leonard. (1978). Social work pactice under capitalism. A Marxist approach. London: The Macmillan Press Ltd.

Davis, A. (1989). Women, culture and politics. New York: Random House.

Davis, L. and E. Proctor. (1989). Race, gender and class. Guidelines for practice with individuals, families, and groups. New Jersey: Prentice Hall.

Dominelli, L. (1988). Anti-racist social work. London: Macmillan.

Dominelli, L. and E. McLeod. (1989). Feminist social work. London: Macmillan.

Doyle, $\mathrm{R}$ and L. Visano. (1987). A time for action! Access to health and social services for members of diverse cultural and racial groups in metropolitan Toronto (Report I). Toronto: Social Planning Council of Metropolitan Toronto.

Epstein, L. (1993). The therapeutic idea in contemporary society. Unpublished manuscript: University of Toronto, Toronto, Ontario. 
Featherstone, B. and B. Fawcett. (1994) Oh no! Not more isms: feminism. postmodernism, poststructuralism and social work education. Paper presented to the 27th Congress, International Association of Schools of Social Work.

Ferguson, S. A. (1996). Towards an anti-racist social service organization. Journal of Multicultural Social Work., Vol. 4(1): 35-48.

Fernandez, J. P. (1991). Managing a diverse work force: Regaining the competitive edge. Toronto: D.C. Heath and Company.

Fook, J. (1986). Feminist contributions to casework practice. In Marchant, H. and B. Wearing (Eds.). Gender reclaimed. Women in social work. (pp. 54-63) Sydney, Australia: Hale and Iremonger.

Fook, J. (1993). Radical casework. Sydney: St. Allen and Unwin.

Forcas, D. (1988). An Antonio Gramsci Reader. New York: Schoken Books.

Foucault, M. (1978). The history of sexuality: An Introduction. Volume 1. New York: Vintage Books.

Foucault, M. (1977). Discipline and punish. The birth of a prison. First American Edition. New York: Pantheon Books.

Foucault, M. (1975). The birth of the clinic: An archeology of medical perception. New York: Vintage Books.

Fraser, N. (1997). Justice interruptus. Critical reflections on the "postsocialist" condition. New York and London: Routledge.

Fraser, N. (1989). Unruly practice: power, discourse and gender in comtemporary social theory. Minneapolis: University of Minneapolis Press.

Friere, P. (1974). Pedagogy of the oppressed. New York: The Seabury Press.

Galper, J. H. (1975). The politics of social services. New Jersey: Prentice Hall.

Gilroy, J. (1990). Social work and the women's movement. In B. Wharf (ed.), Social work and social change in Canada. (pp. 52-78). Toronto: McClelland and Stewart Inc.

Glaser B.G. and A. L. Strauss. (1967). The discovery of grounded theory. Strategies for qualitative research. Chicago: Aldine Publishing Company. 
Gordon, L. (1988). Heroes of Their Own Lives. The Politics and History of Family Violence. New York: Penguin Books.

Gorman, J. (1993). Postmodernism and the conduct of inquiry in social work. Affilia. Vol.8, No. 3, Fall: 351-361.

Gowdy, E. A. (1994). From technical rationality to participating consciousness. Social Work. Vol. 39, No. 4: 362-370. Hill.

Greenspan, M. (1983). A new approach to women and therapy. New York: McGraw-

Green, C. (1993). Thinking through Angela Y. Davis's Women, race and class. In Bannerji, H. (Ed.) Returning the gayze. Essays on racism, feminism and politics. (pp. 153-166) Toronto: Sister Vision Press.

Habermas, J. (1971). Knowledge and Human Interests. Boston: Beacon Press.

Hale, Judy. (1983). Feminism and social work practice. In Jordan, B. \& N. Parton, eds. The political dimensions of social work. (pp. 167-187). Oxford: Basil Blackwell.

Hale, S. (1995). Controversies in sociology. A Canadian introduction. (Second edition). Toronto: Copp Clark Ltd.

Hall, B. (1981). Participatory research, popular knowledge and power: A personal reflection. Convergence. Vol 3.: 6-19.

Hall, B. (1979). Participatory research: Breaking the academic nonopoly. In J. Niemi (Ed.) Viewpoint on adult education. (pp. 44- 69) Illinois: Northern Illinois University. 24-32.

Hall, B. (1975). Participatory research: An approach fc: change. Convergence. Vol. 2:

Hanson, J. (1996). Learning democracy: Working at the university, studying at the brothel. Socialist Studies Bulletin. Number 46 (October-November-December): 60-70.

Harding, S. (1981). What is the real material base of patriarchy and capital." In Sargent, L. (Ed.) Women and revolution. (pp. 135-164) Boston: South End Press.

Hart, J. (1980). It's just a stage we're going through: the sexual politics of casework." In M. Brake. and R. Bailey (Eds.), Radical social work and practice. (pp. 43-63) London: Edward Arnold (Publishers) Ltd. 
Hartman, H. (1981). The unhappy marriage of Marxism and feminism. Towards a more progressive union. In L. Sargent, L. (Ed.) Women and revolution. (pp. 1-42) Boston: South End Press.

Harvey, D. (1989). The condition of postmodernity. Oxford: Blackwell.

Hasenfield, Y. (1987). Power in social work practice. Social Services Review. Sept.

Henry, F., C. Tator, W. Mattis and T. Rees. (1995). The colour of democracy: racism in Canadian society. Toronto: Harcourt Brace and Company.

Hick, S. F. (1991). An ethnography of an Ontario welfare office: The reproduction of labour market relations. Unpublished doctoral thesis, University of Toronto, Toronto, Ontario.

Hick, S. F. (1989). Standpoint social analysis: Towards and analysis of social workers' practice in governing institutions. Unpublished comprehensive paper, University of Toronto, Toronto, Ontario.

Howse, Y. and H. Stalwich. (1990). Social work and the First Nation movement: Our children, our culture" In B. Wharf, (Ed.) Social work and social change in Canada. (pp. 79-113). Toronto: McClelland and Stewart Inc.

Hudson Institue Canada. (1991). Workforce 2000. Montreal: The Hudson Institute.

Hudson, A. (1989). Changing perspectives: Feminism, gender and social work. In Langan, M. and P. Lee (Eds.) Radical social work today. (pp. 70-96) London: Unwin Hyman.

Husband, C. (1980). Culture, context and practice: Racism in social work. In Brake, M. and R. Bailey (Eds.) Radical social work and practice. (pp. 64-85). London: Edward Arnold (Publishers) Ltd.

Hutchinson-Reis, M. (1989). And for those of us who are Black? Black politics in social work. In Langan, M and P. Lee (Eds.) Radical social work today. (pp. 165-177) London: Unwin Hyman.

Irving, A. (1994). From image to simulacra: The modern/postmodern divide and social work. In Chambon, A.S. and A. Irving (Eds.) Essays on postmodernism and social work. (pp. 21-34) Toronto: Canadian Scholars' Press Inc.

Jackson, B. W. and E. Holvino. (1988). Developing multicultural organizations. Creative Change: The Journal of Religion and the Applied Behavioral Sciences, 9. Number 2, Fall: 28-41.

Jacobs, C. and D. Bowles, eds. (1985). Ethnicity and race. Critical concepts in social 
work Silver Springs, MD: National Association of Social Workers,.

Jeffrey, D. (1994). Feminist social workers: Reconciling theory in practice. Unpublished mater's thesis, Ontario Institute for Studies in Education, Toronto, Ontario. Blackwell.

Jordan, B. and N. Parton. (1983). The political dimensions of social work. Oxford: Basil

Kalotay, J. and W. Reynolds. (1991). A workplace of one's own: The experience of feminist social workers moving to private practice. Unpublished Masters' Thesis: Carleton University, Ottawa, Ontario. 30-34.

Karp, H. B. and N. Sutton. (1993). Where diversity training goes wrong. Training. July,

Katz, J. (1978). White awareness: Handbook for anti-racism training. Norman: University of Oklahoma Press.

Keefe, T. (1981). Empathy skills and critical consciousness. Social casework. Vol. 61, No. 7: 307-313.

Kirby, S. L. and K. McKenna. (1989). Experience, research, social change. Methods from the margins. Toronto: Garamond Press.

Krane, J. (1985). The transformation of women into mother protectors: An examination of child protection in cases of child sexual abuse. Unpublished doctoral thesis: University of Toronto, Toronto, Ontario.

Langan, M. and P. Lee. (1989) Whatever happened to radical social work. In Langan, M. and P. Lee (Eds.), Radical social work today. (pp. 1-19) London: Unwin Hyman.

Lather, P. (1991). Getting smart. Feminist research and pedagogy with/in the postmodern. New York: Routledge.

Lather, P. (1988). Feminist perspectives on empowering research methodologies. Women's Studies International Forum. Vol. 11, No. 6: 569-581.

Lather, P. (1986a). Issues of validity in openly ideological research: Between a rock and a soft place. Interchange. Vol. 17, No. 4: 63-79. 257-277.

Lather, P. (1986b). Research as praxis. Harvard Educational Review. Vol. 56, No. 3: 
Leonard, P. (1994). Knowledge/power and postmodernism. Canadian Social Work Review. Vol. 11, No. 1, Winter.

Leonard, P. (1975). Towards a paradigm for radical practice. In Bailey, B. and M. Brake (Eds.), Radical social work. (pp. 46-61). New York: Pantheon Books.

Levine, $H$. (1982). The personal is political: Feminism and the helping professions. In G. Finn and A. Miles (Eds.), Feminism from Pressure to Politics . (pp. 233-267). Montreal: Black Rose Books. Pluto Press.

London Edinburgh Weekend Return Group. (1980). In and against the state. London:

Longres, J. F. (1986). Marxian theory and social work practice. Catalyst: A Socialist Journal of the Social Services, 5 (4): 13-34.

Lourde, A (1990). Age, race, class and sex: Women redefining difference. In Ferguson, R., M. Gever, T.T. Minh-Ha, C. West (Eds.). Out there: Marginalization and comtemporary culture. (pp. 281-288). Cambridge: MIT Press.

Maguire, P. (1993). Challenges, contradictions and celebration: Attempting participatory research as a doctoral student. In Parker et al (Eds.). Vocies of change. Participatory research in the United States and Canada. Westport, CT: Bergin Garvey.

Maguire, P. (1987). Doing participatory research: A feminist approach. Amherst, MA: Center for International Education.

Marchant, H. and B. Wearing. (1986). Introduction. In Marchant, H. and B. Wearing (Eds.), Gender reclaimed: women in social work. (pp. 11-13). Sydney: Hale and Iremonger.

Marcus, G.E. and M.J. Fischer. (1986). Anthropology as cultural critique: An experimental moment in the human sciences. Chicago: University of Chicago Press.

Marshall, T.H. (1950). Citizenship and social class. London: Pluto Press.

Matsuda, M.J., C. R. Lawerence, R. Delgado, K. W. Crenshaw. (1993). Words that wound. Critical race theory, assaultive speech, and the First Amendment. Boulder, Colorado: Westview Press.

Mayo, M. (1975). Community development: A radical alternative? In B. Bailey and M.Brake (Eds.), Radical social work. (pp. 129-143). New York: Pantheon Books.

McCarthy, C. and W. Crichlow. (1993). In McCarthy, C. and W. Crichlow, (Eds.) Race, 
identity and representation in education. (pp. xiii-xxix ) New York: Routledge.

McLaren, P. and P. Leonard. (1993). Paulo Friere: A critical encounter. London and New York: Routledge. Education.

McNiff, J. (1988). Action research. Principles and practice. Hong Kong: Macmillan

Moffat, K.J. (1996). Multiple ways of knowing: Social work knowledge and ethics in the technological era. Unpublished doctoral thesis, University of Toronto, Toronto, Ontario.

Mohanty, C. (1993). On race and voice: Challenges for liberal education in the 1990s. In Thompson, B. and T. Sangeeta, (Eds.) Beyond a dream deferred. (pp.41-64) Minnesota: University of Minnesota Press.

Mohanty, C. (1991a). Introduction: Cartographies of struggle. In C. Mohanty, A. Russo and L. Torres (Eds.), Third world women and the politics of feminism. (pp. 1-50) Indiana: Indiana University Press.

Mohanty, C. (1991b). Under western eyes: Feminist scholarship and colonial discourses. In C. Mohanty, A. Russo and L. Torres (Eds.), Third world women and the politics of feminism. (pp. 51-80) Indiana: Indiana University Press.

Moffat, K.J. (1996). Multiple ways of knowing: Social work knowledge and ethics in the technological era. Unpublished doctoral thesis, University of Toronto, Toronto, Ontario.

Moran, R. and P. Harris. (1991). Managing cultural differences: High-performance strategies for a new world and business (third edition). Houston, Gulf Publishing Company.

Moreau, M. (1989). The politics of social work practice: From a clinical to a structural approach. Montreal: Universite de Montreal, unpublished manuscript.

Moreau, M. J. (1981). A comparative study of the preferred helping networks of women and men. Unpublished doctoral thesis, Columbia University, New York City, New York.

Moreau, M. J. (1979). A structural approach to social work practice. Canadian Journal of Social Work Education. 5, 1: 78-94.

Moreau, M. J. (no date). The politics of social work practice: From a clinical to a structural approach. Draft Paper, Faculty of Social Work, University of Montreal.

Moreau, M. and L. Leonard. (1989). Empowerment through a structural approach to social work. A report from practice. Ottawa: Carleton University Graphic Services. 
Publications.

Morgan, D. (1988). Focus groups as qualitative research. Newbury Park: Sage

Morgan, P. (1981). From battered wife to program client: the state's shapping of social problems. Kapitalistate, 9, 17-39.

Morrow, E, (1996). Telephone interview, Toronto, Ontario.

Mullaly, $\mathbf{R}$ (1995). Working in the belly of the beast: Surviving (and xucceeding) as a social worker in traditional agencies. Toronto: Faculty of Social Work Colloquim, University of Toronto.

Mullaly, R. (1993). Structural social work. Ideology, theory and practice. Toronto: McClelland and Stewart Inc.

Mullaly, R and E. Keating. (1991). Similarities, differences and dialectics of radical social work. Journal of Progressive Human Services. 2, 2: 49-78.

$\mathrm{Ng}, \mathrm{R}$ (1997). Conversations, with Roxana Ng. Ontario Institute for Studies in Education, Toronto, Ontario.

Ng, R. (1993a). Sexism, racism, Canadian nationalism. In H. Bannerji (Ed.), Returning the gaze: essays on racism, feminism and politics. (pp. 182-196). Toronto: Sister Vision Press.

Ng, R. (1993b). Racism, sexism, and nation building in Canada. In McCarthy, C. and W. Critchlow, (Eds.) Race, identity and representation in education. New York: Routledge.

$\mathrm{Ng}, \mathrm{R}$. (1988). The politics of community services - immigrant women, class and the state. Toronto: Garamond Press.

$\mathrm{Ng}, \mathrm{R}, \mathrm{G}$. Walker, and J. Muller. (1990). Problematizing community organization and state. In R. Ng, G. Walker, and J. Muller (Eds.), Community organization and the Canadian state. (pp. 13-30). Toronto: Garamond Press.

O'Brien, C-A. (1993). Theories of Race, Racism and Racial Formation. Toronto: Unpublished manuscript, University of Toronto, Toronto, Ontario, Canada.

Omi, M. and H. Winant. (1986). Racial formation in the United States. From the 1960s to the 1980s. New York: Routledge.

Orloff, A. S. (1993). Gender and the social rights of citizenship: The comparative analysis of gender relations and welfare states." American Sociological Review. Vol.58, \#3, 303-325.

Otter, L. (1986). Domestic violence: A Feminist Perspective with Implications for 
Practice. In $\mathrm{H}$ Marchant and B. Wearing (Eds.), Gender reclaimed: Women in social work. (pp. 104-119). Sydney: Hale and Iremonger.

Pardeck, J. T., J. W. Murphy and J.M. Choi. (1994). Some implications of postmodernism for social work practice." Social Work. Vol. 39, No. 4: 343-345.

Park, P. (1993). Voices of change. Participatory research in the United States and Canada. Westport, CT: Bergin Garvey.

Parton, N. (1994). 'Problematics of government', (post) modernity and social work. British Journal of Social Work. 24, 9-32.

Petruchenia, J. (1990). Anti-racist welfare practice with immigrants. In J. Petruchenia, and R. Thorpe (Eds.), Social change and social welfare practice.(pp. 48-61). Sydney: Hale Iremonger.

Petruchenia, J. and R. Thorpe (1990). Introduction. In J. Petruchenia and R. Thorpe (Eds.), Social change and social welfare practice. Sydney: Hale Iremonger.

Pozatek, E. (1994). The problem of certainty: Clinical social work in the postmodern era. Social Work. Vol. 39, No. 4: 396-345.

Razack, S. (1997). Lecture, Ontario Institute for Studies in Education, Toronto, Ontario.

Razack, S. (1993). Storytelling for social change. In Bannerji, H. (Ed.) Returning the gaze. Essays on racism, feminism and politics. (pp. 83-100) Toronto: Sister Vision Press.

Rebick, J. and K. Roach. (1996). Politically speaking. Toronto: Douglas and McIntyre.

Rees, S. (1992). Achieving power. Practice and policy in social welfare. North Sydney: Allen Unwin.

Reynolds, B. C. (1963). An uncharted journey. New York: Citadel Press.

Reynolds, B. C. (1951). Social work and social living. New York: Citadel Press.

Reynolds, B. C. (1946). Rethinking social casework. San Diego: Social Service Digest.

Rezai-Rashti, G. (1995). Multicultural education antiracist eduction, and a critical pedagogy: Reflections on everyday practice. In Ng, R., P. Staton, and J. Scane (Eds.) Antiracism, feminism and critical approaches in education. (pp. 3-20) Toronto: OISE Press.

Rose, N. (1994). The death of the social. Unpublished manuscript, Goldsmith College, 
London, England.

Rose, N. (1992). Disadvantage and power after the welfare state. Unpublished manuscript, Goldsmith College, London, England.

Rose, N. (1990). Governing the soul: The shaping of the private self. New York: Routledge.

Russo, A. (1991). "We cannot live without our lives". White women, antiracism, and feminism. In Mohanty, C., A. Russo and L. Torres (Eds.) Third world women and the politics of feminism. (pp. 297-313) Indiana: Indiana University Press.

Saleeby, D. (1994). Culture, theory, and narrative: The intersection of meanings in practice. Social Work. Vol. 39, No. 4: 351-361.

Sands, R. G. and K. Nuccio. (1992). Postmodernist feminist theory and social work. Social Work. Vol 37(6): 489-494.

Sargent, L., ed. (1981). Women and revolution. Boston: South End Press.

Sarvasy, W. and J. Van Allen. (1984). Fighting the feminization of poverty: Socialistfeminist analysis and strategy. Review of Radical Political Economy. Vol. 16(4): 89-110.

Sassoon, A. S. (1987a). Women's new social role: Contradictions of the welfare state. In A.S. Sassoon (Ed.), Women and the state. (pp. 158-188). London: Routledge.

Sassoon, A. S. (1987b). Introduction: The personal and the intellectual, fragments and order, international trends and national specificities. In A.S. Sassoon (Ed.), Women and the state. (pp. 15-22). London: Routledge.

Sassoon, A.S. (1980). Gramsci's politics. New York: St. Martin's Press.

Shah, N. (1989). It's up to you sisters: Black women and radical social work. In Langan, M. and P. Lee (Eds.), Radical social work today. London: Unwin Hyman.

Shragge, E. (1984). Foreward. In Lesemann, F. (Ed.) Services and circuses. Community and the welfare state. (pp. 9-26) Montreal: Black Rose Books.

Simon, B. (1990). Rethinking empowerment. Journal of Progressive Social Services. $1,1: 27-39$.

Smith, D. E. (1993). The standard north american family: SNAF as an ideological code. Journal of Family Issues. Vol. 14, No. 1, 50-65. 

Press.

Smith, D. E. (1990). The Conceptual Practices of Power. Toronto: University of Toronto

Smith, D. E. (1987). The everyday world as problematic. Toronto: University of Toronto Press.

Smith, D. E. (1986). Institutional ethnography: A feminist method. Resources for Feminist Research. 15(1):6-12.

Stasiulis, D. (1990). The politics of minority resistance against racism in the local state. In R Ng, G. Walker \& J. Muller (Eds.), Community organization and the Canadian state. (pp. 213-236). Toronto: Garamond Press.

Stolzman, J. and H. Gamberg. (1974). Marxist class analysis versus strategication analysis as general approaches to social inequality. Berkeley Journal of Sociology, 18: 105-125.

Strauss A. L. and J. Corbin. (199). Basics of qualitative research. Grounded Theory procedures and techniques. Newbury Par, CA: Sage Publications.

Suderman, B. (1992). A comparison and assessment of several packaged programs for organizations wishing to implement a policy of valuing cultural diversity. Unpublished manuscript, University of Calgary, Calgary, Alberta.

Stiles, W. B. (1993). Quality control in qualitative research. Unpublished paper presented at the Society for Psychotherapy Research, Pittsburgh, Pennsylvania.

Tanen, D. (1990). You just don't understand. Women and men in conversation. New York: Ballantine Books.

Tator, C. (1996). Anti-racism and the human-service delivery system. In C. James (Ed.) Perspectives on racism and the human services sector: A cwie for change. (pp. 152-170). Toronto: University of Toronto Press.

Thomas, B. (1987). Multiculturalism at work: A guide to organizational change. Toronto: YWCA of Metropolitan Toronto.

Thomas, R. (1991). Beyond race and gender: Unleashing the power of your total workforce by managing diversity. New York: Amacom.

United Way of Greater Toronto. (1991). Action, access, diversity! A guide to multiculture/anti-racist organizational change for social service agencies. Toronto: United Way of Greater Toronto. 
Valverde, M. (1995). The mixed social economy as a Canadian tradition. Studies in Political Economy, 47. Summer: 33-60.

Valverde, M. (1991). As if subjects existed: Analysing social discourses. Canadian Review of Sociology and Anthropology. 28(2): 173-187.

Wagner, D. (1990). The quest for a radical profession. Social service carers and political ideology. Lanham, MD: University Press of America, Inc.

Walker, G. (1990). Family violence and the women's movement. The conceptual practices of power. Toronto: University of Toronto Press.

Walker, G. (1986). The standpoint of women and the dilemma of professionalism in action. Resources for Feminist Research. 15(1): 18-20.

Wearing, B. (1986). Feminist theory and social work. In Marchant, H. and B. Wearing, (Eds.), Gender reclaimed: Women in social work. Sydney: Hale and Iremonger. Blackwell.

Weedon, C. (1987). Feminist practice and poststructuralist theory. Oxford: Basil

Weeks, W. (1994). Women working together. Lessons from feminist women's services. Melbourne, Australia: Longman Cheschire.

Wharf, B. (1990). Lessons from the social movements. In Wharf, B. (Ed.) Social work and social change in Conada. (pp. 144-180) Toronto: McClelland and Stewart Inc.

Wills, G. (1992). Values of community practice. Legacy of the radical social gospel. Canadian Social Work Review. Vol. 9, Number 1, Winter, 28-40.

Wilson, E. (1980). Feminism and social work. In M. Brake and R. Bailey (Eds.) Radical social work practice. London: Edward Arnold.

Wilson, E. (1977). Women and the welfare state. London: Tavistock.

Wineman, S. (1984). The politics of human services. Montreal: Black Rose.

Withorn, A. (1986). What is progressive social work? The Bertha Capen Reynolds Society Newsletter. Vol. 1, No. 2.

Withorn, A. (1984). Serving the people: Social service and social change. New York: Columbia University Press. 
Wood, R.G. and R. Middleman. (1989). The structural approach to direct practice in social work. New York: Columbia University Press.

Yeatman, A. (1994). Postmodern revisionings of the political. New York: Routledge.

Young, I. (1990). Justice and the politics of difference. Princeton: Princieton University Press.

Young, I. (1981). Beyond the unhappy marriage: a critique of the dual systems theory. In L. Sargent (Ed.), Women and revolution. (pp. 43-70) Boston: South End Press. 
